\title{
Laboratory evaluation of laser-induced breakdown spectroscopy (LIBS) as a new in situ chemical sensing technique for the deep ocean
}

Anna Pauline Miranda Michel B.S. Chemical Engineering, B.S. Biology

Massachusetts Institute of Technology (1998)

M.S. Ocean Engineering

Massachusetts Institute of Technology (2002)

Submitted to the MIT/WHOI Joint Program in Oceanography/Applied Ocean Science and Engineering

in partial fulfillment of the requirements for the degree of

Doctor of Philosophy

at the

MASSACHUSETTS INSTITUTE OF TECHNOLOGY

and the

WOODS HOLE OCEANOGRAPHIC INSTITUTION

September 2007

(C) Anna Pauline Miranda Michel, MMVII. All rights reserved.

The author hereby grants to MIT and WHOI permission to reproduce and to distribute publicly paper and electronic copies of this thesis document in whole or in part in any medium now known or hereafter created.

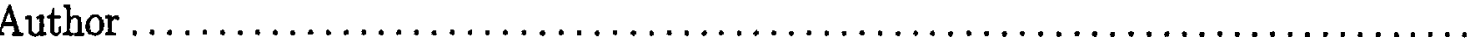

MIT/WHOI Joint Program in Oceanography/Applied Ocean Science and Engineering August 3, 2007

Certified by

Alan D. Chave

Senior Scientist, WHOI

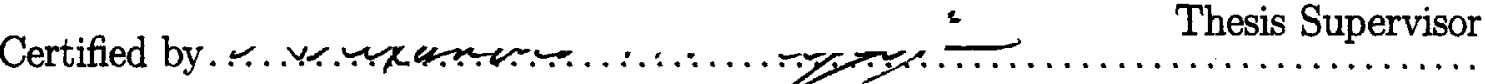

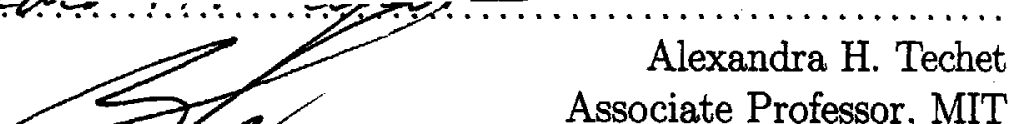

Thesis Supervisor

Accepted by

Henrik Schmidt

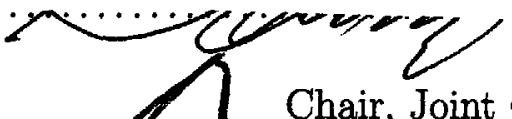

Chair, Joint Committee for Applied Ocean Science and Engineering

Accepted by

\begin{tabular}{c} 
MASSACHUSETTS INSTTUTE, \\
OF TECHNOLOOYY \\
JAN 032008 \\
\hline
\end{tabular}

Lallit Anand

Chairman, Committee on Graduate Students

LIBRARIES 



\title{
Laboratory evaluation of laser-induced breakdown spectroscopy (LIBS) as a new in situ chemical sensing technique for the deep ocean
}

by

\author{
Anna Pauline Miranda Michel
}

Submitted to the MIT/WHOI Joint Program in Oceanography/Applied Ocean

Science and Engineering

on August 3, 2007, in partial fulfillment of the

requirements for the degree of

Doctor of Philosophy

\begin{abstract}
Present-day expeditionary oceanography is beginning to shift from a focus on shortterm ship and submersible deployments to an ocean observatory mode where longterm temporally-focused studies are feasible. As a result, a critical need for in situ chemical sensors is evolving. New sensors take a significant amount of time to develop; thus, the evaluation of techniques in the laboratory for use in the ocean environment is becoming increasingly important. Laser-induced breakdown spectroscopy (LIBS) possesses many of the characteristics required for such in situ chemical sensing, and is a promising technique for field measurements in extreme environments. Although many LIBS researchers have focused their work on liquid jets or surfaces, little attention has been paid to bulk liquid analysis, and especially to the effect of oceanic pressures on LIBS signals. In this work, laboratory experiments validate the LIBS technique in a simulated deep ocean environment to pressures up to $2.76 \times 10^{7} \mathrm{~Pa}$. A key focus of this work is the validation that select elements important for understanding hydrothermal vent fluid chemistry $(\mathrm{Na}, \mathrm{Ca}, \mathrm{Mn}, \mathrm{Mg}, \mathrm{K}$, and $\mathrm{Li}$ ) are detectable using LIBS. A data processing scheme that accurately deals with the extreme nature of laser-induced plasma formation was developed that allows for statistically accurate comparisons of spectra. The use of both single and double pulse LIBS for high pressure bulk aqueous solutions is explored and the system parameters needed for the detection of the key analytes are optimized. Using both single and double pulse LIBS, the limits of detection were found to be higher than expected as a result of the spectrometer used in this experimentation. However, the results of this validation show that LIBS possesses the characteristics to be a viable chemical sensing method for in situ analyte detection in high pressure environments like the deep ocean.
\end{abstract}

Thesis Supervisors:

Alan D. Chave, Senior Scientist, WHOI

Alexandra H. Techet, Associate Professor, MIT 


\section{Acknowledgments}

I would like to first thank my advisor, Dr. Alan Chave (WHOI), for challenging me to this project. When I was looking for a $\mathrm{PhD}$ project and to enter the MIT-WHOI Joint Program, Alan had just been inspired by a former colleague to investigate an exciting technology that had the possibility of becoming a new oceanographic sensor. Although through the years we learned that an actual oceanographic sensor was further off than we had anticipated, Alan supported the laboratory work to show that this sensor will one day work in the ocean. In addition, his statistics knowledge has been invaluable to this work. Aside from this project, Alan also gave me the opportunity to experience sea-going oceanographic research by involving me in two cruises as part of the $\mathrm{H} 20$ project, encouraged me to travel to numerous conferences to present my work, and allowed me to be an independent researcher. I am very grateful to have had such diverse experiences as an oceanographic engineer.

I would like to thank the rest of my committee for their invaluable contributions, conversations, insight, knowledge, and patience. Professor S. Michael Angel allowed me to spend six months working in his lab in collaboration with his graduate students (Marion Lawrence-Snyder and Jon Scaffidi) during two research stints at the University of South Carolina - Columbia learning first about the LIBS technique and then gathering the data needed to publish my first paper on LIBS. In addition, when my spectrometer broke and had to be shipped to German for an extended time, the Angel lab willingly lent me their spectrometer which I am very grateful for. Professor Alexandra Techet (MIT) has been my sounding board for research and life too many times to count over the years. Alex has been an amazing role model and mentor. Norman Farr (WHOI) helped me to take a box full of optics and optomechanics, two lasers, a spectrometer, and a breadboard and turn the small black walled lab into a working LIBS lab. Norm's optics knowledge was invaluable and without his alignment skills, we probably would have burned even more lenses than we did. Meg Tivey (WHOI) was crucial for my knowledge of hydrothermal vent chemistry and for reminding me of the need for new sensors for vent systems. She was also the one that answered all of my vent chemistry questions. I would also like to thank Sheri White (WHOI) for chairing my defense and for sharing her lab space with me. Sheri kindly allowed me to use her sink and lab area so I would not have to mix solutions and wash glassware in the bathroom. Sheri also helped me on an almost daily basis with discussions about spectroscopy, replacement parts when things broke, the lending of tools, and of course our almost daily tea, coffee, and chocolate breaks. 
There are numerous people at WHOI that helped me survive my $\mathrm{PhD}$. Jeff Seewald was extremely helpful in designing the experiments for studying the matrix effect (Chapter 6). Hanu Singh kindly lent me a camera which I used for plasma imaging. Everyone at DSL helped make my experience at WHOI wonderful. I would like to thank Stace Beaulieu for sharing a bunk and standing Jason watch with me for two months, for all the chats, for drinking about 1000 cups of coffee with me, for eating about 300 bowls of tomato bisque with me, for all the swims and dives in the ocean, and for being an amazingly supportive friend. I would like to thank Karen Schwamb for being my "grad school mom". Whenever I had a question or needed anything, Karen had the answer, found the answer, and got me what I needed in an amazingly efficient manner. Karen has made me laugh and cry and kept me amused and given me advice so many times. John Bailey, Alan Gardner, and Fritz Sonnichsen helped me numerous times when I needed tools, a soldering iron, a random part, or just help lifting heavy breadboards.

I would like to thank the Academic Programs office, Marsha Gomes, Julia Westwater, Laishona Vitelli, Jim Yoder, Jim Price, Judy McDowell, Valerie Caron, Christine Charette and John Farrington for all of their help and support personally, professionally, and financially.

I owe many thanks to the girls of the Joint Program (Cara, Jessica, Clare, Petra, Diane, Rachel, and Emily (and Carolyn - who we adopted as a JP student)) for keeping me sane with all the walks, the coffee, the lunches and dinners, the chats on the elliptical machines, the swims, the engagements, the gelato, the X-gals articles, the girls' nights and the trips. As we go our separate ways, I will miss each of you. You are amazing friends and amazing scientists. I'd also like to thank all of the other wonderful friends that I made while at WHOI: Greg for being an awesome friend and for helping me in countless ways, including fixing my pump, even if he only wishes that he is an engineer; Brian for all the fun times we had both at WHOI and on the many trips; Matt for making my climb all the way to the top of Mt. St. Helens, and his wonderful wife Anna Skuladottir; and Lara who, although she moved away before the girls finished, has been a great cheerleader for all of us! Katy Croff has kept me amused since the day I started my masters degree at MIT, whether it was by making me a birthday cake that actually erupted and came with 20 lbs of dry ice, by making me rice krispies jelly fish, by sending me photos of Mr. T's latest travels, or by decorating the trailer we shared our first summer at DSL (which I later watched get demolished after it was condemned). My non-WHOI friends have also been very supportive of me during grad school. Lindsey, Sarah, and Heather have 
been supportive friends from afar always checking in on me through email and always being available to take a break to root for the Red Sox! Nao Teshima has been a wonderful friend since we were twelve and she wasn't about to miss hearing about the ups and downs of grad school and I thank her tremendously for that. Joshua Davis has been a great friend for many years and has shared my love of the ocean for even longer. He has been invaluable when I needed help with Matlab or needed a second and sometimes first opinion about an engineering problem. His Matlab coding skills are brilliant and I thank him for all the times that I called him for his brain power. Luckily he never charged me the consulting rate that he charges his real clients!

I would like to thank my family for believing in me and for encouraging me for all these years in science and engineering and especially in my love for the ocean. Probably not many parents would let their fifteen year old child fly to the Galapagos Islands to go on a research cruise, but luckily mine did and I thank them for that!

Last but definitely not least I would like to thank Masaya who, when I started grad school, was my boyfriend, and by the end was my husband. Somehow through it all he endured my living in another state from him so that I could pursue my lifelong goal of getting my $\mathrm{PhD}$. I thank him for not only the devotion and the support he showed me but also for the sacrifices he made for me all during my graduate school. During the last three years of grad school, he put 50,000 miles on his car driving from Manhattan every weekend so that I could work to finish my degree and I thank him immensely for that. Finally, I thank him for helping me with all the day-to-day chores that just would not have gotten done otherwise.

I would like to acknowledge the National Science Foundation for support of this research under grants OCE0352278 and OCE0352242. Additional support was received from WHOI's Deep Ocean Exploration Institute who awarded this research with two grants. I am also very personally thankful to the WHOI Ocean Ventures Fund who awarded me a student grant which allowed me to build the titanium pressure cell and to buy many of the optical components that I needed. This funding came at a time when I was in need of laboratory funding and it was much appreciated. I also thank the Department of Defense for awarding me a National Defense Science and Engineering Graduate Fellowship which gave me the flexibility to choose a project that interested me without having to worry about funding. 


\section{Contents}

1 Introduction $\quad 19$

1.1 Laser-Induced Breakdown Spectroscopy . . . . . . . . . . . . . . . 19

1.1.1 How LIBS Works . . . . . . . . . . . . . . . . 20

1.1.2 Advantages and Disadvantages of the LIBS Technique . . . . 21

1.1 .3 LIBS in Liquids . . . . . . . . . . . . . . . . . . 23

1.2 Scientific Application: Hydrothermal Vent

Chemistry . . . . . . . . . . . . . . . . 24

1.3 Thesis Overview . . . . . . . . . . . . . . . 27

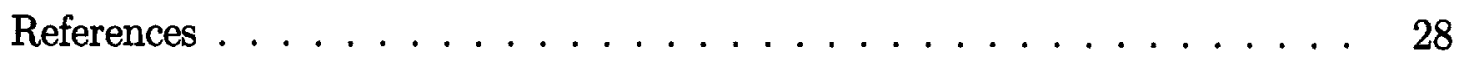

2 Laser-induced breakdown spectroscopy of bulk aqueous solutions at oceanic pressures: evaluation of key measurement parameters $\quad 33$

2.1 Abstract . . . . . . . . . . . . . . . . 33

2.2 Introduction $\ldots \ldots \ldots \ldots \ldots \ldots \ldots \ldots \ldots \ldots$

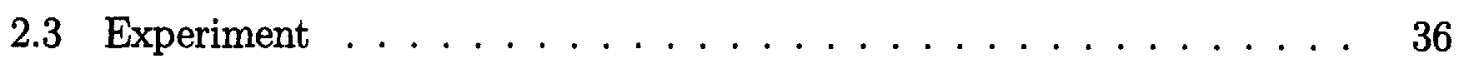

2.4 Results and Discussion . . . . . . . . . . . . . . . . 39

2.4.1 The Effect of Pulse Energy on LIBS Emission . . . . . . . 39

2.4.2 Interrelationship of pulse energy, gate delay, and pressure for Lithium . . . . . . . . . . . . . . . 47

2.4.3 Effect of $\mathrm{NaCl}$ Concentration on LIBS Spectra . . . . . . . 47

2.4.4 Detection of Calcium at Varying Concentrations . . . . . . . 50

2.4.5 Solution Temperature Effects on Calcium Spectra . . . . . . 50

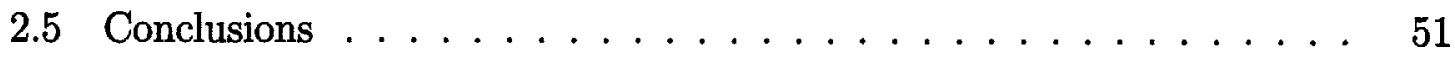

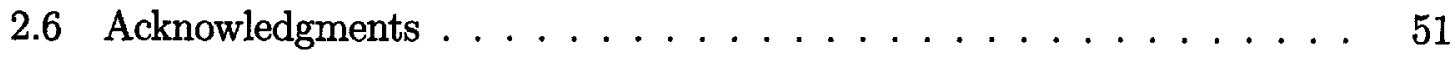

References . . . . . . . . . . . . . . . . 52

3 Analysis of laser-induced breakdown spectroscopy (LIBS) spectra: The case for extreme value statistics 


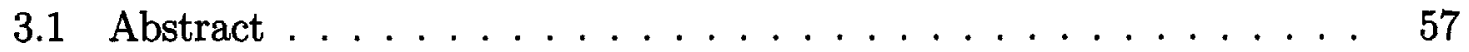

3.2 Introduction . . . . . . . . . . . . . . . . . 58

3.3 Experimental . . . . . . . . . . . . . . . . . . . . . . . . . 61

3.3.1 Echelle Spectrometer Set-up . . . . . . . . . . . . . . 61

3.3.2 Czerny-Turner Spectrometer Set-up . . . . . . . . . . . . . . 62

3.4 Results and Discussion . . . . . . . . . . . . . . . 63

3.4.1 The Generalized Extreme Value Distribution . . . . . . . . . 63

3.4.2 Applicability of Extreme Value Statistics . . . . . . . . . 65

3.4.3 Extreme Value Statistical Parameters . . . . . . . . . . . 70

3.4 .4 Variability . . . . . . . . . . . . . . 75

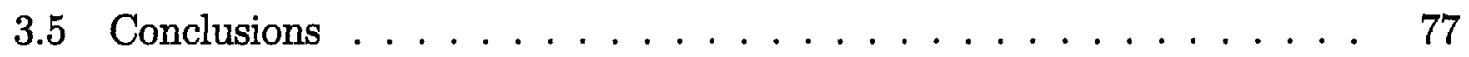

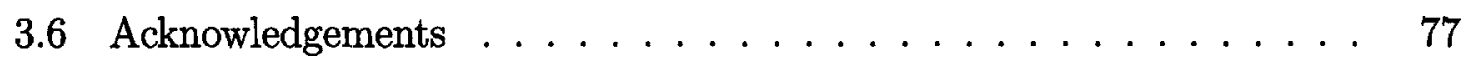

References . . . . . . . . . . . . . . . . . 78

4 Single pulse laser-induced breakdown spectroscopy of bulk aqueous solutions at oceanic pressures: Interrelationship of gate delay and $\begin{array}{lc}\text { pulse energy } & 81\end{array}$

4.1 Abstract . . . . . . . . . . . . . . . . . . . . . 81

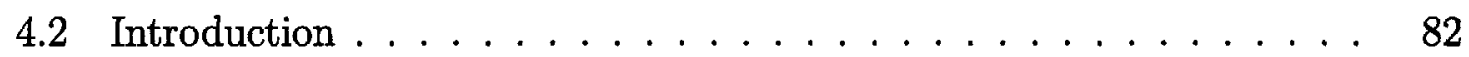

4.3 Experimental . . . . . . . . . . . . . . . . 83

4.4 Results and Discussion . . . . . . . . . . . . . . 87

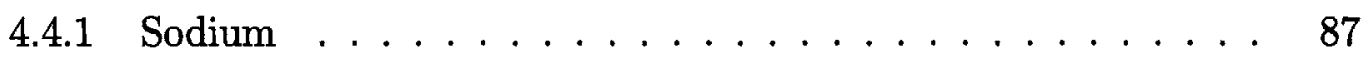

4.4 .2 Manganese . . . . . . . . . . . . . . . . 95

4.4 .3 Calcium . . . . . . . . . . . . . . . . . 101

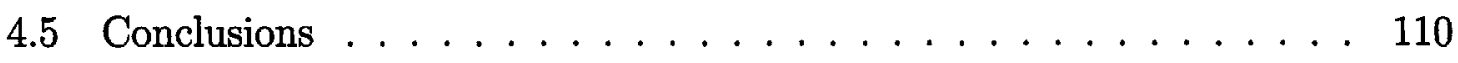

4.6 Acknowledgments . . . . . . . . . . . . . . . . 110

References . . . . . . . . . . . . . . . . . . 111

5 Double pulse laser-induced breakdown spectroscopy of bulk aqueous solutions at oceanic pressures: Interrelationship of gate delay, pulse energies, interpulse delay, and pressure $\quad 115$

5.1 Abstract . . . . . . . . . . . . . . . . . . 115

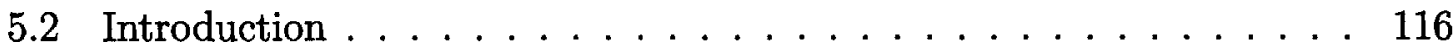

5.3 Experimental . . . . . . . . . . . . . . . . . . 118

5.4 Results and Discussion . . . . . . . . . . . . . . . . 121

5.4 .1 Magnesium . . . . . . . . . . . . . . 122

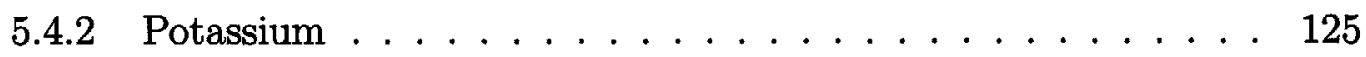


$5.4 .3 \quad$ Calcium . . . . . . . . . . . . . . . . . . . . 128

5.4 .4 Manganese . . . . . . . . . . . . . . . . . . . 132

5.4 .5 Sodium $\ldots \ldots \ldots \ldots \ldots \ldots \ldots \ldots \ldots \ldots$

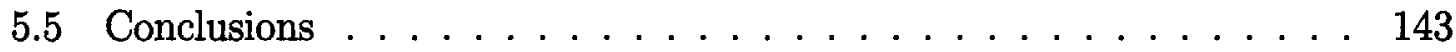

5.6 Acknowledgments . . . . . . . . . . . . . . . . . . . 144

References . . . . . . . . . . . . . . . . . . . . 145

6 Preliminary investigations on matrix effects of $\mathrm{Na}, \mathrm{K}$, and $\mathrm{Ca}$ for bulk liquids at oceanic pressures $\quad 149$

6.1 Abstract . . . . . . . . . . . . . . . . . . . . 149

6.2 Introduction . . . . . . . . . . . . . . . . . 149

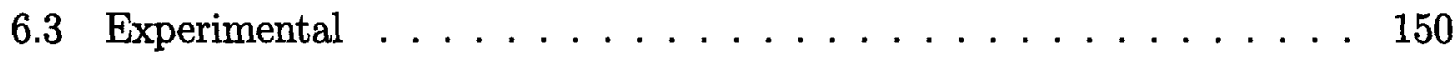

6.4 Results and Discussion . . . . . . . . . . . . . . . . . . 151

6.4 .1 Matrix Effects of $\mathrm{K}$ and $\mathrm{Na} \ldots \ldots \ldots \ldots 151$

6.4.2 Matrix Effects of $\mathrm{Ca}$ and $\mathrm{Na} \ldots \ldots \ldots \ldots \ldots . \ldots . \ldots 155$

6.4.3 Detection of $\mathrm{Na}$ and $\mathrm{K}$ in a Chloride Versus Sulfate Matrix . . 161

6.5 Conclusions . . . . . . . . . . . . . . . . . 163

6.6 Acknowledgments . . . . . . . . . . . . . . . . . . . . 163

References . . . . . . . . . . . . . . . . . . . . . . 164

7 Conclusions and Future Directions $\quad 165$

7.1 Conclusions . . . . . . . . . . . . . . . . . 165

7.1.1 Development of a New Data Processing Scheme . . . . . . 165

7.1 .2 Single Pulse LIBS . . . . . . . . . . . . . . . . . . . 166

7.1 .3 Double Pulse LIBS . . . . . . . . . . . . . . . . . . 167

7.1 .4 Matrix . . . . . . . . . . . . . . . 168

7.2 Future Work . . . . . . . . . . . . . . . . . . 168

7.2 .1 Laboratory Work . . . . . . . . . . . . . . . . 168

7.2.2 Design of an Ocean-Going Sensor . . . . . . . . . . . 170

References . . . . . . . . . . . . . . . . . . . . 173 


\section{List of Figures}

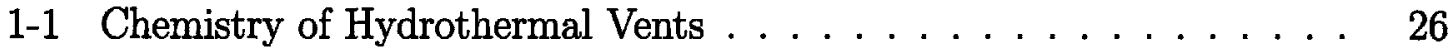

2-1 Schematic of the laboratory LIBS apparatus . . . . . . . . . . . . 37

2-2 Optical arrangements . . . . . . . . . . . . . . . 38

2-3 Effect of laser pulse energy on the LIBS signal intensity of $\mathrm{Na}(\mathrm{I}) \ldots \quad 40$

2-4 Effect of laser pulse energy on the LIBS emission intensity of Mn (I) . 42

2-5 Effect of pressure on LIBS emission intensity . . . . . . . . . . . 43

2-6 Spectra of Ca under four dual pulse conditions . . . . . . . . 45

2-7 Ca emission at different interpulse delays . . . . . . . . . 46

2-8 Spectra of Mn under four dual pulse conditions . . . . . . . . . 47

2-9 Effect of gate delay on the LIBS signal for $\mathrm{Li} \ldots \ldots \ldots \ldots$

2-10 Effect of the addition of $\mathrm{NaCl}$ on spectra of $\mathrm{Ca} \ldots \ldots \ldots . \ldots 49$

2-11 Detection of $\mathrm{Ca}$ in a simulated vent fluid . . . . . . . . . 50

3-1 Laboratory set-up using an Echelle spectrometer . . . . . . . . . . . 61

3-2 Laboratory set-up using a Czerny-Turner spectrometer . . . . . . . 63

3-3 q-q plots for the $588.9953 \mathrm{~nm} \mathrm{Na}$ I peak for halite using the Echelle set-up . . . . . . . . . . . . . . . . . . 67

3-4 q-q plots for the $588.9953 \mathrm{~nm} \mathrm{Na}$ I peak for bulk aqueous solution using the Echelle set-up . . . . . . . . . . . . . . . . 68

3-5 q-q plots for the $588.9953 \mathrm{~nm} \mathrm{Na}$ I peak for bulk aqueous solution using the Czerny-Turner set-up . . . . . . . . . . . . . . . . . 69

3-6 Shape parameter, location parameter, and sample mean for halite using the Echelle set-up . . . . . . . . . . . . . . . . 72

3-7 Shape parameter, location parameter, and sample mean for bulk aqueous solution using the Echelle set-up . . . . . . . . . . . 73

3-8 Shape parameter, location parameter, and sample mean for bulk aqueous solution using the Czerny-Turner set-up . . . . . . . . 74

3-9 Images of plasmas formed in bulk aqueous solution $\ldots \ldots \ldots .76$ 
3-10 Comparison of laser energies $\ldots \ldots \ldots \ldots \ldots$

4-1 Laboratory set-up . . . . . . . . . . . . . . . . . . . . . 84

4-2 Timing parameters . . . . . . . . . . . . . . 85

4-3 Optical Configuration . . . . . . . . . . . . . . . 85

4-4 Interrelationship of gate delay, laser pulse energy, and peak intensity for $\mathrm{Na}(588.995 \mathrm{~nm}) \ldots \ldots \ldots \ldots$

4-5 Interrelationship of Pressure, Gate Delay, Energy, and Intensity for $\mathrm{Na}$ $(589.6 \mathrm{~nm}) \ldots \ldots \ldots \ldots \ldots \ldots$

4-6 Interrelationship of pressure, gate delay, E, and SBR for Na (588.995

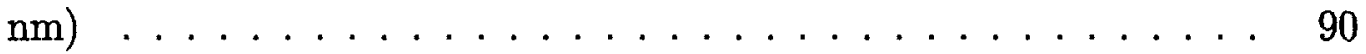

4-7 Interrelationship of pressure, gate delay, energy, and SBR for $\mathrm{Na}(589.6$

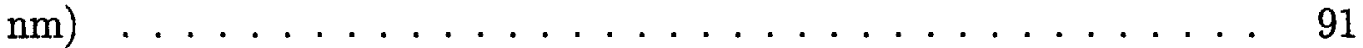

4-8 Na spectra taken with a pulse energy of $40 \mathrm{~mJ}$ and a gate delay of $50 \mathrm{~ns} 92$

4-9 Sodium calibration curves . . . . . . . . . . . . . . . . 93

4-10 Spectra of sodium made over a range of $\mathrm{NaCl}$ concentrations . . . . . 94

4-11 Interrelationship of pressure, $t_{d}, E$, and intensity for $\mathrm{Mn}(403.076 \mathrm{~nm}) 96$

4-12 Interrelationship of pressure, $t_{d}, E$, and SBR for Mn (403.076 nm) . 97

4-13 Manganese spectra using a $30 \mathrm{~mJ}$ energy pulse and a gate delay of $50 \mathrm{~ns} 98$

4-14 Mn calibration curve . . . . . . . . . . . . . . . . . . 99

4-15 Spectra of manganese made at a range of concentrations . . . . . 100

4-16 Interrelationship of pressure, $t_{d}, E$, and intensity for $\mathrm{Ca}(393 \mathrm{~nm})$. . 101

4-17 Interrelationship of pressure, $t_{d}$, energy, and intensity for Ca $(396 \mathrm{~nm}) 102$

4-18 Interrelationship of pressure, $t_{d}$, energy, and intensity for Ca $(422 \mathrm{~nm}) 103$

4-19 Interrelationship of pressure, $t_{d}, \mathrm{E}$, and $\mathrm{SBR}$ for Ca $(393 \mathrm{~nm}) \ldots \ldots 104$

4-20 Interrelationship of pressure, $t_{d}$, E, and SBR for Ca $(396 \mathrm{~nm}) \ldots \ldots 105$

4-21 Interrelationship of pressure, $\mathrm{t}_{d}, \mathrm{E}$, and SBR for Ca $(422 \mathrm{~nm}) \ldots \ldots 106$

4-22 Calcium spectra using $30 \mathrm{~mJ}$ and a $50 \mathrm{~ns}$ gate delay . . . . . . 107

4-23 Calcium calibration curves . . . . . . . . . . . . . . . 108

4-24 Calcium spectra at $2.76 \times 10^{7} \mathrm{~Pa} \ldots \ldots \ldots \ldots \ldots$

$5-1 \quad$ Laboratory set-up . . . . . . . . . . . . . . . . . . 119

5-2 Timing parameters . . . . . . . . . . . . . . 120

5-3 $\mathrm{Mg}(\mathrm{I})$ optimization at $1 \times 10^{5} \mathrm{~Pa} \ldots \ldots \ldots \ldots \ldots \ldots . \ldots \ldots$

5-4 $\mathrm{Mg}(\mathrm{I})$ optimization at $1.38 \times 10^{7} \mathrm{~Pa} \ldots \ldots \ldots \ldots \ldots \ldots . \ldots 123$

$5-5 \mathrm{Mg}(\mathrm{I})$ optimization at $2.76 \times 10^{7} \mathrm{~Pa} \ldots \ldots \ldots \ldots \ldots \ldots . \ldots \ldots$

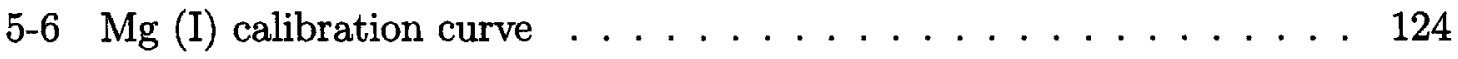




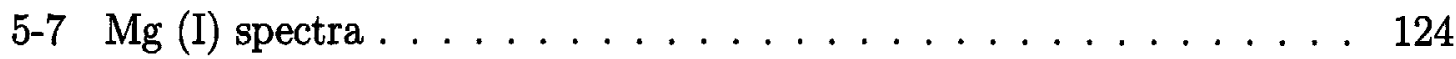

$5-8 \quad \mathrm{~K}(\mathrm{I})$ optimization at $1 \times 10^{5} \mathrm{~Pa} \ldots \ldots \ldots \ldots \ldots \ldots$

$5-9 \quad \mathrm{~K}(\mathrm{I})$ optimization at $1.38 \times 10^{7} \mathrm{~Pa} \ldots \ldots \ldots \ldots \ldots \ldots$

$5-10 \mathrm{~K}$ (I) optimization at $2.76 \times 10^{7} \mathrm{~Pa} \ldots \ldots \ldots \ldots \ldots \ldots$

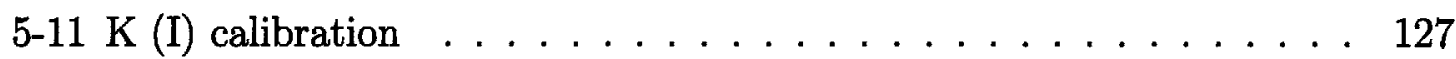

$5-12$ K (I) spectra . . . . . . . . . . . . . . . . . . . . . 127

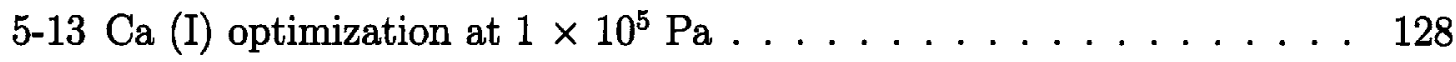

$5-14 \mathrm{Ca}$ (I) optimization at $1.38 \times 10^{7} \mathrm{~Pa} \ldots \ldots \ldots \ldots \ldots \ldots$

$5-15 \mathrm{Ca}$ (I) optimization at $2.76 \times 10^{7} \mathrm{~Pa} \ldots \ldots \ldots \ldots \ldots . \ldots . \ldots 129$

$5-16$ Ca calibration . . . . . . . . . . . . . . . . . 130

$5-17$ Ca spectra . . . . . . . . . . . . . . . . . . . 131

5-18 Mn (I) optimization at $1 \times 10^{5} \mathrm{~Pa} \ldots \ldots \ldots \ldots \ldots \ldots$

$5-19 \mathrm{Mn}(\mathrm{I})$ optimization at $1.38 \times 10^{7} \mathrm{~Pa} \ldots \ldots \ldots \ldots \ldots . \ldots .133$

$5-20 \mathrm{Mn}(\mathrm{I})$ optimization at $2.76 \times 10^{7} \mathrm{~Pa} \ldots \ldots \ldots \ldots \ldots \ldots$

$5-21$ Mn (I) calibration curve $\ldots \ldots \ldots \ldots \ldots \ldots \ldots$

$5-22 \mathrm{Mn}(\mathrm{I})$ spectra . . . . . . . . . . . . . . . . . . . 135

$5-23 \mathrm{Na}$ (I) optimization at $1 \times 10^{5} \mathrm{~Pa} \ldots \ldots \ldots \ldots \ldots \ldots \ldots$

$5-24 \mathrm{Na}$ (I) optimization at $1.38 \times 10^{7} \mathrm{~Pa} \ldots \ldots \ldots \ldots \ldots \ldots . \ldots \ldots$

$5-25 \mathrm{Na}$ (I) optimization at $2.76 \times 10^{7} \mathrm{~Pa} \ldots \ldots \ldots \ldots \ldots \ldots$

$5-26 \mathrm{Na}$ (I) calibration . . . . . . . . . . . . . . . . . . 138

5-27 Spectra of $\mathrm{Na}$ (I) peaks . . . . . . . . . . . . . . . . . . 139

5-28 Effect of interpulse delay on intensity for $\mathrm{Na}$ at $1 \times 10^{5} \mathrm{~Pa} \ldots \ldots 141$

$5-29 \mathrm{Na}$ calibration curve at $1 \times 10^{5} \mathrm{~Pa} \ldots \ldots \ldots \ldots 141$

$5-30 \mathrm{Na}(\mathrm{I})$ spectra . . . . . . . . . . . . . . . . . . . . . 142

6-1 Effect of presence of $\mathrm{Na}$ on peak intensity on $\mathrm{K} \ldots \ldots \ldots$

6-2 Effect of presence of $\mathrm{K}$ on peak intensity on $\mathrm{Na} \ldots \ldots \ldots \ldots$

6-3 Effect of presence of $\mathrm{Na}$ on peak intensity on $\mathrm{Ca}$ (II) $\ldots \ldots \ldots 156$

6-4 Effect of presence of $\mathrm{Na}$ on peak intensity on $\mathrm{Ca}(\mathrm{I}) \ldots \ldots \ldots . . .157$

6-5 Ratio of $393 \mathrm{~nm} \mathrm{Ca} \mathrm{(II)} \mathrm{peak} \mathrm{to} 422 \mathrm{~nm} \mathrm{Ca} \mathrm{(I)} \mathrm{peak} \mathrm{\ldots ...} \mathrm{.} \mathrm{.} \mathrm{.} 158$

6-6 Effect of presence of $\mathrm{Ca}$ on peak intensity on $\mathrm{Na} \ldots \ldots \ldots \ldots$

6-7 Detection of potassium in a chloride versus sulfate matrix . . . . . . 161

6-8 Detection of sodium in a chloride versus sulfate matrix. . . . . . . . 162

$7-1 \quad$ Future oceanic LIBS system $\ldots \ldots \ldots \ldots \ldots \ldots$. . . . . . . . 172 


\section{List of Tables}

2.1 Conditions used to study the effect of dual pulse energies . . . . . . 44

2.2 Dual pulse emission intensity $\ldots \ldots \ldots \ldots \ldots \ldots$

4.1 Calibration curve conditions $\ldots \ldots \ldots \ldots \ldots \ldots$

6.1 Conditions used to study the K-Na matrix effect . . . . . . . . . . 151

6.2 Conditions used to study the Na-K matrix effect . . . . . . . . . 153

6.3 Conditions used to study the Ca-Na Matrix Effect . . . . . . . . . . 155

6.4 Conditions used to study the effect of $\mathrm{CaCl}_{2} \cdot 2 \mathrm{H}_{2} \mathrm{O}$ on $\mathrm{Na} \ldots \ldots . .159$ 


\section{Chapter 1}

\section{Introduction}

The development of in situ chemical sensors is needed to explore and understand the ocean and its processes. In present day oceanographic work, new sensors are required for expeditionary science with underwater vehicles such as ROVs, AUVs, and submersibles. A new paradigm for ocean study has begun with the implementation of ocean observatories. As these permanent observatories become the new mode of oceanography, there will be a critical need for chemical sensors capable of long-term deployment for ocean observatories to reach their full potential. The time required to transform a bench-top laboratory technique into a full ocean-going system is significant. The development phase initially requires validation that an analytical technique will work under in situ conditions. In this thesis, laser-induced breakdown spectroscopy (LIBS) is evaluated in the laboratory to determine if this bench-top analytical technique is viable for development into a field-going oceanographic chemical sensor.

\subsection{Laser-Induced Breakdown Spectroscopy}

Laser-induced breakdown spectroscopy is a type of atomic emission spectroscopy that was first reported in the literature in 1962 and has since evolved into a technique for laboratory chemical analysis [1]. LIBS technology is currently undergoing transformation from a benchtop analytical technique into a viable tool for field measurements, and is emerging as a tool for chemical, geochemical, and environmental analysis in extreme and hostile environments [2]. LIBS has been used in the analysis of a wide variety of sample types including soils [3], archaeological artifacts [4], metal alloys [5], bacterial spores, molds, pollens, and proteins [6], pharmaceuticals [7], glass [8], nuclear power station steam generator tubes [9], and pigments in artwork [10]. A 
mobile instrument has been designed for studying polluted soils [11, 12]. LIBS is also capable of stand-off, non-contact measurements, and a field deployable system has been proposed by Palanco et al. with a detection range on the order of hundreds of meters [13]. A field-portable LIBS system has been developed for landmine detection [14]. Along with land-based environmental applications, LIBS is finding applicability to space exploration [15-20]. LIBS will be part of the ChemCam instrument package for the Mars Science Laboratory Rover that will be launched in 2009 for geological analysis.

Although there are many proposed land and space based applications of LIBS field-going sensors, it also holds promise for in situ ocean use. There are numerous possible applications in the areas of chemical, geological, and biological oceanography ranging from laboratory experimentation to fieldwork in environments from estuaries to the coastal zone to the deep ocean. The development of an oceanographic LIBS sensor could allow scientists to determine the chemical composition of sediments, rocks, or ocean fluids in an in situ, real-time mode. Several researchers have already applied the LIBS technology to marine-related applications. For example, Niu et al. successfully used LIBS to determine strontium levels in marine algae [21] and Barbini et al. used LIBS shipboard to analyze marine sediments [22]. In the laboratory, De Giacomo et al. have explored the use of LIBS for the detection of submerged solid targets [23-26].

\subsubsection{How LIBS Works}

The LIBS technique is based on the analysis of the spectral emission from laserinduced plasmas, and is a type of atomic emission spectroscopy. Atomic emission spectroscopy uses an external energy source to excite ground state atoms. The atoms spontaneously emit radiation as they revert back to a lower energy state, with the emission intensity being proportional to the concentration of atoms in the ground state [27]. In the LIBS technique, one or two high-power, pulsed lasers, typically Q-switched Nd:YAG units, are used as the excitation source. The lasers are usually operated at the fundamental wavelength of $1064 \mathrm{~nm}$, although other wavelengths can be used; for example, the lasers can be frequency doubled to deliver $532 \mathrm{~nm}$. Additional components of a typical LIBS system include focusing and collection optics, a spectrometer, and a data acquisition computer. Commercially available broadband spectrometers span the $200-1000 \mathrm{~nm}$ wavelength region, allowing for the simultaneous detection of multiple elements [28]. 
To generate a plasma spark, a short duration, high power laser beam is focused onto or into a sample. An optically-induced plasma or spark is formed on the surface (of a solid or on a liquid) or in the sample (in bulk liquid or in a gaseous medium) when the laser power density or irradiance exceeds the breakdown threshold of the sample [27]. Breakdown threshold irradiances using a 7-ns pulse width, $1064 \mathrm{~nm}$ Nd:YAG laser have been reported by Kennedy et al. to be $5.6 \times 10^{9} \mathrm{~W} / \mathrm{cm}^{2}$ for tap water and $8.31 \times 10^{9} \mathrm{~W} / \mathrm{cm}^{2}$ for saline solutions [29]. The plasma radiates both a continuum component due to inverse Bremsstrahlung radiation from electron-ion collisions, which decays rapidly, and an emission line component that decays more slowly. Therefore, the plasma emission can be analyzed by spectroscopic methods by time gating. The plasma light is initially dominated by a white light continuum which contains little intensity variation as a function of wavelength. After breakdown, the plasma expands outwards and back towards the focusing lens. The expansion occurs at $10^{5} \mathrm{~m} / \mathrm{s}$ and creates an audible shock wave [30]. Plasma temperatures in bulk liquids are in the range of $7,000-12,000 \mathrm{~K}$ [30]. Plasma decay occurs by radiative, quenching, and electron-ion recombination processes that result in the formation of neutral species [31].

A gated spectrometer covering part or all of the ultraviolet through near infrared range $(200 \mathrm{~nm}-1000 \mathrm{~nm})$ is used to capture the plasma spectrum. For simultaneous multi-element analysis, an Echelle spectrometer can be used which contains an Echelle diffraction grating with coarse grooves and large blaze angles. The grooves have steep sides to cover the full range of wavelengths, and a prism is needed to separate overlapping orders of the grating $[27,32]$. CCDs (charge coupled devices) or ICCDs (intensified charge coupled devices) serve as the detector devices within the spectrometers. The spectral line wavelengths and intensities obtained from plasma ablation can be compared with a standard atomic line reference and/or calibrated against samples of known makeup to determine the elemental composition of the sample. The intensity of the spectral lines provides a quantitative description of the elemental concentration $[28,33]$.

\subsubsection{Advantages and Disadvantages of the LIBS Technique}

LIBS as a spectrochemical technique possesses many advantages which make it especially attractive for development into an in situ sensor for oceanographic research. However, the technique also possesses several disadvantages that must be addressed. 
LIBS can provide rapid multi-element analysis and has the capability to detect elements in the parts-per-million (ppm) range. All elements emit in the $200-940 \mathrm{~nm}$ wavelength region and every element has its own unique spectral signature; therefore, all elements can theoretically be detected with LIBS. The emission lines obtained from plasma ablation can be compared with a standard reference of atomic lines to determine the chemical composition of the sample by comparison of wavelengths. For example, the National Institute of Standards and Technology (NIST) maintains an online atomic spectrum database (http://physics.nist.gov/PhysRefData/ASD/index.html). Unlike other techniques that are useful for analyzing one form of material, LIBS can chemically analyze all three states of matter (solid, liquid, and gas). The sample size for LIBS is minimal with typically, $0.1 \mu \mathrm{g}-0.1 \mathrm{mg}$ of material ablated if a solid sample is analyzed. The sample size required minimizes the destructiveness and invasiveness of the technique. LIBS does not require any preparation of a sample before analysis and unlike many analytical techniques, does not require chemical reagents to dissolve the sample [27]. This avoids contamination problems and reduces the time for analysis. These characteristics makes LIBS suitable for real-time, in situ analysis. Most analytical methods (e.g., wet chemistry techniques) cannot produce instant results in a field environment. Other methods can be time-intensive, with several days needed before results are available. Rapid analysis is possible with LIBS as it only requires one laser pulse to generate a plasma, although typically numerous accumulations of plasmas are obtained. A large number of measurements can be taken quickly, making the elemental composition of the sample identifiable on a nearly real-time basis.

LIBS has been identified as a viable technique for use in extreme environments because direct contact with the sample is not necessary; only optical access is required. Fiber optics can be used to reach distances far from the laser. The laser can also be focused on a sample at a distance, making LIBS useful for remote measurements. The stand-off analysis capabilities of LIBS make it a viable in situ analytical technique. The components of the system can also be made small and rugged. Unlike many traditional analytical techniques that require collection of a sample followed by the transport of the sample to a laboratory, LIBS measurements can be made directly in the field. This eliminates the need to store the sample in conditions that differ from the natural environment. This is an important advantage for oceanography due to pressure and temperature effects. LIBS can also be used for surface cleaning of a sample. Repetitive sampling at the same spot can be used for ablation through weathered surfaces to reach underlying material. This could be useful for rocks which could be "drilled" through to areas beneath fouling and to determine chemical makeup 
of the fouling. These benefits make LIBS useful for chemical analysis in extreme environments suggesting that it is a viable technique for use in the deep ocean [28, $31,34-36]$.

Although there are many advantages to the LIBS technique, there are several disadvantages that must be acknowledged. LIBS is a semi-quantitative technique as it is often difficult to obtain suitable standards. LIBS does not have the sensitivity and precision of many state-of-the-art laboratory analytical techniques. Furthermore, measurements are highly variable. There are also chemical interference (matrix) effects between analytes that must be addressed [27].

\subsubsection{LIBS in Liquids}

Several researchers have been successful in causing plasma ablation to occur on materials submerged in water and on liquid surfaces. However, only a few researchers have focused their work on LIBS of dissolved analytes within bulk aqueous solutions $[23,37-42]$ due to the inherent difficulty of detection. If the liquid is transparent at the laser wavelength, a plasma can be formed in the bulk liquid below the surface [37]. The plasma formed in a bulk liquid compared to that formed on a solid or in air displays reduced light intensity and emission lifetime due to quenching [37, 38, 43, 44]. This emission time interval is on the order of $1 \mu \mathrm{s}$ or less in liquid, which is significantly lower than at the air-liquid interface where the time interval averages $5-20$ $\mu$ s. In addition, spectral lines are broadened by the Stark effect which results from ion and electron collisions [37, 45]. Furthermore, "moving breakdown" occurs that randomly changes the distance between the plasma and the collection optics, a phenomenon that is not relevant to solids in air. The plasma expands along the beam path, resulting in an elongated plasma that cavitates cylindrically [46]. For many aqueous applications, these issues can be avoided by analysis on a liquid surface, jet, or film; however, for the development of an in situ oceanic system, it is necessary to work directly with bulk liquids.

As early as 1984, Cremers et al. [37] were able to identify many elements in an aqueous solution. This work showed that the use of two laser sparks, (double or dual pulse LIBS), with a short interpulse delay, improved the detection limit for dissolved species. Using two laser pulses allowed lower concentrations of elements to be detected. The first spark creates a cavitation bubble. The second pulse is fired into the bubble, forming a plasma within it, allowing the measurement to be made in a gaseous environment. 
Few LIBS researchers have focused on liquids and no work has been done at high pressures, and therefore little is known about the pressure effect. Relatively few studies have focused on dissolved species in liquids and therefore much work on the experimental parameters for measurements of such species is necessary.

\subsection{Scientific Application: Hydrothermal Vent Chemistry}

Study of in situ hydrothermal vent chemistry could benefit greatly from the development of a LIBS sensor. At mid-ocean ridges, seawater circulates through the fractured and permeable crust. Interactions with the surrounding rock induces major chemical changes to the fluid. At vent orifices, exit temperatures reach $200-405^{\circ} \mathrm{C}$ at ambient pressures of $8.1 \times 10^{6} \mathrm{~Pa}$ to $3.6 \times 10^{7} \mathrm{~Pa}$ corresponding to ocean depths of $800 \mathrm{~m}$ to $3600 \mathrm{~m}$ [47]. The circulation is driven by the direct or indirect thermal effects of magma at sub-seafloor depths of up to a few $\mathrm{km}$; additionally, substantial changes in fluid composition occur due to interaction with the host rock, phase separation, and possibly magma degassing [48]. For example, many alkalis (e.g., $\mathrm{Li}, \mathrm{Na}$, and $\mathrm{Ca}$ ) and transition metals (e.g., $\mathrm{Fe}, \mathrm{Mn}, \mathrm{Cu}$, and $\mathrm{Zn}$ ) are leached from the host rock and concentrated to varying degrees in the fluid, while $\mathrm{Mg}$ and $\mathrm{SO}_{4}$ are largely removed from the fluid [47].

As vent fluids exit the seafloor, the very hot fluids mix with ambient seawater which rapidly changes the chemistry (Figure 1-1). Measuring the fluid properties in situ is very difficult. Collecting samples for measurement shipboard or back in a shore laboratory is usually done by using non-reactive titanium samplers to extract water, which is then brought to the surface. Some elements remain in solution as the temperature and pressure changes, however, others precipitate out [49]. In addition, the chemistry of some vents are known to change over short (days to years) time scales [50]. The use of a method like LIBS, therefore, is attractive for obtaining an understanding of the chemistry of vents that has thus far been impossible to achieve.

Six elements (sodium, calcium, manganese, magnesium, potassium, and lithium) were selected as the primary focus of this work because of their key importance at hydrothermal vents. Sodium $(\mathrm{Na})$ is the most abundant cation in vent fluids and its study is important for gaining an understanding of phase separation processes [48]. Manganese (Mn) exists as a trace metal in seawater but has a higher concentration in vent fluids due to leaching from the host rock [48]. Mn can also be studied si- 
multaneously with $\mathrm{Fe}$ as an indication of subsurface deposition as Fe precipitates out while $\mathrm{Mn}$ stays in solution. Calcium (Ca) is the second most abundant cation in vent fluids, and is typically enriched in vent fluids compared to seawater [50]. Ca is released into vent fluids when sodium is taken up during albitization reactions with the host rock [50]. Magnesium $(\mathrm{Mg})$ is very low to nonexistent in hydrothermal vent fluids; however, it is present in seawater [48]. If $\mathrm{Mg}$ is detected in vent fluid samples, it is evidence for contamination; thus, a sensor that can detect $\mathrm{Mg}$ is desirable. Potassium $(\mathrm{K})$ and Lithium $(\mathrm{Li})$ are typically highly enriched in vent fluids due to leaching from basalts [48]. In vent fluids, concentrations range from approximately 250 - 23,163 ppm for $\mathrm{Na}, 0.6$ - $399 \mathrm{ppm}$ for $\mathrm{Mn},-54-4477 \mathrm{ppm}$ for $\mathrm{Ca},-47-3166$ ppm for $\mathrm{K}, 0 \mathrm{ppm}$ for $\mathrm{Mg}$, and $0.7-1073 \mathrm{ppm}$ for $\mathrm{Li}$ [47]. In seawater, concentrations are approximately $10933 \mathrm{ppm} \mathrm{Na},<0.001 \mathrm{Mn}, 419 \mathrm{ppm} \mathrm{Ca}, 405$ ppm K, 1300 ppm $\mathrm{Mg}$, and $0.2 \mathrm{ppm} \mathrm{Li} \mathrm{[47].}$ 


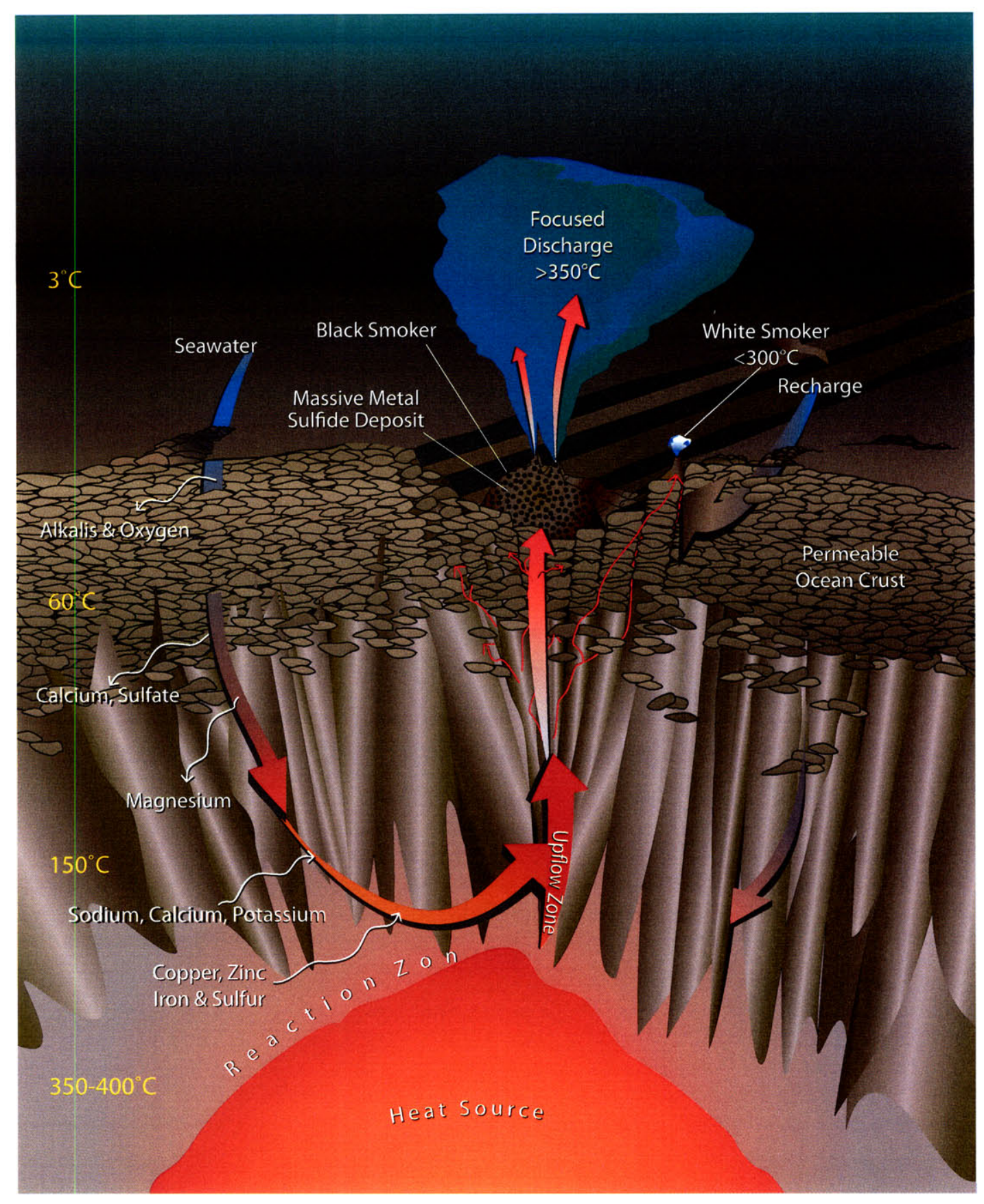

Figure 1-1: At hydrothermal vents, the cold seawater seeps down through the permeable seafloor where it undergoes chemical changes. The hot vent fluid finally vents at the seafloor. Illustration by E. Paul Oberlander. Reprinted from Oceanus, Dec. 1, 1998 with permission from Susan Humphris, WHOI. 


\subsection{Thesis Overview}

New sensors take a significant amount of time to develop; thus, the evaluation of techniques in the laboratory for use in the ocean environment is becoming increasingly important. This thesis focuses on this proof-of-concept phase, in which the LIBS analytical technique is evaluated in the laboratory under in situ conditions. It is divided into five chapters that cover single and double pulse LIBS and delves into the parameters that must be optimized for the detection of elements in high pressure aqueous solutions. A new data processing scheme for dealing with the inherent variability of laser-induced plasmas is developed in this thesis. This processing scheme is applied to all data presented in Chapters 4 - 6 .

Chapter Two, "Laser-induced breakdown spectroscopy of bulk aqueous solutions at oceanic pressures: Evaluation of key measurement parameters," is a manuscript that appeared in the 1 May 2007 issue of Applied Optics [40]. It presents preliminary investigations on the feasibility of using LIBS to detect analytes in bulk liquids at oceanic pressures. This work was completed as part of two extensive research visits to the University of South Carolina.

Chapter Three, "Analysis of laser-induced breakdown spectroscopy (LIBS) spectra: The case for extreme value statistics," is a manuscript that has been accepted for publication by Spectrochimica Acta: Part B [51]. It presents a new data processing approach for LIBS spectra.

Chapters Four and Five are complementary chapters that look at the detection of analytes in bulk aqueous solutions at oceanic pressures using single pulse (Chapter 4) and double pulse (Chapter 5) LIBS. These two chapters focus on the optimization of the key experimental parameters for the detection of analytes. Chapter Four deals with the detection of three elements: sodium, calcium, and manganese and the interrelationship of pressure, gate delay, and pulse energy. Chapter Five concentrates on the detection of sodium, calcium, manganese, potassium, and magnesium and the interrelationship of pressure, gate delay, pulse energies, and interpulse delay. In both chapters, calibration curves and limits of detection are presented.

Chapter Six presents preliminary investigations into matrix effects for three elements: sodium, calcium, and potassium. This chapter also explores the effect of a chloride versus sulfate background matrix on the detection of sodium and potassium. 


\section{Bibliography}

[1] F. Brech and L. Cross. Optical microemission stimulated by a a ruby maser. Applied Spectroscopy, 16:59, 1962.

[2] R. S. Harmon, F. C. DeLucia, C. E. McManus, N. J. McMillan, T. F. Jenkins, M. E. Walsh, and A. Miziolek. Laser-induced breakdown spectroscopy - an emerging chemical sensor technology for real-time field-portable, geochemical, mineralogical, and environmental applications. Applied Geochemistry, 21(5):730747, May 2006.

[3] A. S. Eppler, D. A. Cremers, D. D. Hickmott, M. J. Ferris, and A. C. Koskelo. Matrix effects in the detection of $\mathrm{Pb}$ and $\mathrm{Ba}$ in soils using laser-induced breakdown spectroscopy. Applied Spectroscopy, 50:1175-1181, 1996.

[4] D. Anglos. Laser-induced breakdown spectroscopy in art and archaeology. Applied Spectroscopy, 55:186A-205A, 2001.

[5] G. Galbacs, I. B. Gornushkin, B. W. Smith, and J. D. Winefordner. Semiquantitative analysis of binary alloys using laser-induced breakdown spectroscopy and a new calibration approach based on linear correlation. Spectrochimica Acta Part B, 56:1159-1173, 2001.

[6] A. C. Samuels, F. C. DeLucia, Jr., K. L. McNesby, and A. W. Miziolek. Laserinduced breakdown spectroscopy of bacterial spores, molds, pollens, and protein: initial studies of discrimination potential. Applied Optics, 42(30):6205-6209, 2003.

[7] L. St-Onge, E. Kwong, M. Sabsabi, and E. B. Vadas. Quantitative analysis of pharmaceutical products by laser-induced breakdown spectroscopy. Spectrochimica Acta Part B, 57(7):1131-1140, 2002.

[8] N. Carmona, M. Oujjab, E. Rebollar, H. Romich, and M. Castillejo. Analysis of corroded glasses by laser induced breakdown spectroscopy. Spectrochimica Acta Part B, 2005.

[9] A. I. Whitehouse, J. Young, I. M. Botheroyd, S. Lawson, C. P. Evans, and J. Wright. Remote material analysis of nuclear power station steam generator tubes by laser-induced breakdown spectroscopy. Spectrochimica Acta Part B, 56:821-830, 2001.

[10] D. Anglos, S. Couris, and C. Fotakis. Artworks: laser-induced breakdown spectroscopy in pigment identification. Applied Spectroscopy, 51:1025-1030, 1997.

[11] A. Bertolini, G. Carelli, F. Francesconi, M. Francesconi, L. Marchesini, P. Marsili, F. Sorrentino, G. Cristoforetti, S. Legnaioli, V. Palleschi, L. Pardini, and A. Salvetti. Modi: a new mobile instrument for in situ double-pulse LIBS analysis. Analytical and Bioanalytical Chemistry, V385(2):240-247, May 2006. 
[12] M. Corsi, G. Cristoforetti, M. Hidalgo, S. Legnaioli, V. Palleschi, A. Salvetti, E. Tognoni, and C. Vallebona. Double pulse, calibration-free laser-induced breakdown spectroscopy: A new technique for in situ standard-less analysis of polluted soils. Applied Geochemistry, 21(5):748-755, 2006.

[13] S. Palanco, C. Lopez-Moreno, and J. J. Laserna. Design, construction and assessment of a field-deployable laser-induced breakdown spectrometer for remote elemental sensing. Spectrochimica Acta Part B, 61(1):88-95, January 2006.

[14] R. S. Harmon, F. C. DeLucia, A. LaPointe, R. J. Winkel, and A. W. Miziolek. LIBS for landmine detection and discrimination. Analytical and Bioanalytical Chemistry, V385(6):1140-1148, 2006.

[15] Z. A. Arp, D. A. Cremers, R. C. Wiens, D. M. Wayne, B. Sallé, and S. Maurice. Analysis of water ice and water ice/soil mixtures using laser-induced breakdown spectroscopy: Application to Mars polar exploration. Applied Spectroscopy, 58:897-909, 2004.

[16] Z. A. Arp, D. A. Cremers, R. D. Harris, D. M. Oschwald, G. R. Parker Jr., and D. M. Wayne. Feasibility of generating a useful laser-induced breakdown spectroscopy plasma on rocks at high pressure: preliminary study for a Venus mission. Spectrochimica Acta Part B, 59:987-999, 2004.

[17] G. B. Courrèges-Lacoste, B. Ahlers, and F. R. Pérez. Combined Raman spectrometer/laser-induced breakdown spectrometer for the next ESA mission to Mars. Spectrochimica Acta Part A, In Press, 2007.

[18] R. Brennetot, J. L. Lacour, E. Vors, A. Rivoallan, D. Vailhen, and S. Maurice. Mars analysis by laser-induced breakdown spectroscopy (MALIS): Influence of Mars atmosphere on plasma emission and study of factors influencing plasma emission with the use of Doehlert designs. Applied Spectroscopy, 57(7):744-752, 2003.

[19] A. Knight, N. Scherbarth, D. Cremers, and M. Ferris. Characterization of laserinduced breakdown spectroscopy (LIBS) for application to space exploration. Applied Spectrosopy, 54:331-340, 2000.

[20] B. Sallé, J.-L. Lacour, P. Mauchien, P. Fichet, S. Maurice, and G. Manhes. Comparative study of different methodologies for quantitative rock analysis by laser-induced breakdown spectroscopy in a simulated Martian atmosphere. Spectrochimica Acta Part B, 61:301-313, 2006.

[21] L. Niu, H. Cho, K. Song, H. Cha, Y. Kim, and Y. Lee. Direct determination of strontium in marine algae samples by laser-induced breakdown spectrometry. Applied Spectroscopy, 56:1511-1514, 2002.

[22] R. Barbini, F. Colao, V. Lazic, R. Fantoni, A. Palucci, and M. Angelone. On board LIBS analysis of marine sediments collected during the XVI Italian campaign in Antarctica. Spectrochimica Acta B, 57:1203-1218, 2002. 
[23] A. De Giacomo, M. Dell'Aglio, F. Colao, R. Fantoni, and V. Lazic. Double-pulse LIBS in bulk water and on submerged bronze samples. Applied Surface Science, 247:157-162, 2005.

[24] A. De Giacomo, M. Dell'Aglio, F. Colao, and R. Fantoni. Double pulse laser produced plasma on metallic target in seawater: basic aspects and analytical approach. Spectrochimica Acta B, 59:1431-1438, 2004.

[25] A. De Giacomo, M. Dell'Aglio, A. Casavola, G. Colonna, O. De Pascale, and M. Capitelli. Elemental chemical analysis of submerged targets by double-pulse laser-induced breakdown spectroscopy. Analytical and Bioanalytical Chemistry, V385(2):303-311, 2006.

[26] A. De Giacomo, M. Dell'Aglio, O. De Pascale, and M. Capitelli. From single pulse to double pulse ns-laser induced breakdown spectroscopy under water: elemental analysis of aqueous solutions and submerged solid samples. Spectrochimica Acta Part $B$, in press, 2007.

[27] Y. Lee, K. Song, and J. Sneddon. Laser-induced breakdown spectrometry. Nova Science Publishers, Inc, Huntington, NY, 2000.

[28] X. Hou and B. T. Jones. Field instrumentation in atomic spectroscopy. Microchemical Journal, 66:115-145, 2000.

[29] P. K. Kennedy, S. A. Boppart, D. X. Hammer, B. A. Rockwell, G. D. Noojin, and W. P. Roach. A first-order model for computation of laser-induced breakdown thresholds in ocular and aqueous media: Part II - comparison to experiment. IEEE Journal of Quantum Electronics, 31:2250-2257, 1995.

[30] D. A. Cremers and L. J. Radziemski. Laser-Induced Breakdown Spectroscopy (LIBS): Fundamentals and Applications, chapter History and Fundamentals of LIBS, pages 1-39. Cambridge University Press, 2006.

[31] D. A. Rusak, B. C. Castle, B. W. Smith, and J. D. Winefordner. Recent trends and the future of laser-induced plasma spectroscopy. Trends in Analytical Chemistry, 17:453-461, 1998.

[32] J. Ingle Jr. and S. Crouch. Spectrochemical Analysis. Prentice Hall, New Jersey, 1988.

[33] R. Nyga and W. Neu. Double-pulse technique for optical emission spectroscopy of ablation plasmas of samples in liquids. Optics Letters, 18:747-749, 1993.

[34] R. T. Wainner, R. S. Harmon, A. W. Miziolek, K. L. McNesby, and P. D. French. Analysis of environmental lead contamination: Comparison of LIBS field and laboratory instruments. Spectrochimica Acta Part B, 56:777-793, 2001. 
[35] D. A. Rusak, B. C. Castle, B. W. Smith, and J. D. Winefordner. Fundamentals and applications of laser-induced breakdown spectroscopy. Critical Reviews in Analytical Chemistry, 27:257-290, 1997.

[36] E. Tognoni, V. Palleschi, M. Corsi, and G. Cristoforetti. Quantitative microanalysis by laser-induced breakdown spectroscopy: A review of the experimental approaches. Spectrochimica Acta Part B, 57:1115-1130, 2002.

[37] D. A. Cremers, L. J. Radziemski, and T. R. Loree. Spectrochemical analysis of liquids using the laser spark. Applied Spectroscopy, 38:721-729, 1984.

[38] R. Knopp, F. J. Scherbaum, and J. I. Kim. Laser induced breakdown spectroscopy (LIBS) as an analytical tool for the detection of metal ions in aqueous solutions. Fresenius' Journal of Analytical Chemistry, 355:16-20, 1996.

[39] W. Pearman, J. Scaffidi, and S. M. Angel. Dual-pulse laser-induced breakdown spectroscopy in bulk aqueous solution with an orthogonal beam geometry. $A p$ plied Optics, 42:6085-6093, 2003.

[40] A. P. M. Michel, M. Lawrence-Snyder, S. M. Angel, and A. D. Chave. Laserinduced breakdown spectroscopy of bulk aqueous solutions at oceanic pressures: evaluation of key measurement parameters. Applied Optics, 46, 2007.

[41] M. Lawrence-Snyder, J. Scaffidi, S. M. Angel, A. P.M. Michel, and A. D. Chave. Sequential-pulse laser-induced breakdown spectroscopy of high-pressure bulk aqueous solutions. Applied Spectroscopy, 61:171-176, 2007.

[42] M. Lawrence-Snyder, J. Scaffidi, S. M. Angel, A. P. M. Michel, and A. D. Chave. Laser-induced breakdown spectroscopy of high-pressure bulk aqueous solutions. Applied Spectroscopy, 60:786-790, 2006.

[43] A. E. Pichahchy, D. A. Cremers, and M. J. Ferris. Elemental analysis of metals under water using laser-induced breakdown spectroscopy. Spectrochimica Acta Part B, 52:25-39, 1997.

[44] C. Haisch, J. Liermann, U. Panne, and R. Niessner. Characterization of colloidal particles by laser-induced plasma spectroscopy (LIPS). Analytica Chimica Acta, 346:23-25, 1997.

[45] D. A. Cremers and L. J. Radziemski. Handbook of Laser-Induced Breakdown Spectroscopy. John Wiley and Sons, Ltd., 2006.

[46] P. K. Kennedy, D. X. Hammer, and B. A. Rockwell. Laser-induced breakdown in aqueous media. Progress in Quantum Electronics, 21:155-248, 1997.

[47] C. R. German and K. L. Von Damm. Treatise on Geochemistry, chapter Hydrothermal Processes, pages 181-222. Elsevier, 2003. 
[48] K. L. Von Damm. Controls on the chemisty and temporal variability of seafloor hydrothermal fluids. Seafloor hydrothermal systems: physical, chemical, biological, and geological interactions: Geophysical Monograph 91, pages 222-247, 1995.

[49] J. H. Trefry, D. B. Butterfield, S. Metz, G. J. Massoth, R. P. Trocine, and R. A. Feely. Trace metals in hydrothermal solutions from Cleft segment on the southern Juan de Fuca Ridge. Journal of Geophysical Research, 99:4925-4935, 1994.

[50] K. L. Von Damm. Chemistry of hydrothermal vent fluids from $9^{\circ}-10^{\circ} \mathrm{N}$, East Pacific Rise: 'Time zero,' The immediate posteruptive period. Journal of Geophysical Research, 105:11203-11222, 2000.

[51] A. P. M. Michel and A. D. Chave. Analysis of laser-induced breakdown spectroscopy (LIBS) spectra: The case for extreme value statistics. Spectrochimica Acta Part B, In Press. 


\section{Chapter 2}

\section{Laser-induced breakdown}

spectroscopy of bulk aqueous

solutions at oceanic pressures:

evaluation of key measurement

\section{parameters}

The work in this chapter is published in the 1 May 2007 issue of Applied Optics as A. P. M. Michel, M. Lawrence-Snyder, S. M. Angel, and A. D. Chave, "Laser-induced breakdown spectroscopy of bulk aqueous solutions at oceanic pressures: evaluation of key measurement parameters."

\subsection{Abstract}

The development of in situ chemical sensors is critical for present day expeditionary oceanography and the new mode of ocean observing systems that we are entering. New sensors take a significant amount of time to develop; therefore, validation of techniques in the laboratory for use in the ocean environment is necessary. Laser-induced breakdown spectroscopy (LIBS) is a promising in situ technique for oceanography. Laboratory investigations on the feasibility of using LIBS to detect analytes in bulk liquids at oceanic pressures were carried out. LIBS was successfully used to detect dissolved $\mathrm{Na}, \mathrm{Mn}, \mathrm{Ca}, \mathrm{K}$, and $\mathrm{Li}$ at pressures up to $2.76 \times 10^{7} \mathrm{~Pa}$. The effects of pressure, laser pulse energy, interpulse delay, gate delay, temperature, and $\mathrm{NaCl}$ 
concentration on the LIBS signal were examined. An optimal range of laser pulse energies was found to exist for analyte detection in bulk aqueous solutions at both low and high pressures. No pressure effect was seen on the emission intensity for $\mathrm{Ca}$ and $\mathrm{Na}$ and an increase in emission intensity with increased pressure was seen for Mn. Using the dual pulse technique for several analytes, a very short interpulse delay resulted in the greatest emission intensity. The presence of $\mathrm{NaCl}$ enhanced the emission intensity for $\mathrm{Ca}$, but had no effect on peak intensity of $\mathrm{Mn}$ or $\mathrm{K}$. Overall, increased pressure, the addition of $\mathrm{NaCl}$ to a solution, and temperature did not inhibit detection of analytes in solution and sometimes even enhanced the ability to detect the analytes. The results suggest that LIBS is a viable chemical sensing method for in situ analyte detection in high pressure environments like the deep ocean.

\subsection{Introduction}

Since laser-induced breakdown spectroscopy (LIBS) was first reported in 1962, the technique has evolved into a widely used method for laboratory analytical chemistry [1-8]. Due to several advantages over other methods, LIBS has been identified as a viable tool for in situ measurements, especially in extreme environments [9, 10]. The technique yields simultaneous sensitivity to virtually all elements in the partsper-million (ppm) or better range in solids, gases, aerosols, and at the gas-liquid interface. LIBS is effectively non-invasive, requiring only a small sample (typically, pg to ng of material are ablated). Unlike for many analysis techniques, the sample does not need to be prepared. LIBS requires only optical access to a sample and therefore can be used in a stand-off mode without perturbing the sample environment. LIBS measurements are essentially real-time, with typical sampling rates of less than one second per cycle. These characteristics are all required for in situ chemical sensing in the ocean [11-15].

Although researchers have been successful at inducing plasma ablation on submerged materials [16], on a water surface or film [17-22], and in liquid jets, droplets, and flowing solutions, [23-29] only limited LIBS work has focused on analyte detection within bulk aqueous solutions [30-32]. Furthermore, the work within bulk aqueous solutions has been at atmospheric pressure. Pioneering work by Cremers et al. [30] showed that LIBS could identify $\mathrm{Li}, \mathrm{Na}, \mathrm{K}, \mathrm{Rb}, \mathrm{Cs}, \mathrm{Be}, \mathrm{Ca}, \mathrm{B}$, and $\mathrm{Al}$ in aqueous solutions with varying detection limits, but typically at the ppm level. Several studies in bulk liquids have displayed a reduction in the time during which plasma emission can be observed as compared to that in air [16, 30, 31, 33]. The 
plasma lifetime is typically $\leq 1 \mu \mathrm{s}$ in bulk liquids, whereas at an air-liquid interface it averages 5-20 $\mu$ s. Laser-induced plasmas formed in solution are also characterized by a reduction in plasma light intensity.

The effects of elevated pressure and temperature on LIBS spectra have received limited attention. Although a few researchers report on LIBS at super-atmospheric pressures, they do not extend beyond $1 \times 10^{7} \mathrm{~Pa}$ (note: $1 \mathrm{~Pa}=1 \times 10^{-5}$ bars), which is well below the ambient pressure in the deep ocean [9, 34]; yet, none of these studies were for liquids. Although, we have previously reported preliminary findings that show the ability to detect analytes in high pressure bulk aqueous solutions [35], we now focus on the key measurement parameters that are needed for analyte detection. The influence of in situ temperature is anticipated to be weak because of the high plasma temperature $(\approx 8000 \mathrm{~K}$ at early times) [36-39].

For many years, oceanography has been in an expeditionary mode where research vessels are used for short term instrument deployments with limited resolution in time. Although oceanographers will continue to study the ocean in this way, a new paradigm using ocean observatories for long term in situ observing is upon us. As this shift towards long term ocean observing systems becomes recognized, we must also acknowledge the need for in situ sensors; especially those capable of temporal studies. A major need is for chemical sensors. The development of new sensors for oceanography takes a significant amount of time, and hence laboratory validation of techniques such as LIBS is necessary now to identify techniques that are viable for chemical detection in high pressure, high salinity, aqueous environments.

Although LIBS has the potential for use in numerous ocean environments, and has applicability to solids and liquids, we have focused on the feasibility of detecting elements at one extreme ocean environment, hydrothermal vents. Hydrothermal venting occurs on mid-ocean ridges where seawater circulates through the fractured and permeable oceanic crust. Exit temperatures at discrete (orifice diameters of a few centimeters) high-temperature vents range from $200-405^{\circ} \mathrm{C}$ at ambient pressures of $1.5 \times 10^{7}$ to $3.7 \times 10^{7} \mathrm{~Pa}$. Low-temperature (usually $<35^{\circ} \mathrm{C}$ ) diffuse flow seeping from porous surfaces or cracks is frequently observed [40]. The circulation is driven by the direct or indirect thermal effects of magma at sub-seafloor depths of up to a few $\mathrm{km}$. Substantial changes in fluid composition occur due to interaction with the host rock, phase separation into a mixed liquid-vapor form, and possibly magma degassing. Many alkalis (e.g., $\mathrm{Li}, \mathrm{Na}$, and $\mathrm{Ca}$ ) and transition metals (e.g., $\mathrm{Fe}, \mathrm{Mn}$, $\mathrm{Cu}$, and $\mathrm{Zn}$ ) are leached from the host rock and concentrated to varying degrees in the hydrothermal fluid, while $\mathrm{Mg}$ and $\mathrm{SO}_{4}$ are largely removed from the fluid by pre- 
cipitation into $\mathrm{Mg}-\mathrm{OH}-\mathrm{Si}$ minerals and anhydrite, respectively [40]. Von Damm and Butterfield et al. provide comprehensive reviews of the chemistry of hydrothermal vent fluids [40,41].

In this paper, we explore the effect of vent system environmental factors such as pressure, temperature, and $\mathrm{NaCl}$ concentration on the LIBS signal to assess the feasibility of developing LIBS for in situ chemical sensing in the ocean. In addition, several system parameters (laser energy per pulse, interpulse spacing, and gate delay) are optimized for high pressures for the first time.

\subsection{Experiment}

A laboratory LIBS system was designed to operate with a high pressure cell (Figure 21). For single pulse experiments, a Continuum Surelite III laser (5-ns pulse width) was utilized. For dual pulse experiments, a Quantel Nd 580 (9-ns pulse width) was used for the first laser pulse followed by a second pulse from the Surelite laser. Both lasers were Q-switched Nd:YAG types operated at the fundamental wavelength with a repetition rate of $5 \mathrm{~Hz}$. For dual pulse experiments, a variable clock (Stanford Instruments Model SR250) and a delay generator (Stanford Instruments Model DG535) controlled laser triggering.

The laser pulses were focused into a high pressure cell, designed to reach pressures of $3.45 \times 10^{7} \mathrm{~Pa}$ and constructed of stainless steel Swagelok fittings with six 1"-ID $(1$ in. $=2.54 \mathrm{~cm})$ and $1-\frac{1}{4}^{\prime \prime}-\mathrm{OD}$ ports. Stainless steel tubing $\left(\frac{1}{8}^{\prime \prime}\right)$ connected one port to a pump (Isco Syringe Pump Model 260D, Teledyne Technologies Incorporated) that allowed aqueous solutions to flow into the cell and the cell to be pressurized. A second port was equipped with the same tubing and a regulating valve for cell drainage. Two ports were fitted with $1^{\prime \prime}$ diameter, $\frac{1}{8}$ " thick circular sapphire windows (MSW100/125, Meller Optics Incorporated) held in place by hex nuts and sealed

with rubber washers, allowing $\frac{3}{4}$ " of each window to be visible outside the cell. The remaining two ports were sealed with Swagelok plugs (SS-1610-P).

Three different optical arrangements for focusing the laser pulses into the cell and for collection of the plasma emission were used in these experiments, as detailed in Figure 2-2. Because the purpose of these experiments was initial investigation into the feasibility of using LIBS for ocean applications, one of the goals was determining the best optical set-up. For dual pulse operation, the lasers were collinear. In some single pulse configurations, light collection was collinear to the laser pulse, while in others it was orthogonal for ease of alignment. All optics were mounted on micrometer stages, 


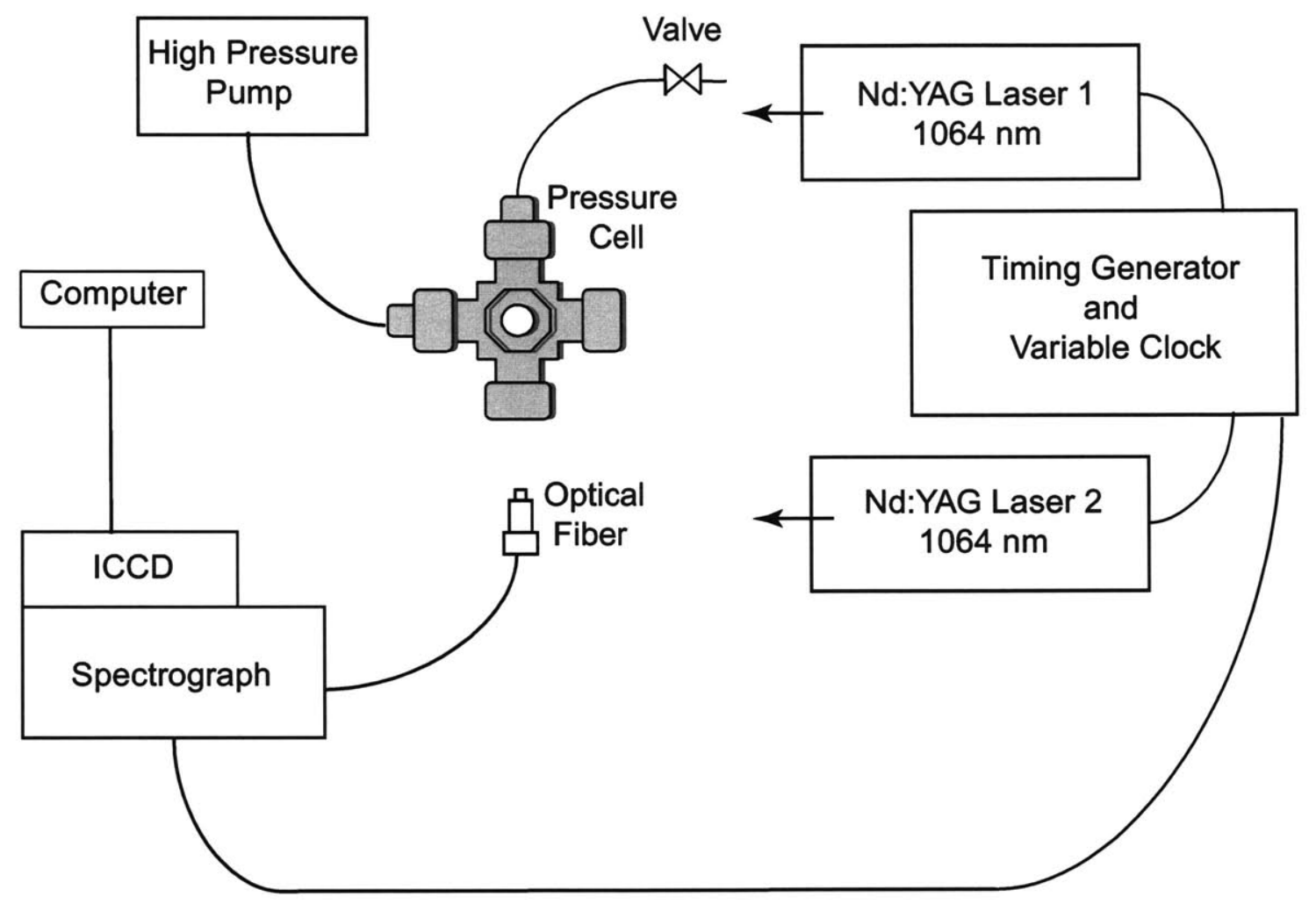

Figure 2-1: Schematic of the laboratory LIBS apparatus. Note that in the drawing, the laser pulses are simply represented by arrows as their optical paths are described in Figure 2-2. 


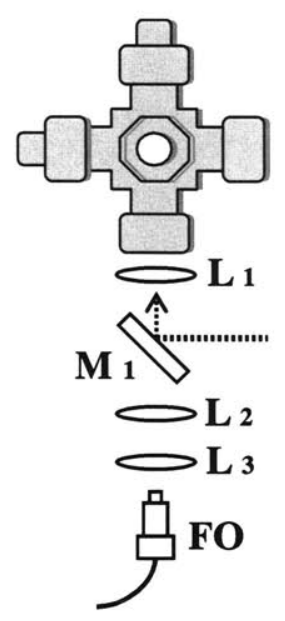

(a)

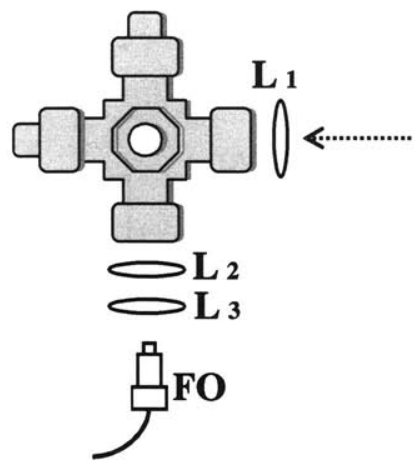

(b)

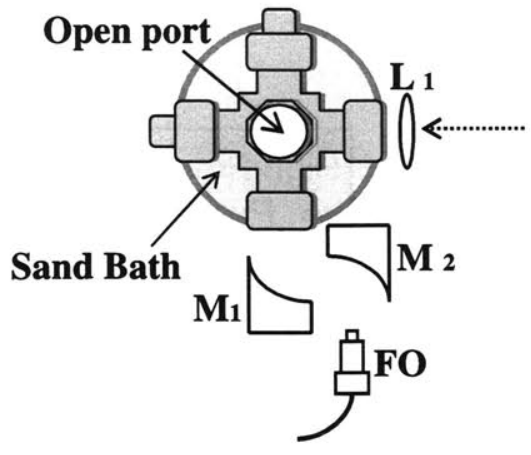

(c)

Figure 2-2: Optical arrangements used in experiments showing the high pressure cell with respect to incoming laser pulses (signified by a dashed line). $F O=$ Optical Fiber. (a) $\mathrm{L}_{1}, \mathrm{~L}_{2}$, and $\mathrm{L}_{3}=f / 4$ lenses; $\mathrm{M}_{1}=$ dielectric coated mirror, (b) $\mathrm{L}_{1}=f / 4$, To study the effect of $\mathrm{NaCl}$ concentration on spectra: $\mathrm{L}_{2}=f / 3$ lens, $\mathrm{L}_{3}=f / 2$ lens. To study the detection of Ca at varying concentrations: $\mathrm{L}_{2}=f / 4$ lens, $\mathrm{L}_{3}=f / 3$ lens, (c) $\mathrm{L}_{1}=f / 4, \mathrm{M}_{1}$ and $\mathrm{M}_{2}=$ parabolic off-axis mirrors

enabling precise control of beam overlap and collection field of view within the high pressure cell. All lenses were made of fused silica. In all optical configurations, the plasma emission was focused onto a 2-mm-core-diameter, 0.51-N.A. light guide (Edmund Scientific Co. Model 02551). The light guide was connected to a 0.25-m, f/4 spectrograph (Chromex model 250is/RF) with a 1200-groove/mm grating blazed at $500 \mathrm{~nm}$. The slit width (W) ranged from $25-250 \mu \mathrm{m}$. Data were collected on an intensified CCD detector (Princeton Instruments, I-Max 1024E) and acquired with a computer running WinSpec/32 software. All spectra were accumulations of 250 shots at the maximum gain setting of 255 . All error bars represent $\pm 1 \sigma$. A similar apparatus and set-up was previously used to demonstrate the feasibility of high pressure LIBS [35].

The key LIBS timing parameters have been previously described [16, 32]. The first and second laser pulse energies are referred to as $E_{1}$ and $E_{2}$. For dual pulse experiments, the time interval between the two pulses or interpulse delay, is referred to as $\Delta \mathrm{T}$. The gate delay, $\mathrm{t}_{d}$, is the time between the last laser pulse and turn-on of the detector. The plasma emission is recorded by the detector for the length of time set by the gate width, $\mathrm{t}_{b}$, which was set at $1 \mu$ s for all experiments reported here. 
Laser beam waist width $\mathrm{d}_{\sigma_{o}}$ can be estimated by:

$$
d_{\sigma_{\circ}}=\frac{4 f \lambda M^{2}}{\pi D}
$$

where $\mathrm{f}$ is the focal length of the focusing lens $(100 \mathrm{~mm}), \lambda$ is the laser wavelength $(1064 \mathrm{~nm}), \mathrm{M}^{2}$ is the beam propagation ratio which is typically $2-10$ for Nd:YAG lasers (we use a value of 6 ), and $\mathrm{D}$ is the diameter of the illuminated aperture of the focusing lens $(\approx 25 \mathrm{~mm})$ [42]. The beam waist width for the system is approximately $0.03 \mathrm{~mm}$. The average irradiance $\left(\mathrm{I}_{f}\right)$ at the beam waist can be estimated using:

$$
I_{f}=\frac{\pi E_{L} D^{2}}{4 \tau_{L} f^{2} \lambda^{2} M^{4}}
$$

where $\mathrm{E}_{L}$ is the laser pulse energy and $\tau_{L}$ is the pulse duration at the full peak width at half of the maximum intensity (FWHM) [42] (for the Continuum laser, $\tau_{L}=5 \mathrm{ns,}$ and for the Quantel laser, $\tau_{L}=9 \mathrm{~ns}$ ). The pulse energies of the Continuum laser used vary between $\approx 10-100 \mathrm{~mJ}$. The irradiance of the beam at the beam waist thus varies from $\approx 2.4 \times 10^{11}$ to $\approx 2.4 \times 10^{12} \mathrm{~W} / \mathrm{cm}^{2}$. The pulse energies of the Quantel laser used vary between $\approx 10-125 \mathrm{~mJ}$ with the irradiance thus varying from $1.3 \times$ $10^{11}$ to $1.7 \times 10^{12} \mathrm{~W} / \mathrm{cm}^{2}$.

Sample solutions were made by dissolving $\mathrm{NaCl}, \mathrm{CaCl}_{2}, \mathrm{LiCl}$, and $\mathrm{MnSO}_{4} \cdot \mathrm{H}_{2} \mathrm{O}$ in deionized water. Where noted, $\mathrm{NaCl}$ was added to the solutions to simulate a seawater environment. All concentrations are listed in parts per million (ppm wt./vol.).

\subsection{Results and Discussion}

\subsubsection{The Effect of Pulse Energy on LIBS Emission}

\section{Single-Pulse LIBS}

Two key constraints on the design of an oceanographic sensor system are instrument power consumption and form factor, both of which must be minimized. LIBS operation with a small, low power laser would simplify the design of an oceanographic LIBS instrument. The effect of pulse energy on signal intensity for analytes in solution at elevated pressure was investigated with the goal of minimizing power consumption. The peak signal intensity for four analytes $(\mathrm{Li}, \mathrm{Ca}, \mathrm{Na}$, and $\mathrm{Mn}$ ) was measured at laser pulse energies ranging from 11 to $91 \mathrm{~mJ}$ at both low $\left(7 \times 10^{5} \mathrm{~Pa}\right)$ and high $(2.76$ $\times 10^{7} \mathrm{~Pa}$ ) pressures using the collinear optical configuration shown in Figure 2-2(a) 


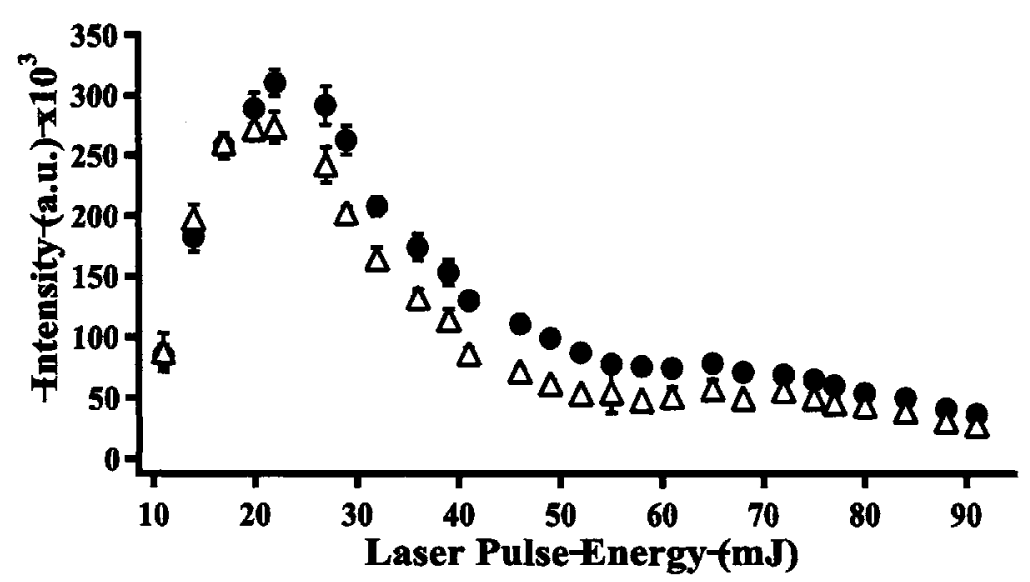

(a) Data taken at $7 \times 10^{5} \mathrm{~Pa}()^{\circ}$ and $2.76 \times 10^{7} \mathrm{~Pa}(\triangle)$.

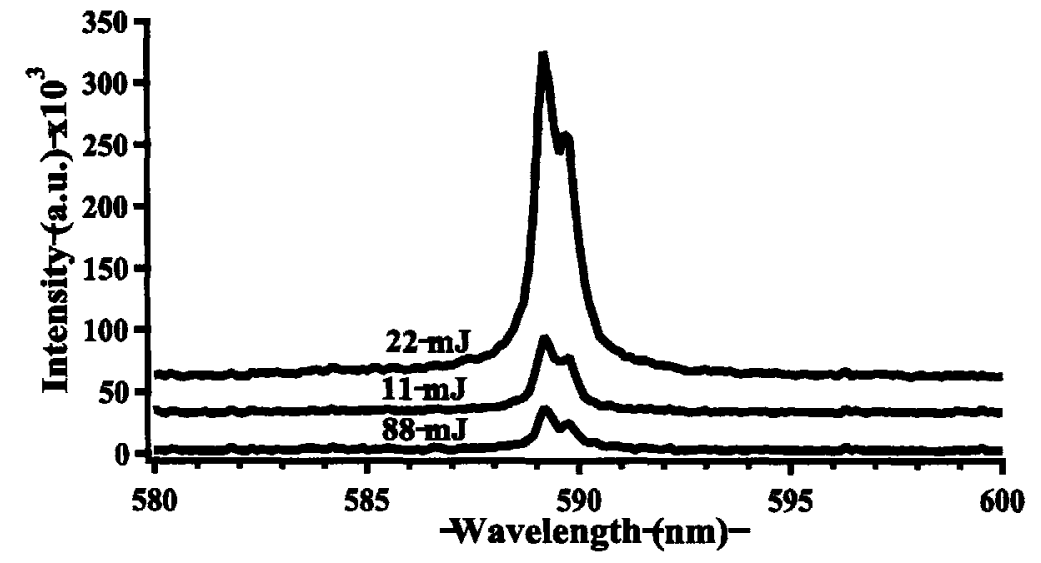

(b) $\mathrm{Na}$ (I) spectra taken at $2.76 \times 10^{7} \mathrm{~Pa}$. Spectra offset for clarity.

Figure 2-3: Effect of laser pulse energy on the LIBS signal intensity of $100 \mathrm{ppm} \mathrm{Na(I)}$ $(588.995 \mathrm{~nm})$.

$\left(\mathrm{t}_{d}=350 \mathrm{~ns}, \mathrm{~W}=75 \mu \mathrm{m}\right.$ for $\mathrm{Na}, \mathrm{Mn}$, and Ca studies, and $\mathrm{W}=250 \mathrm{~nm}$ for $\mathrm{Li}$ ). Ten spectra were recorded and averaged for each condition.

Figure 2-3 shows the dependence of the $\mathrm{Na}(\mathrm{I})(588.995 \mathrm{~nm})$ emission line on laser pulse energy for $100 \mathrm{ppm} \mathrm{Na}$. In both low and high pressure experiments, as pulse energy increases, a corresponding increase in peak intensity occurs until a maximum intensity is reached at $22 \mathrm{~mJ}$ (Figure 2-3(a)). Above this value, emission intensity decreases sharply up to $\approx 50 \mathrm{~mJ}$, above which a more gradual decrease with energy is observed. These data suggest that, independent of pressure, a low laser pulse energy yields greater emission intensity providing the energy exceeds a threshold value. Figure 2-3(b) compares spectra taken at laser pulse energies below, above, and in the optimal energy range for $\mathrm{Na}$. The top trace $(22 \mathrm{~mJ})$ shows a significantly greater intensity than at either a very low (middle trace, $11 \mathrm{~mJ}$ ) or a high (bottom trace, $88 \mathrm{~mJ}$ ) pulse energy. 
The effect of laser pulse energy on $\mathrm{Ca}(422.673 \mathrm{~nm})$ and $\mathrm{Li}(670.776 \mathrm{~nm}$ and $670.791 \mathrm{~nm}$, unresolved doublet) emission displayed similar trends. When less than $14 \mathrm{~mJ}$ was used, Ca was virtually undetectable. As the pulse energy was increased above this level, emission intensified until a maximum was achieved at $36 \mathrm{~mJ}$ for low pressure $\left(7 \times 10^{5} \mathrm{~Pa}\right)$ and at $29 \mathrm{~mJ}$ for high pressure $\left(2.76 \times 10^{7} \mathrm{~Pa}\right)$. This range for both the low and high pressure environments was $\approx 25$ to $50 \mathrm{~mJ}$. At energy levels beyond the optimal range, intensity decreased slowly with increasing pulse energy, possibly due to plasma shielding. Plasma shielding occurs when the plasma itself reduces the transmission of the laser pulse energy along the beam path. Calcium displayed a more gradual increase and then decrease in intensity and a wider range of optimal energy compared to Na. Similar trends were observed for Li. At both low and high pressures, plasma emission was not detectable below $11 \mathrm{~mJ}$. At higher pulse energies and both pressures, the emission maximum was recorded at $27 \mathrm{~mJ}$, above which a sharp decrease in intensity to $46 \mathrm{~mJ}$ was observed, followed by flattening to $72 \mathrm{~mJ}$.

The relationship between emission intensity and laser pulse energy for the unresolved $403 \mathrm{~nm} \mathrm{Mn(I)} \mathrm{triplet} \mathrm{was} \mathrm{slightly} \mathrm{different} \mathrm{than} \mathrm{for} \mathrm{the} \mathrm{other} \mathrm{three} \mathrm{analytes.}$ Figure 2-4(a) shows that the lowest laser pulse energy $(11 \mathrm{~mJ})$ resulted in the highest emission intensity. At pulse energies greater than $11 \mathrm{~mJ}$, the emission intensity gradually decreased until it was no longer detectable above $\approx 40 \mathrm{~mJ}$ and $\approx 70 \mathrm{~mJ}$ for low and high pressures, respectively. The peak intensity was greater at high than at low pressure. Figure 2-4(b) compares spectra taken at 11, 22, and $88 \mathrm{~mJ}$ at 2.76 $\times 10^{7} \mathrm{~Pa}$.

The data for $\mathrm{Na}, \mathrm{Ca}, \mathrm{Li}$, and $\mathrm{Mn}$ suggest that the pulse energy required to optimize the LIBS signal is analyte-dependent due to different ionization energies, but is minimally pressure dependent. A pulse energy threshold is also observed. For the four analytes studied, a relatively low laser pulse energy (less than $50 \mathrm{~mJ}$ ) produced the greatest signal intensity. A low energy optimal range may exist due to effects from plasma shielding or moving breakdown. Plasmas can expand back along the laser beam path towards the laser resulting in elongated plasmas [43]. A higher energy pulse may form a more elongate plasma or a series of plasmas as the breakdown threshold of the liquid is exceeded before the pulse reaches the focal point. This may result in non-optimal collection of the plasma emission. Further studies using imaging techniques are needed to elucidate the effect of pulse energy on the plasma.

Figure 2-5 shows the effect of pressure on the LIBS signal for $\mathrm{Na}(588.995 \mathrm{~nm}), \mathrm{Mn}$ (403 nm unresolvable triplet) and $\mathrm{Ca}(422.673 \mathrm{~nm})$ using a low energy single pulse. 


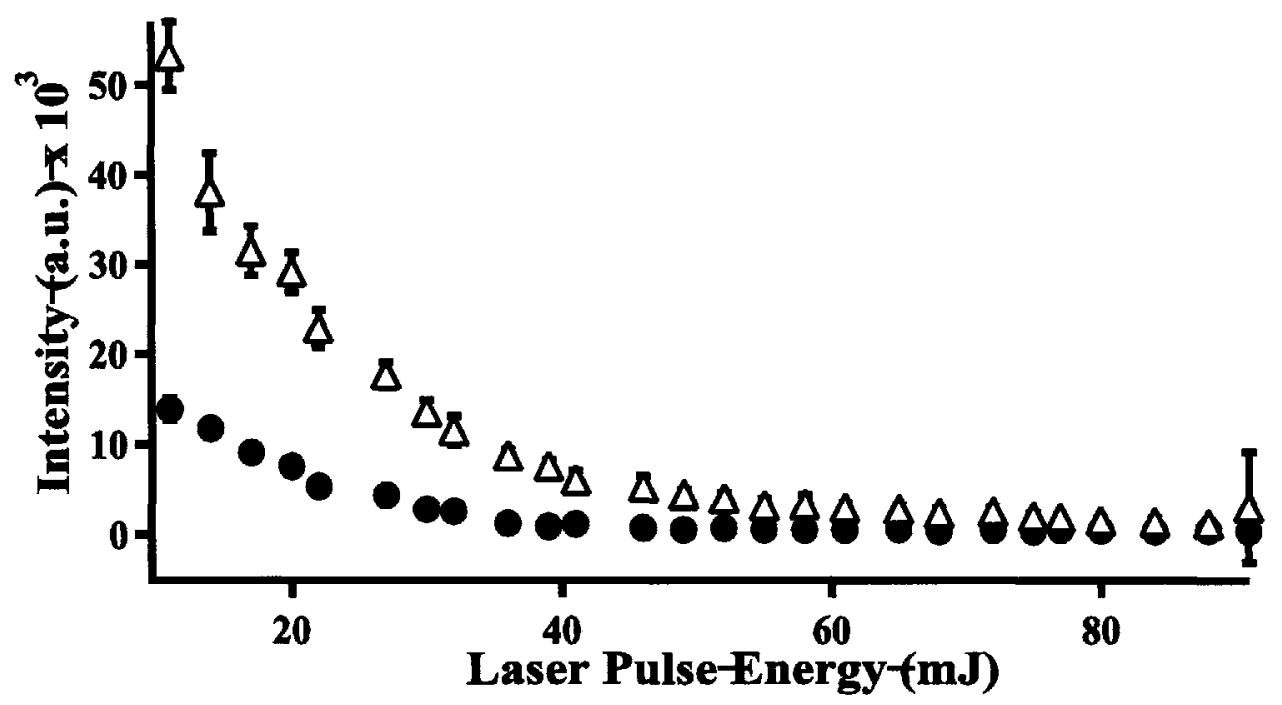

(a) Data taken at $7 \times 10^{5} \mathrm{~Pa}(-)$ and $2.76 \times 10^{7} \mathrm{~Pa}(\triangle)$

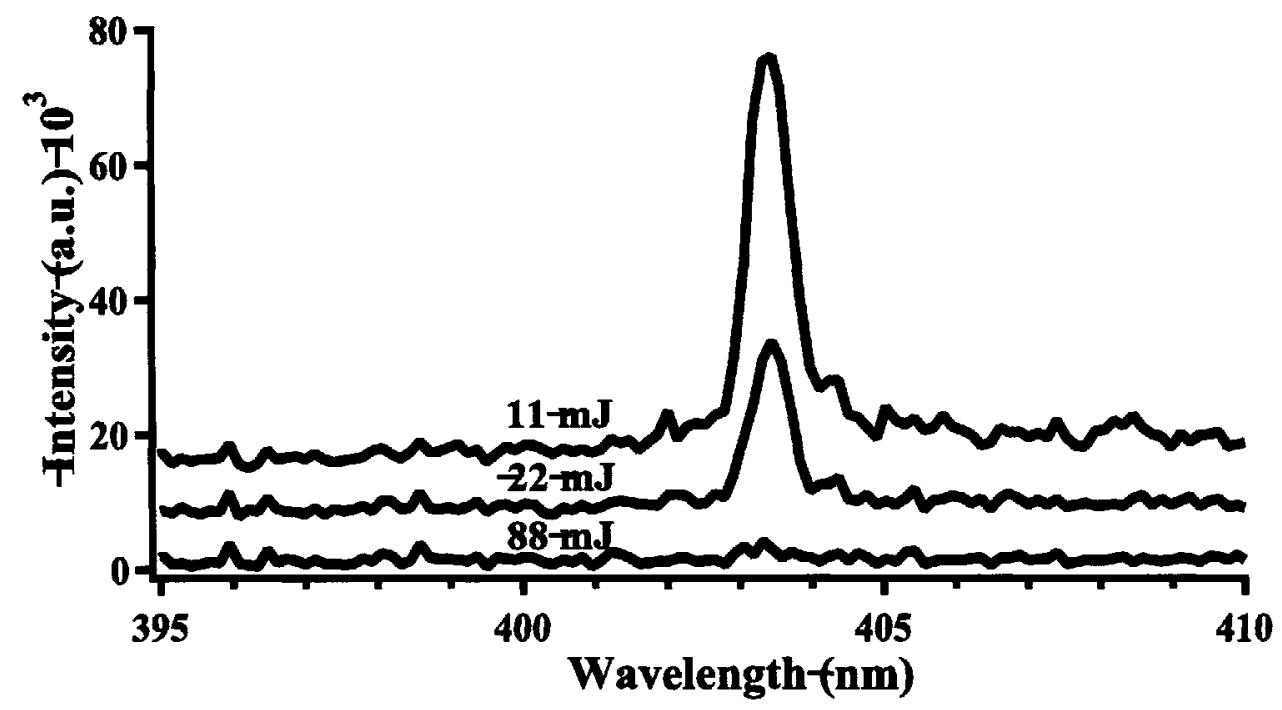

(b) $\mathrm{Mn}(\mathrm{I})$ spectra taken at $2.76 \times 10^{7} \mathrm{~Pa}$. Spectra offset for clarity

Figure 2-4: Effect of laser pulse energy on the LIBS emission intensity of the unresolvable $\mathrm{Mn}(\mathrm{I})$ triplet $(403 \mathrm{~nm})(5,000 \mathrm{ppm} \mathrm{Mn}$ in $2,540 \mathrm{ppm} \mathrm{NaCl})$. 


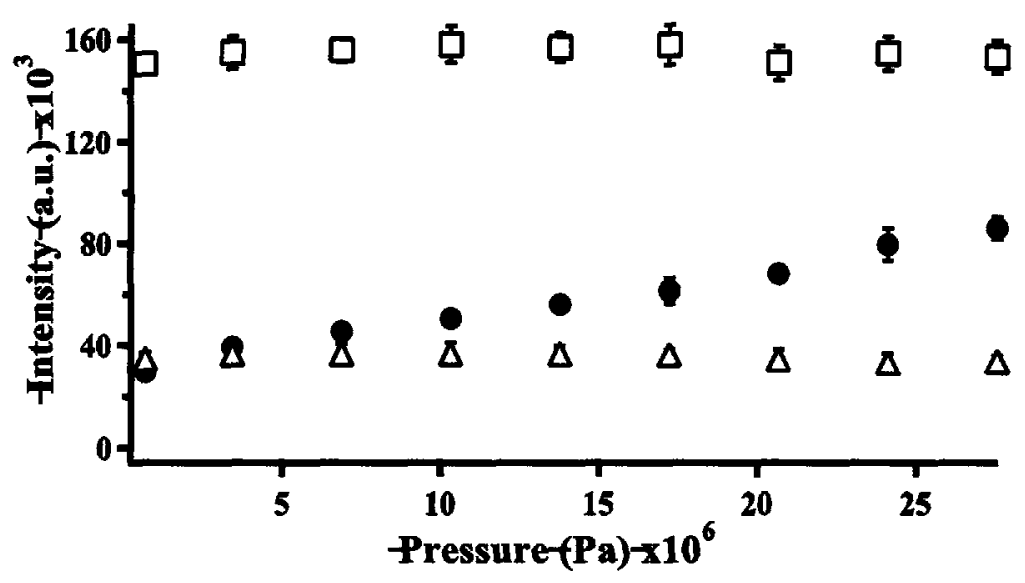

Figure 2-5: Effect of pressure on LIBS emission intensity. $\square=100 \mathrm{ppm} \mathrm{Na}(588.995$ $\mathrm{nm}$ ) with $\mathrm{E}=22 \mathrm{~mJ} ; \quad=5,000 \mathrm{ppm} \mathrm{Mn}$ (403 nm unresolvable triplet) with 2,540 $\mathrm{ppm} \mathrm{NaCl}, \mathrm{E}=14 \mathrm{~mJ} ; \triangle=500 \mathrm{ppm} \mathrm{Ca}(422.673 \mathrm{~nm})$ with $2,540 \mathrm{ppm} \mathrm{NaCl}, \mathrm{E}=$ $20 \mathrm{~mJ}$.

The gate delay was fixed at $350 \mathrm{~ns}$ and the slit width was fixed at $75 \mu \mathrm{m} . \mathrm{Na}$ and Ca display no change in signal intensity with increasing pressure, but Mn shows an increase. For all analytes examined, the FWHM did not change with pressure. Pressure under oceanic conditions does not induce a deleterious effect on signal intensity or on FWHM.

In these single pulse energy experiments, the same gate delay and gate width were used for all energy levels and pressures. As discussed later in this paper, optimal gate delay may be energy dependent. Optimal gate width was not investigated and may be pressure and/or energy level dependent. As a result, the selected gate width and gate delay may influence the measured emission intensity. Optimal gate delay could also be analyte dependent, and hence a different gate delay could yield another trend with pulse energy. However, the selected conditions demonstrate that low energy single laser pulses at high pressures are viable for measuring analytes in bulk aqueous liquids. This is promising toward the development of an ocean-going instrument where a small, low power laser will be critical.

\section{Dual Pulse LIBS at High Pressure}

An evaluation of dual pulse LIBS for high pressure bulk solutions shows that analyte detection is highly dependent on the interpulse delay. If the interpulse delay is short ( $\ll 1 \mu \mathrm{s}$ ), signal intensity is greatly enhanced when compared to that measured using longer delay times. However, such a small interpulse delay may not be sufficient for a cavitation bubble to fully form before the second laser pulse creates a spark. 
Dual pulse LIBS has been shown to enhance the signal intensity for some analytes in bulk aqueous solutions at atmospheric pressure [30,32]. However, such enhancements using longer interpulse delay times do not occur for high pressure liquids.

To demonstrate the coupled effect of interpulse delay and pulse energy on emission intensity, four energy level conditions were compared for four analytes at high pressure $\left(2.76 \times 10^{7} \mathrm{~Pa}\right)$ over a range of interpulse delay times. The four conditions were: 1$)$ low $\mathrm{E}_{1}$, low $\mathrm{E}_{2}$ (low-low), 2) high $\mathrm{E}_{1}$, high $\mathrm{E}_{2}$ (high-high), 3) low $\mathrm{E}_{1}$, high $\mathrm{E}_{2}$ (lowhigh), and 4) high $\mathrm{E}_{1}$, low $\mathrm{E}_{2}$ (high-low), and are detailed in Table 2.1, ( $\mathrm{t}_{d}=350 \mathrm{~ns}$, $\left.\mathrm{t}_{b}=1 \mu \mathrm{s}\right)$. These experiments were completed using the optical configuration shown in Figure 2-2(a).

For $\mathrm{Ca}(\mathrm{W}=100 \mu \mathrm{m})$, using a low $\mathrm{E}_{1}$ followed by a low $\mathrm{E}_{2}$ resulted in the highest peak intensity, possibly because when summed they give a low total energy (Figure 2-6). The greatest emission is observed for $E_{1}=13 \mathrm{~mJ}$ and $E_{2}=6 \mathrm{~mJ}$ and yields the ionic Ca peaks ( $393.366 \mathrm{~nm}$ and $396.847 \mathrm{~nm}$ in addition to the atomic peak 422.673 $\mathrm{nm}$ ). For this low-low condition, Figure 2-7(a) shows the emission intensity change with $\Delta \mathrm{T}$. For $\Delta \mathrm{T}$ greater than $1 \mu \mathrm{s}$, the intensity remained stable at a value of 1.5 $\times 10^{4}$ a.u.

For $\Delta \mathrm{T}$ less than $1 \mu \mathrm{s}$, the low-low configuration yielded intensities between 2.5 $\times 10^{4}$ and $8.7 \times 10^{4}$ a.u. Figure 2-7(b) compares spectra at very short (30 ns - upper trace) to long (30 $\mu \mathrm{s}$ - lower trace) $\Delta \mathrm{T}$ values. When a short $\Delta \mathrm{T}$ is used, three $\mathrm{Ca}$ peaks (Ca(II) $393.366 \mathrm{~nm}, \mathrm{Ca}$ (II) $396.847 \mathrm{~nm}$, and $\mathrm{Ca}(\mathrm{I}) 422.673 \mathrm{~nm}$ ) are visible, while for long $\Delta \mathrm{T}$, only the $\mathrm{Ca}(\mathrm{I})$ peak is present with a much lower intensity. When $\Delta T$ is $30 \mathrm{~ns}$, the low-low configuration yields significantly greater emission intensity

Table 2.1: Conditions used to study the effect of dual pulse energies on LIBS emission

\begin{tabular}{|l|c|c|c|c|c|c|c|c|}
\hline & \multicolumn{2}{|c|}{$\begin{array}{c}\text { Low } \mathrm{E}_{1} \\
\text { Low } \mathrm{E}_{2}\end{array}$} & \multicolumn{2}{c|}{$\begin{array}{c}\text { High } \mathrm{E}_{1} \\
\text { High } \mathrm{E}_{2}\end{array}$} & \multicolumn{2}{c|}{$\begin{array}{c}\text { Low } \mathrm{E}_{1} \\
\text { High } \mathrm{E}_{2}\end{array}$} & \multicolumn{2}{c|}{$\begin{array}{c}\text { High } \mathrm{E}_{1} \\
\text { Low } \mathrm{E}_{2}\end{array}$} \\
\hline & $\begin{array}{c}\mathrm{E}_{1} \\
(\mathrm{~mJ})\end{array}$ & $\begin{array}{c}\mathrm{E}_{2} \\
(\mathrm{~mJ})\end{array}$ & $\begin{array}{c}\mathrm{E}_{1} \\
(\mathrm{~mJ})\end{array}$ & $\begin{array}{c}\mathrm{E}_{2} \\
(\mathrm{~mJ})\end{array}$ & $\begin{array}{c}\mathrm{E}_{1} \\
(\mathrm{~mJ})\end{array}$ & $\begin{array}{c}\mathrm{E}_{2} \\
(\mathrm{~mJ})\end{array}$ & $\begin{array}{c}\mathrm{E}_{1} \\
(\mathrm{~mJ})\end{array}$ & $\begin{array}{c}\mathrm{E}_{2} \\
(\mathrm{~mJ})\end{array}$ \\
\hline $\begin{array}{l}1,000 \mathrm{ppm} \mathrm{Ca}, \\
2,540 \mathrm{ppm} \mathrm{NaCl}\end{array}$ & 13 & 6 & 105 & 84 & 13 & 84 & 105 & 6 \\
\hline $100 \mathrm{ppm} \mathrm{Li}$ & 31 & 20 & 105 & 84 & 31 & 84 & 105 & 20 \\
\hline $100 \mathrm{ppm} \mathrm{Na}$ & 13 & 6 & 105 & 84 & 13 & 84 & 105 & 6 \\
\hline $\begin{array}{l}5,000 \mathrm{ppm} \mathrm{Mn}, \\
2,540 \mathrm{ppm} \mathrm{NaCl}\end{array}$ & 13 & 6 & 105 & 84 & 13 & 84 & 105 & 6 \\
\hline
\end{tabular}




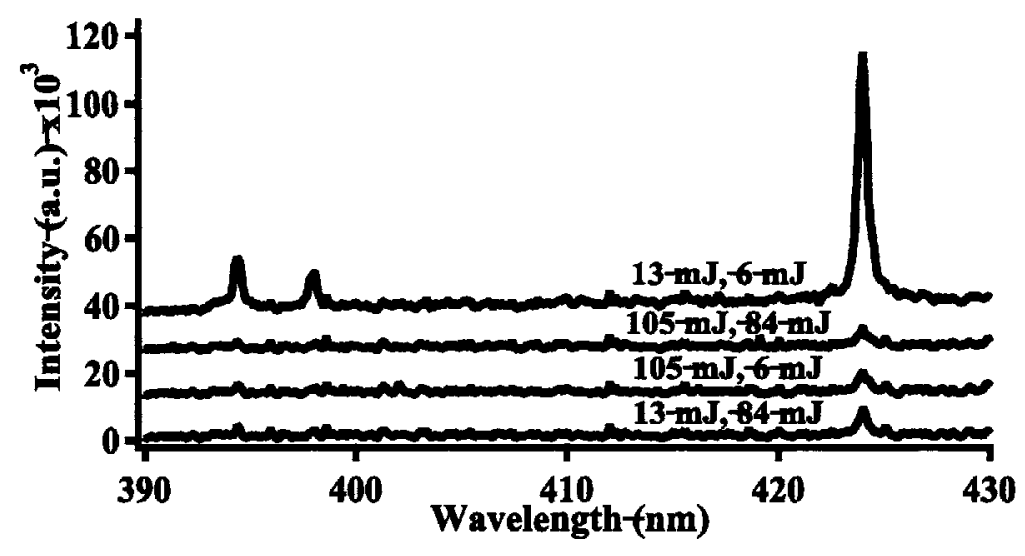

Figure 2-6: Spectra of 1,000 ppm Ca with 2,540 ppm $\mathrm{NaCl}$ at $2.76 \times 10^{7} \mathrm{~Pa}$ under four dual pulse conditions.

than the other pulse energy configurations. For $\mathrm{Li}(\mathrm{W}=250 \mu \mathrm{m})$, a low $\mathrm{E}_{1}$ followed by a low $E_{2}$ resulted in the greatest emission intensity. Table 2.2 shows peak emission for $\mathrm{Li}$ for four different dual pulse conditions for $\Delta \mathrm{T}$ between $50 \mathrm{~ns}$ and $1 \mu \mathrm{s}$.

A small delay time $(<1 \mu \mathrm{s})$ enhanced the emission as compared to a longer delay time when the low-high and low-low energy levels were used. For $\mathrm{Na}(\mathrm{I})$, the low-high and low-low conditions yielded similar intensities at all delay times, with maximum values of $9.3 \times 10^{5}$ a.u. and $8.3 \times 10^{5}$ a.u., respectively, $(\mathrm{W}=75 \mu \mathrm{m})$. After these four runs were compared, an additional configuration consisting of a $13 \mathrm{~mJ}$ first pulse followed by a $22 \mathrm{~mJ}$ second pulse was tested as a low-low dual pulse condition with a slightly increased second pulse energy. This resulted in peaks with intensities of 2.4 $\mathrm{x} 10^{6}-2.9 \times 10^{6}$ a.u. for all $\Delta \mathrm{T}$ values between $10 \mathrm{~ns}$ and $100 \mu \mathrm{s}$, suggesting again that a low-low energy condition produces the greatest emission intensity. For Mn (W $=250 \mu \mathrm{m}$ ), at all interpulse delay times between $20 \mathrm{~ns}$ and $100 \mu \mathrm{s}$, a low $\mathrm{E}_{1}$ followed by a high $\mathrm{E}_{2}$, resulted in the highest emission intensity (Figure 2-8).

These results show that the best dual pulse conditions vary by analyte. However,

Table 2.2: Dual pulse emission intensity (a.u.)

\begin{tabular}{|r|r|r|r|r|}
\hline & Condition 1 & Condition 2 & Condition 3 & Condition 4 \\
\hline & Low E1 & High E1 & Low E1 & High E1 \\
& Low E2 & High E2 & High E2 & Low E2 \\
\hline $100 \mathrm{ppm} \mathrm{Li}$ & $2.5 \times 10^{5}-$ & $2 \times 10^{4}-$ & $5 \times 10^{4}-$ & $1.5 \times 10^{4}-$ \\
& $3.7 \times 10^{5}$ & $7 \times 10^{4}$ & $1.5 \times 10^{5}$ & $5.3 \times 10^{4}$ \\
\hline $5,000 \mathrm{ppm} \mathrm{Mn}$ & $4 \times 10^{3}-$ & $2.1 \times 10^{5}-$ & $7 \times 10^{5}-$ & $1.6 \times 10^{3}-$ \\
$2,540 \mathrm{ppm} \mathrm{NaCl}$ & $4.2 \times 10^{5}$ & $5 \times 10^{5}$ & $8.3 \times 10^{5}$ & $2.6 \times 10^{5}$ \\
\hline
\end{tabular}




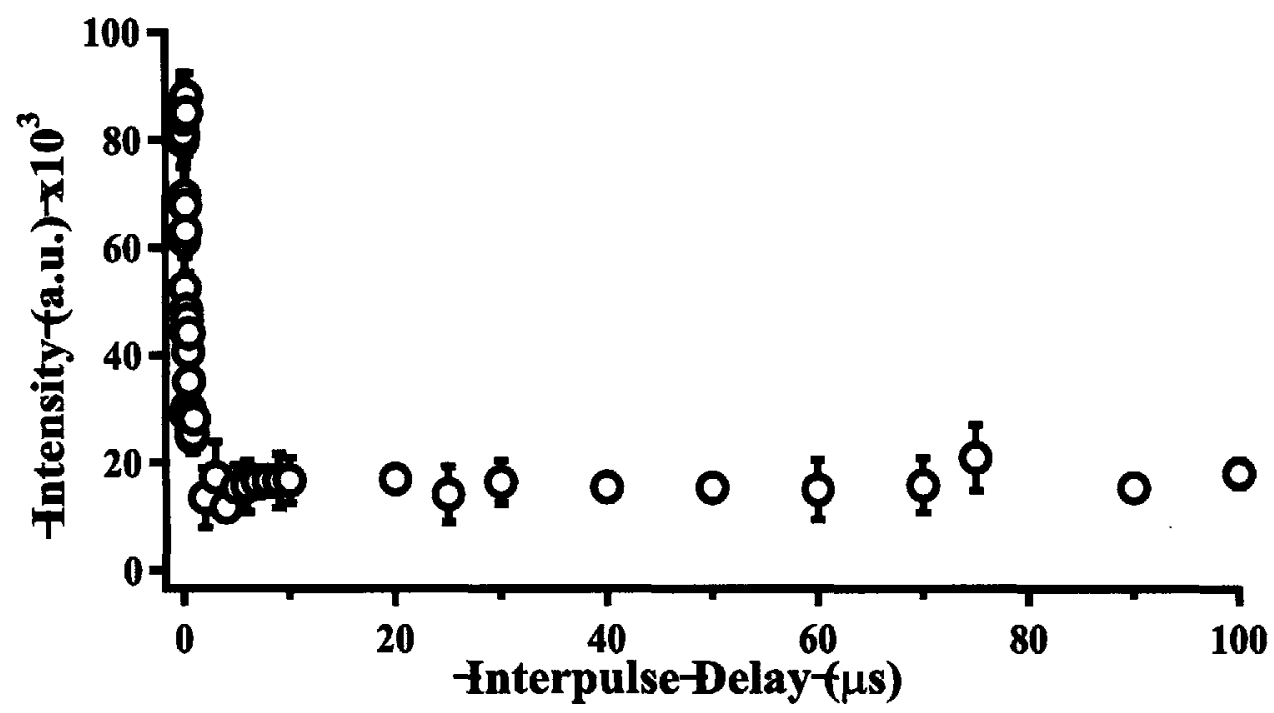

(a) Effect of dual laser pulse energies on emission intensity at $2.76 \times 10^{7} \mathrm{~Pa}$ for 1,000 $\mathrm{ppm} \mathrm{Ca}$ in $2,540 \mathrm{ppm} \mathrm{NaCl}$ at various interpulse delays. Each data point is the average of 5 spectra.

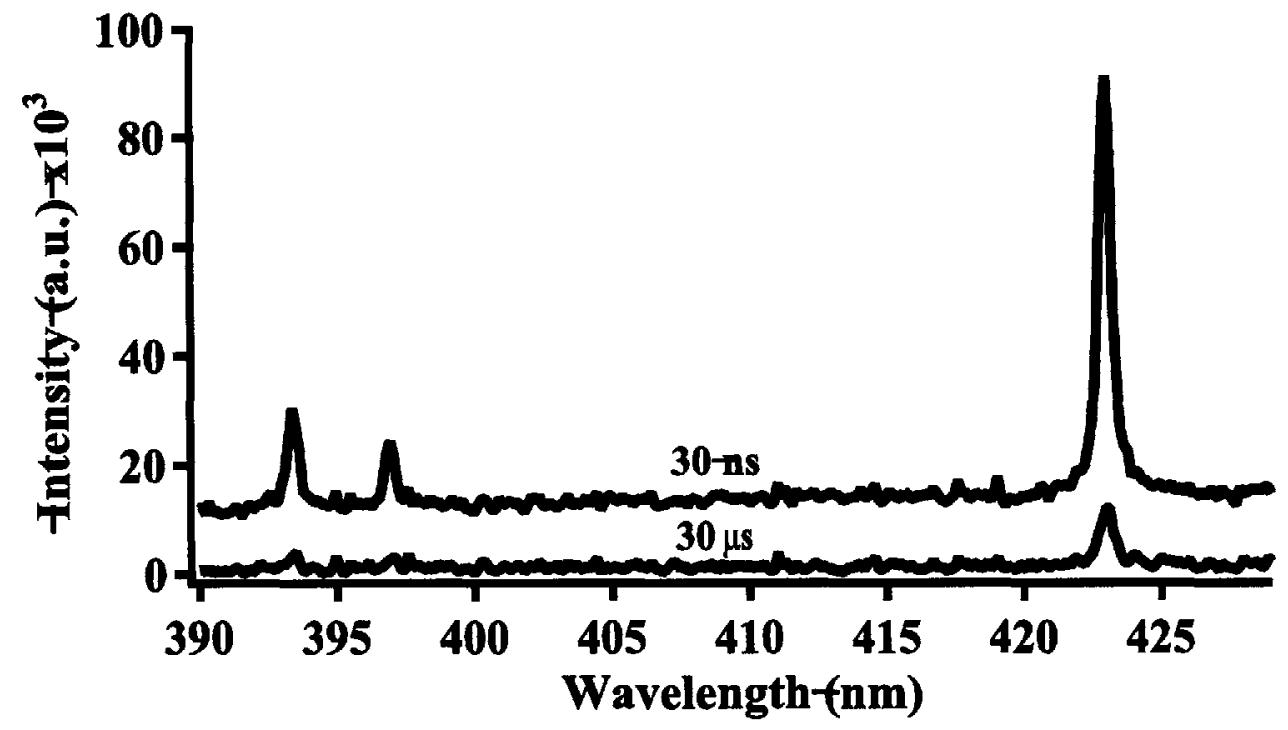

(b) Spectra of Ca showing the enhancement in signal for $\Delta T=30 \mathrm{~ns}$ over $\Delta \mathrm{T}=30$ $\mu \mathrm{s}$.

Figure 2-7: $\mathrm{Ca}$ emission at different interpulse delays. $\left(\mathrm{E}_{1}=13 \mathrm{~mJ}, \mathrm{E}_{2}=6 \mathrm{~mJ}.\right)$ 


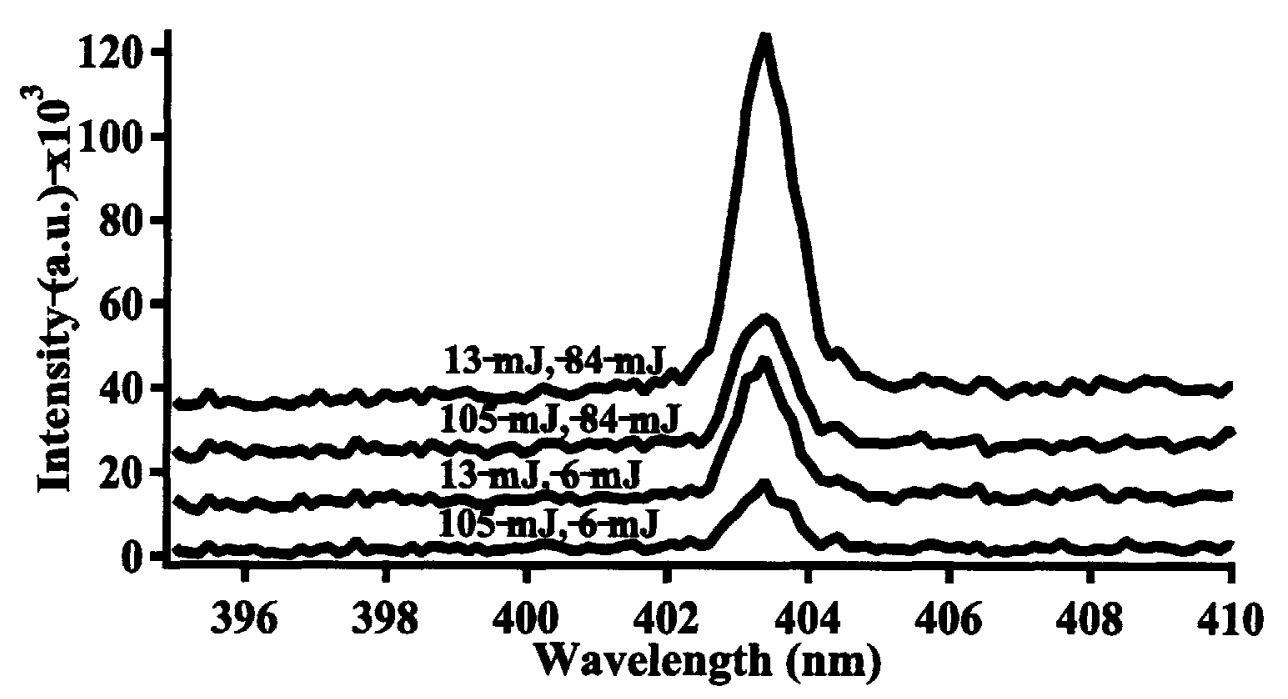

Figure 2-8: Spectra of 5,000 ppm Mn with $2,540 \mathrm{ppm} \mathrm{NaCl}$ at $2.76 \times 10^{7} \mathrm{~Pa}$ under four dual pulse conditions. The highest emission intensity is observed for a low-high pulse combination.

it is important to note that at high pressure, very short interpulse spacing results in a higher signal intensity than when dual pulses are separated by a more significant delay in time. The need for such rapid firing of the two pulses is only accomplished using two independent lasers instead of firing one laser rapidly. Two pulses separated by a short $\Delta \mathrm{T}$ approaches single pulse conditions, suggesting that dual pulse LIBS may not be advantageous at elevated pressure.

\subsubsection{Interrelationship of pulse energy, gate delay, and pres- sure for Lithium}

Emission intensity was recorded for the unresolved $\mathrm{Li}(\mathrm{I})$ doublet $(670.776 \mathrm{~nm}$ and $670.791 \mathrm{~nm})$ at two single pulse energies $(27 \mathrm{~mJ}$ and $68 \mathrm{~mJ})$ at both low $\left(7 \times 10^{5}\right.$ $\mathrm{Pa})$ and high pressure $\left(2.76 \times 10^{7} \mathrm{~Pa}\right)$ over a range of gate delays $(0.1-3.7 \mu \mathrm{s}),\left(\mathrm{t}_{b}\right.$ $=1 \mu \mathrm{s}, \mathrm{W}=25 \mu \mathrm{m})$ using the optical configuration of Figure 2-2(a). Comparing the two curves in Figure 2-9, it is clear that a short gate delay should be used to enhance emission intensity. These results also suggest that the optimal gate delay may be pulse energy but not pressure dependent.

\subsubsection{Effect of $\mathrm{NaCl}$ Concentration on LIBS Spectra}

Understanding how pervasive $\mathrm{Na}$ and $\mathrm{Cl}$ ions in solution affect the detection of other analytes is important for assessing the feasibility of using LIBS in the ocean, where 


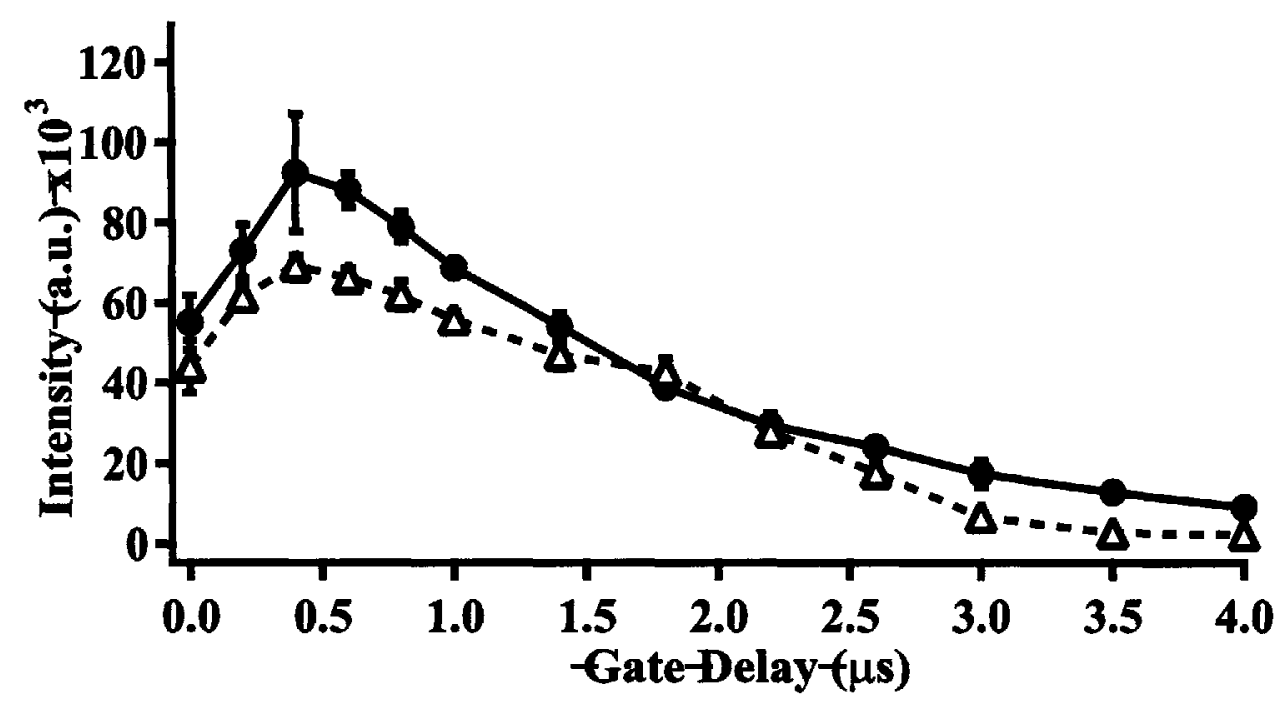

(a) Data taken with a single low energy pulse $(27 \mathrm{~mJ})$

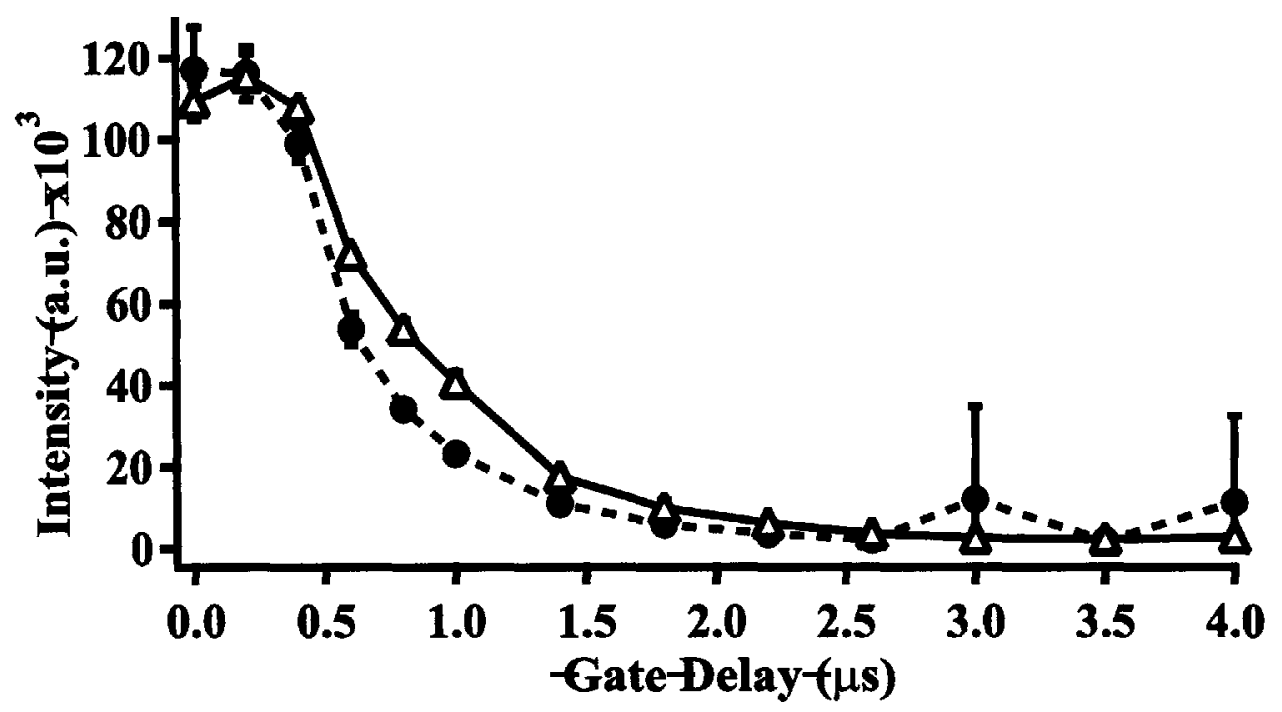

(b) Data taken with a single high energy pulse (68 $\mathrm{mJ})$.

Figure 2-9: Effect of gate delay on the LIBS signal for $1,000 \mathrm{ppm}$ Li (670 nm unresolvable doublet). $=7 \times 10^{5} \mathrm{~Pa}, \triangle=2.57 \times 10^{7} \mathrm{~Pa}$. 


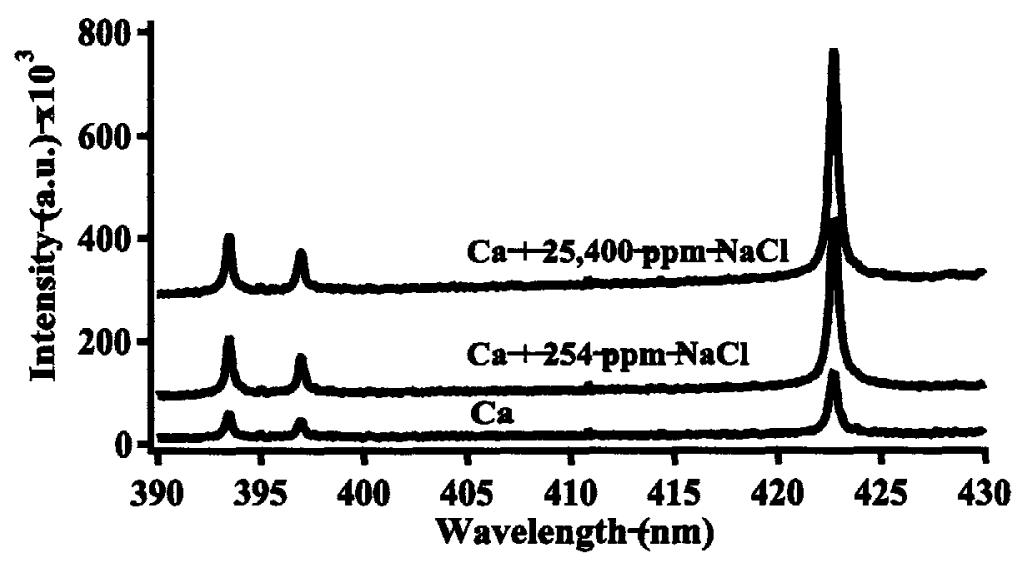

Figure 2-10: Effect of the addition of $\mathrm{NaCl}$ in solution on spectra of $1,000 \mathrm{ppm} \mathrm{Ca}$ at $2.57 \times 10^{7} \mathrm{~Pa}$.

the nominal concentrations of $\mathrm{Na}$ and $\mathrm{Cl}$ are $1.08 \times 10^{4} \mathrm{ppm}$ and $1.95 \times 10^{4} \mathrm{ppm}$, respectively [44]. Cremers et al. previously reported a decrease in the intensity ratio of $\mathrm{Ca}$ II/Ca I with the addition of $\mathrm{NaCl}$ [30]. The peak signal intensity for three analytes (1,000 ppm Ca, $100 \mathrm{ppm} \mathrm{Mn}$, and 1,000 ppm K) was compared in three solutes: 1) deionized water, 2) $2,540 \mathrm{ppm} \mathrm{NaCl}$ dissolved in deionized water, and 3) $25,400 \mathrm{ppm} \mathrm{NaCl}$ dissolved in deionized water using the optical configuration of Figure 2-2(b) and for a range of pressures $\left(3 \times 10^{5}, 7 \times 10^{5}, 1.7 \times 10^{6}, 3.4 \times 10^{6}, 6.9\right.$ $\times 10^{6}, 1.38 \times 10^{7}, 2.07 \times 10^{7}, 2.76 \times 10^{7} \mathrm{~Pa}$ ). These studies were carried out with $\mathrm{E}_{1}$ $=40 \mathrm{~mJ}, \mathrm{E}_{2}=125 \mathrm{~mJ}, \Delta \mathrm{T}=46 \mathrm{~ns}, \mathrm{~W}=35 \mu \mathrm{m}$, and $\mathrm{t}_{d}=100 \mathrm{~ns}$ for $\mathrm{Ca}$ and $\mathrm{K}$ and $\mathrm{t}_{d}$ $=200 \mathrm{~ns}$ for $\mathrm{Mn}$. The addition of $\mathrm{NaCl}$ significantly increased the emission intensity of the $422.673 \mathrm{~nm} \mathrm{Ca}(\mathrm{I})$ atomic line whereas no significant effect was seen on the $393.366 \mathrm{~nm}$ and $396.847 \mathrm{~nm} \mathrm{Ca(II)} \mathrm{ionic} \mathrm{lines} \mathrm{(Figure} \mathrm{2-10).} \mathrm{The} \mathrm{signal:noise} \mathrm{ratio}$ for the $\mathrm{Ca}$ (II) ionic lines showed no significant change with the addition of $\mathrm{NaCl}$, whereas the signal:noise ratio of $\mathrm{Ca}(\mathrm{I})$ increased from 22 to 30 with the addition of $\mathrm{NaCl}$. The same increase was seen with the addition of $254 \mathrm{ppm} \mathrm{NaCl}$ and 25,400 $\mathrm{ppm} \mathrm{NaCl}$. In atomic emission, adding an easily ionizable element, for example $\mathrm{Na}$, can suppress ionization of other elements. This suggests that ionization suppression by $\mathrm{Na}$ increases the $\mathrm{Ca}(\mathrm{I})$ emission relative to the $\mathrm{Ca}(\mathrm{II})$ lines. No intensity change was seen for $\mathrm{Mn}(\mathrm{I})$ (403 nm unresolvable triplet) or $\mathrm{K}(\mathrm{I})$ (766.491 nm and 769.897 $\mathrm{nm})$. However, since only atomic lines were detectable for $\mathrm{Mn}$ and $\mathrm{K}$, the relative increase of atomic to ionic lines could not be compared.

These two outcomes (enhancement of the signal or no change to the signal) suggest that the high $\mathrm{NaCl}$ concentration in the ocean will not have a deleterious effect on the ability to detect $\mathrm{Ca}, \mathrm{Mn}$, and $\mathrm{K}$ analytes. It also suggests that further work is 


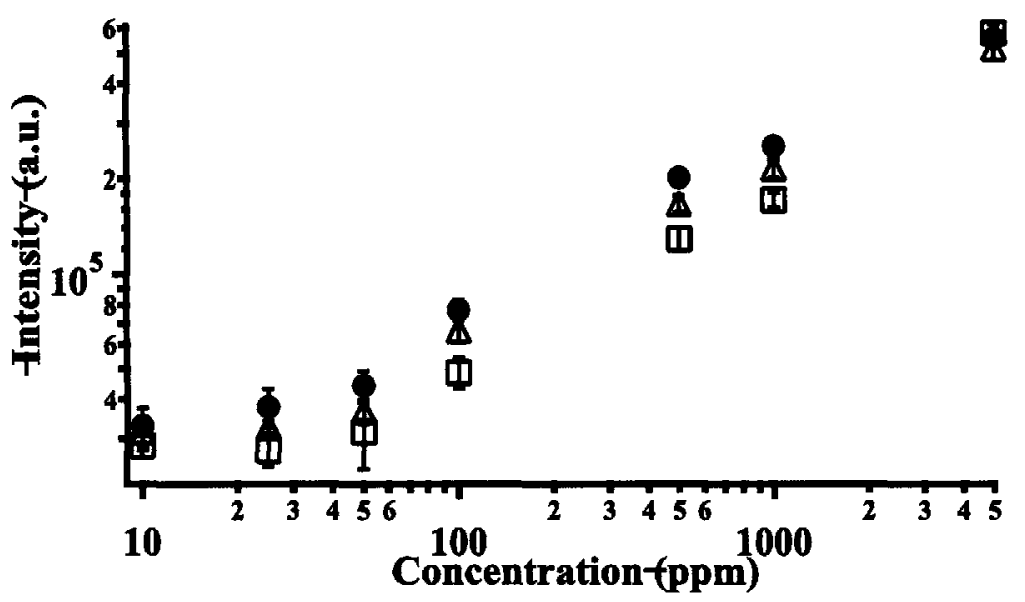

Figure 2-11: Detection of $\mathrm{Ca}(422.673 \mathrm{~nm})$ in a simulated vent fluid at varying pressures and concentrations. $\quad=7 \times 10^{5} \mathrm{~Pa}, \triangle=7 \times 10^{6} \mathrm{~Pa}, \square=2.76 \times 10^{7}$ $\mathrm{Pa}$.

needed to elucidate the effect $\mathrm{NaCl}$ has on other analytes.

\subsubsection{Detection of Calcium at Varying Concentrations}

Ca was used to determine whether increased pressure affects the limit of detection. Five pressures ranging from $7 \times 10^{5} \mathrm{~Pa}$ to $2.76 \times 10^{7} \mathrm{~Pa}$ were investigated at concentrations ranging from 10 to $5,000 \mathrm{ppm}$ in a solution containing several analytes (69 ppm Br, 10,828 ppm Na, 89 ppm Fe, 958 ppm K, 46 ppm Mn, 18,932 ppm Cl in DI water) found in hydrothermal vent fluids at representative concentrations (10 ppm, $25 \mathrm{ppm}, 50 \mathrm{ppm}, 100 \mathrm{ppm}, 500 \mathrm{ppm}, 1000 \mathrm{ppm}, 5000 \mathrm{ppm}$ ), using the optical configuration of Figure 2-2(b) $\left(\mathrm{E}_{1}=31 \mathrm{~mJ} ; \mathrm{E}_{2}=15 \mathrm{~mJ} ; \Delta \mathrm{T}=72 \mathrm{~ns} ; \mathrm{t}_{d}=700 \mathrm{~ns} ; \mathrm{t}_{d}\right.$ $=1 \mu \mathrm{s},=35 \mu \mathrm{m})$. Figure $2-11$ shows that varying concentrations of $\mathrm{Ca}$ are detectable at pressure and with a minimal change in intensity, suggesting that detection limits to the ppm level will be obtainable at high pressure.

\subsubsection{Solution Temperature Effects on Calcium Spectra}

To characterize the temperature effect for $\mathrm{Ca}$ spectra, the sample cell was placed in a sand bath heated by a hot plate. The drainage port was removed and a thermocouple was inserted to record the temperature of the aqueous solution. We investigated the effect of temperature on the peak intensity of $\mathrm{Ca}(\mathrm{I})(422.673 \mathrm{~nm})$ over the range 27 $-99^{\circ} \mathrm{C}$. Once the solution reached $99^{\circ} \mathrm{C}$, the hot plate was turned off and allowed to cool. Spectra were taken repeatedly using single-pulse LIBS as the temperature dropped. Ca line intensities were measured for a solution of $1,000 \mathrm{ppm} \mathrm{Ca}$ and 2,540 
ppm NaCl at atmospheric pressure using a single laser pulse of $37 \mathrm{~mJ},\left(\mathrm{t}_{d}=100 \mathrm{~ns}\right.$, $\left.\mathrm{t}_{b}=1 \mu \mathrm{s}, \mathrm{W}=35 \mu \mathrm{m}\right)$, and the optical configuration shown in Figure 2-2(c). Over this range, temperature had no effect on peak intensity.

\subsection{Conclusions}

An optimal range of low laser pulse energies exists for the detection of $\mathrm{Li}, \mathrm{Ca}, \mathrm{Mn}, \mathrm{K}$, and $\mathrm{Na}$ in bulk aqueous solutions at both low and high pressures. No pressure effect was seen on the emission intensity for $\mathrm{Ca}$ and $\mathrm{Na}$, and an increase in intensity with increased pressure was seen for $\mathrm{Mn}$. No line broadening due to pressure was observed for $\mathrm{Ca}, \mathrm{Na}$, or $\mathrm{Mn}$ emission. A low energy pulse may create a smaller, more tightly focused plasma that forms only at the focal spot. However, for a high energy pulse, the high energy density may cause breakdown even before the pulse reaches the focal spot. This may allow breakdown to occur over a longer distance. In addition, plasma shielding may occur. Further studies using imaging techniques will help to elucidate the relationship between the laser pulse energy and the subsequent plasma that is formed. Using the dual pulse technique for several analytes, a very short interpulse delay resulted in the greatest emission intensity. Since this condition approaches single pulse conditions, dual pulse LIBS may not be advantageous for some elements at high pressure. For different gate delays at fixed pressure, laser pulse energy affects peak intensity. The addition of $\mathrm{NaCl}$ enhanced the emission intensity for $\mathrm{Ca}$, but had no effect on the intensity of $\mathrm{Mn}$ or $\mathrm{K}$ peaks. Ca was detectable over a wide range of concentrations and pressures. In addition, temperature changes below $99^{\circ} \mathrm{C}$ had no noticeable effect on the emission intensity of Ca. Overall, increased pressure, the addition of $\mathrm{NaCl}$ to a solution, and temperature did not inhibit detection of analytes in solution. The results presented here suggest that LIBS is a viable technique for in situ chemical analysis in the deep ocean and further work should be carried out to develop LIBS into an in situ oceanographic sensor.

\subsection{Acknowledgments}

We acknowledge the National Science Foundation for support of this research under grants OCE0352278 and OCE0352242. Additional support was received from the Deep Ocean Exploration Institute of the Woods Hole Oceanographic Institution. 


\section{Bibliography}

[1] F. Brech and L. Cross. Optical microemission stimulated by a a ruby maser. Applied Spectroscopy, 16:59, 1962.

[2] V. Majidi and M. R. Joseph. Spectroscopic applications of laser-induced plasmas. Critical Reviews in Analytical Chemistry, 23:143-162, 1992.

[3] L. J. Radziemski. Review of analytical applications of laser plasmas and laser ablation, 1987-1994. Microchemical Journal, 50:218-234, 1994.

[4] D. A. Rusak, B. C. Castle, B. W. Smith, and J. D. Winefordner. Fundamentals and applications of laser-induced breakdown spectroscopy. Critical Reviews in Analytical Chemistry, 27:257-290, 1997.

[5] K. Song, Y. Lee, and J. Sneddon. Applications of laser-induced breakdown spectrometry. Applied Spectroscopy Reviews, 32:183-235, 1997.

[6] J. Sneddon and Y. Lee. Novel and recent applications of elemental determination by laser-induced breakdown spectroscopy. Analytical Letters, 32:2143-2162, 1999.

[7] D. A. Rusak, B. C. Castle, B. W. Smith, and J. D. Winefordner. Recent trends and the future of laser-induced plasma spectroscopy. Trends in Analytical Chemistry, 17:453-461, 1998.

[8] W. Lee, J. Wu, Y. Lee, and J. Sneddon. Recent applications of laser-induced breakdown spectrometry: a review of material approaches. Applied Spectroscopy Reviews, 39:27-97, 2004.

[9] Z. A. Arp, D. A. Cremers, R. D. Harris, D. M. Oschwald, G. R. Parker Jr., and D. M. Wayne. Feasibility of generating a useful laser-induced breakdown spectroscopy plasma on rocks at high pressure: preliminary study for a Venus mission. Spectrochimica Acta Part B, 59:987-999, 2004.

[10] B. Salle, J. Lacour, E. Vors, P. Fichet, S. Maurice, D. A. Cremers, and R. C. Wiens. Laser-induced breakdown spectroscopy for Mars surface analysis: capabilities at stand-off distances and detection of chlorine and sulfur elements. Spectrochim. Acta, 59:1413-1422, 2004.

[11] W. E. Seyfried, Jr., K. S. Johnson, and M. K. Tivey, editors. In-Situ Sensors: Their Development and Application for the Study of Chemical, Physical and Biological Systems at Mid-Ocean Ridges NSF/RIDGE-Sponsored Workshop, October 2000 .

[12] The next generation of in situ biological and chemical sensors in the ocean: a workshop report. 2004. 
[13] K. L. Daly, R. H. Byrne, A. G. Dickson, S. M. Gallager, M. J. Perry, and M. K. Tivey. Chemical and biological sensors for time-series research: current status and new directions. Journal of the Marine Technology Society, 38:121-143, 2004.

[14] T. Dickey. The role of new technology in advancing ocean biogeochemical studies. Oceanography, 14:108-120, 2001.

[15] M. S. Varney, editor. Chemical Sensors in Oceanography. Gordon and Breach, 2000.

[16] A. E. Pichahchy, D. A. Cremers, and M. J. Ferris. Elemental analysis of metals under water using laser-induced breakdown spectroscopy. Spectrochimica Acta Part B, 52:25-39, 1997.

[17] P. Fichet, D. Menut, R. Brennetot, E. Vors, and A. Rivoallan. Analysis by laserinduced breakdown spectroscopy of complex solids, liquids, and powders with an Echelle spectrometer. Appied Optics, 42:6029-6039, 2003.

[18] P. Fichet, P. Mauchien, J.-F. Wagner, and C. Moulin. Quantitative elemental determination in water and oil by laser induced breakdown spectroscopy. Analytica Chimica Acta, 429:269-278, 2001.

[19] G. Arca, A. Ciucci, V. Palleschi, S. Rastelli, and E. Tognoni. Trace element analysis in water by the laser-induced breakdown spectroscopy technique. Applied Spectroscopy, 51:1102-1105, 1997.

[20] O. Samek, D. C. S. Beddows, J. Kaiser, S. V. Kukhlevsky, M. Liska, H. H. Telle, and J. Young. Application of laser-induced breakdown spectroscopy to in situ analysis of liquid samples. Optical Engineering, 39:2248-2262, 2000.

[21] J. R. Wachter and D. A. Cremers. Determination of uranium in solution using laser-induced breakdown spectroscopy. Applied Spectroscopy, 41:1042-1048, 1987.

[22] A. Kuwako, Y. Uchida, and K. Maeda. Supersensitive detection of sodium in water with use of dual-pulse laser-induced breakdown spectroscopy. Applied Optics, 42:6052-6056, 2003.

[23] V. N. Rai, F. Y. Yueh, and J. P. Singh. Study of laser-induced breakdown emission from liquid under double pulse excitation. Applied Optics, 42:20942101, 2003.

[24] X. Y. Pu and N. H. Cheung. ArF laser induced plasma spectroscopy of lead ions in aqueous solutions: Plume reheating with a second Nd:YAG laser pulse. Applied Spectroscopy, 57:588-590, 1997.

[25] W. F. Ho, C. W. Ng, and N. H. Cheung. Spectrochemical analysis of liquids using laser-induced plasma emissions: effect of laser wavelength. Applied Spectroscopy, 51:87-91, 1997. 
[26] S. Nakamura, Y. Ito, and K. Sone. Determination of an iron suspension in water by laser-induced breakdown spectroscopy with two sequential laser pulses. Analytical Chemistry, 68:2981-2986, 1996.

[27] K. M. Lo and N. H. Cheung. ArF laser-induced plasma spectroscopy for partper-billion analysis of metal ions in aqueous solutions. Applied Spectroscopy, $56: 682-688,2002$.

[28] L. St-Onge, E. Kwong, M. Sabsabi, and E. B. Vadas. Rapid analysis of liquid formulations containing sodium chloride using laser-induced breakdown spectroscopy. Journal of Pharmaceutical and Biomedical Analysis, 36:277-284, 2004.

[29] J. Huang, C. Ke, and K. Lin. Matrix effect on emission/current correlated analysis in laser-induced breakdown spectroscopy of liquid droplets. Spectrochimica Acta Part B, 59:321-326, 2004.

[30] D. A. Cremers, L. J. Radziemski, and T. R. Loree. Spectrochemical analysis of liquids using the laser spark. Applied Spectroscopy, 38:721-729, 1984.

[31] R. Knopp, F. J. Scherbaum, and J. I. Kim. Laser induced breakdown spectroscopy (LIBS) as an analytical tool for the detection of metal ions in aqueous solutions. Fresenius' Journal of Analytical Chemistry, 355:16-20, 1996.

[32] W. Pearman, J. Scaffidi, and S. M. Angel. Dual-pulse laser-induced breakdown spectroscopy in bulk aqueous solution with an orthogonal beam geometry. $A p$ plied Optics, 42:6085-6093, 2003.

[33] C. Haisch, J. Liermann, U. Panne, and R. Niessner. Characterization of colloidal particles by laser-induced plasma spectroscopy (LIPS). Analytica Chimica Acta, 346:23-25, 1997.

[34] M. Noda, Y. Deguchi, S. Iwasaki, and N. Yoshikawa. Detection of carbon in a high-temperature and high-pressure environment using laser-induced breakdown spectroscopy. Spectrochimica Acta, 57:701-709, 2002.

[35] M. Lawrence-Snyder, J. Scaffidi, S. M. Angel, A. P. M. Michel, and A. D. Chave. Laser-induced breakdown spectroscopy of high-pressure bulk aqueous solutions. Applied Spectroscopy, 60:786-790, 2006.

[36] C. Aragon, J. A. Aguilers, and J. Campos. Determination of carbon content in molten steel using laser-induced breakdown spectroscopy. Applied Spectroscopy, 47:606-608, 1993.

[37] J. I. Yun, R. Klenze, and J. I. Kim. Laser-induced breakdown spectroscopy for the on-line multielement analysis of highly radioactive glass melt simulants: Part II analyses of molten glass samples. Applied Spectroscopy, 56:852-858, 2002.

[38] A. K. Rai, F. Y. Yueh, and J. P. Singh. Laser-induced breakdown spectroscopy of molten aluminum alloy. Applied Optics, 42:2078-2084, 2003. 
[39] L. G. Blevins, C. R. Shaddix, S. M. Sickafoose, and P. M. Walsh. Laser-induced breakdown spectroscopy at high temperatures in industrial boilers and furnaces. Applied Optics, 42:6107-6118, 2003.

[40] K. L. Von Damm. Chemistry of hydrothermal vent fluids from $9^{\circ}-10^{\circ} \mathrm{N}$, East Pacific Rise: 'Time zero,' The immediate posteruptive period. Journal of Geophysical Research, 105:11203-11222, 2000.

[41] D. A. Butterfield, I. R. Jonasson, G. J. Massoth, R. A. Feely, K. K. Roe, R. E. Embley, J. F. Holden, R. E McDuff, M. D. Lilley, and J. R. Delaney. Seafloor eruptions and evolution of hydrothermal fluid chemistry. Philosophical Transactions: Mathematical, Physical and Engineering Sciences, 355, 1997.

[42] R. Noll. Terms and notations for laser-induced breakdown spectroscopy. Analytical and Bioanalytical Chemistry, V385(2):214-218, 2006.

[43] P. K. Kennedy, D. X. Hammer, and B. A. Rockwell. Laser-induced breakdown in aqueous media. Progress in Quantum Electronics, 21:155-248, 1997.

[44] J. Brown, A. Colling, D. Park, J. Phillips, D. Rothery, and J. Wright. Seawater: its composition, properties and behaviour. The Open University, Milton Keynes, England, 1989. 


\section{Chapter 3}

\section{Analysis of laser-induced breakdown spectroscopy (LIBS) spectra: The case for extreme value statistics}

The work in this chapter is currently in press in Spectrochimica Acta Part B as, A. P. M. Michel and A. D. Chave, "Analysis of laser-induced breakdown spectroscopy (LIBS) spectra: The case for extreme value statistics."

\subsection{Abstract}

In most instances, laser-induced breakdown spectroscopy (LIBS) spectra are obtained through analog accumulation of multiple shots in the spectrometer CCD. The average acquired in the CCD at a given wavelength is assumed to be a good representation of the population mean, which in turn is implicitly regarded to be the best estimator for the central value of the distribution of the spectrum at the same wavelength. Multiple analog accumulated spectra are taken and then in turn averaged wavelength-by-wavelength to represent the final spectrum. In this paper, the statistics of single-shot and analog accumulated LIBS spectra of both solids and liquids were examined to evaluate whether the typically used spectrum averaging approach is statistically defensible. At a given wavelength, LIBS spectra are typically drawn from a Frechet extreme value distribution, and hence the mean of an ensemble of LIBS spectra is not necessarily an optimal summary statistic. Under circumstances 
that are broadly general, the sample mean for LIBS data is statistically inconsistent and the central limit theorem does not apply. This result appears to be due to very high shot-to-shot plasma variability in which a very small number of spectra are high in intensity while the majority are very weak, yielding the extreme value form of the distribution. The extreme value behavior persists when individual shots are analog accumulated. An optimal estimator in a well-defined sense for the spectral average at a given wavelength follows from the maximum likelihood method for the extreme value distribution. Example spectra taken with both an Echelle and a Czerny-Turner spectrometer are processed with this scheme to create smooth, high signal-to-noise summary spectra. Plasma imaging was used in an attempt to visually understand the observed variability and to validate the use of extreme value statistics. The data processing approach presented in this paper is statistically reliable and should be used for accurate comparisons of LIBS spectra instead of arithmetic averaging on either complete or censored data sets.

\subsection{Introduction}

Laser-induced breakdown spectroscopy (LIBS) is a spectrochemical technique that has been successfully used for elemental analysis of solids, liquids, gases, and aerosols, and is finding increasing application in basic and applied research. However, one of the major problems that precludes more quantitative use is a lack of reproducibility of spectra at a given wavelength on a shot-to-shot basis.

Dramatic peak intensity fluctuations at the shot-to-shot level, suggesting the presence of high random variability, has been noted by many LIBS researchers [1-15]. There are numerous potential causes for this, including repetitive laser pulse instability, unstable laser pulse characteristics, laser pulse-plasma interactions, lens-tosample distance variation (which in turn changes the distance from the plasma to the collection fiber), laser-material coupling, variable sample ablation, plasma position instability, matrix effects, perturbations of the plasma due to physical and chemical characteristics of the sample (i.e., composition, homogeneity, roughness, color, and moisture content), scattering of light, atmospheric conditions, weak ionization of the plasma, and non-optimal collection of plasma emission [1,3-11, 16]. Optical instability affects the ablation process, the plasma profile, and the plasma volume [7]. Carranza and Hahn [16] suggest that above a threshold value, absorption of pulse energy by the plasma saturates, reducing variability at higher levels. A given plasma is not completely homogeneous, and there may be property gradients due to boundary 
effects and its transient nature. Spatial variation in the position of the plasma changes the coupling of the plasma light into the collection optics. Carranza and Hahn further suggest that shot-to-shot variation may be reduced by using sufficient laser pulse energy to achieve saturation and a suitable collection geometry (backscatter mode) to minimize spatial variability. The intensity of the laser itself can fluctuate by $1-5 \%$ [8]. However, Castle et al. simultaneously measured the analyte signal and the laser pulse energy, and found no significant correlation, suggesting laser pulse variance has only a minor influence on overall variability [13].

The sample type also influences variability. For aqueous samples, additional fluctuation can be caused by "moving breakdown" that changes the distance between the spark and the collection fiber as the plasma moves in the solution. The plasma typically expands along the beam path toward the laser, inducing elongate plasmas that cavitate radially [17]. Variability in aqueous solutions can also be caused by suspended ablated particles [2, 18] and bubbles [19] both by reducing the energy delivered to a sample and the light transmitted to the collection optics. Bubbles, formed when breakdown occurs, and dissolved gases can scatter or absorb incident laser radiation $[17,19]$.

Lazic et al. [2] report high variability of the plasma intensity for both aqueous solutions (including bulk water) and solid samples immersed in water. Significant variability was not observed when high laser pulse energies were used to measure the elemental composition of flat homogeneous solid samples. In aqueous solution, LIBS emission was sometimes not detectable even when the maximum laser energy was used. The lack of emission was also observed for rough inhomogeneous solids. For flat samples, the only time no breakdown occurred was when low laser energies were used; yet, shot-to-shot signal variability was always present. Lazic et al. [10] reported peak intensity histograms. The distributions of these data sets are clearly not Gaussian, and show that a very high intensity peak is a rare event, with very low intensity occurring for the bulk of the trials.

For a solid sample, inhomogeneity, porosity, or surface roughness can change the distance between the focusing optics and the sample, either from prior crater formation or by changing the location of ablation. Panne et al. [12] report significant pulse-to-pulse variation of the plasma electronic excitation temperature and electron density from material-laser interaction for homogeneous glass samples.

Laser ablation is highly nonlinear, and even more so in aerosol samples as the plasma may form at different positions along the beam [8]. For aerosols, the location of the particles within the plasma volume and the focal volume of the optics con- 
tribute to variability [14]. Schechter's [15] analysis of spectral fluctuations of aerosols showed large shot-to-shot variability possibly caused by laser pulses hitting different numbers of particles, particle characteristic variation (size, mass, and location), and location variation of the plasma. Whatever the cause of observed LIBS intensity variability, analog averaging of multiple plasma emissions, where light from numerous laser shots is accumulated on a CCD to create a single spectrum, is an often used experimental approach in order to increase the signal and the signal-to-noise ratio in the presence of shot-to-shot variability [20]. Analog averaged spectra are replicated and the ensemble of replicates are in turn averaged to create a representative spectrum. However, this implicitly assumes that the sample mean is a reasonable estimator for the statistical average, and this condition may not hold for some non-Gaussian distributions.

LIBS researchers have recognized the potential impact of intensity variability, and have devised a variety of methods to reduce the effect of spectral variability. Schechter used a rejection algorithm to eliminate anomalous spectra (e.g., spectra with no elemental lines, spectra with a too weak or too intense baseline due to laser fluctuations, and weak spectra) from the ensemble. This typically removed $75 \%$ of measured spectra [15]. Carranza and Hahn [16] used a sorting algorithm to remove irregular spectra, eliminating $60-70 \%$ of single shot data. Lazic et al. [2] removed spectra below a threshold value to increase the signal-to-noise ratio and make emission lines more readily visible.

In the present work, rather than using an ad hoc approach, the statistical variability of LIBS spectral intensity has been quantified and a data processing scheme based on the observed statistics has been devised. It will be demonstrated that LIBS intensity (whether single shot or analog averaged) typically has a Frechet extreme value distribution, and that for the characteristic range of statistical parameters, the distribution may not possess a variance. As a consequence, the sample mean is not an appropriate estimator for the average intensity, the central limit theorem does not apply, and Gaussian-based inference will be in error. Instead, a maximum likelihood estimator for the extreme value distribution is advocated as an alternative. The result is illustrated using single shot and analog averaged LIBS spectra for a solid target using one experimental set-up and for bulk aqueous solutions using two experimental set-ups. 


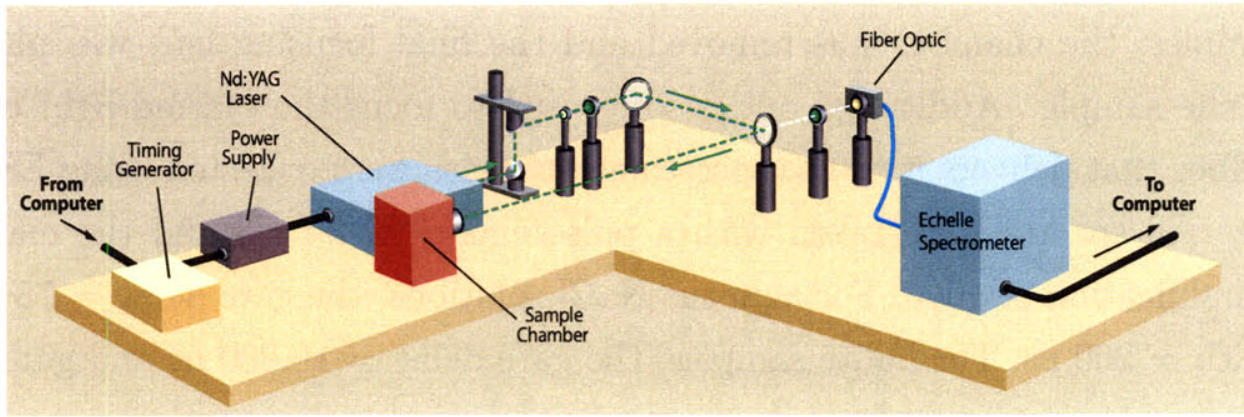

Figure 3-1: Laboratory set-up of LIBS using an Echelle spectrometer.

\subsection{Experimental}

\subsubsection{Echelle Spectrometer Set-up}

To examine the variability of LIBS at shot-to-shot and analog averaged levels, the peak intensity was examined over the $580-600 \mathrm{~nm}$ range for $\mathrm{Na}$ using both solid $\mathrm{NaCl}$ (halite) obtained from Fisher Scientific and an aqueous $\mathrm{NaCl}$ solution. Solutions were made using de-ionized water and $\mathrm{NaCl}$ to yield a $\mathrm{Na}$ concentration of 100 parts per million (ppm, wt./vol.). The variability of intensity was measured for the solid sample using an Echelle spectrometer and for aqueous solutions using both Echelle and Czerny-Turner units. A dark background spectrum was initially subtracted from all raw spectra. For the halite specimen, 100 single shot and 10 shot analog averaged spectra were obtained. For the aqueous specimen, 100 single shot and 100 shot analog averaged spectra were collected.

The first experimental set-up utilizing an Echelle spectrometer (LLA Echelle ESA 3000) is shown in Figure 3-1. The spectrometer is capable of detecting elements over the $200-780 \mathrm{~nm}$ range with a spectral resolution of 10 to $50 \mathrm{pm}$. A Big Sky CFR$200 \mathrm{Nd}$ :YAG laser (7.5-ns pulse width) operated at the fundamental wavelength of $1064 \mathrm{~nm}$ with a repetition rate of $5 \mathrm{~Hz}$ was used for plasma excitation. The laser is equipped with a variable attenuator controlled by a computer that allows laser pulse energy to range from 0 to $200 \mathrm{~mJ}$ in increments of $<1 \mathrm{~mJ}$. A timing box (Berkeley Nucleonics Corporation Model 565) was used to accurately control firing of the laser in relation to turn-on of the spectrometer.

For liquid samples, a cubic titanium sample chamber $(8.89 \mathrm{~cm} \times 8.89 \mathrm{~cm} \times 8.89$ $\mathrm{cm}$ ) equipped with two sapphire windows (Meller Optics $-2.54 \mathrm{~cm}$ diameter $\times 0.64$ $\mathrm{cm}$ thick, AR coated at $1064 \mathrm{~nm}$, custom part) that allows laser pulses to enter the cell and the plasma to be imaged from the side of the cell (orthogonal to the entering laser beam) was used. AR-coated optics focus the laser beam into the chamber. For 
solid samples, the chamber was removed and the final focusing lens was placed in front of the sample. Additional optics were used to focus the plasma light onto an optical fiber that delivers it to the spectrometer. Data were collected using ESAWIN software. All spectra were taken with a pulse energy of $80 \mathrm{~mJ}$ and the maximum $\mathrm{MCP}$ amplification of 4000 . For aqueous $\mathrm{NaCl}$ solutions, the gate delay $=75 \mathrm{~ns}$ and gate width $=200 \mathrm{~ns}$. For halite samples, the gate delay $=10,000 \mathrm{~ns}$ and gate width $=100 \mathrm{~ns}$.

Plasma images were taken using a Pixelfly camera with a microscope lens and an iris diaphragm. The images were taken through the sapphire window on the pressure chamber, orthogonal to the incoming laser pulses ( $80 \mathrm{~mJ} /$ pulse). The shutter remained open for $5 \mu \mathrm{s}$ and was externally synched to the Q-switch of the laser.

\subsubsection{Czerny-Turner Spectrometer Set-up}

The second set-up used a Czerny-Turner spectrometer and is shown in Figure 3-2. A Continuum Surelite III laser (5-ns pulse width, $1064 \mathrm{~nm}, 1 \mathrm{~Hz}$ repetition rate) was used for plasma excitation with a pulse energy of $81 \mathrm{~mJ}$. Laser pulses were focused into a chamber constructed of stainless steel Swagelok fittings with six $2.54 \mathrm{~cm}$-ID and $3.18 \mathrm{~cm}-\mathrm{OD}$ ports. Two ports were fitted with $2.54 \mathrm{~cm}$ diameter, $0.32 \mathrm{~cm}$ thick circular sapphire windows (MSW100/125, Meller Optics Incorporated) held in place by hex nuts and sealed with rubber washers, allowing $1.91 \mathrm{~cm}$ of each window to be visible outside the cell. The plasma emission was focused onto a 2-mm-corediameter, 0.51-N.A. light guide (Edmund Scientific Co. Model 02551). The light guide was connected to a $0.25-\mathrm{m}, \mathrm{f} / 4$ spectrograph (Chromex model $250 \mathrm{is} / \mathrm{RF}$ ) with a 1200 -groove $/ \mathrm{mm}$ grating blazed at $500 \mathrm{~nm}$. Data were collected on an intensified CCD detector (Princeton Instruments, I-Max 1024E) and acquired with a computer running WinSpec/32 software.

All spectra were taken at the maximum gain setting of 255 , with gate delay $=175$ $\mathrm{ns}$ and gate width $=200 \mathrm{~ns}$. Solutions were made using de-ionized water, $\mathrm{MnSO}_{4}$, $\mathrm{ZnBr}_{2}$, and $\mathrm{NaSO}_{4}$. The solution contained 5000 parts per million (ppm, wt./vol.) $\mathrm{Mn}, 5000 \mathrm{ppm} \mathrm{Zn}$, and $2000 \mathrm{ppm} \mathrm{Na}$. 


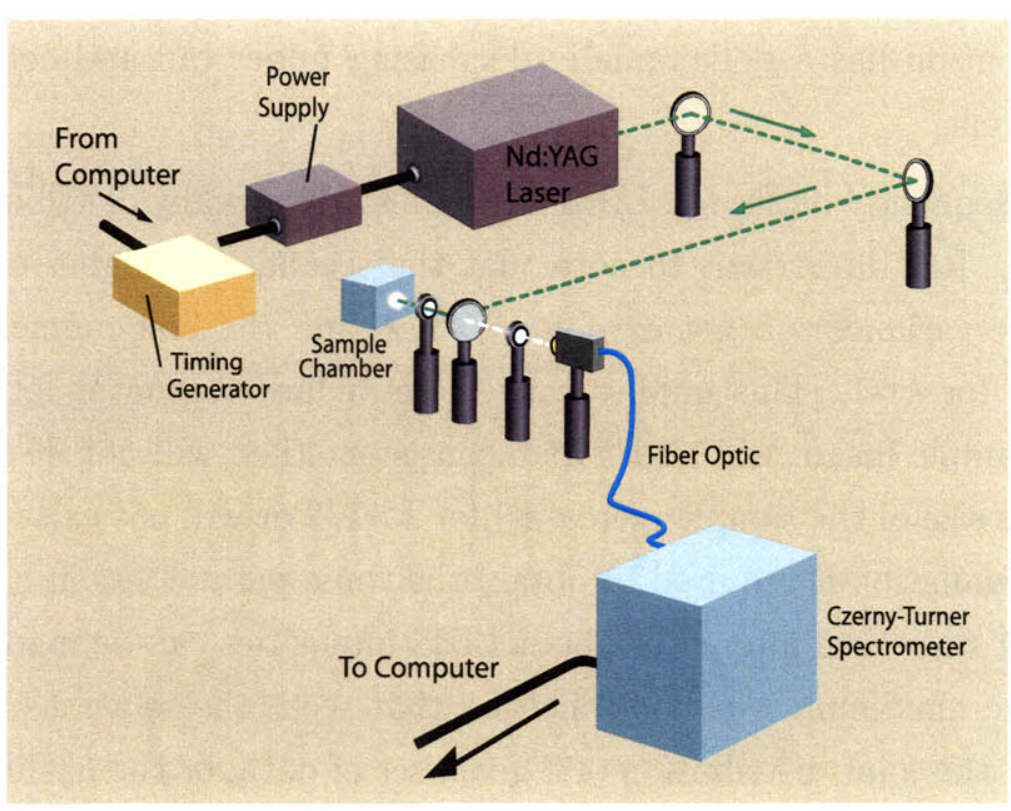

Figure 3-2: Laboratory set-up of LIBS using a Czerny-Turner spectrometer.

\subsection{Results and Discussion}

\subsubsection{The Generalized Extreme Value Distribution}

Extreme value distributions describe the stochastic behavior of the maximum or minimum of independent and identically distributed random variables drawn from some parent distribution. There are three types of extreme value distributions: Weibull, Gumbel, and Frechet. The von Mises-Jenkinson or generalized extreme value distribution (GEVD) combines the three into a single functional form [21, 22]. The probability density function for the GEVD is given by

$$
f(x \mid k, \mu, \sigma)=\left(\frac{1}{\sigma}\right) \exp \left(-\left(1+k \frac{(x-\mu)}{\sigma}\right)^{-\frac{1}{k}}\right)\left(1+k \frac{(x-\mu)}{\sigma}\right)^{\left(-1-\frac{1}{k}\right)}
$$

where the distribution is Weibull, Gumbel and Frechet for the shape parameter $k<0$, $k=0$, and $k>0$, respectively. The remaining parameters in Equation 3.1 are the location parameter $\mu$ (analogous to the mean for the Gaussian distribution) and the scale parameter $\sigma$ (analogous to the standard deviation for the Gaussian distribution). The Gumbel distribution is obtained through an appropriate limiting process, but is not of interest in the present work. For the Weibull and Frechet distributions, the range of the variate is respectively $-\infty<x \leq \mu-\sigma / k$ and $\mu-\sigma / k \leq x<\infty$. The Weibull distribution has a finite upper endpoint and hence corresponds to a short-tailed parent. The 
Frechet distribution has a polynomially decreasing upper tail and corresponds to a long-tailed parent.

As will subsequently be shown, LIBS intensities are typically distributed as Frechet extreme value. It is important to note that the second and higher order moments (and hence the variance) do not exist for $k>1 / 2$, and the first moment (the mean) does not exist for $k>1$. This implies that the standard estimator for the ensemble average, the sample mean, will either be inconsistent (i.e., will not display a reduced variance as the size of the sample increases) for $k>1 / 2$ or will not exist at all for $k>1$. A different formulation is required to obtain the three parameters in Equation 3.1 so that defensible statistical inferences about LIBS intensities can be made. A standard approach is the maximum likelihood method that seeks the solutions for $k, \mu$ and $\sigma$ that maximize the joint distribution of a given set of data, or the likelihood function. For independent samples, the joint distribution of $N$ data is the product of Equation 3.1 for each datum with common shape, location and scale parameters

$$
L\left(k, \mu, \sigma \mid x_{i}\right)=\prod_{i=1}^{N}\left(\frac{1}{\sigma}\right) \exp \left(-\left(1+k \frac{x_{i}-\mu}{\sigma}\right)^{-\frac{1}{k}}\right)\left(1+k \frac{x_{i}-\mu}{\sigma}\right)^{-1-\frac{1}{k}}
$$

This is maximized by setting the first derivative of Equation 3.2, or its logarithm, for each parameter to zero, yielding a set of three equations

$$
\begin{aligned}
& \frac{1}{\sigma} \sum_{i=1}^{N}\left[-\left(1+\frac{k\left(x_{i}-\mu\right)}{\sigma}\right)^{-\left(\frac{1}{k}+1\right)}+\frac{k+1}{1+k \frac{x_{i}-\mu}{\sigma}}\right]=0 \\
& \frac{1}{k^{2}}\left[\sum_{i=1}^{N} \log \left(1+k \frac{x_{i}-\mu}{\sigma}\right)-k\left((1+k) \sum_{i=1}^{N} \frac{x_{i}-\mu}{\sigma\left(1+\frac{k\left(x_{i}-\mu\right)}{\sigma}\right)}\right)+\right. \\
& \left.k \sum_{i=1}^{N}\left(1+\frac{k\left(x_{i}-\mu\right)}{\sigma}\right)^{-\frac{1}{k}}\left(\frac{\log \left(1+\frac{k\left(x_{i}-\mu\right)}{\sigma}\right)}{k^{2}}-\frac{\left(x_{i}-\mu\right)}{k \sigma\left(1+\frac{k\left(x_{i}-\mu\right)}{\sigma}\right)}\right)\right]=0 \\
& -\frac{N}{\sigma}+\sum_{i=1}^{N}\left[-\left(\frac{\mu-x}{\sigma^{2}}\right)\left(1+k\left(\frac{x_{i}-\mu}{\sigma}\right)\right)^{-\left(\frac{1}{k}+1\right)}-\left(1+\frac{1}{k}\right)\left(\frac{1}{1+k\left(\frac{x_{i}-\mu}{\sigma}\right)}\right)\left(\frac{k}{\sigma^{2}}\right)\left(\mu-x_{i}\right)\right]=0
\end{aligned}
$$

These are coupled and nonlinear, and must be solved iteratively for the maximum likelihood estimators (mles) $\hat{k}, \hat{\mu}$ and $\hat{\sigma}$ using an appropriate algorithm. For the GEVD, the mles are asymptotically efficient (loosely speaking, highly concentrated about the true value for large numbers of data), normal and unbiased, but are nei- 
ther unbiased nor fully efficient for finite samples. However, neither is the sample mean when the second and higher moments do not exist. The mles have the distinct advantage of being defined when the moments of the distribution do not exist, and are relatively easy to compute. Presuming that the extreme value distribution is a good fit to LIBS intensity data, the maximum likelihood estimate for the location parameter $\hat{\mu}$ is a good representation of the peak intensity at a given wavelength, and the scale parameter $\hat{\sigma}$ and asymptotic normality can be used to compute approximate confidence intervals on $\hat{\mu}$.

\subsubsection{Applicability of Extreme Value Statistics}

Quantile-quantile (q-q) plots will be used to demonstrate that LIBS intensities are typically distributed as the Frechet extreme value distribution. The $N$ quantiles of a target distribution are the abscissa values that divide the area under the pdf into $N+1$ equal probability intervals. They are easily obtained from the pdf by solving for $Q_{j}$ in

$$
\int_{-\infty}^{Q_{j}} f(x) d x=\frac{j-\frac{1}{2}}{N}
$$

where $j=1, \ldots, N$. The order statistics of the intensity data are obtained by sorting them into ascending order. The order statistics divide the area under the target pdf into intervals that will correspond to equal probability if the data are drawn from it, and hence a plot of the quantiles against the order statistics will be a straight line. Systematic departures of the data from the distribution are visible as changes in slope, and anomalous values or outliers are manifest at the extremes, and hence a q-q plot is a useful qualitative tool to assess the suitability of the target distribution as a statistical model.

The fit may be quantified by testing the null hypothesis that the data are drawn from the target distribution against the alternate hypothesis that they are not using the nonparametric Kolmogorov-Smirnov statistic [23] that compares the empirical and target cumulative distribution functions. The Komogorov-Smirnov test statistic may be assessed at the standard 0.95 level for which the critical value is 0.134 for 100 realizations, as were used throughout this work. The null hypothesis is rejected if the test statistic exceeds the critical value.

Figure 3-3 shows q-q plots for the $588.9953 \mathrm{~nm}$ Na I peak for single shot and 10 shot analog accumulations on halite using the Echelle set-up. Both are approximately straight, and both accept the null hypothesis that the extreme value distribution is correct (Kolmogorov-Smirnov test statistics of 0.067 and 0.066, respectively). Figure 
3-4 shows q-q plots at the same wavelength for single shot and 100 shot analog accumulations for $\mathrm{Na}$ in bulk aqueous solution using the Echelle set-up. The single shot data exhibit a shift in slope that reflects the fact that the vast majority of the data correspond to no signal, and hence are only instrument noise. The 100 shot analog accumulations are slightly short-tailed at the upper end. Nevertheless, both pass the Kolmogorov-Smirnov test with test statistics of 0.113 and 0.098 , respectively. Figure 3-5 compares q-q plots at the same peak for single shot and 100 shot analog accumulations using the Czerny-Turner set up with a bulk aqueous target. Both are slightly short tailed at the top of the distribution, but both accept the null hypothesis that the data are extreme value (Kolmogorov-Smirnov test statistics of 0.084 and 0.058 , respectively). Similar results are observed for the $589.5923 \mathrm{~nm}$ Na peak (not shown), or at other wavelengths where signal is present. Further, the shape parameter persistently lies in the region corresponding to the Frechet extreme value distribution, and in many instances exceeds 0.5 so that the variance does not exist. 


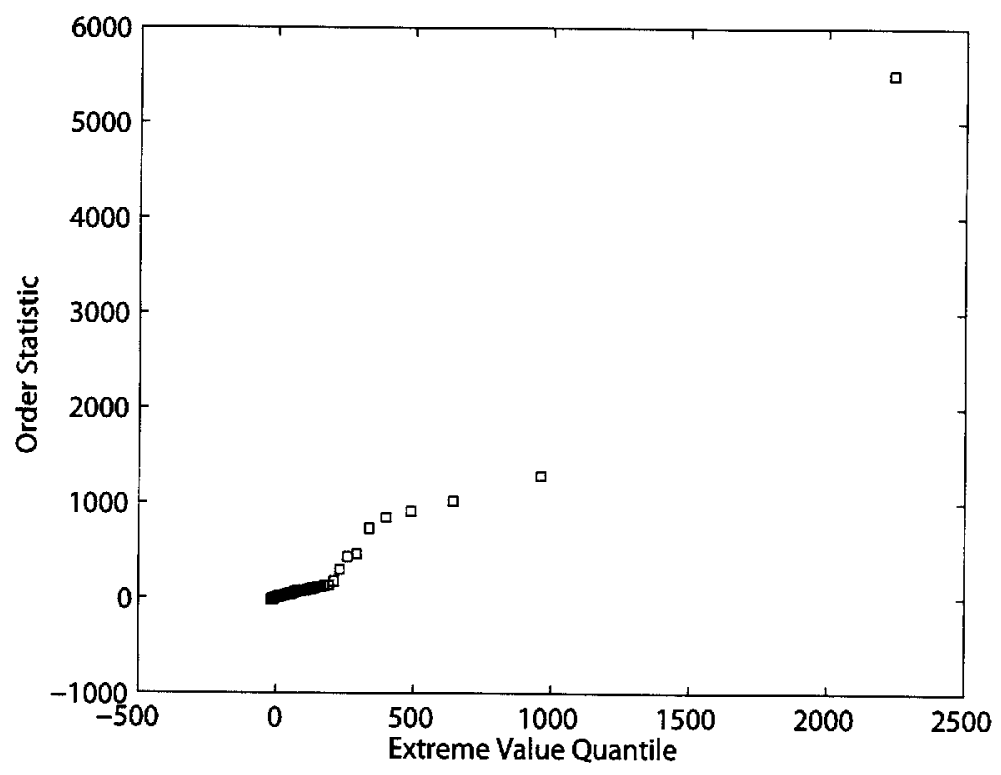

(a) Single Shot

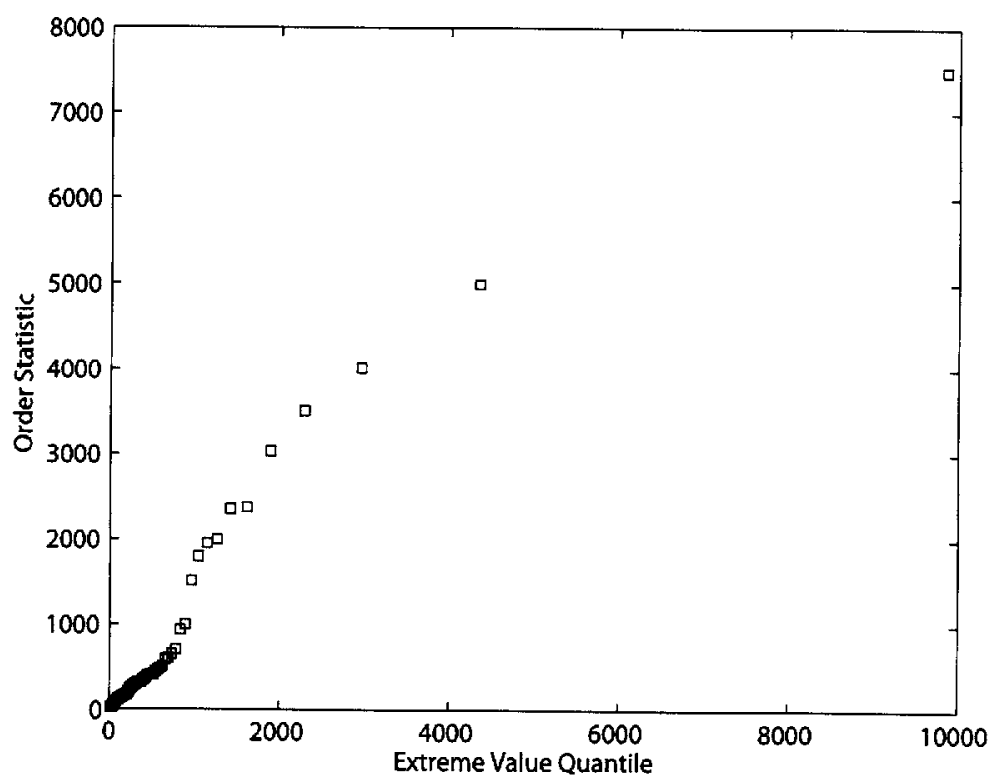

(b) 10 Shot Accumulations

Figure 3-3: q-q plots for the $588.9953 \mathrm{~nm} \mathrm{Na}$ I peak for halite using the Echelle set-up 


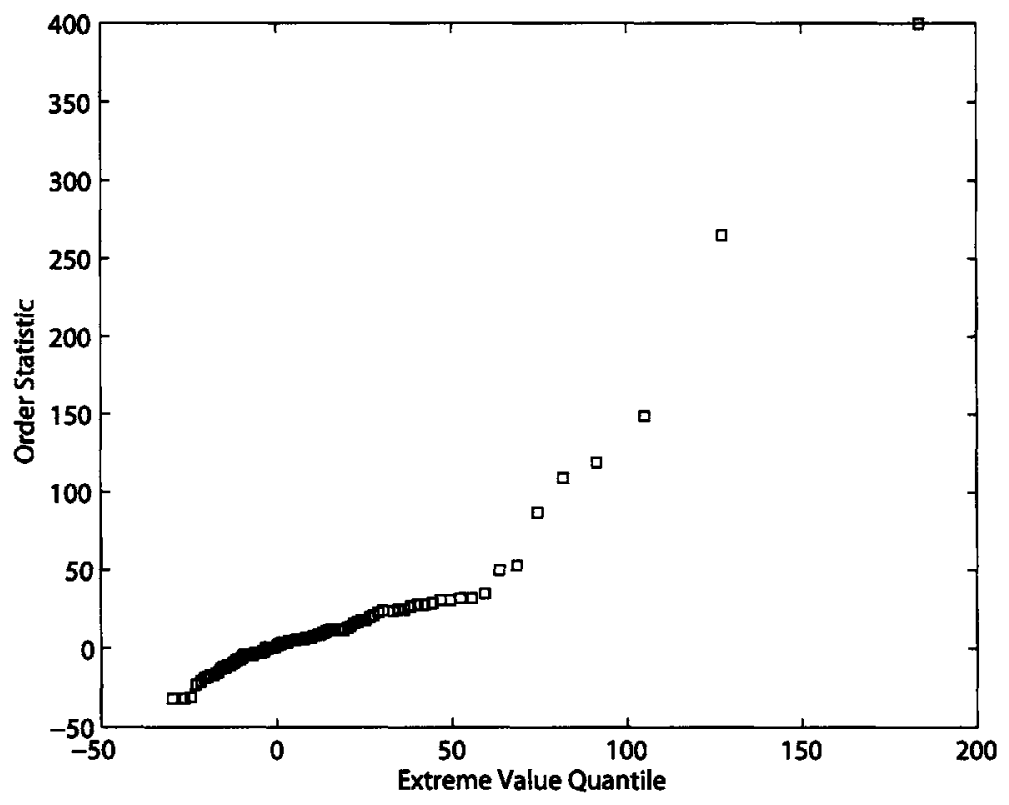

(a) Single Shot

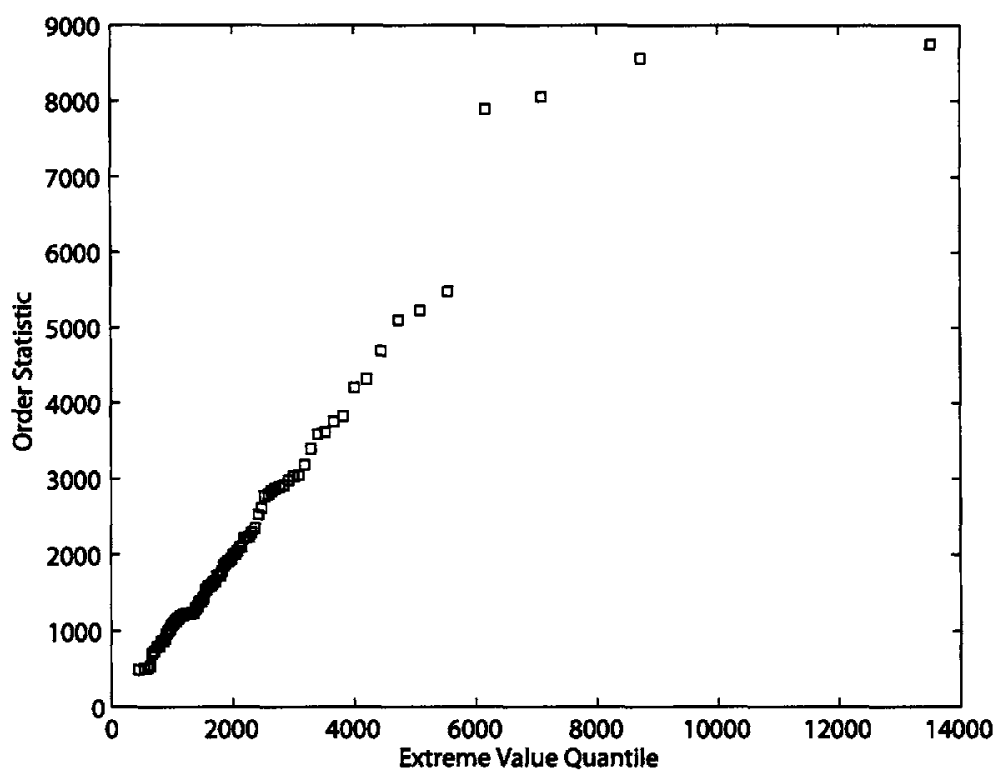

(b) 100 Shot Accumulations

Figure 3-4: q-q plots for the $588.9953 \mathrm{~nm} \mathrm{Na}$ I peak for bulk aqueous solution using the Echelle set-up 


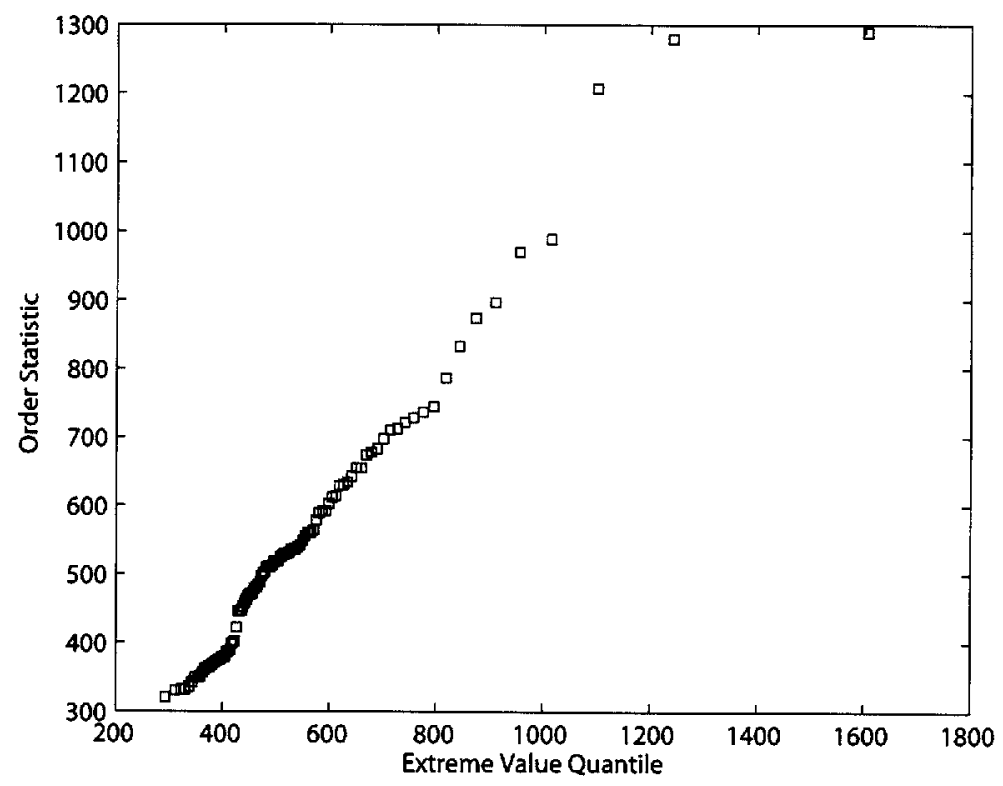

(a) Single Shot

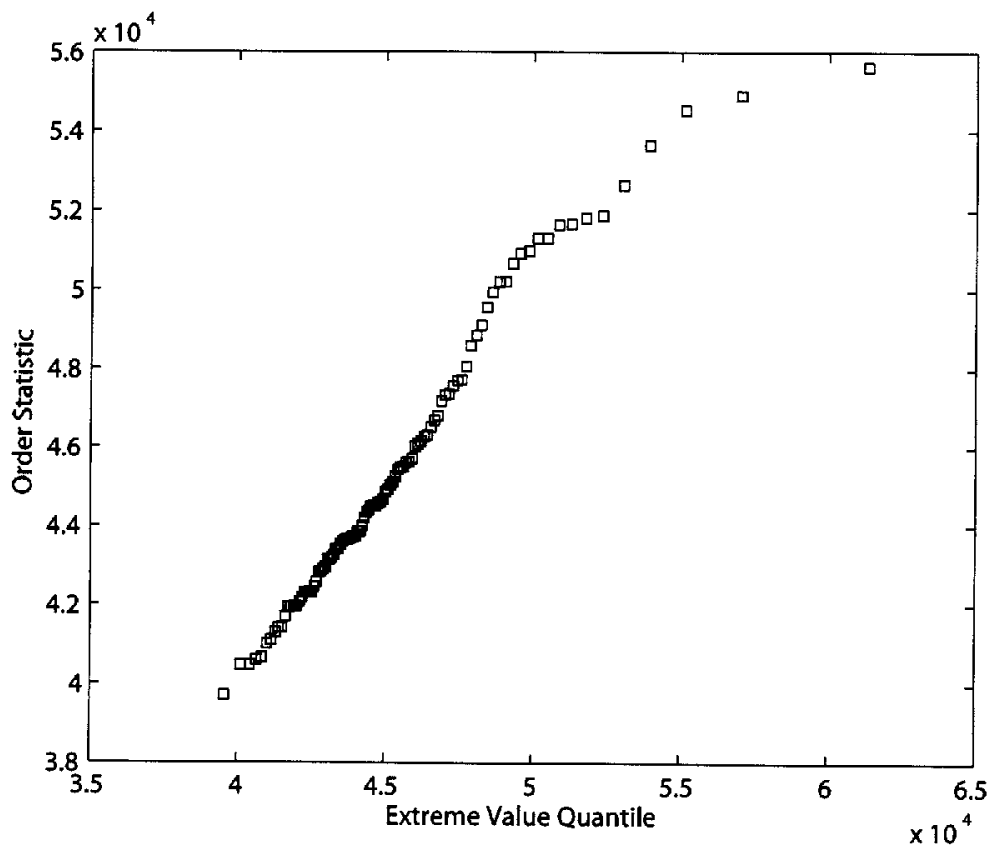

(b) 100 Shot Accumulations

Figure 3-5: q-q plots for the $588.9953 \mathrm{~nm} \mathrm{Na}$ I peak for bulk aqueous solution using the Czerny-Turner set-up 


\subsubsection{Extreme Value Statistical Parameters}

As a demonstration of the importance of using an appropriate set of statistical estimators for LIBS intensity data, the extreme value mles and the sample mean were computed over the wavelength band $578.5-605.9 \mathrm{~nm}$ for the halite and aqueous $\mathrm{Na}$ samples using both the Echelle and Czerny-Turner set-ups. At each wavelength, 100 realizations of 10 (halite) or 100 (aqueous samples) analog-accumulated shots serve as the data from which the mles (Equations $3.3-3.5$ ) and the sample mean are estimated.

Figure 3-6 compares the shape parameter, the location parameter, and the sample mean for halite using the Echelle set-up. While there is wavelength-by-wavelength statistical variability, the shape parameter is persistently above the 0.5 threshold beyond which the variance does not exist, and frequently exceeds the 1.0 threshold beyond which the mean does not exist, especially in the vicinity of the $589 \mathrm{~nm} \mathrm{Na}$ doublet and over two bands slightly above $600 \mathrm{~nm}$. The extreme value location parameter produces a smooth representation of the LIBS spectrum with limited statistical variability that is consistent with the number of samples. By contrast, the sample mean displays substantial statistical variability with two anomalous nulls amid the $\mathrm{Na}$ doublet band. These correspond to the wavelengths where the shape parameter dips below 1.0, so that the mean becomes defined. For data that are long-tailed, such as those drawn from a Frechet extreme value distribution, the sample mean will be dominated by a few large values. This results both in the large wavelength-to-wavelength variability that is apparent in the sample mean and the substantial difference in am-

plitude between the sample mean and the location parameter. In addition, two large peaks are observed above $600 \mathrm{~nm}$ that are barely visible in the extreme value location parameter. These correspond to peaks well above 1.0 in the shape parameter where the extreme value distribution is very long-tailed, and serve as graphic illustration of the sort of erroneous conclusions that can be derived through use of inappropriate statistical estimators.

Figure 3-7 compares the shape parameter, the location parameter, and the sample mean for $\mathrm{Na}$ in bulk aqueous solution using the Echelle set-up. The shape parameter is much more uniform with wavelength than for halite (Figure 3-6), but persistently lies around 0.75 where the variance does not exist. As a consequence, the extreme value location parameter displays much less variability than the sample mean, as in Figure 3-6. Figure 3-7 is another example where the use of a standard sample mean estimator may lead to incorrect inferences.

Figure 3-8 compares the shape parameter, the location parameter, and the sample 
mean for $\mathrm{Na}$ in bulk aqueous solution using the Czerny-Turner set-up. In contrast to the results with the Echelle set-up, the shape parameter is persistently below 0.5 , and displays occasional excursions below 0 where the distribution is Weibull. Since both the mean and variance exist throughout the wavelength domain, the extreme value location parameter and the sample mean yield qualitatively similar results. However, the distribution remains extreme value rather than simple Gaussian, and the uncertainty inferred for the sample mean will be inaccurate.

While LIBS intensity data (whether single shot or analog accumulated) empirically appear to persistently be drawn from an extreme value distribution, systematic differences are observed between different experimental set-ups. Whether this is due to the spectrometer or laser design, the experimental geometry, the element under study or some other factor remains unknown. Since incorrect conclusions might be drawn from the use of an inappropriate statistical model, it is strongly urged that LIBS practitioners examine their data to determine the correct approach for each set-up and sample. 


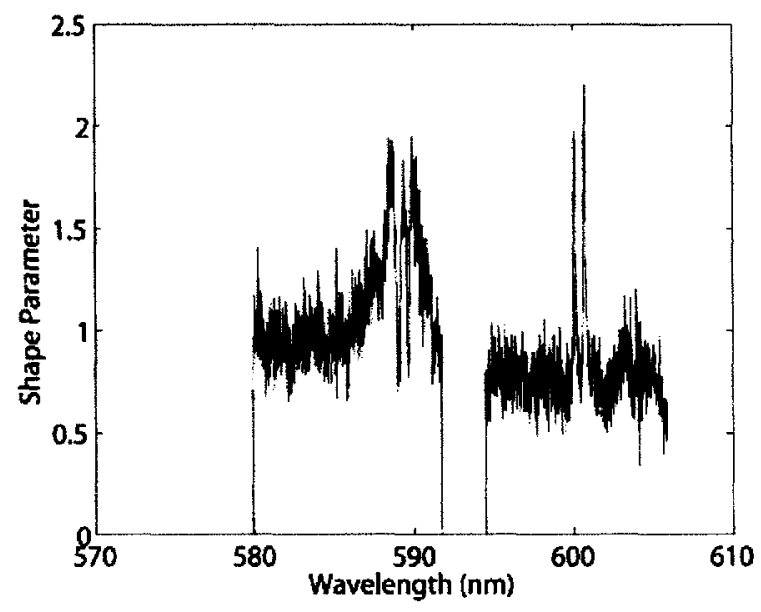

(a) Shape Parameter

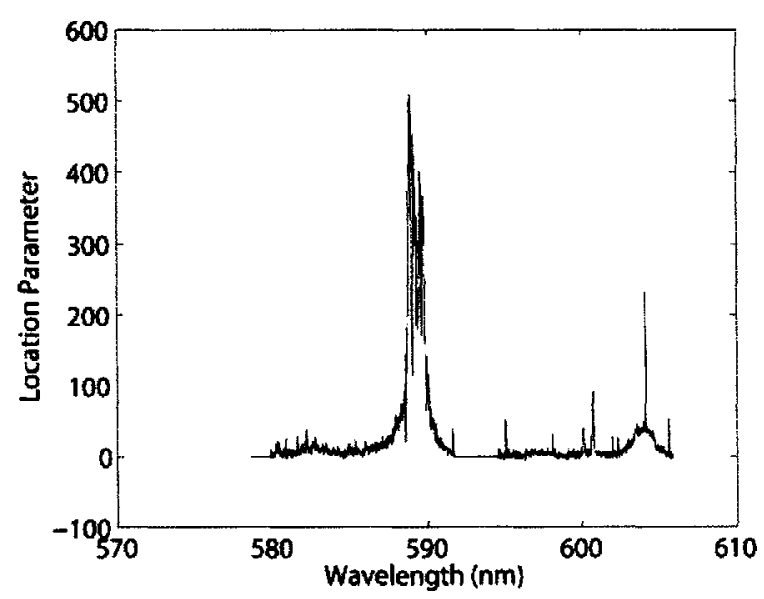

(b) Location Parameter

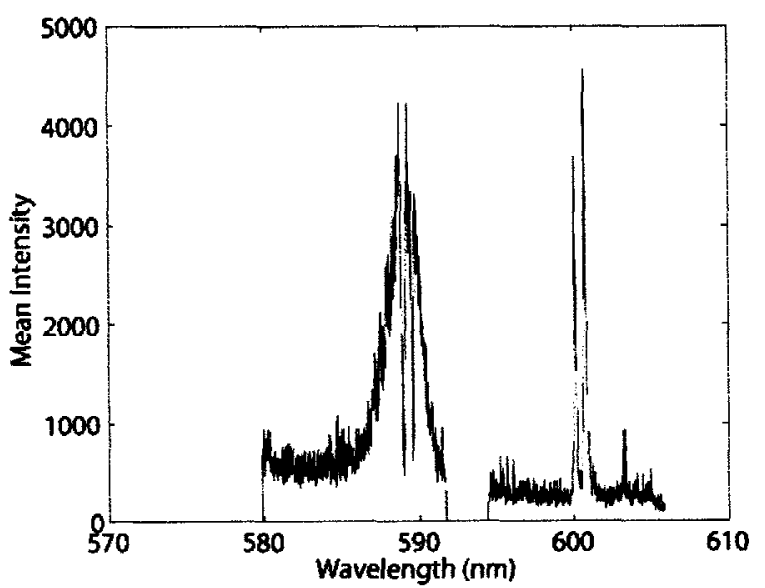

(c) Sample Mean

Figure 3-6: Shape parameter, location parameter, and sample mean for halite using the Echelle set-up 


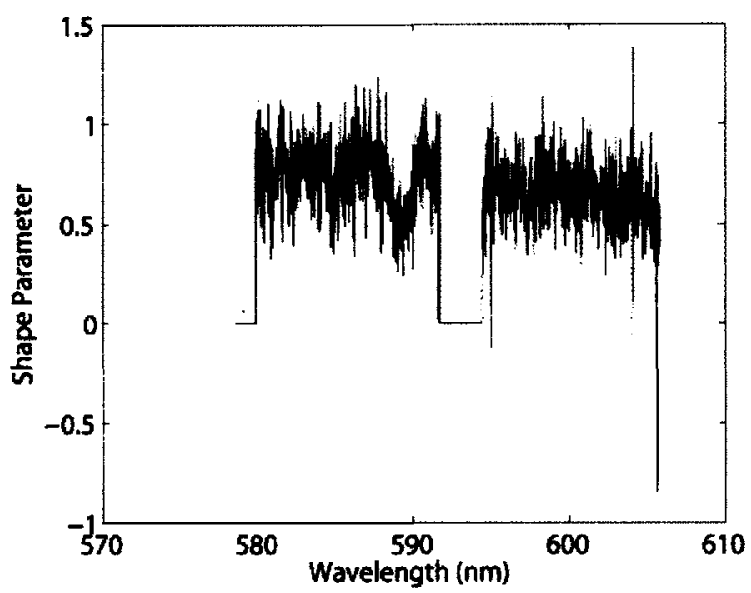

(a) Shape Parameter

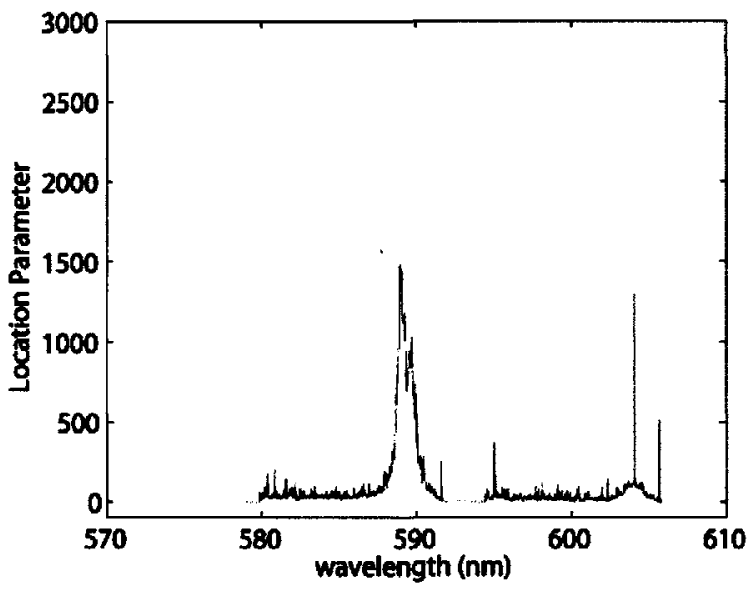

(b) Location Parameter

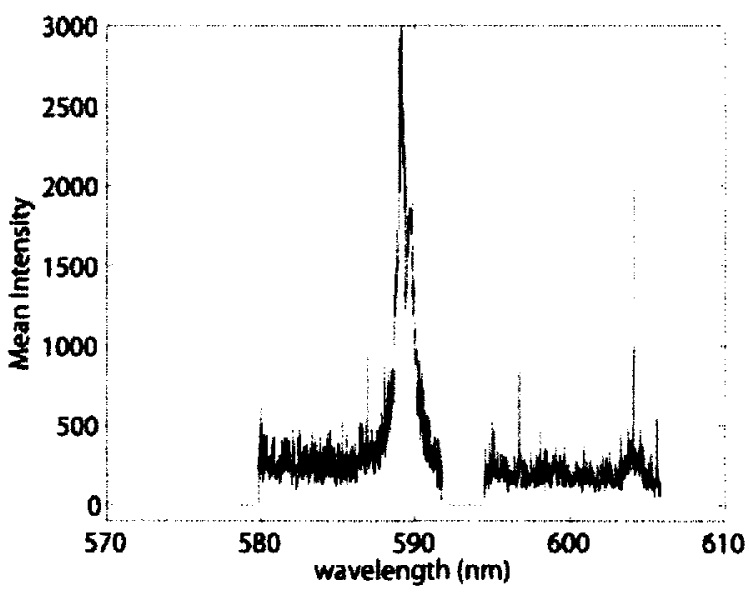

(c) Sample Mean

Figure 3-7: Shape parameter, location parameter, and sample mean for bulk aqueous solution using the Echelle set-up 


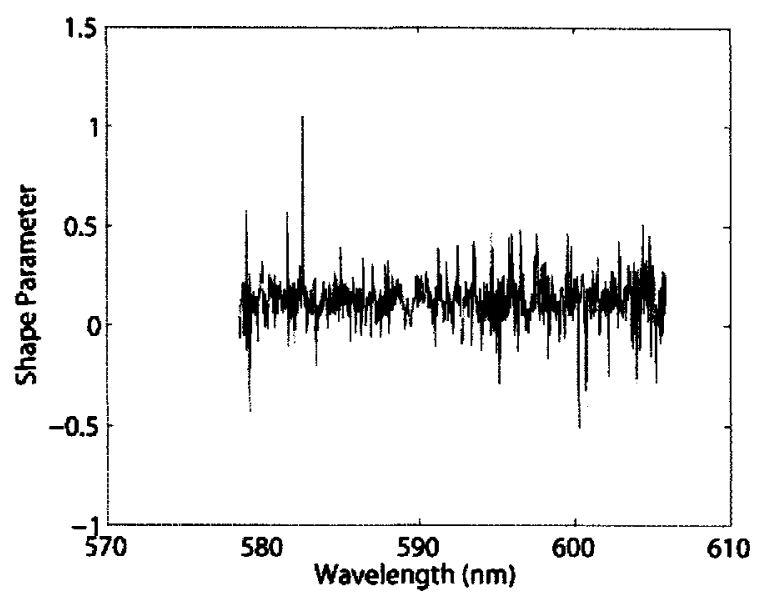

(a) Shape Parameter

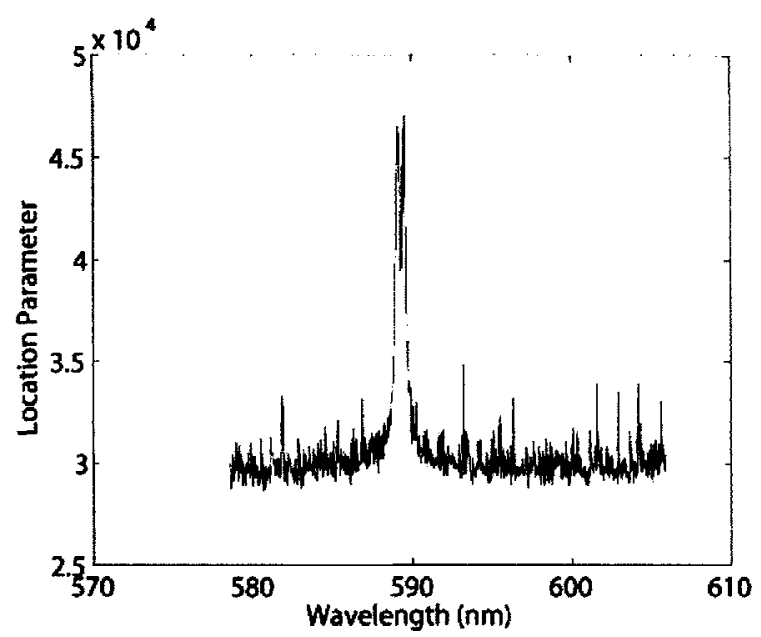

(b) Location Parameter

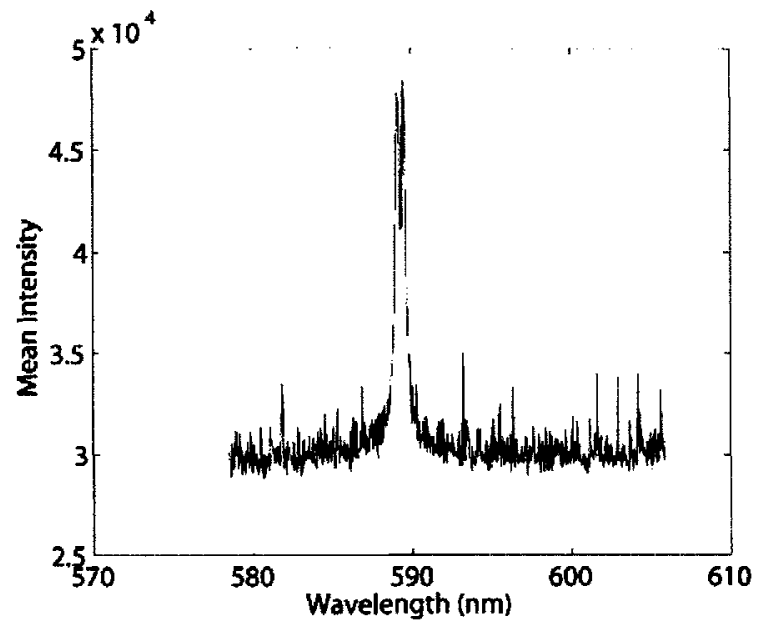

(c) Sample Mean

Figure 3-8: Shape parameter, location parameter, and sample mean for bulk aqueous solution using the Czerny-Turner set-up 


\subsubsection{Variability}

In an attempt to understand the source of data variability, images of plasmas in liquids were taken and the energies of numerous single shot laser pulses were compared. Figure 3-9 shows three sample plasma images taken under the same conditions that visually demonstrates the significant variability of plasma formation. The images are time averaged over $5 \mu \mathrm{s}$. Although hundreds of plasma images were taken, these images were selected to illustrate the variation in intensity, size, and location of formation of the plasma within a bulk liquid. The plasma shown in Figure 3-9(c) displays significantly greater emission intensity and size than those in (a) and (b), illustrating the extreme nature of some plasmas. In contrast, the plasma in Figure 39(b) is very weak, with very little emission produced. The distinct differences shown between these three plasmas is a clear indication that on a shot-to-shot basis that plasma variability exists and that extreme plasmas are formed which could account for the extreme intensities recorded.

The energy of 500 laser pulses was measured to examine the contribution of laser pulse energy fluctuations to plasma variability. Figure 3-10 shows that shot-to-shot pulse energy fluctuations do exist; however, the variability is not extreme in nature, suggesting that laser pulse energy variation is not the dominant cause of plasma and peak intensity variations. This suggests that the variability of the plasma formation is due to other effects. 


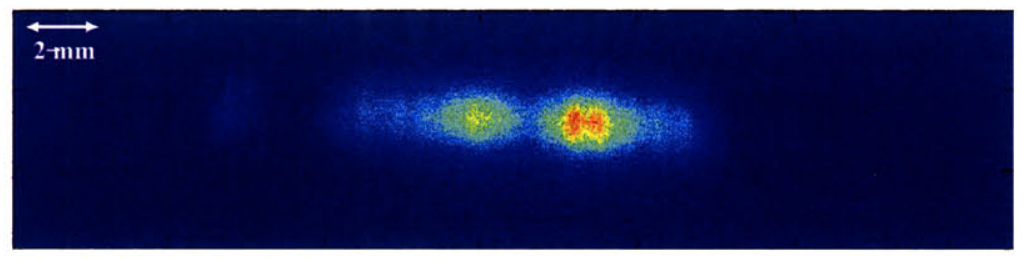

(a) Plasma Image 1

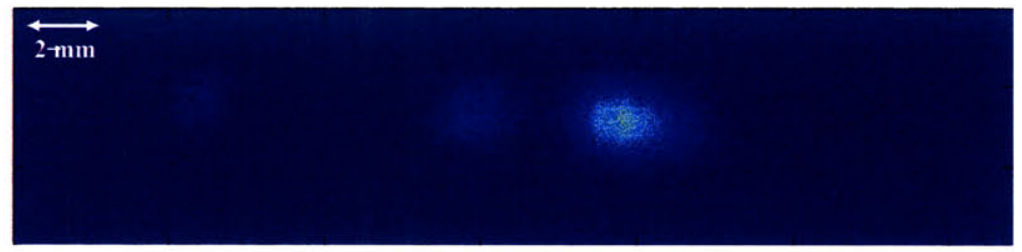

(b) Plasma Image 2

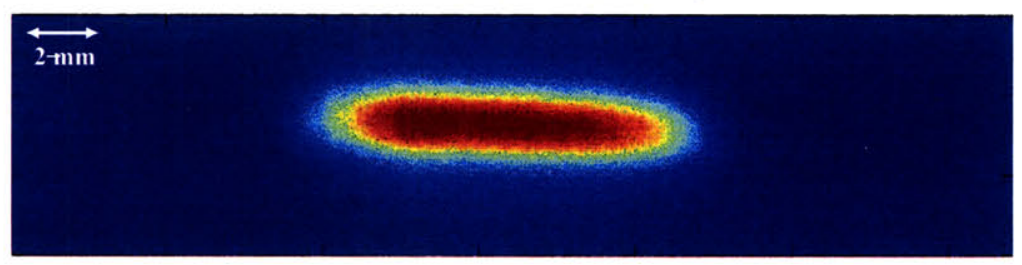

(c) Plasma Image 3

Figure 3-9: Images of plasmas formed in bulk aqueous solution that illustrate the shot-to-shot variability of formation. Images were taken orthogonal to the incoming laser beam. In the images shown, the beam enters from the left. Plasmas were formed using $80 \mathrm{~mJ}$ of laser pulse energy.

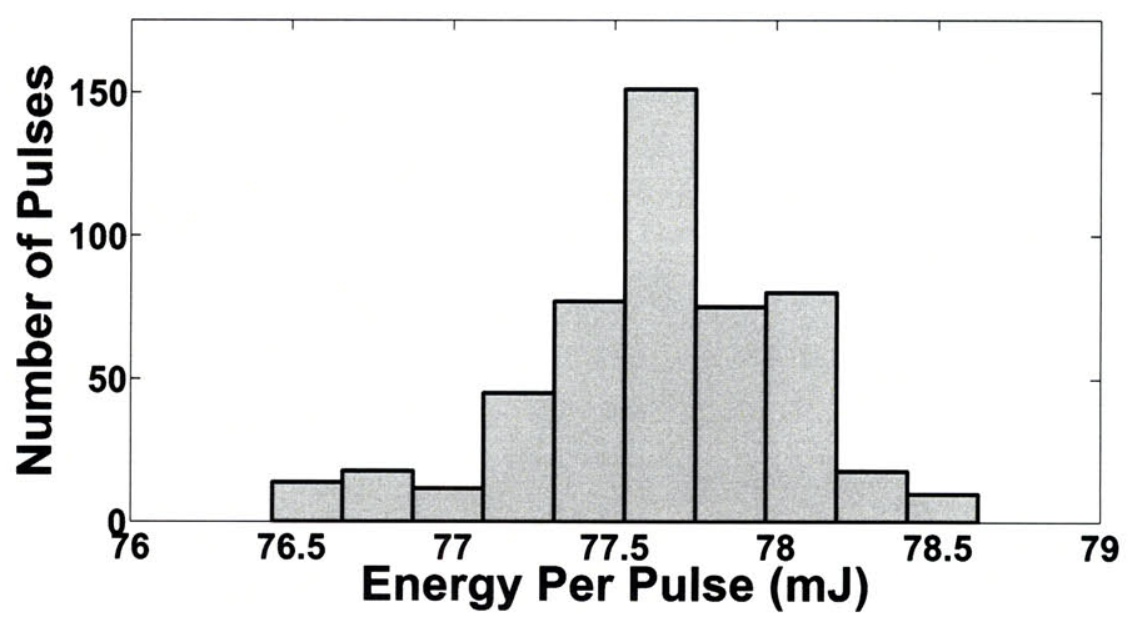

Figure 3-10: Comparison of laser energies measured for 500 individual laser pulses. 


\subsection{Conclusions}

Examination of the variability of peak intensity for both single shot and analog accumulated LIBS spectra reveals that such data are drawn from an extreme value distribution. In many instances, the distribution has no variance, and in some cases the mean is also undefined. Under either circumstance, the use of the sample mean or variants that include censoring will be statistically inconsistent and the central limit theorem will not apply. A maximum likelihood estimator data processing scheme is presented that accurately deals with the extreme value nature of laser-induced plasma formation. It is strongly urged that this approach be used to ensure accurate scientific inference from LIBS data, and that use of estimators based on the sample mean be discontinued. Plasma images reveal large spatial and intensity differences on a shot-to-shot basis. Laser pulse energy fluctuations are shown to contribute to the variability but are not the primary source.

\subsection{Acknowledgements}

We acknowledge the National Science Foundation for support of this research under grant OCE0352278. Additional support was received from the Deep Ocean Exploration Institute and the Ocean Ventures Fund of the Woods Hole Oceanographic Institution (WHOI). We thank Norman Farr (WHOI) for his assistance in setting up the imaging system and Hanumant Singh (WHOI) for lending us the camera. We thank the laboratory of S. Michael Angel at the University of South Carolina Columbia for use of their Czerny-Turner spectrometer. 


\section{Bibliography}

[1] E. Tognoni, V. Palleschi, M. Corsi, G. Cristoforetti, N. Omenetto, I. Gornushkin, B. W. Smith, and J. D. Winefordner. Laser-Induced Breakdown Spectroscopy (LIBS): Fundamentals and Apllications, chapter From Sample to signal in LIBS, pages 122-170. Cambridge University Press, 2006.

[2] V. Lazic, F. Colao, R. Fantoni, and V. Spizzicchino. Laser-induced breakdown spectroscopy in water: Improvement of the detection threshold by signal processing. Spectrochimica Acta Part B, 60:1002-1013, 2005.

[3] D. A. Cremers and L. J. Radziemski. Handbook of Laser-Induced Breakdown Spectroscopy. John Wiley and Sons, Ltd., 2006.

[4] D. A. Rusak, B. C. Castle, B. W. Smith, and J. D. Winefordner. Recent trends and the future of laser-induced plasma spectroscopy. Trends in Analytical Chemistry, 17:453-461, 1998.

[5] V. Hohreiter, J. E. Carranza, and D. W. Hahn. Temporal analysis of laserinduced plasma properties as related to laser-induced breakdown spectroscopy. Spectrochimica Acta Part B, 59(3):327-333, March 2004.

[6] C. V. Bindhu, S. S. Harilal, M. S. Tillack, F. Najmabadi, and A. C. Gaeris. Energy absorption and propagation in laser-created sparks. Applied Spectroscopy, 58(6):719-726, June 2004.

[7] R. Wisbrun, I. Schechter, R. Niessner, H. Schroder, and K. L. Kompa. Detector for trace elemental analysis of solid environmental samples by laser plasma spectroscopy. Analytical Chemistry, 66:2964-2975, 1994.

[8] L. Xu, V. Bulatov, V. V. Gridin, and I. Schechter. Absolute analysis of particulate materials by laser-induced breakdown spectroscopy. Analytical Chemistry, 69:2103-2108, 1997.

[9] C. V. Bindhu, S. S. Harilal, M. S. Tillack, F. Najmabadi, and A. C. Gaeris. Laser propagation and energy absorption by an argon spark. Journal of Applied Physics, 94(12):7402-7407, December 2003.

[10] V. Lazic, F. Colao, R. Fantoni, and V. Spizzicchino. Recognition of archeological materials underwater by laser induced breakdown spectroscopy. Spectrochimica Acta Part B, 60:1014-1024, 2005.

[11] J. Huang, C. Ke, and K. Lin. Matrix effect on emission/current correlated analysis in laser-induced breakdown spectroscopy of liquid droplets. Spectrochimica Acta Part B, 59:321-326, 2004.

[12] U. Panne, C. Haisch, M. Clara, and R. Niessner. Analysis of glass and glass melts during the vitrification process of fly and bottom ashes by laser-induced plasma 
spectroscopy. Part I: Normalization and plasma diagnostics. Spectrochimica Acta Part B, 53:1957-1968, 1998.

[13] B. C. Castle, K. Talabardon, B. W. Smith, and J. D. Winefordner. Variables influencing the precision of laser-induced breakdown spectroscopy measurements. Applied Spectroscopy, 52(5):649-657, 1998.

[14] G. A. Lithgow and S. G. Buckley. Effects of focal volume and spatial inhomogeneity on uncertainty in single-aerosol laser-induced breakdown spectroscopy measurements. Applied Physics Letters, 87:011501-1 -011501-3, 2005.

[15] I. Schechter. Direct aerosol analysis by time resolved laser plasma spectroscopyimprovement by single shot measurements. Analytical Science and Technology, 8(4):779-786, 1995.

[16] J. E. Carranza and D. W. Hahn. Sampling statistics and considerations for single-shot analysis using laser-induced breakdown spectroscopy. Spectrochimica Acta Part B, 57:779-790, 2002.

[17] P. K. Kennedy, D. X. Hammer, and B. A. Rockwell. Laser-induced breakdown in aqueous media. Progress in Quantum Electronics, 21:155-248, 1997.

[18] Y. Ito, O. Ueki, and S. Nakamura. Determination of colloidal iron in water by laser-induced breakdown spectroscopy. Analytica chimica acta, 299:401-405, 1995.

[19] N. F. Bunkin and A. V. Lobeyev. Influence of dissolved gas on optical breakdown and small-angle scattering of light in liquids. Physics Letters A, 229:327-333, 1997.

[20] U. Panne and D. Hahn. Laser-Induced Breakdown Spectroscopy (LIBS) Fundamentals and Applications, chapter Analysis of aerosols by LIBS, pages 194-253. Cambridge University Press, 2006.

[21] S. Kotz and S. Nadarajah. Extreme Value Distributions: Theory and Applications. Imperial College Press, 2000.

[22] N. L. Johnson, S. Kotz, and N. Balakrishnan. Continuous Univariate Distributions: Volume 2. John Wiley \& Sons, 2nd edition, 1995.

[23] E. L. Lehmann and J. P. Romano. Testing Statistical Hypotheses: 3rd Edition. Springer, 2005. Section 14.2. 


\section{Chapter 4}

\section{Single pulse laser-induced}

\section{breakdown spectroscopy of bulk}

aqueous solutions at oceanic

\section{pressures: Interrelationship of gate delay and pulse energy}

\subsection{Abstract}

The ability to make sustained measurements of ocean processes is limited by the number of sensors that are usable for long-term in situ analysis. In recent years, laser-induced breakdown spectroscopy (LIBS) has been identified as a viable technique for development into an oceanic chemical sensor. In this paper, single pulsed laserinduced breakdown spectroscopy of high pressure bulk aqueous solutions is used to detect three analytes (sodium, manganese, and calcium) which are of key importance in hydrothermal vent fluids, an ocean environment that would greatly benefit from the development of an oceanic LIBS sensor. The interrelationship of the key experimental parameters, pulse energy and gate delay, for a range of pressures up to $2.76 \times 10^{7} \mathrm{~Pa}$, are studied. A minimal effect of pressure on the peak intensity is observed. A short gate delay (less than $200 \mathrm{~ns}$ ) must be used at all pressures. The need for a relatively low laser pulse energy (less than $\approx 60 \mathrm{~mJ}$ ) for optimal detection of analytes at high pressure is also estabilshed. $\mathrm{Na}, \mathrm{Mn}$, and $\mathrm{Ca}$ are detectable at pressures up to $2.76 \times$ $10^{7} \mathrm{~Pa}$ at $50 \mathrm{ppm}, 500 \mathrm{ppm}$, and $50 \mathrm{ppm}$, respectively, using an Echelle spectrometer. 


\subsection{Introduction}

New chemical sensors are needed for use in process studies, and are of critical importance as oceanography shifts to a new operational mode using permanent ocean observatories. New sensors take significant time to develop and transform from benchtop laboratory prototypes to ocean-going systems. The development phase requires validation that an analytical technique will work under in situ conditions.

LIBS is a type of atomic emission spectroscopy that has been identified as a viable technique for use as a field-going sensor for geochemical and environmental sensing [1]. For example, a new mobile instrument has been developed for evaluating polluted soils $[2,3]$. Palanco et al. have proposed a field deployable laser-induced breakdown spectrometer system for stand-off measurements at hundreds of meters range [4]. Several groups have investigated LIBS for space exploration [5-10]. Courrèges-Lacoste et al. [7] are developing a combined Raman/LIBS instrument for investigating past and present life on Mars. Arp et al. [6] have investigated the use of LIBS in the high temperature $\left(>700 \mathrm{~K}\right.$ ), high pressure (order of $9 \times 10^{6} \mathrm{~Pa}$ ) environment of Venus. Another proposed in situ application of LIBS is its development into an oceanic chemical sensor.

One ocean environment that would benefit greatly from the development of such a sensor is hydrothermal vents that occur at mid-ocean ridges where seawater circulates through the permeable ocean crust. As seawater moves through the crust, the fluid interacts with the surrounding rock, inducing major chemical changes to the rock and the fluid. At vent orifices, exit temperatures reach $200-405^{\circ} \mathrm{C}$ at ambient pressures of $8.1 \times 10^{6} \mathrm{~Pa}$ to $3.6 \times 10^{7} \mathrm{~Pa}$ corresponding to ocean depths of $800 \mathrm{~m}$ to 3600 $\mathrm{m}$ [11]. In situ chemical measurement of the fluids is difficult due to the corrosive nature of the vent environment and irreversible changes in composition that occur when they are removed to the surface. Three elements of importance in vent fluids are sodium, calcium, and manganese. Sodium is the most abundant cation in vent fluids and can be studied to understand phase separation processes [12]. Manganese exists as a trace metal in seawater but is leached from the host rock making it present at higher concentrations in vent fluids [12]. When measured simultaneously with $\mathrm{Fe}$, Mn can be used as an indication of subsurface deposition as Fe precipitates out while Mn stays in solution. Calcium is the second most abundant cation in vent fluids, and is typically enriched in vent fluids, when compared to seawater [13]. Ca is released into vent fluids when sodium is taken up during albitization reactions with the host rock. In vent fluids, concentrations range from approximately $250-23,163 \mathrm{ppm}$ for 
$\mathrm{Na}, 0.6$ - $399 \mathrm{ppm}$ for $\mathrm{Mn}$, and -54 - $4477 \mathrm{ppm}$ for $\mathrm{Ca}$ [11]. In seawater, concentrations are approximately 10,933 ppm Na, $<0.001 \mathrm{ppm} \mathrm{Mn}$, and $419 \mathrm{ppm} \mathrm{Ca}$ [11].

There is limited prior work on the study of dissolved analytes within bulk aqueous solutions [14-20] due to inherent difficulties in detection. The plasma formed in a bulk liquid displays reduced light intensity and a reduction in emission lifetime due to quenching $[14,15,21,22]$. In addition, spectral lines are broadened through the Stark effect [14]. Furthermore, "moving breakdown" occurs that randomly changes the distance between the plasma and the collection optics, a phenomenon that is not important for solids in air. The plasma expands along the beam path of the laser, resulting in an elongated plasma that cavitates cylindrically [23]. For many aqueous applications, these issues can be avoided by analysis on a liquid surface, jet, or film; however, for the development of an in situ oceanic system, it is necessary to work directly with bulk liquids.

Although we have previously reported on the successful use of LIBS for detection of bulk aqueous analytes at high pressure (up to $2.76 \times 10^{7} \mathrm{~Pa}$ ) [17-19], the development of LIBS into an oceanic chemical sensor requires the optimization of the experimental system to maximize the signal-to-background ratio (SBR) of the spectra and improve the limit of detection. In this work, a comprehensive study of the effect of the two key parameters for single pulse LIBS on SBR was completed. Peak intensities were measured to determine optimal conditions for the detection of $\mathrm{Na}, \mathrm{Ca}$, and $\mathrm{Mn}$ at high

pressure. Subsequently, calibration curves were constructed to estimate the limits of detection using an Echelle spectrometer.

\subsection{Experimental}

The laboratory set-up for simulating a LIBS sensor in the deep ocean is depicted in Figure 4-1. Plasma formation is induced with a Big Sky CFR-200 Nd:YAG laser operated at $1064 \mathrm{~nm}$ with a $5 \mathrm{~Hz}$ repetition rate. The laser is equipped with a motorized variable attenuator, serially controlled by a computer, enabling the laser pulse energy (E) to be varied from $0 \mathrm{~mJ}$ to $200 \mathrm{~mJ}$ in increments of approximately $1 \mathrm{~mJ}$. Plasma emission is collected with an Echelle spectrometer (LLA Echelle ESA 3000) capable of detecting wavelengths of $200-780 \mathrm{~nm}$ with a spectral resolution of $10-50 \mathrm{pm}$. Timing control of the laser and turn-on of the spectrometer is managed by a timing box (Berkeley Nucleonics Corporation Model 565). The LIBS timing parameters are gate delay $\left(\mathrm{t}_{d}\right.$, the time between the laser pulse and turn-on of the spectrometer) and gate width $\left(\mathrm{t}_{b}\right.$, the integration time of the spectrometer), both 


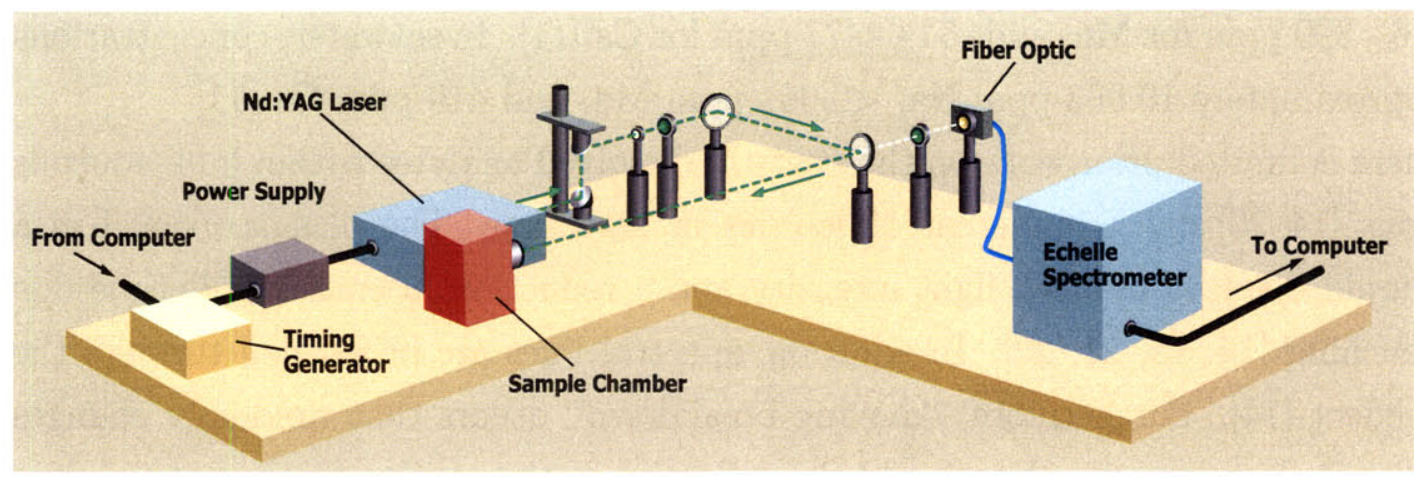

Figure 4-1: LIBS laboratory set-up

shown in Figure 4-2.

An $8.89 \mathrm{~cm} \times 8.89 \mathrm{~cm} \times 8.89 \mathrm{~cm}$ titanium sample chamber that holds $27 \mathrm{ml}$ of liquid is connected to a high pressure metering pump (Eldex Model A-30-S) that is used to pressurize samples to $4.1 \times 10^{7} \mathrm{~Pa}$. The sample chamber is equipped with a sapphire window (Meller Optics, $2.54 \mathrm{~cm}$ diameter $\times 0.64 \mathrm{~cm}$ thickness, ARcoated at $532 \mathrm{~nm} / 1064 \mathrm{~nm}$, custom part) that enables laser pulses to enter the sample chamber. A series of AR-coated optics are used to focus the laser beam into the sample chamber (Figure 4-3), with the final focusing lens fit into the sample chamber. An additional lens is used to focus the plasma light onto an optical fiber and delivers it to the Echelle spectrometer (Figure 4-3). The plasma light is collected collinear to the incoming laser beam. This optical geometry was selected because it is the only practical configuration for an ocean-going LIBS system. Data were collected using ESAWIN software. Laser energy is measured using a laser energy sensor (Coherent J25LP-MB) combined with an energy meter (Coherent FieldMaxII-Top).

To determine optimal conditions for the detection of the three analytes, spectral intensities were measured over a range of LIBS system parameters. For $\mathrm{Na}$ and $\mathrm{Mn}$, detailed studies were conducted at five pressures $\left(1 \times 10^{5} \mathrm{~Pa}, 6.89 \times 10^{6} \mathrm{~Pa}, 1.38 \times\right.$ $10^{7} \mathrm{~Pa}, 2.07 \times 10^{7} \mathrm{~Pa}$, and $2.76 \times 10^{7} \mathrm{~Pa}$ ). For $\mathrm{Ca}$, the studies were conducted at three pressures $\left(1 \times 10^{5} \mathrm{~Pa}, 1.38 \times 10^{7} \mathrm{~Pa}\right.$, and $\left.2.76 \times 10^{7} \mathrm{~Pa}\right)$. The gate delay and laser pulse energy were systematically varied to determine their effect on both plasma intensity and SBR. Five spectra were taken for each parameter pair, each composed of 100 accumulated shots. The laser pulse energy ranged from 10 to $170 \mathrm{~mJ}$ in $10 \mathrm{~mJ}$ increments. Laser beam waist width $\mathrm{d}_{\sigma_{o}}$ can be estimated from

$$
d_{\sigma_{o}}=\frac{4 f \lambda M^{2}}{\pi D}
$$

where $\mathrm{f}$ is the focal length of the focusing lens $(35 \mathrm{~mm}), \lambda$ is the laser wavelength 


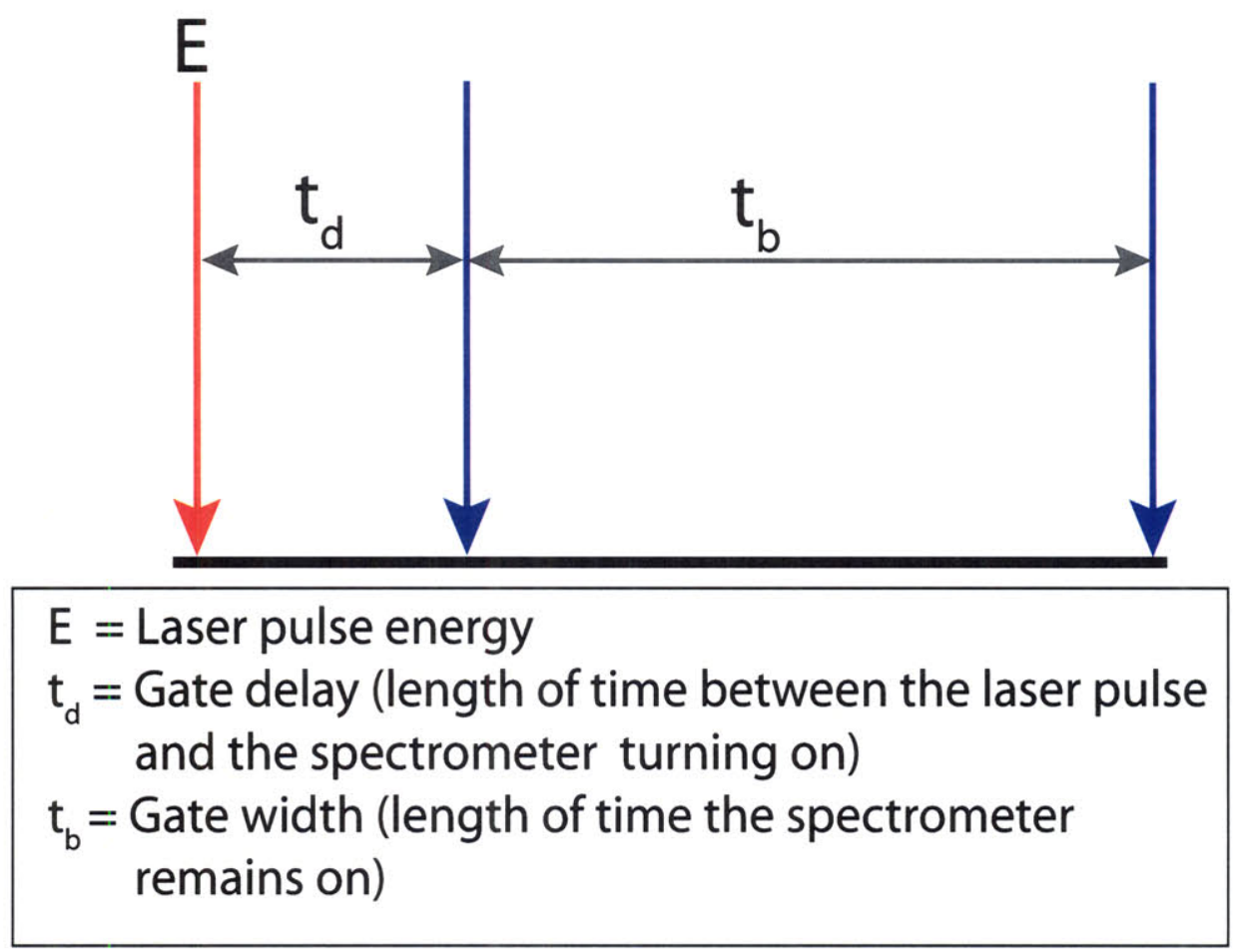

Figure 4-2: Timing parameters

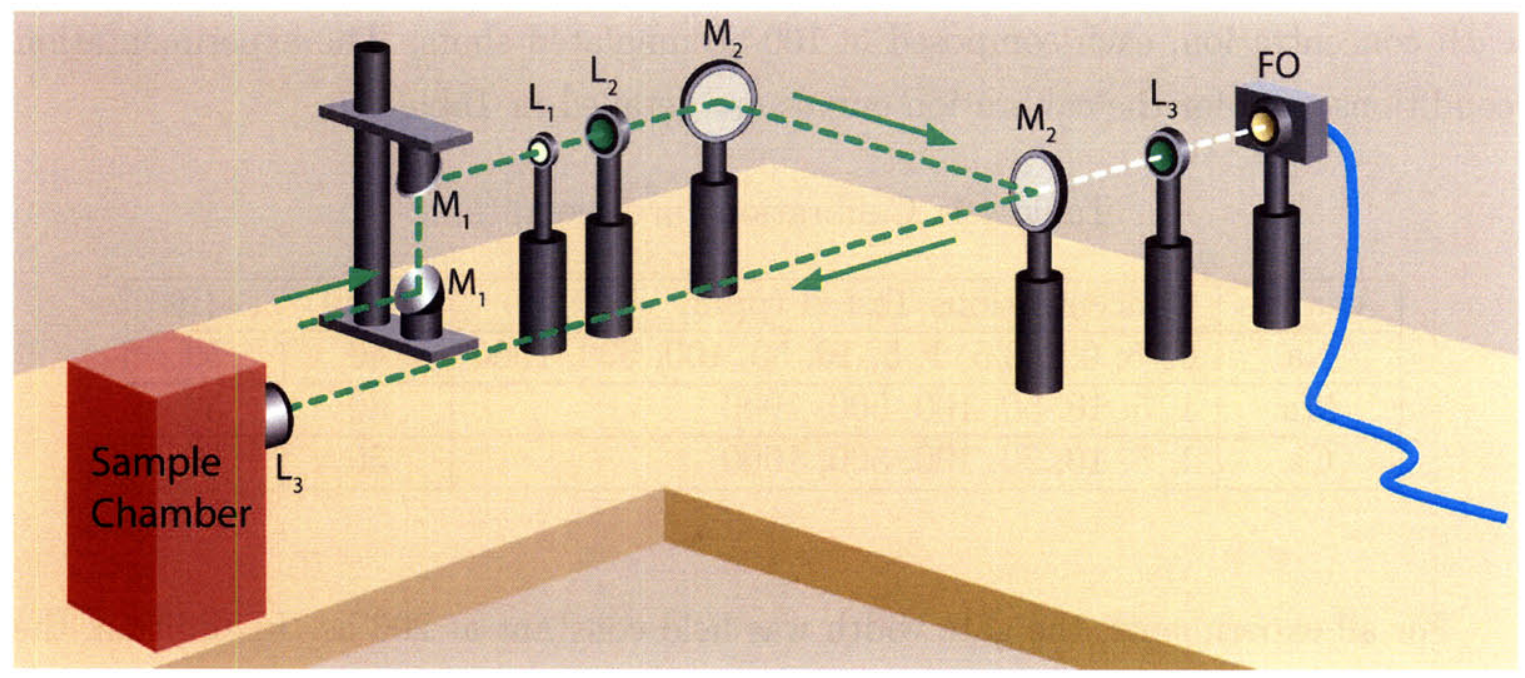

Figure 4-3: Optical Configuration. $\mathrm{M}_{1}=25 \mathrm{~mm}$ diameter $1064 \mathrm{~nm}$ Nd:YAG mirror; $\mathrm{L}_{1}=12 \mathrm{~mm} \times-12 \mathrm{~mm}$ lens; $\mathrm{L}_{2}=25 \mathrm{~mm} \times 50 \mathrm{~mm}$ lens; $\mathrm{M}_{2}=50 \mathrm{~mm}$ diameter 1064 $\mathrm{nm}$ Nd:YAG mirror; $\mathrm{L}_{3}=25 \mathrm{~mm} \times 35 \mathrm{~mm}$ lens; $\mathrm{FO}=$ Fiber Optic 
(1064 nm), $\mathrm{M}^{2}$ is the beam propagation ratio which is typically $2-10$ for Nd:YAG lasers (we therefore choose a value of 6 ), and $D$ is the diameter of the illuminated aperture of the focusing lens $(\approx 25 \mathrm{~mm})$ [24]. The beam waist width for the system is approximately $0.07 \mathrm{~mm}$. The average irradiance $\left(\mathrm{I}_{f}\right)$ at the beam waist is

$$
I_{f}=\frac{\pi E_{L} D^{2}}{4 \tau_{L} f^{2} \lambda^{2} M^{4}}
$$

where $\mathrm{E}_{L}$ is the laser pulse energy and $\tau_{L}(=7.5 \mathrm{~ns})$ is the pulse duration at the full peak width at half of the maximum intensity (FWHM) [24]. The pulse energy was varied between $10-170 \mathrm{~mJ}$ resulting in variation of irradiance at the beam waist from $\approx 1.31 \times 10^{12}$ to $2.23 \times 10^{13} \mathrm{~W} / \mathrm{cm}^{2}$. The gate delay was $50,75,100,125,150,200$, 300 , and 500 ns. Each combination of energy and gate delay was tested, resulting in 136 different conditions for the optimization studies.

The signal-to-background ratio is

$$
S B R=20 \log _{10} \frac{\text { Amplitude }_{\text {peak }}}{\text { Amplitude }}
$$

where the amplitude of the background is defined as the spectral average over a region where no peaks are expected. The background was calculated for $\mathrm{Na}$ by using the spectral region $200 \mathrm{~nm}$ to $500 \mathrm{~nm}$ and for $\mathrm{Mn}$ and Ca by using the spectral region $430 \mathrm{~nm}$ to $530 \mathrm{~nm}$.

Calibration curves were made for $\mathrm{Na}, \mathrm{Ca}$, and $\mathrm{Mn}$ with ten spectra being taken at each concentration, each composed of 100 accumulated shots. The experimentation conditions used for the calibration curves are detailed in Table 4.1.

Table 4.1: Calibration curve conditions

\begin{tabular}{|c|l|c|c|}
\hline Analyte & Concentrations Tested $(\mathrm{ppm})$ & $\mathrm{E}(\mathrm{mJ})$ & $\mathrm{t}_{d}(\mathrm{~ns})$ \\
\hline $\mathrm{Na}$ & $0.05,0.1,0.5,1,5,10,50,100,500,1000$ & 40 & 50 \\
\hline $\mathrm{Mn}$ & $1,5,10,50,100,500,1000$ & 30 & 50 \\
\hline $\mathrm{Ca}$ & $1,5,10,50,100,500,1000$ & 30 & 50 \\
\hline
\end{tabular}

For all experiments, the gate width was held constant at $200 \mathrm{~ns}$. In addition, the amplification of the Echelle spectrometer was set to the maximum value of 4000 .

All raw spectra were processed using extreme value distribution statistics detailed in a paper by Michel and Chave [25]. Data from 9 wavelengths were grouped for processing. Where shown, error bars represent the double sided $95 \%$ confidence limits [25]. 
Solutions were made from $\mathrm{NaCl}, \mathrm{MnSO}_{4} \cdot \mathrm{H}_{2} \mathrm{O}$, and $\mathrm{CaCl}_{2} \cdot 2 \mathrm{H}_{2} \mathrm{O}$ dissolved in deionized water for the $\mathrm{Na}, \mathrm{Mn}$, and $\mathrm{Ca}$ studies, respectively. All concentrations are given in parts per million (ppm, wt./vol.).

\subsection{Results and Discussion}

\subsubsection{Sodium}

The interrelationship of gate delay and laser pulse energy for sodium was studied using a concentration of $100 \mathrm{ppm}$. The intensities of the $588.995 \mathrm{~nm}$ and $589.6 \mathrm{~nm}$ Na peaks were measured, and are shown in Figures 4-4 and 4-5. As pressure rises, an increase in signal intensity is observed with the maximum peak intensity present at $2.76 \times 10^{7}$ Pa. An examination of these figures shows that the greatest peak intensity exists at the shortest gate delay. As $t_{d}$ increases, peak intensity decreases, independent of both the laser pulse energy and ambient pressure. The data variability present in the plots is indicative of significant plasma variability. Overall, there appears to be little effect of energy on intensity. Examination of the SBR provides important information for selecting optimal parameters. Figures 4-6 and 4-7 detail the interrelationship of $t_{d}$, energy, and SBR. A smaller $t_{d}$ tends to exhibit a higher SBR due to a stronger signal, as seen in Figures 4-4 and 4-5. Furthermore, Figure 4-4 suggests that a lower energy pulse consistently provides a higher SBR. As pressure increases, the SBR again tends to increase. The data suggest that the highest SBR exists when a low energy pulse $(20-60 \mathrm{~mJ})$ and a relatively small $t_{d}$ are used $(50-150 \mathrm{~ns})$. As first reported in Michel et al. [17], this suggests that an optimal range of laser energies exists that tend to be relatively low.

For the best SBR, a pulse energy of $40 \mathrm{~mJ}$ and a gate delay of $50 \mathrm{~ns}$ were identified for detection of $\mathrm{Na}$ over a range of pressures and spectra of this condition are plotted in Figure 4-8. Calibration curves for sodium were constructed to determine the limit of detection (Figure 4-9). These suggest that sodium can be detected at a concentration of approximately $50 \mathrm{ppm}$ using the present apparatus. Spectra of the Na calibration data are shown in Figure 4-10 that illustrate that $50 \mathrm{ppm}$ is the lowest concentration where $\mathrm{Na}$ is detectable. 


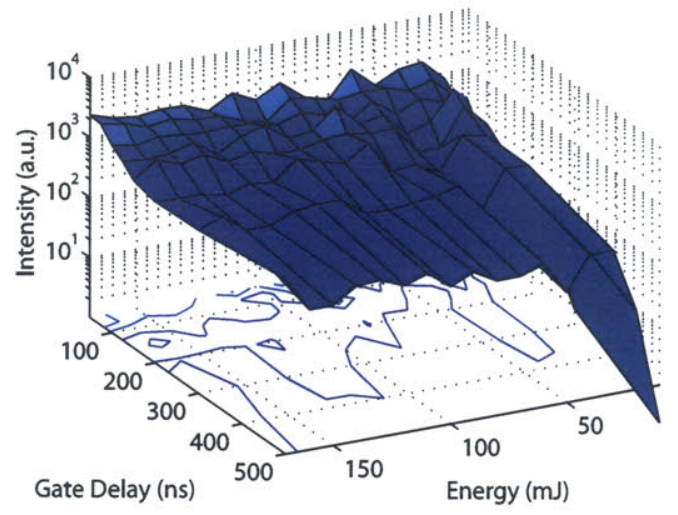

(a)

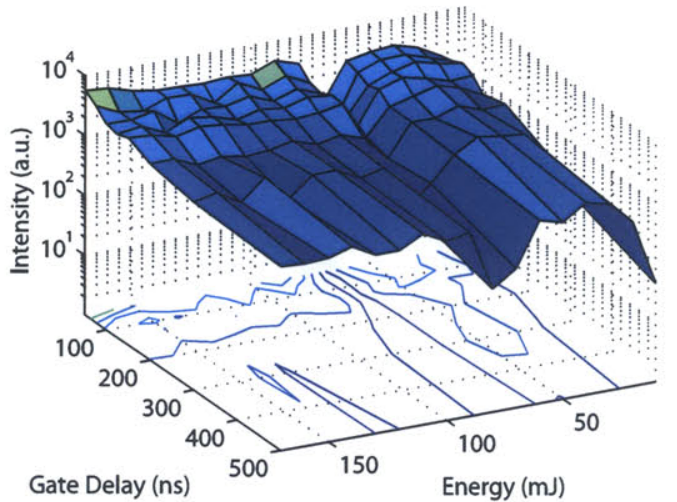

(c)

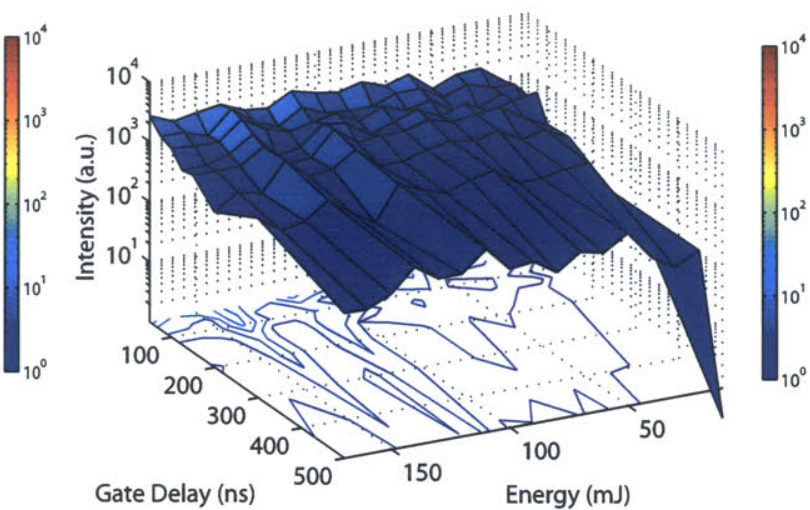

(b)

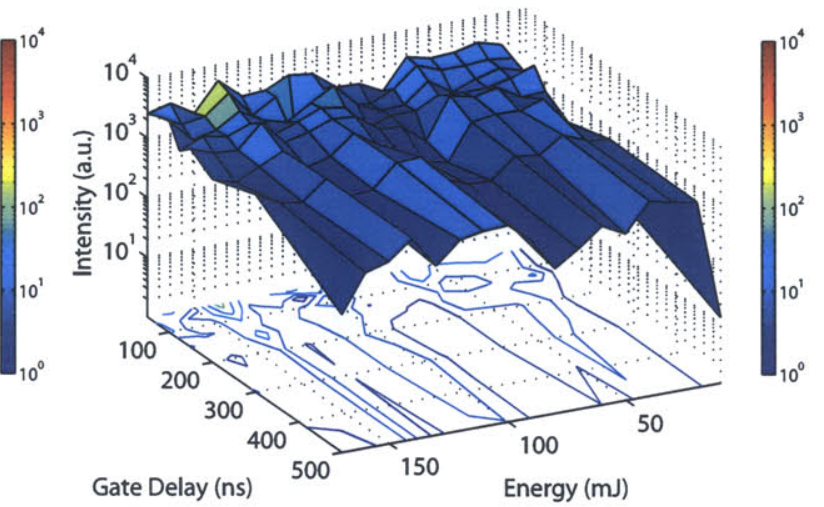

(d)

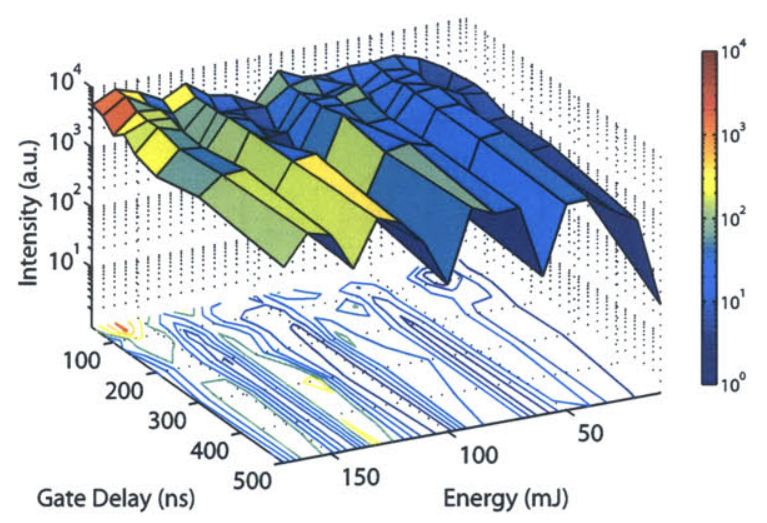

(e)

Figure 4-5: Interrelationship of gate delay, laser pulse energy, and peak intensity for $\mathrm{Na}(589.6 \mathrm{~nm})$ over a range of pressures (a) $1 \times 10^{5} \mathrm{~Pa}$ (b) $6.89 \times 10^{6} \mathrm{~Pa}$ (c) $1.38 \times$ $10^{7} \mathrm{~Pa}(\mathrm{~d}) 2.07 \times 10^{7} \mathrm{~Pa}(\mathrm{e}) 2.76 \times 10^{7} \mathrm{~Pa}$ 


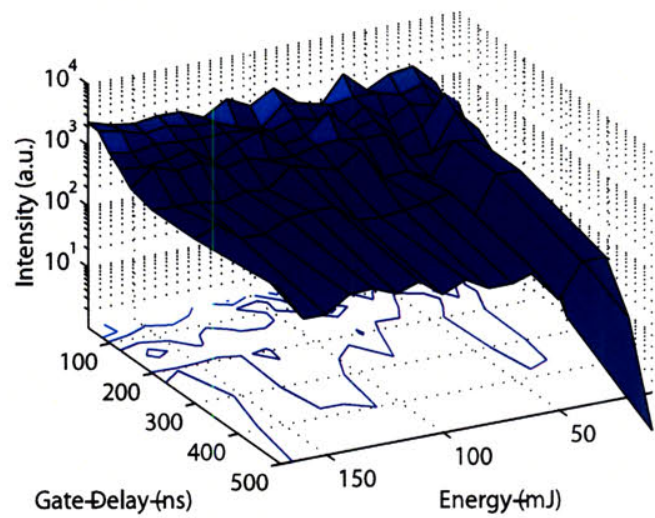

(a)

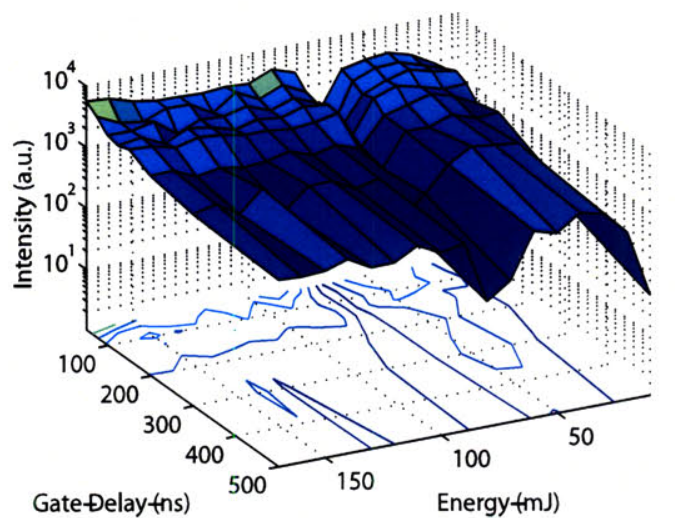

(c)
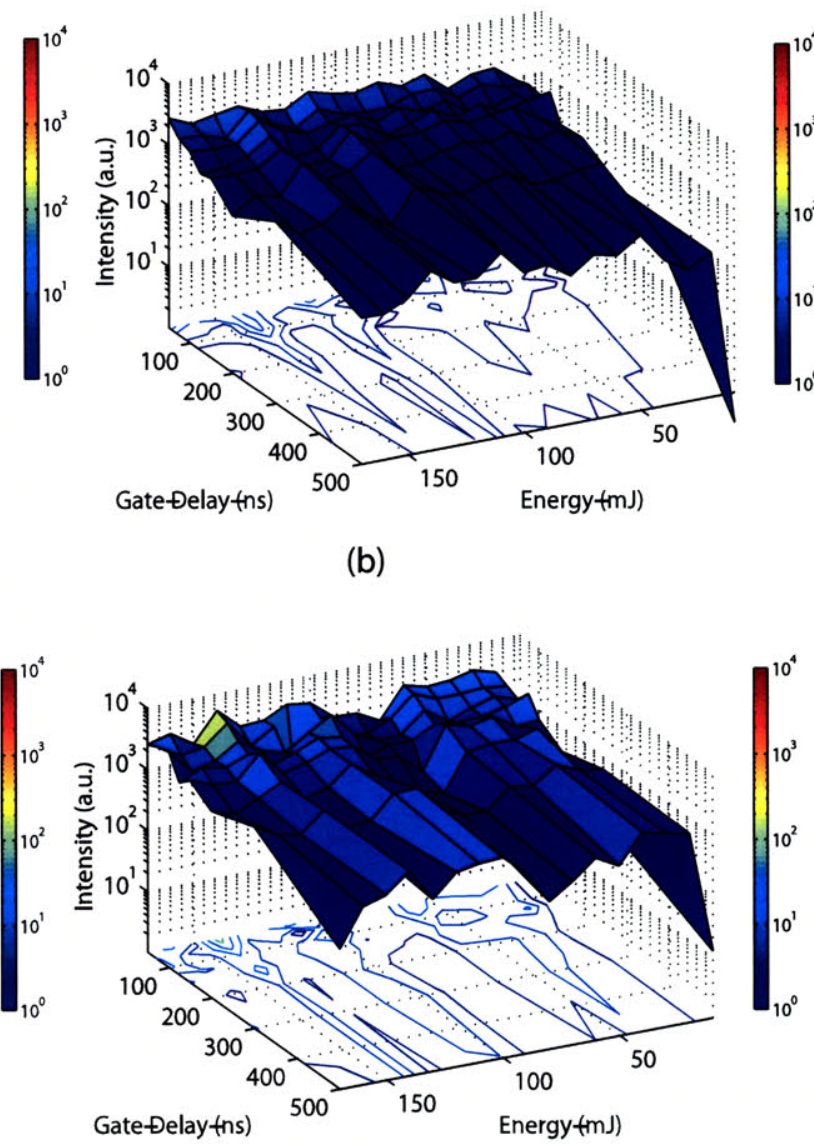

(d)

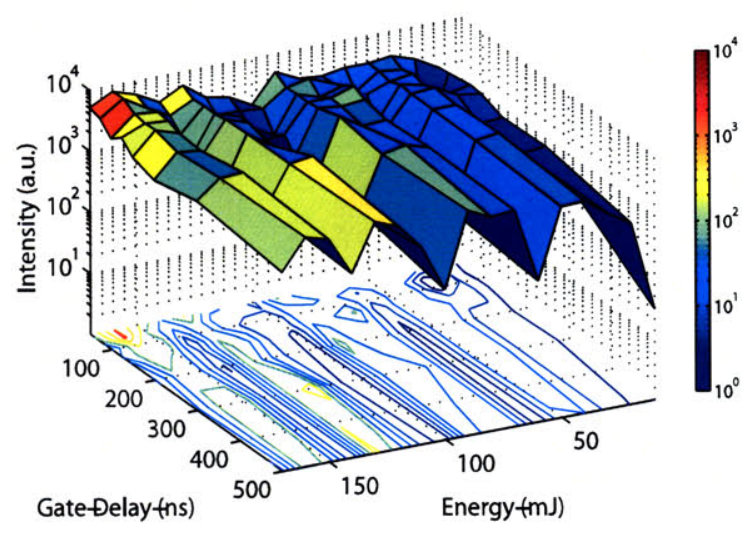

(e)

Figure 4-5: Interrelationship of gate delay, laser pulse energy, and peak intensity for $\mathrm{Na}(589.6 \mathrm{~nm})$ over a range of pressures (a) $1 \times 10^{5} \mathrm{~Pa}$ (b) $6.89 \times 10^{6} \mathrm{~Pa}$ (c) $1.38 \times$ $10^{7} \mathrm{~Pa}$ (d) $2.07 \times 10^{7} \mathrm{~Pa}$ (e) $2.76 \times 10^{7} \mathrm{~Pa}$ 


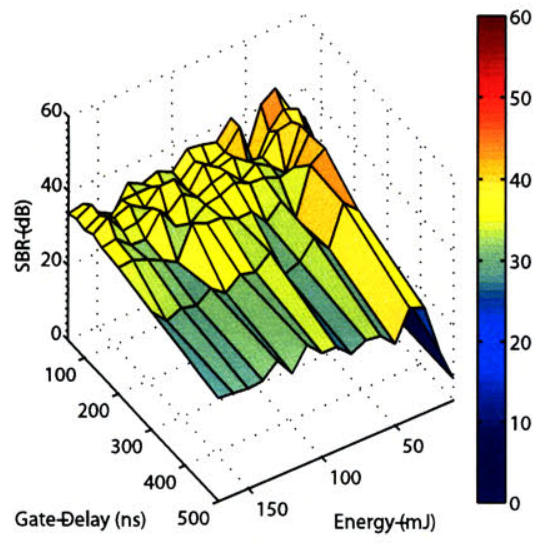

(a)

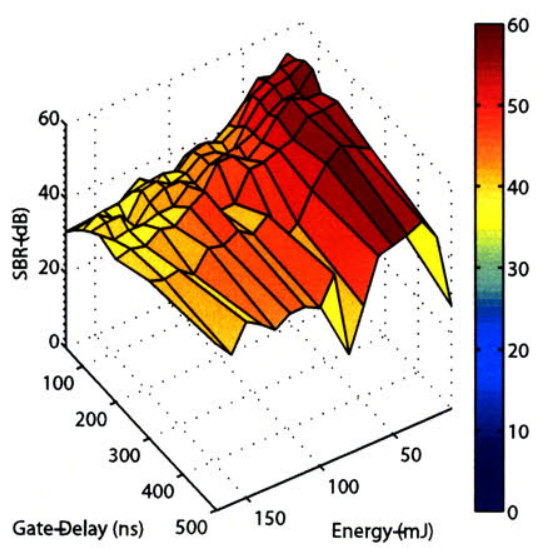

(c)

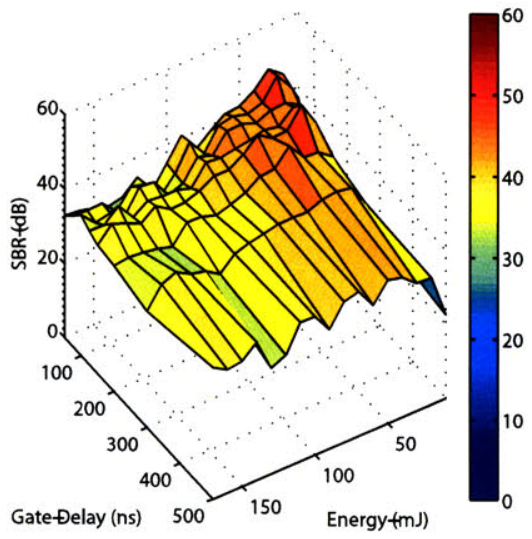

(b)

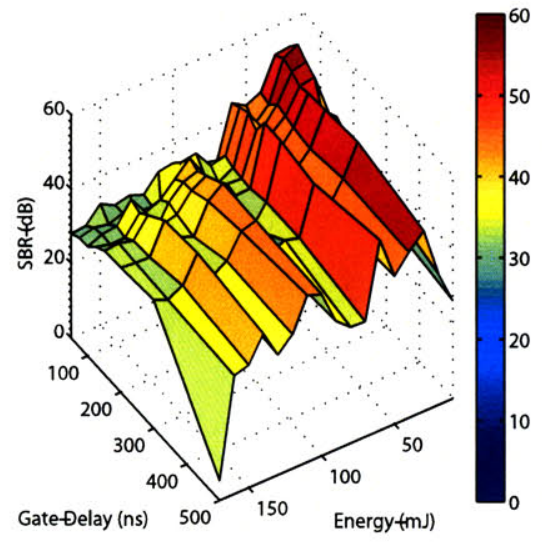

(d)

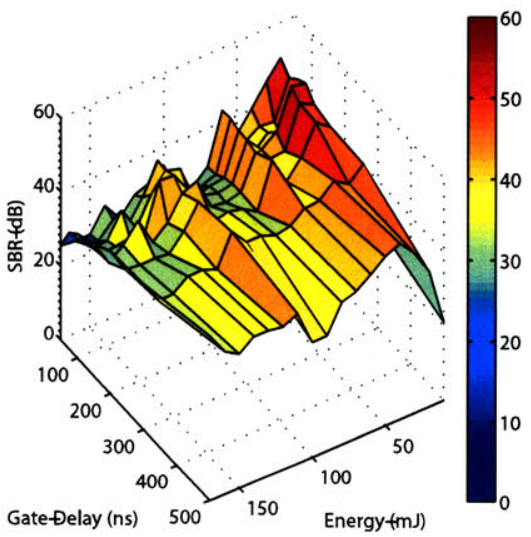

(e)

Figure 4-6: Interrelationship of pressure, gate delay, energy, and signal-to-background for $\mathrm{Na}(588.995 \mathrm{~nm})$ (a) $1 \times 10^{5} \mathrm{~Pa}$ (b) $6.89 \times 10^{6} \mathrm{~Pa}$ (c) $1.38 \times 10^{7} \mathrm{~Pa}$ (d) $2.07 \times$ $10^{7} \mathrm{~Pa}(\mathrm{e}) 2.76 \times 10^{7} \mathrm{~Pa}$ 


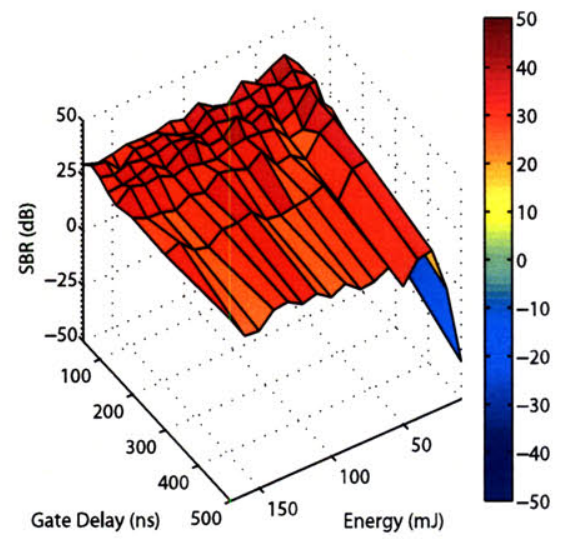

(a)

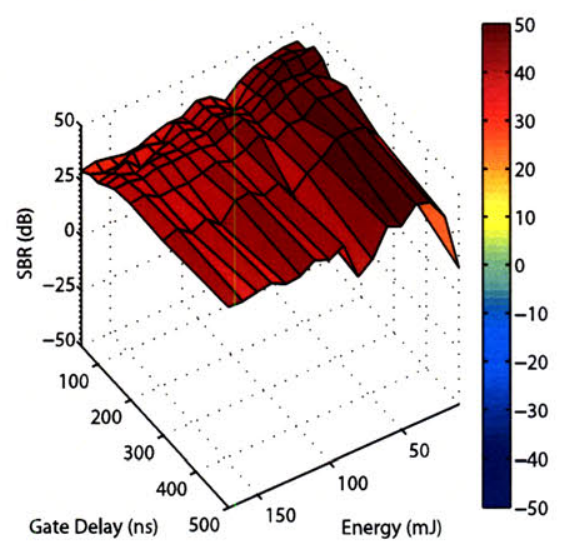

(c)

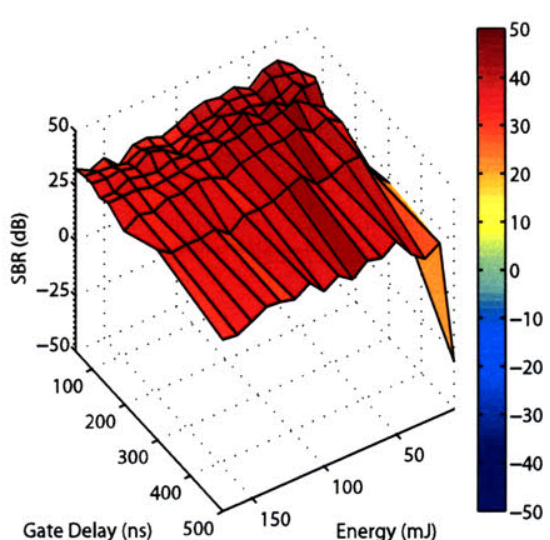

(b)

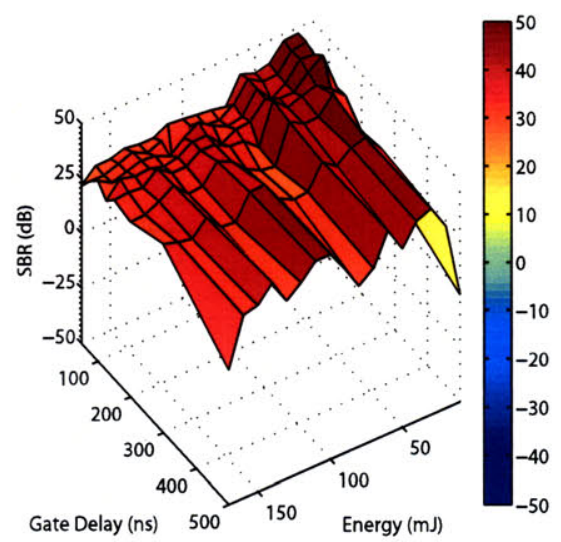

(d)

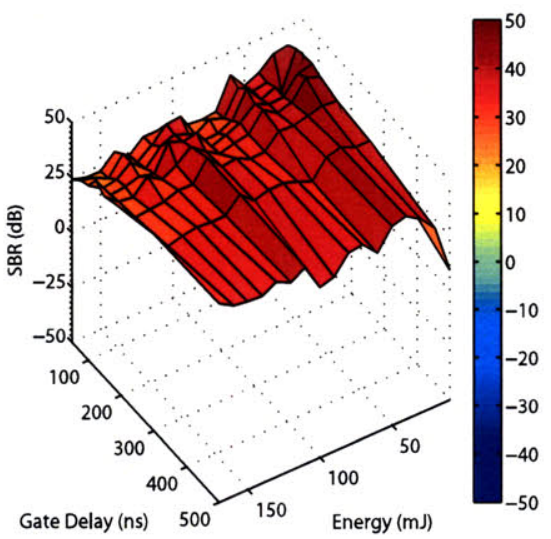

(e)

Figure 4-7: Interrelationship of pressure, gate delay, energy, and signal-to-background for $\mathrm{Na}(589.6 \mathrm{~nm})(\mathrm{a}) 1 \times 10^{5} \mathrm{~Pa}$ (b) $6.89 \times 10^{6} \mathrm{~Pa}$ (c) $1.38 \times 10^{7} \mathrm{~Pa}$ (d) $2.07 \times 10^{7}$ $\mathrm{Pa}(\mathrm{e}) 2.76 \times 10^{7} \mathrm{~Pa}$ 


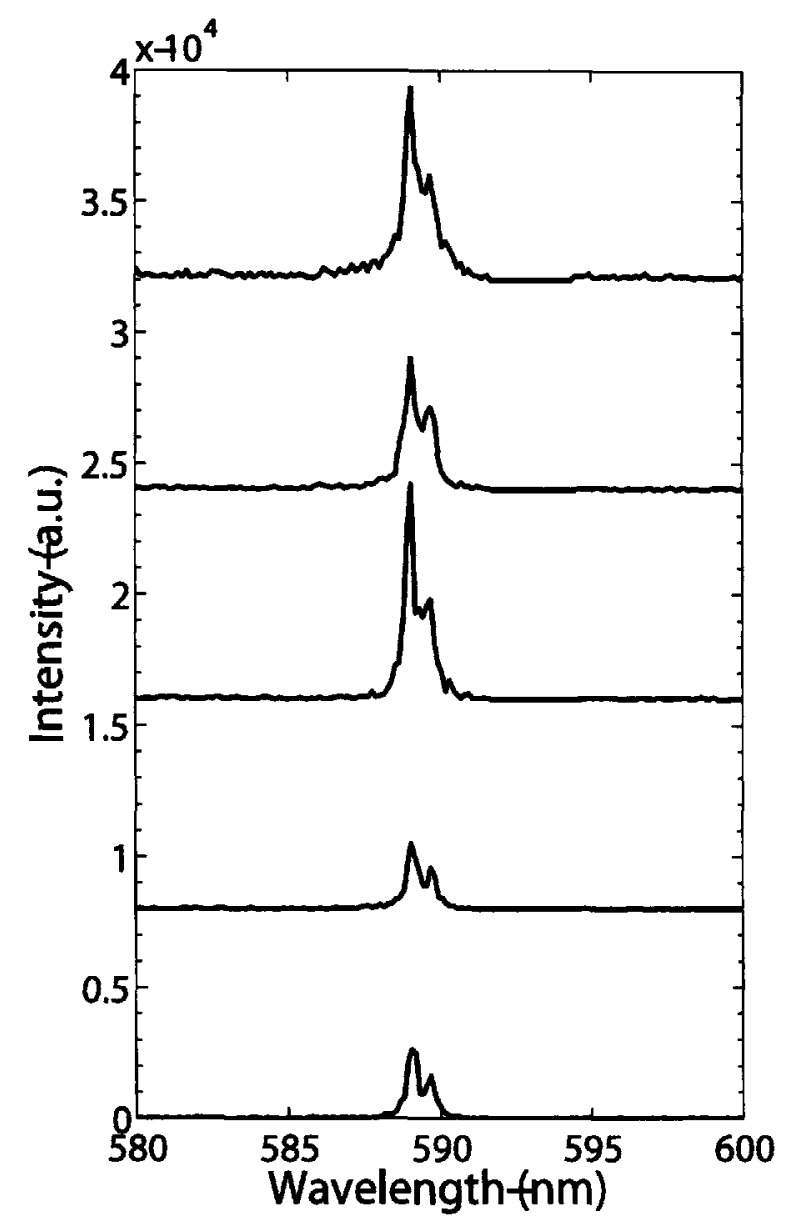

Figure 4-8: Spectra of $\mathrm{Na}(588.995 \mathrm{~nm}$ and $589.6 \mathrm{~nm})$ taken with a pulse energy of $40 \mathrm{~mJ}$ and a gate delay of $50 \mathrm{~ns}$. From bottom to top, the spectra were taken at 1 $\times 10^{5} \mathrm{~Pa}, 6.89 \times 10^{6} \mathrm{~Pa}, 1.38 \times 10^{7} \mathrm{~Pa}, 2.07 \times 10^{7}$, and $2.76 \times 10^{7} \mathrm{~Pa}$. For clarity, the spectra have been offset from each other by 8000 a.u. 


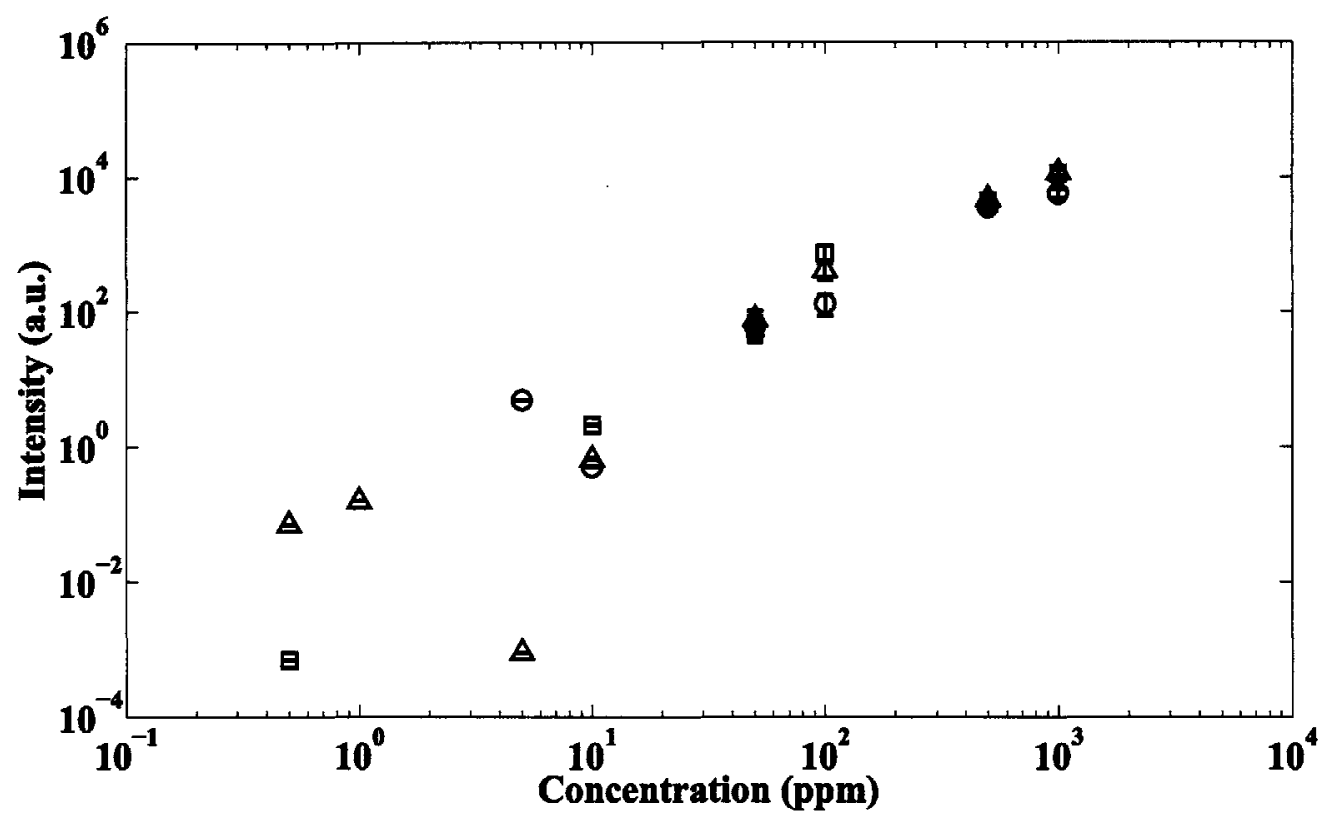

(a)

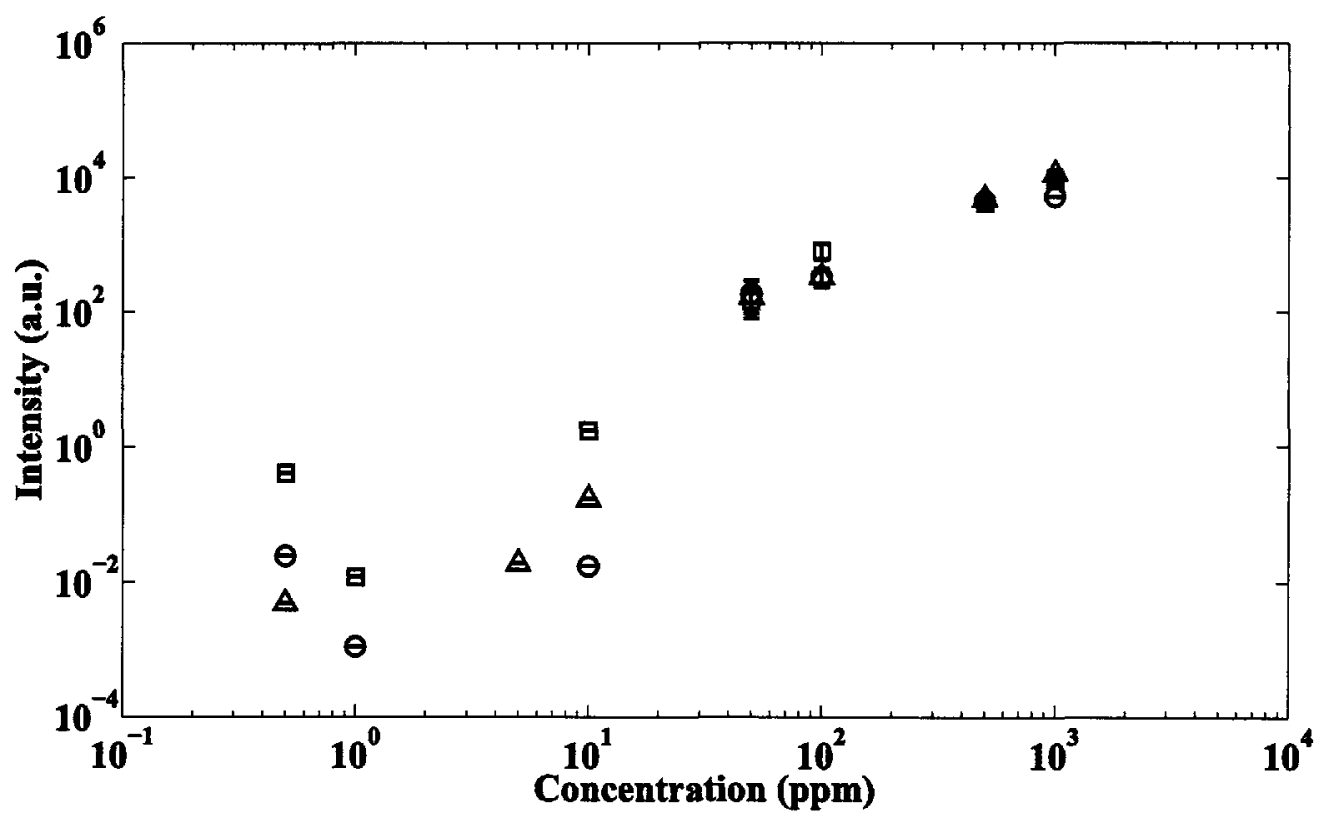

(b)

Figure 4-9: Sodium calibration curves of the (a) $588.995 \mathrm{~nm}$ peak and the (b) 589.6 nm peak. $\mathrm{O}=1 \times 10^{5} \mathrm{~Pa}, \square=1.38 \times 10^{7} \mathrm{~Pa}, \triangle=2.76 \times 10^{7} \mathrm{~Pa}$ 


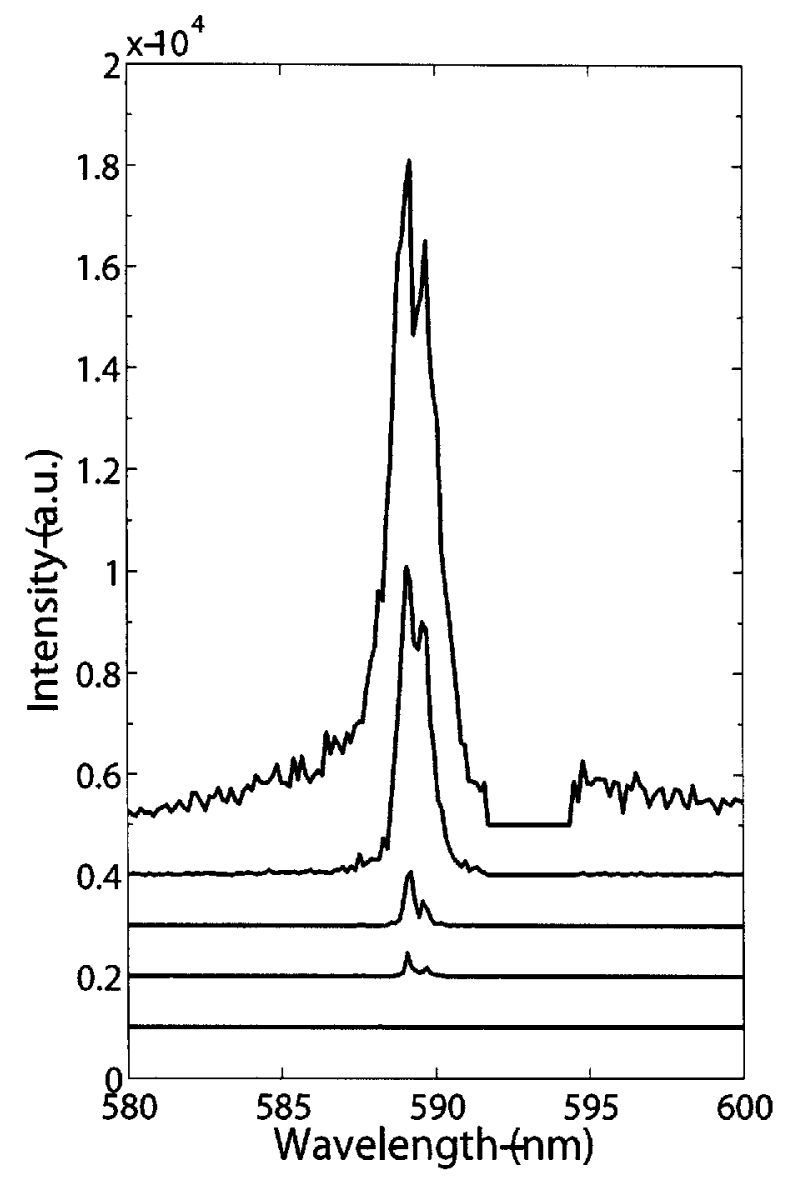

Figure 4-10: Spectra of sodium (588.995 $\mathrm{nm}$ and $589.6 \mathrm{~nm})$ at $2.76 \times 10^{7} \mathrm{~Pa}$ made over a range of $\mathrm{NaCl}$ concentrations The concentrations from bottom to top are 10 $\mathrm{ppm}, 50 \mathrm{ppm}, 100 \mathrm{ppm}, 500 \mathrm{ppm}$, and $1000 \mathrm{ppm}$. For clarity, the spectra have been offset from each other by 1000 a.u. 


\subsubsection{Manganese}

The effect of laser pulse energy and gate delay on spectra for manganese were studied using a concentration of $1000 \mathrm{ppm} \mathrm{Mn}$ over a range of pressures. Although a $\mathrm{Mn}$ triplet exists at $403 \mathrm{~nm}$, peak broadening in liquids causes it to be unresolvable, and therefore we report a single $403 \mathrm{~nm}$ peak. The interrelationship of pressure, gate delay, energy, and intensity are shown in Figure 4-11. As pressure increases, peak intensity also rises. A similar finding was reported by Michel et al. under a single tested condition (single $\mathrm{E}$ and $\mathrm{t}_{d}$ ) [17]. Figure 4-11 shows that irrespective of gate delay and energy the peak intensity of $\mathrm{Mn}$ increases with pressure. $\mathrm{Mn}$ also exhibits a higher peak intensity at a lower laser pulse energy at a shorter $t_{d}$. When the corresponding SBR plots are examined (Figure 4-12), SBR is shown to be smallest at the lowest pressure $\left(1 \times 10^{5} \mathrm{~Pa}\right)$. Again, the need for a short $\mathrm{t}_{d}$ and a low $\mathrm{E}$ is evident.

From the optimization studies, an energy of $30 \mathrm{~mJ}$ with a gate delay of $50 \mathrm{~ns}$ was selected as a condition that would provide good detection of $\mathrm{Mn}$ over a broad range of pressures. The selected condition is plotted at all five pressure conditions in Figure 4-13. To determine the limit of detection of $\mathrm{Mn}$, a calibration curve was constructed using $30 \mathrm{~mJ}$ and $\mathrm{t}_{d}$ of $50 \mathrm{~ns}$ (Figure 4-14). Figure 4-15 shows spectra made at these conditions at $2.76 \times 10^{7} \mathrm{~Pa}$ over a range of concentrations. The limit of detection was found to be $500 \mathrm{ppm}$ which is higher than the concentration found in vent fluids. 


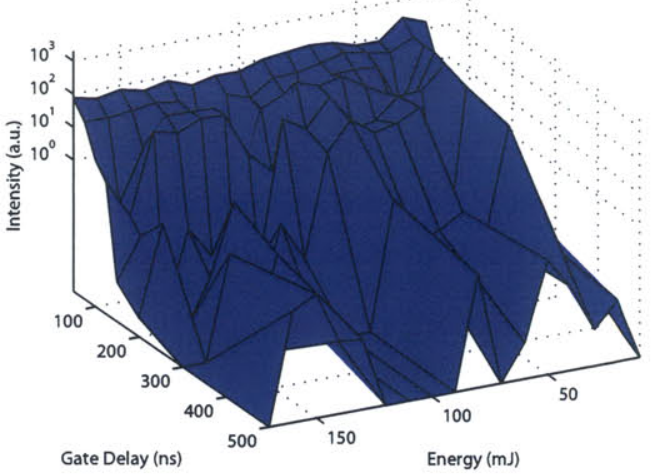

(a)

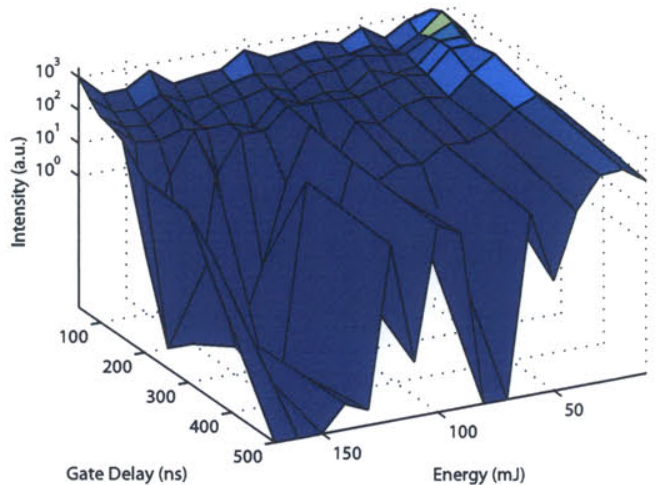

(c)
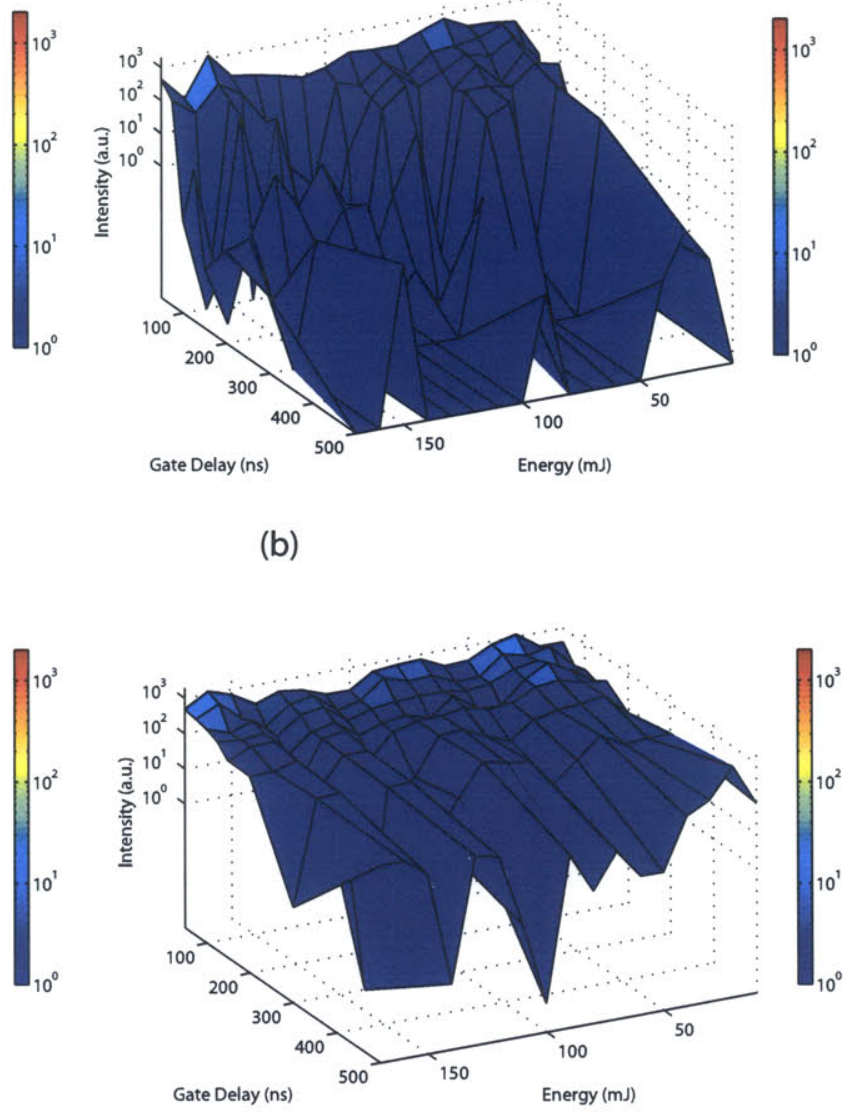

(d)

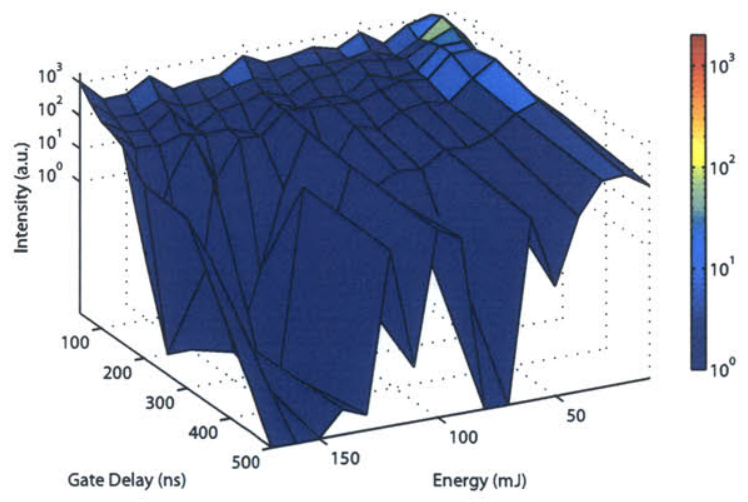

(e)

Figure 4-11: Interrelationship of pressure, gate delay, energy, and intensity for Mn $(403.076 \mathrm{~nm})(\mathrm{a}) 1 \times 10^{5} \mathrm{~Pa}$ (b) $6.89 \times 10^{6} \mathrm{~Pa}$ (c) $1.38 \times 10^{7} \mathrm{~Pa}$ (d) $2.07 \times 10^{7} \mathrm{~Pa}$ (e) $2.76 \times 10^{7} \mathrm{~Pa}$ 


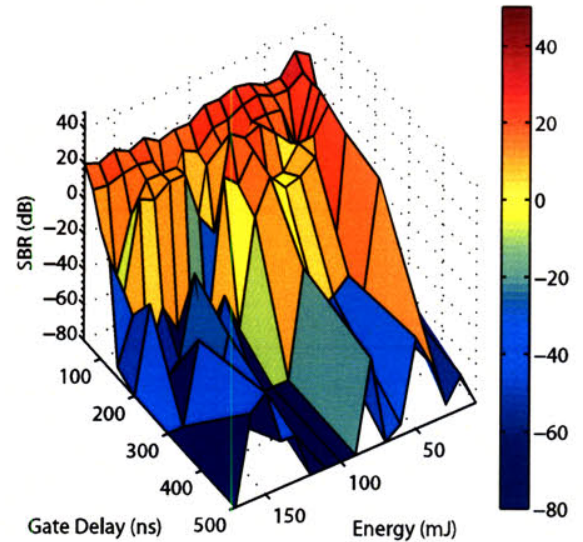

(a)

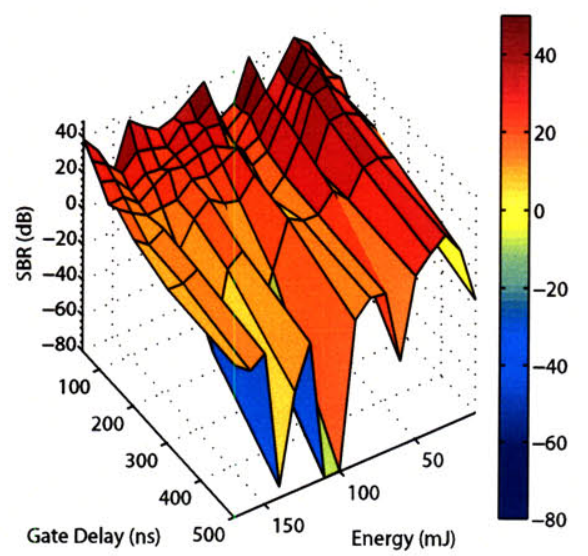

(c)

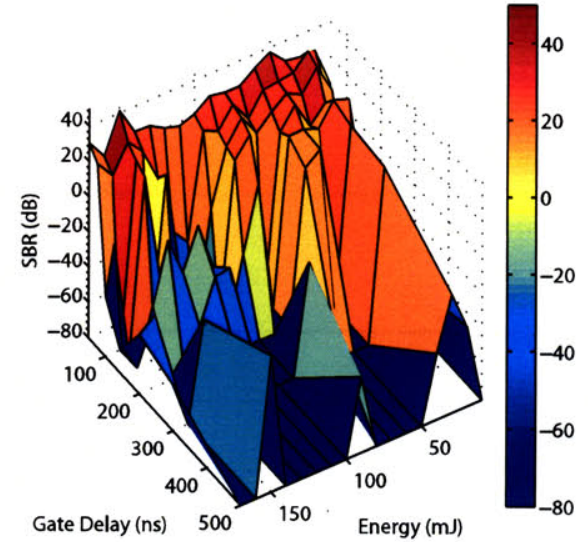

(b)

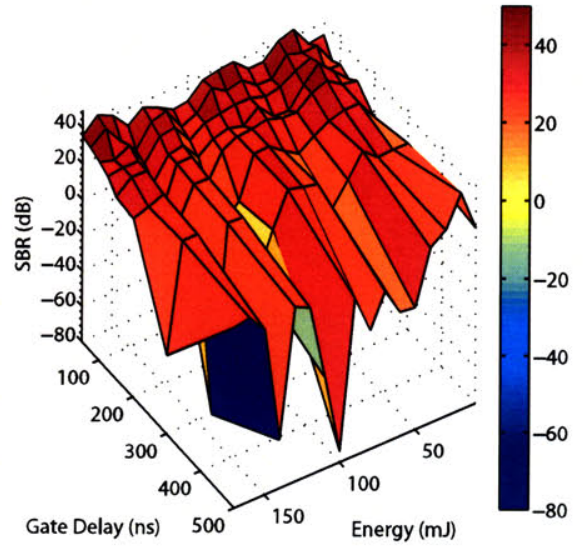

(d)

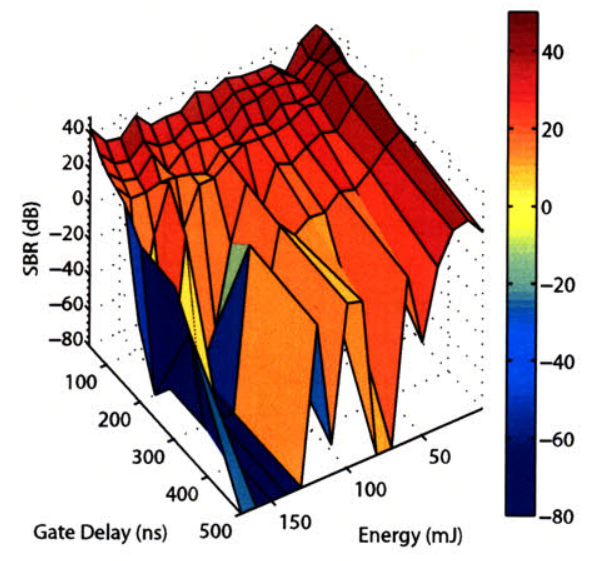

(e)

Figure 4-12: Interrelationship of pressure, $\mathrm{t}_{d}, \mathrm{E}$, and SBR for Mn (403.076 nm) (a) 1 $\times 10^{5} \mathrm{~Pa}$ (b) $6.89 \times 10^{6} \mathrm{~Pa}$ (c) $1.38 \times 10^{7} \mathrm{~Pa}$ (d) $2.07 \times 10^{7} \mathrm{~Pa}$ (e) $2.76 \times 10^{7} \mathrm{~Pa}$ 


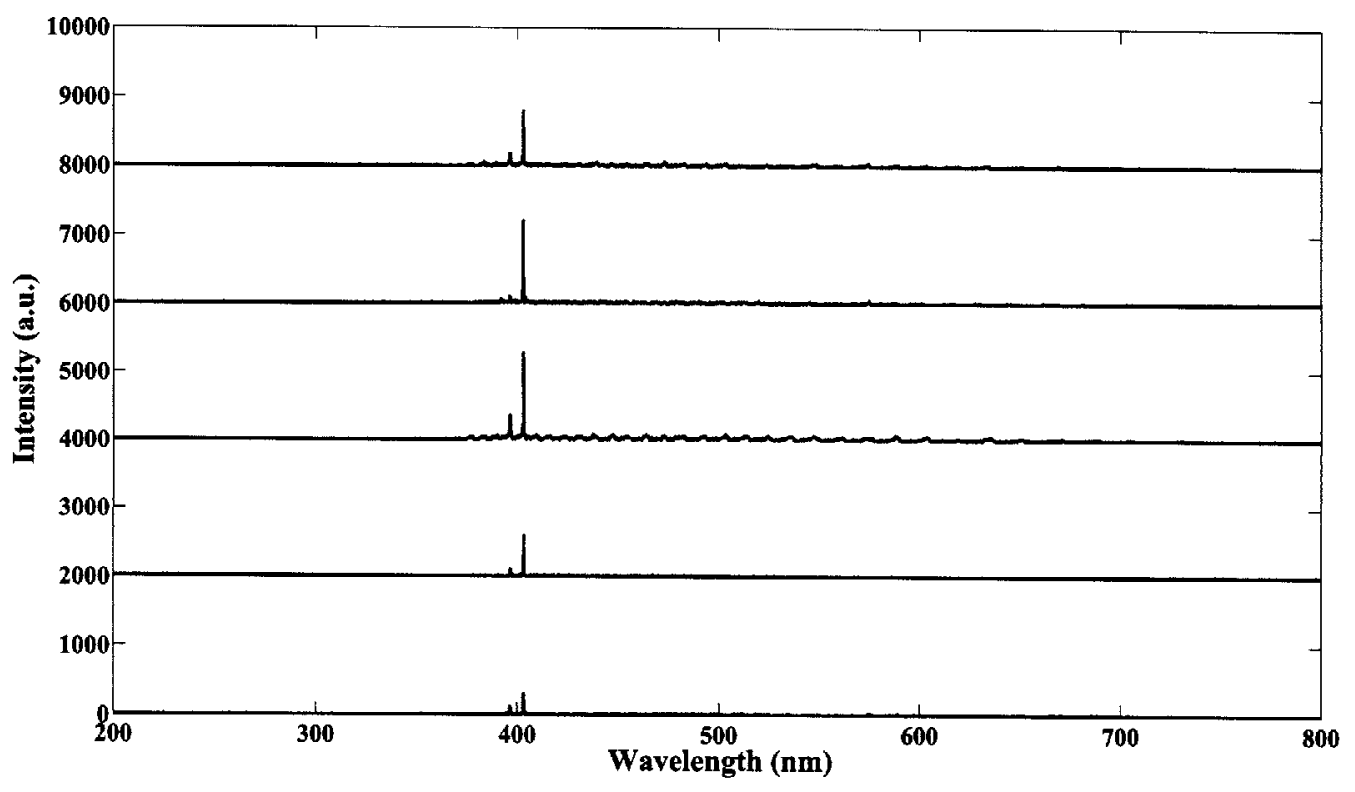

(a)

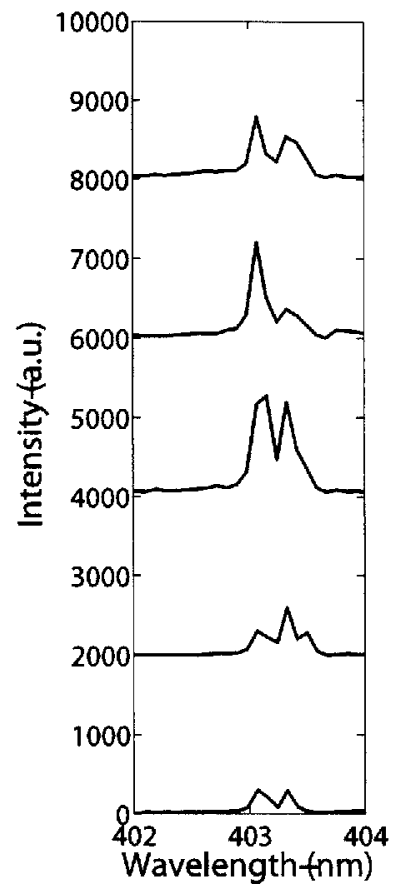

(b)

Figure 4-13: Manganese spectra using a $30 \mathrm{~mJ}$ energy pulse and a gate delay of 50 ns. (a) Full spectral region. (b) Manganese (403 nm peak) In (a) and (b) the spectra from bottom to top are at $1 \times 10^{5} \mathrm{~Pa}, 6.89 \times 10^{6} \mathrm{~Pa}, 1.38 \times 10^{7} \mathrm{~Pa}, 2.07 \times 10^{7} \mathrm{~Pa}$, $2.76 \times 10^{7}$, respectively. For clarity, the spectra have been offset from each other by 2000 a.u. 


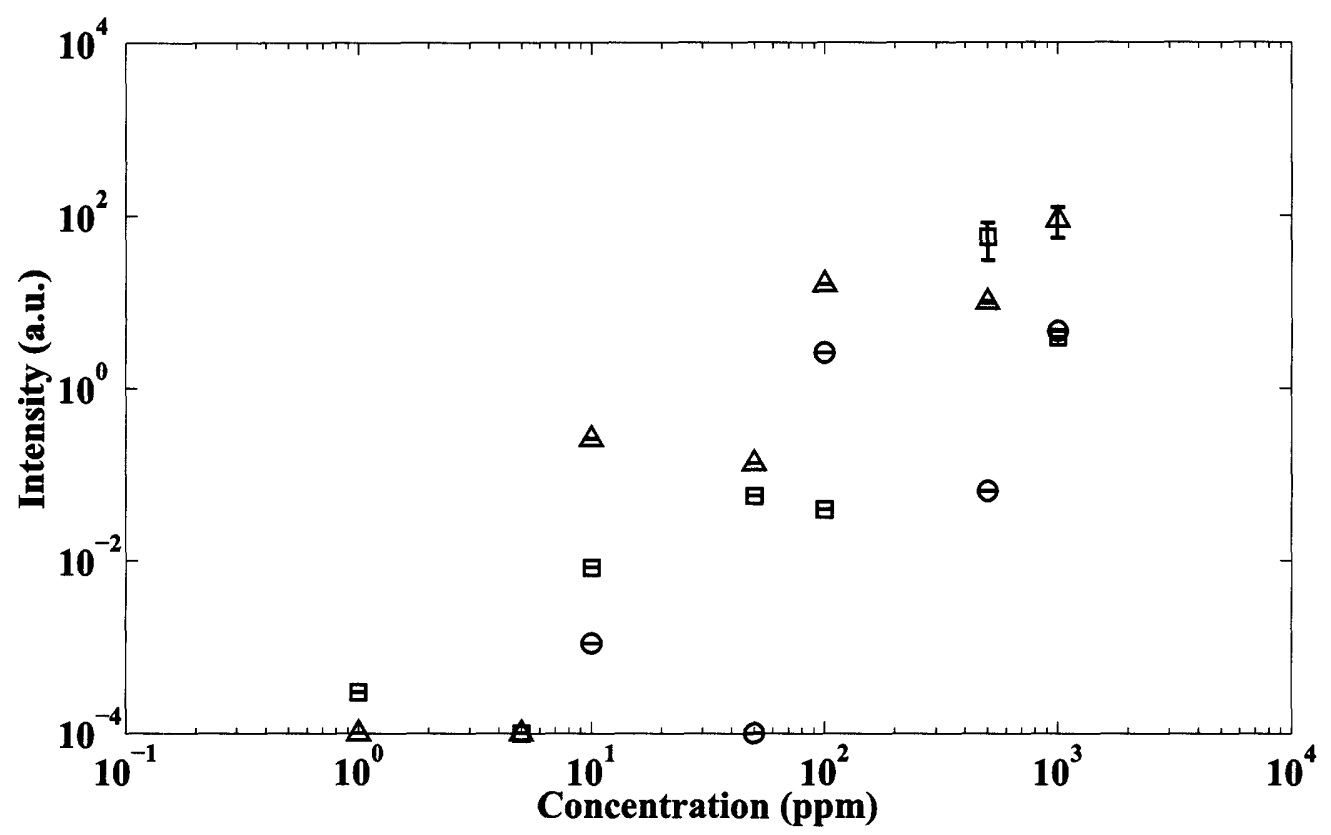

Figure 4-14: $\mathrm{Mn}(403 \mathrm{~nm})$ calibration curve. $\mathrm{O}=1 \times 10^{5} \mathrm{~Pa}, \square=1.38 \times 10^{7} \mathrm{~Pa}$, $\triangle=2.76 \times 10^{7} \mathrm{~Pa}$. 


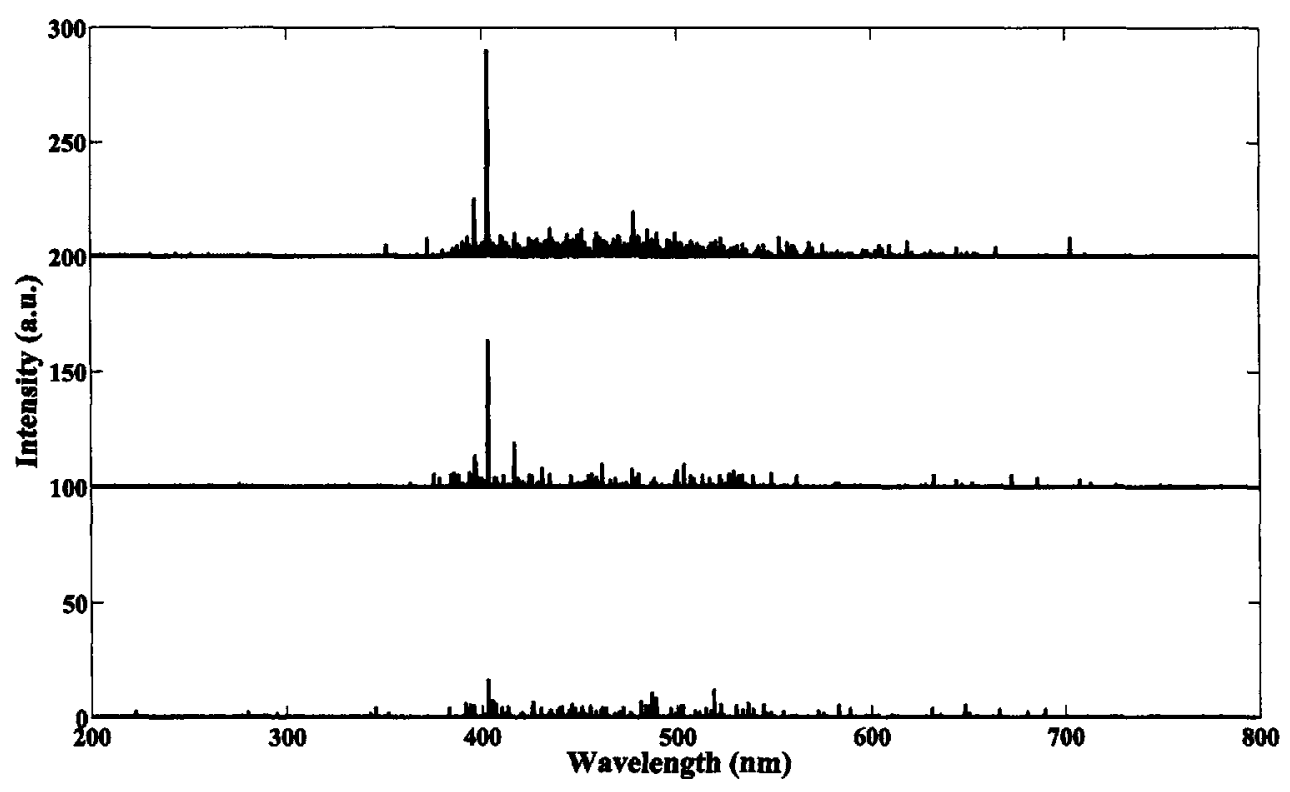

(a)

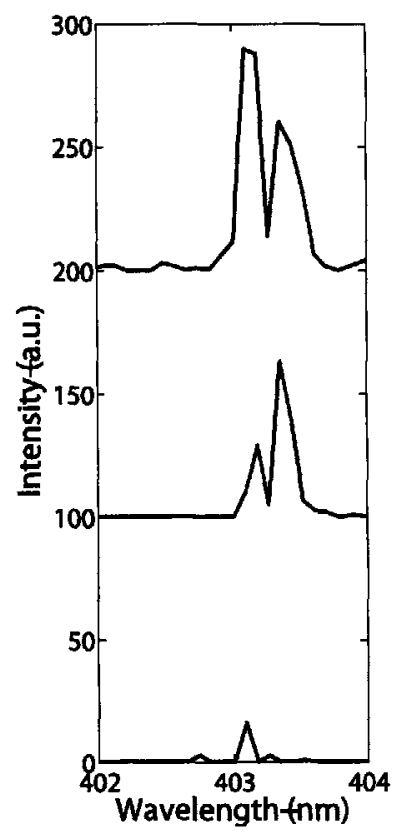

(b)

Figure 4-15: Spectra of manganese at $2.76 \times 10^{7} \mathrm{~Pa}$ made at a range of $\mathrm{Mn}$ concentrations (a) Full spectral region (b) Manganese. In (a) and (b) the concentrations of the spectra from bottom to top are $100 \mathrm{ppm}, 500 \mathrm{ppm}$, and $1000 \mathrm{ppm}$. For clarity, the spectra have been offset from each other by 100 a.u. 


\subsubsection{Calcium}

Three calcium peaks, $393 \mathrm{~nm}$ (ionic), $396 \mathrm{~nm}$ (ionic) and $422 \mathrm{~nm}$ (atomic), were studied. The interrelationship of the measurement parameters of Ca were determined and are shown in Figures 4-16 to 4-21. The importance of a short $t_{d}$ is evident when SBR is examined (Figures 4-19 to 4-21). Although three calcium peaks are detectable, the $422 \mathrm{~nm}$ peak is the strongest, and therefore the selection of an optimal condition was based on this peak. A laser energy pulse of $30 \mathrm{~mJ}$ with a gate delay of $50 \mathrm{~ns}$ was selected as the optimal condition for detection of $\mathrm{Ca}$, and spectra illustrating this condition are shown in Figure 4-22. Calcium calibration curves were constructed using these conditions and are shown in Figure 4-23 for both the $393 \mathrm{~nm}$ and the 422 $\mathrm{nm}$ peaks. These suggest the limit of detection for $\mathrm{Ca}$ is $50 \mathrm{ppm}$ using the present apparatus. Spectra for selected concentrations are illustrated in Figure 4-24.

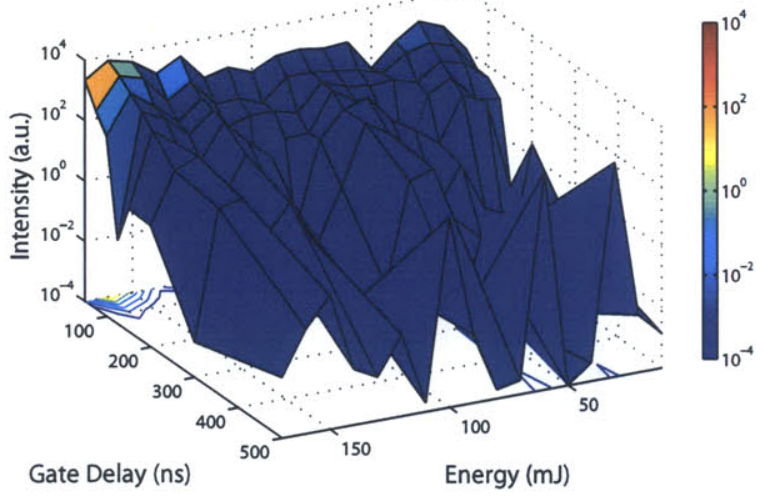

(a)

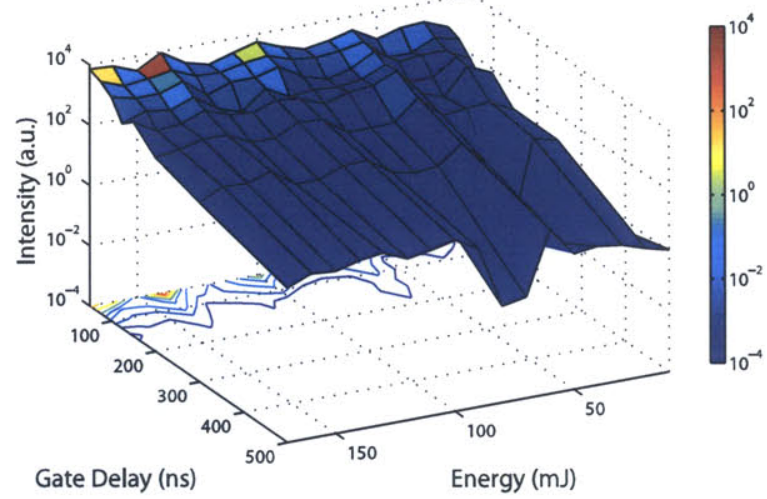

(b)

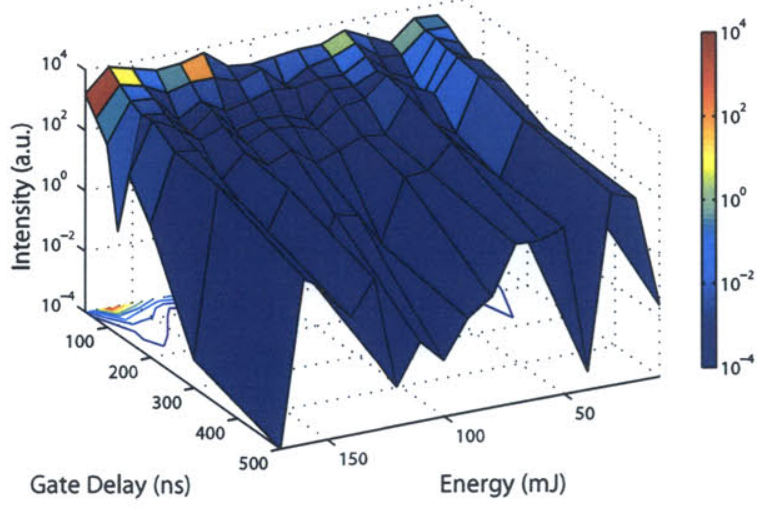

(c)

Figure 4-16: Interrelationship of pressure, $\mathrm{t}_{d}, \mathrm{E}$, and intensity for $\mathrm{Ca}(393 \mathrm{~nm})$ (a) 1 $\times 10^{5} \mathrm{~Pa}$ (b) $1.38 \times 10^{7} \mathrm{~Pa}$ (c) $2.76 \times 10^{7} \mathrm{~Pa}$ 


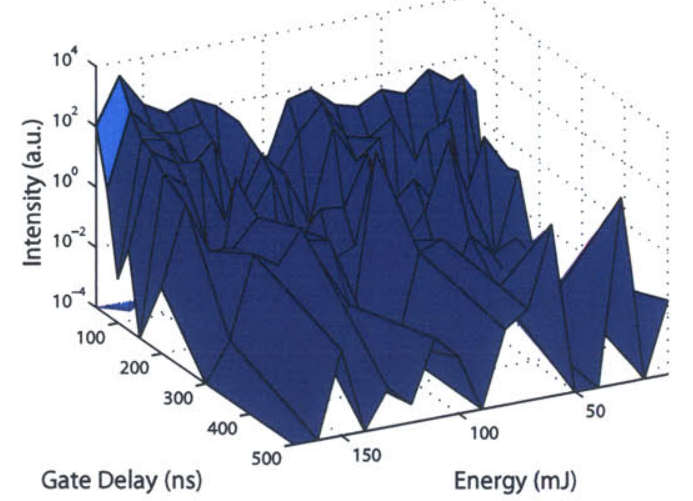

(a)
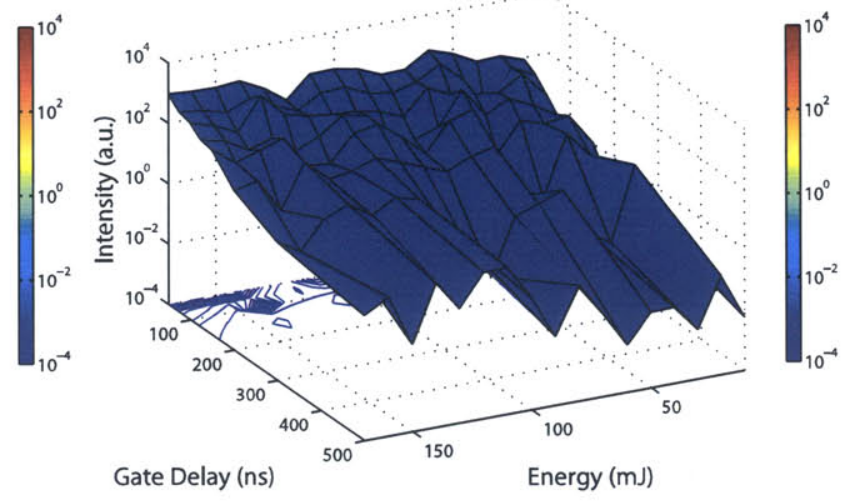

(b)

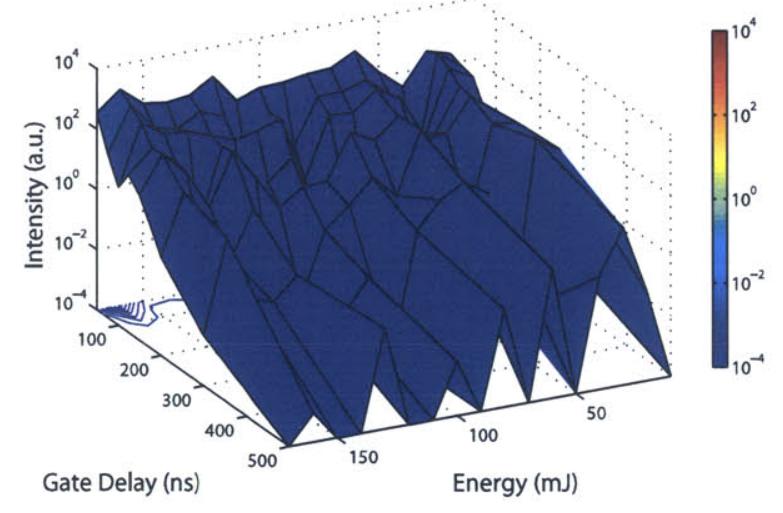

(c)

Figure 4-17: Interrelationship of pressure, $\mathrm{t}_{d}$, energy, and intensity for Ca (396 nm) (a) $1 \times 10^{5} \mathrm{~Pa}$ (b) $1.38 \times 10^{7} \mathrm{~Pa}$ (c) $2.76 \times 10^{7} \mathrm{~Pa}$ 


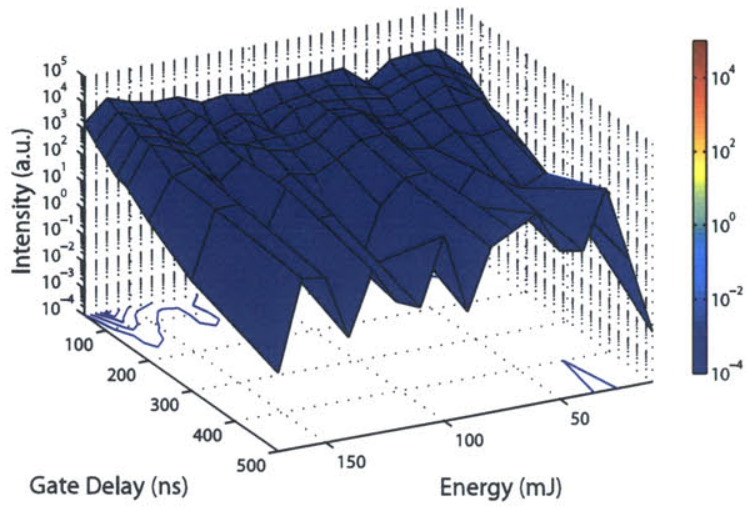

(a)

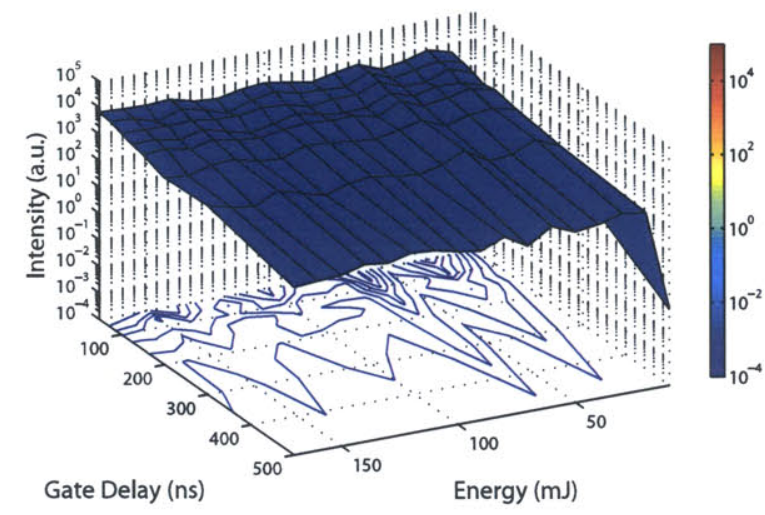

(b)

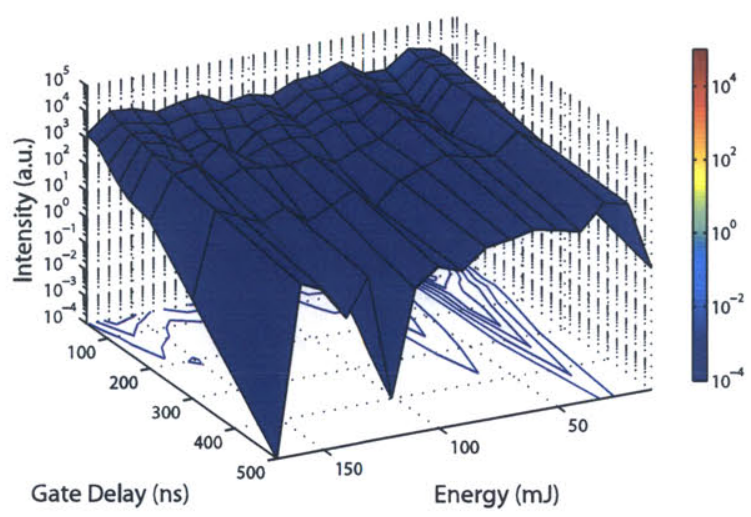

(c)

Figure 4-18: Interrelationship of pressure, $\mathrm{t}_{d}, \mathrm{E}$, and intensity for Ca (422 nm) (a) 1 $\times 10^{5} \mathrm{~Pa}$ (b) $1.38 \times 10^{7} \mathrm{~Pa}$ (c) $2.76 \times 10^{7} \mathrm{~Pa}$ 


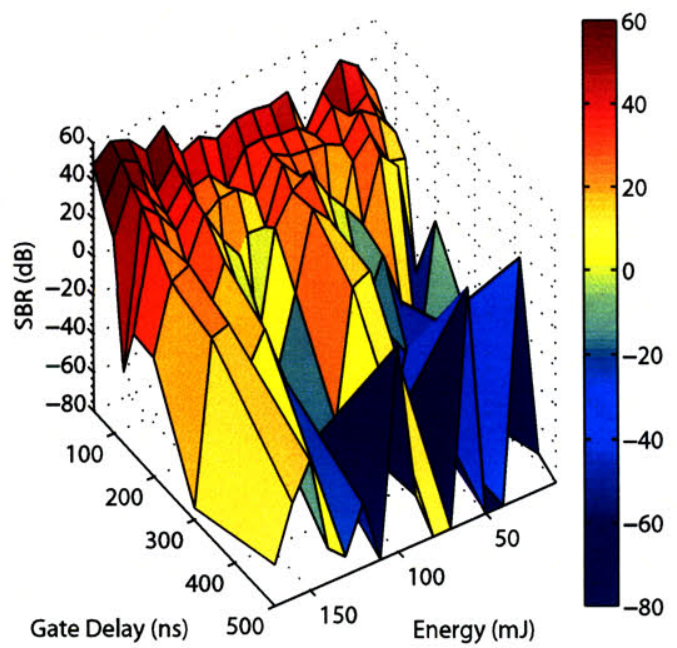

(a)

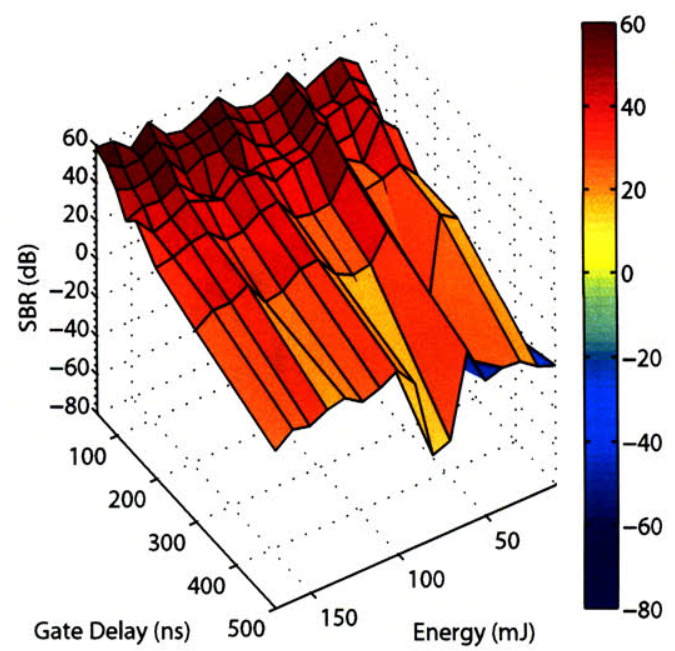

(b)

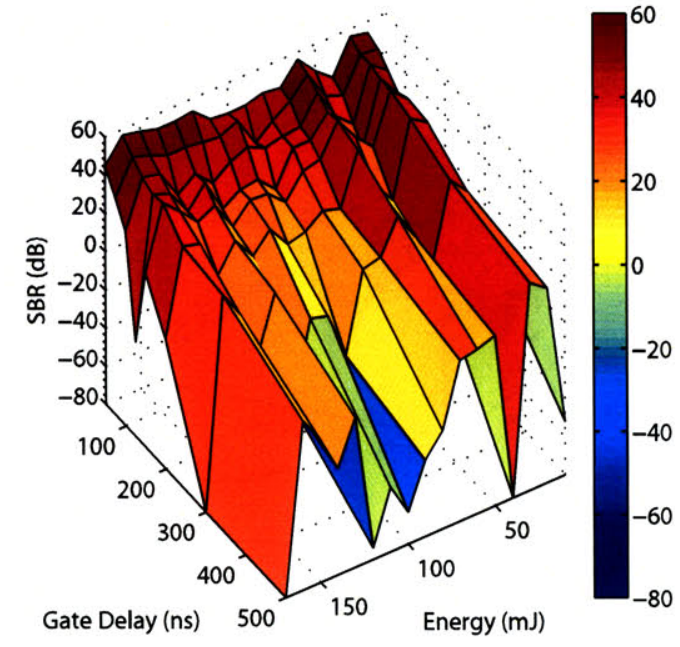

(c)

Figure 4-19: Interrelationship of pressure, $\mathrm{t}_{d}, \mathrm{E}$, and signal-to-background for $\mathrm{Ca}$ (393 nm) (a) $1 \times 10^{5} \mathrm{~Pa}$ (b) $1.38 \times 10^{7} \mathrm{~Pa}$ (c) $2.76 \times 10^{7} \mathrm{~Pa}$ 


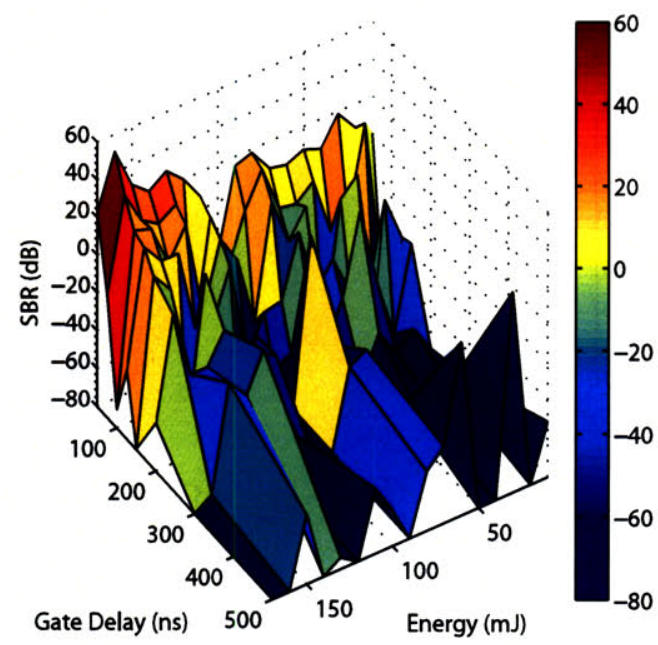

(a)

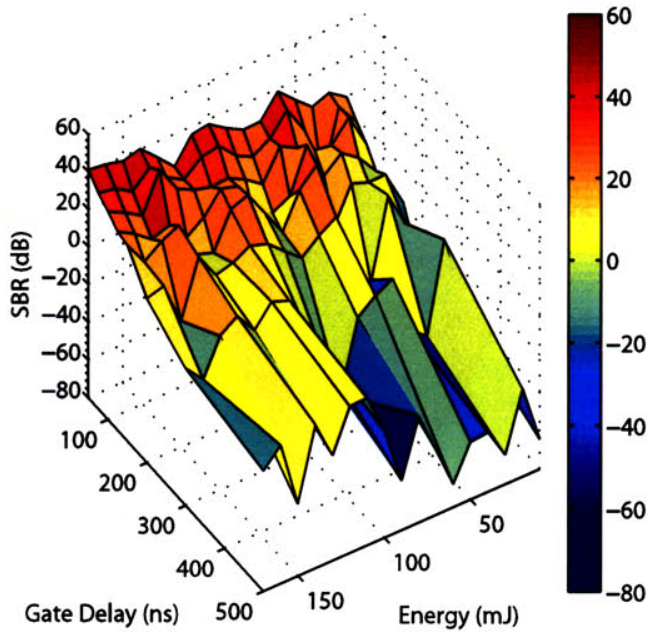

(b)

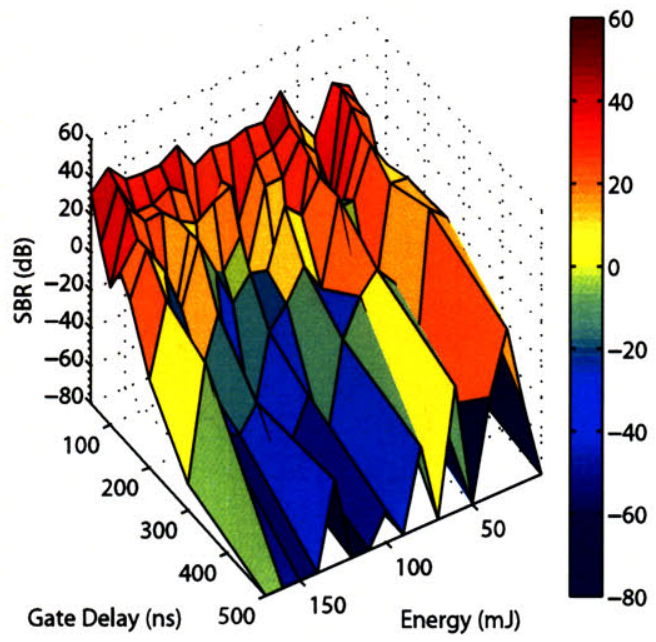

(c)

Figure 4-20: Interrelationship of pressure, $t_{d}, E$, and signal-to-background for Ca (396 nm) (a) $1 \times 10^{5} \mathrm{~Pa}$ (b) $1.38 \times 10^{7} \mathrm{~Pa}$ (c) $2.76 \times 10^{7} \mathrm{~Pa}$ 


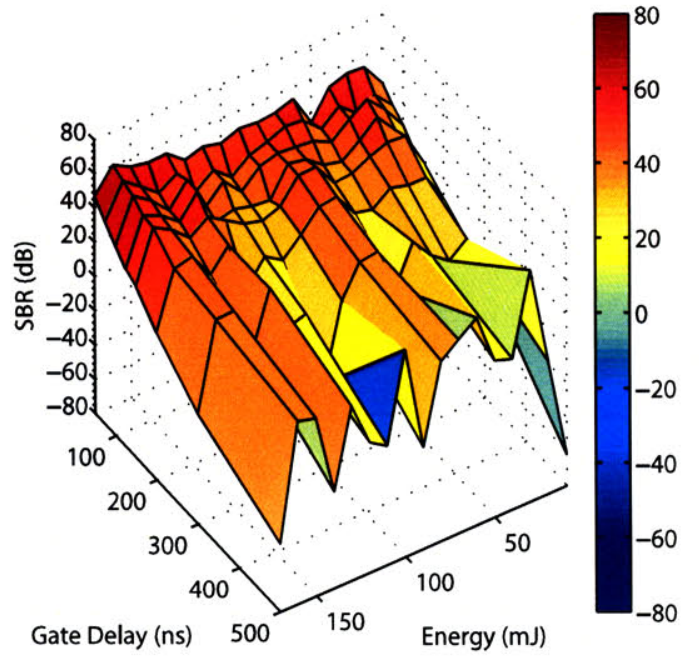

(a)

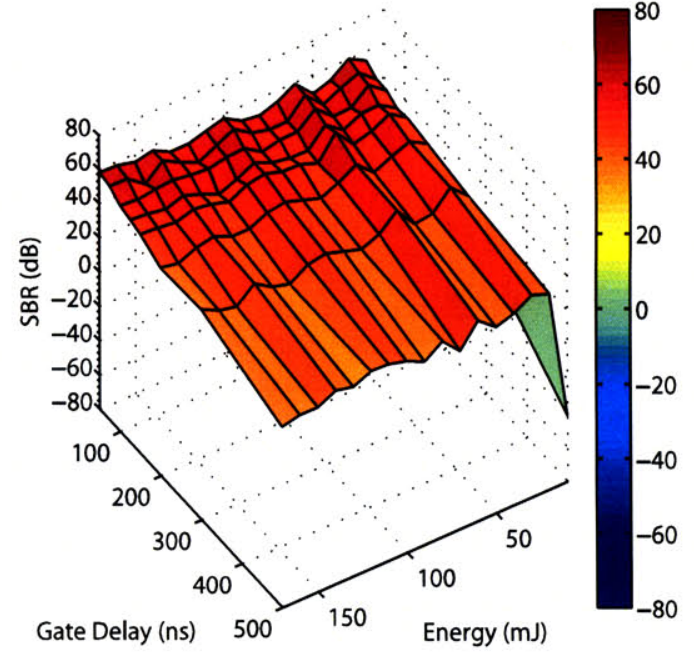

(b)

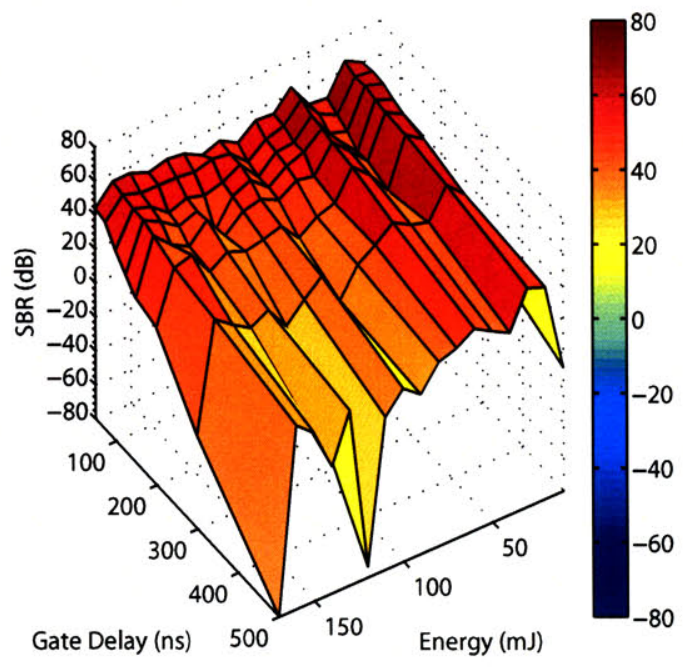

(c)

Figure 4-21: Interrelationship of pressure, $\mathrm{t}_{d}, \mathrm{E}$, and signal-to-background for Ca (422 nm) (a) $1 \times 10^{5} \mathrm{~Pa}$ (b) $1.38 \times 10^{7} \mathrm{~Pa}$ (c) $2.76 \times 10^{7} \mathrm{~Pa}$ 


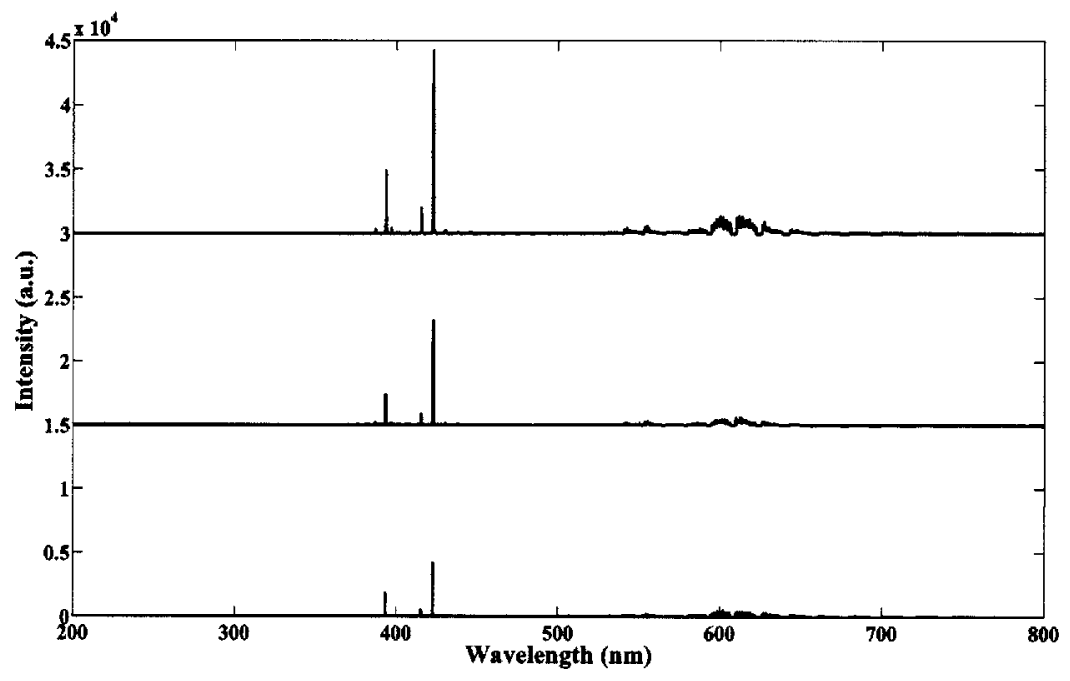

(a)

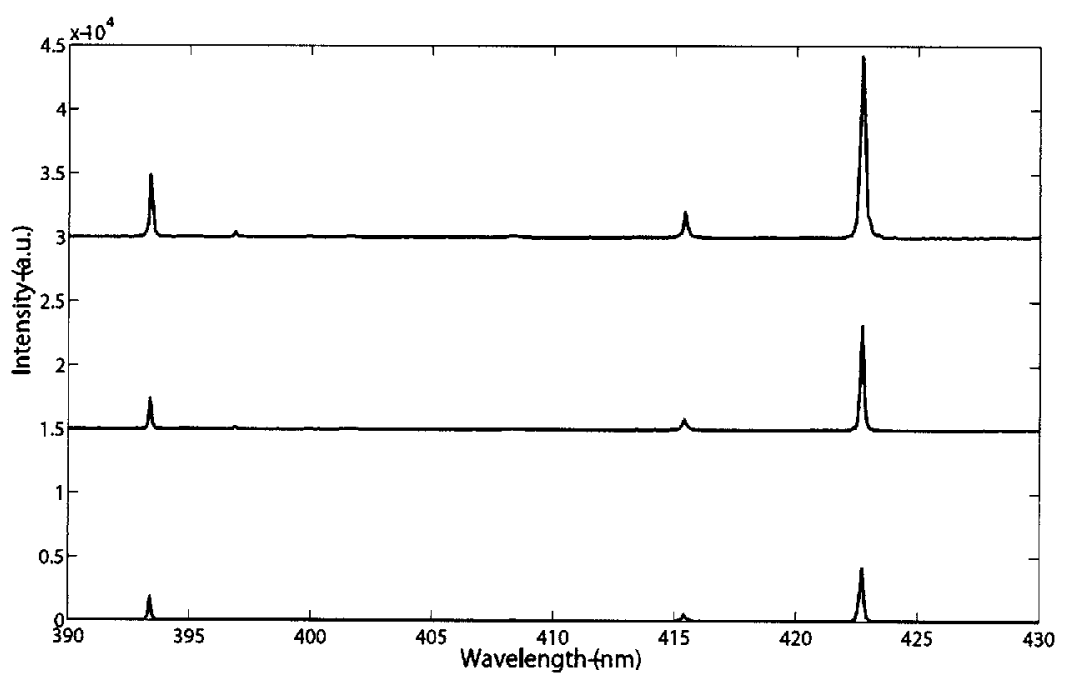

(b)

Figure 4-22: Calcium spectra using $30 \mathrm{~mJ}$ and a $50 \mathrm{~ns}$ gate delay. (a) Full spectrum (b) Calcium peaks (393 nm, $396 \mathrm{~nm}$, and $422 \mathrm{~nm}$ ). Both (a) and (b) spectra from bottom to top: $1 \times 10^{5} \mathrm{~Pa}, 1.38 \times 10^{7} \mathrm{~Pa}$, and $2.76 \times 10^{7} \mathrm{~Pa}$. For clarity, the spectra have been offset from each other by 15,000 a.u. 


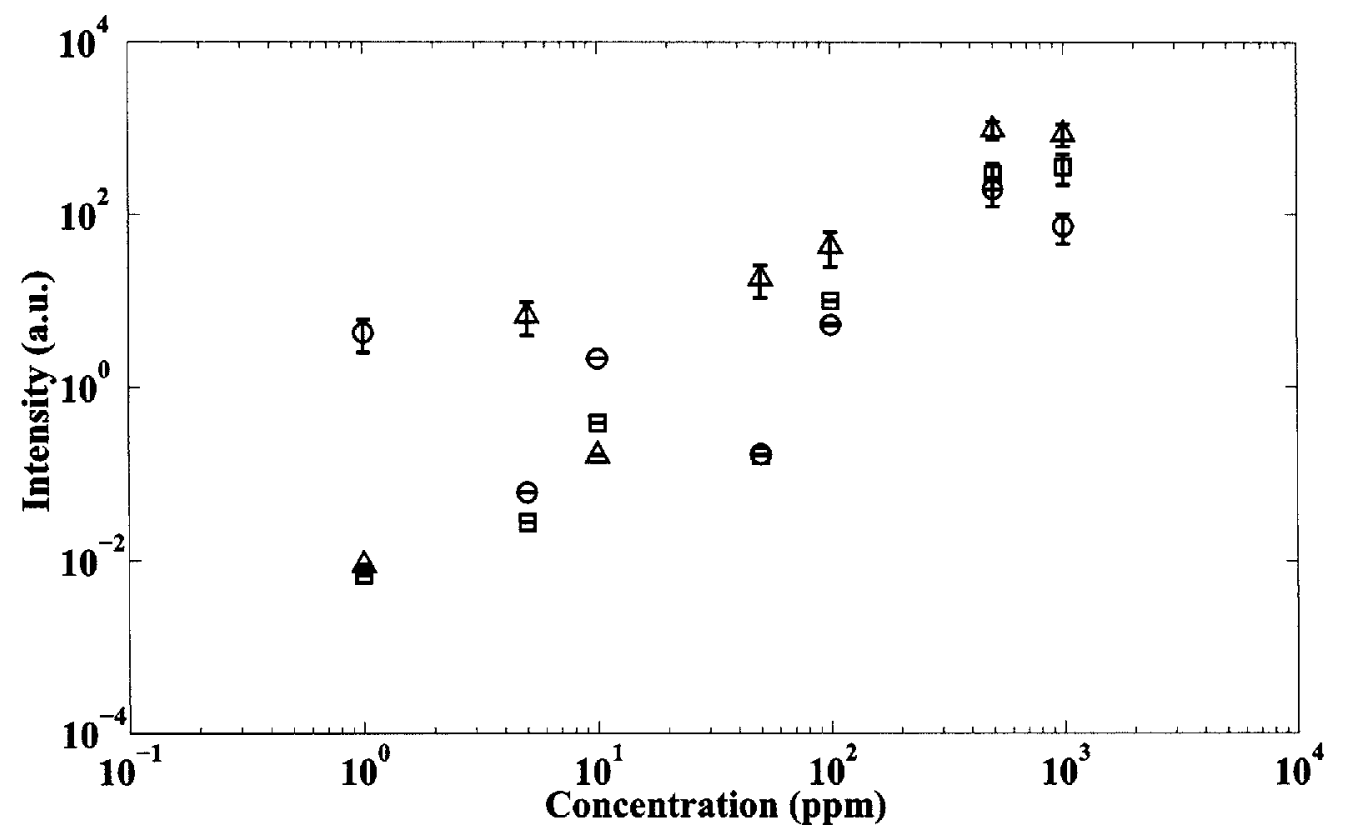

(a) Calcium (393 nm) calibration curve

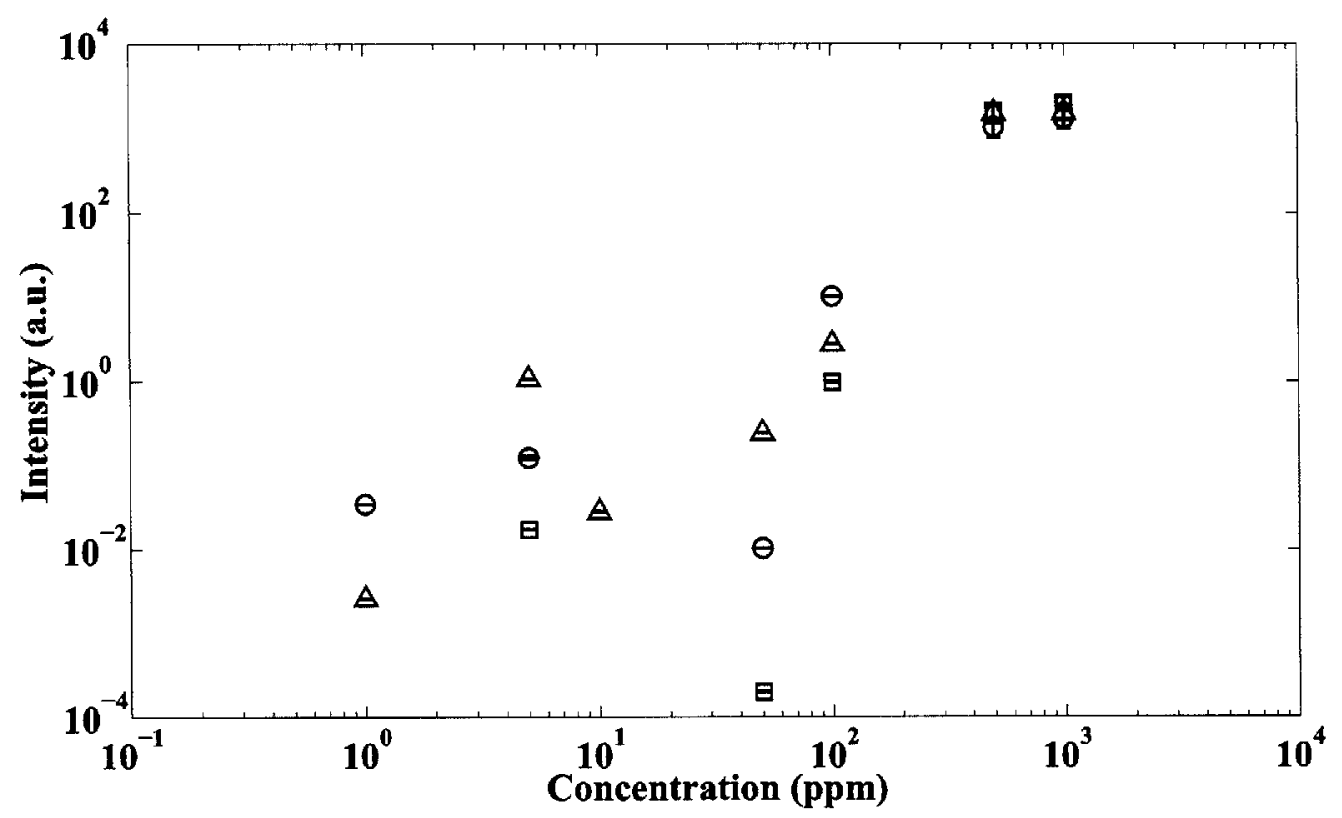

(b) Calcium (422 nm) calibration curve

Figure 4-23: Calcium calibration curves (a) $393 \mathrm{~nm}$ (b) $422 \mathrm{~nm}, \mathrm{O}=1 \times 10^{5} \mathrm{~Pa}$, $=1.38 \times 10^{7} \mathrm{~Pa}, \triangle=2.76 \times 10^{7} \mathrm{~Pa}$. 


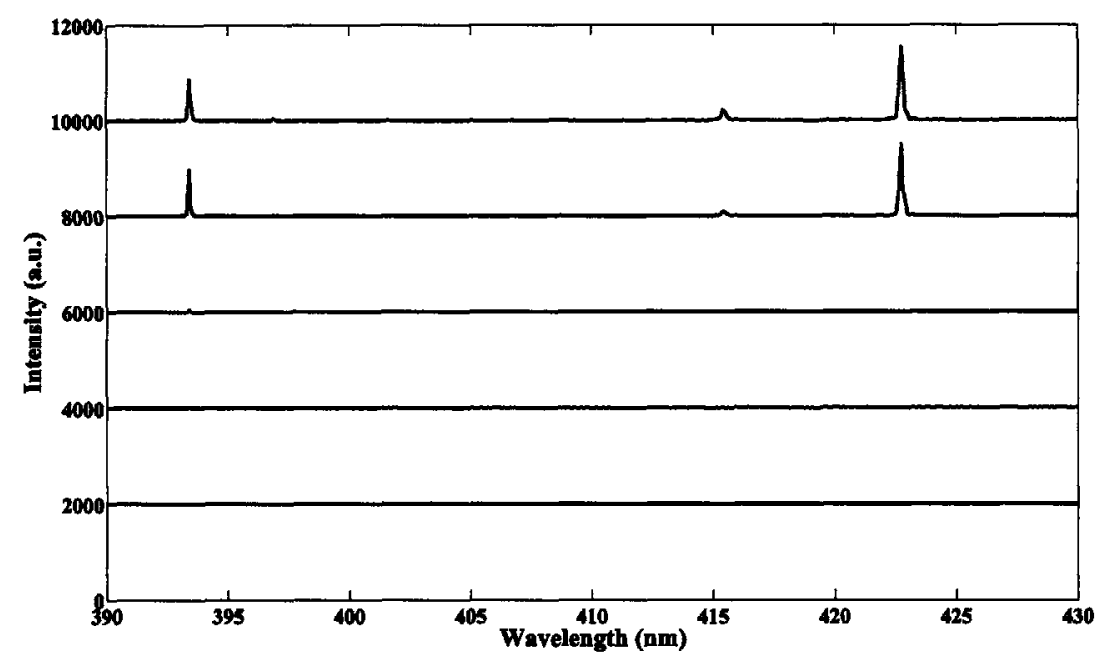

(a)

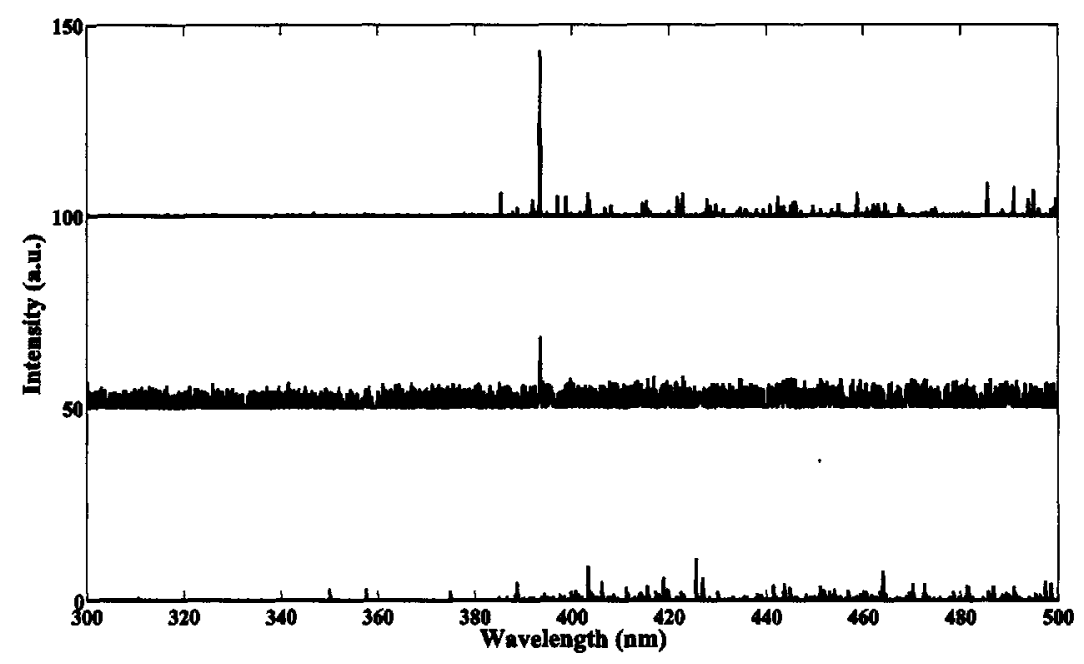

(b)

Figure 4-24: Calcium spectra at $2.76 \times 10^{7} \mathrm{~Pa}$, Calcium peaks are present at 393 $\mathrm{nm}, 396 \mathrm{~nm}$, and $422 \mathrm{~nm}$. (a) Spectra from bottom to top are $10 \mathrm{ppm}, 50 \mathrm{ppm}, 100$ $\mathrm{ppm}, 500 \mathrm{ppm}, 1000 \mathrm{ppm}$ respectively. For clarity, the spectra have been offset from each other by 2000 a.u. (b) Spectra from bottom to top are $10 \mathrm{ppm}, 50 \mathrm{ppm}$, and $100 \mathrm{ppm}$ respectively. For clarity, the spectra have been offset from each other by 50 a.u. 


\subsection{Conclusions}

Sodium, manganese, and calcium are all detectable in high pressure, bulk aqueous solutions using single pulse LIBS with little effect of pressure on the spectra. This comprehensive study of the interrelationship of gate delay and energy for selecting the optimal condition for detection of these analytes has shown that, irrespective of the laser pulse energy selected, the gate delay should be very short (less than $200 \mathrm{~ns}$ ) for the detection of analytes in bulk aqueous solutions. The need for a short gate delay is independent of pressure. This study has also shown that a low energy pulse (less than $\approx 60 \mathrm{~mJ}$ ) is optimal.

Calibration curves were made to determine limits of detection using the current system set-up and further work is needed to look at reproducibility of the actual curves. Calibration curves show that $\mathrm{Na}, \mathrm{Mn}$, and $\mathrm{Ca}$ can be detected at $50 \mathrm{ppm}, 500$ $\mathrm{ppm}$, and $50 \mathrm{ppm}$, respectively. The calibration curves also demonstrate a minimal effect of pressure on spectra. However, the limits of detection were higher than expected. With the current LIBS set-up, the detection limits of $\mathrm{Na}$ and $\mathrm{Ca}$ are below the levels found in vent fluids. However, Mn would not be detectable. This can be attributed to the low light throughput of the $f / 10$ Echelle system. To significantly improve the light throughput, it would be advisable to use a spectrometer with a smaller $f$ number. For example, using a spectrometer with an $f$ number of 2 could improve the throughput by a factor of approximately 25 and therefore improve the ability to detect $\mathrm{Na}, \mathrm{Mn}$, and $\mathrm{Ca}$ in high pressure aqueous environments. For example, with the use of a PMT as the detector, Cremers et al. [14] showed substantially improved detection limits for bulk liquids for $\mathrm{Na} \mathrm{I}(589.00 \mathrm{~nm})$ at a level of 0.014 ppm and Ca II (393.37 nm) at a level of $0.8 \mathrm{ppm}$. Therefore, additional work is necessary to optimize the light collection by changing the system components.

\subsection{Acknowledgments}

We acknowledge the National Science Foundation for support of this research under grant OCE-0527927. Additional support was received from the Deep Ocean Exploration Institute and the Ocean Ventures Fund of the Woods Hole Oceanographic Institution. 


\section{Bibliography}

[1] R. S. Harmon, F. C. DeLucia, C. E. McManus, N. J. McMillan, T. F. Jenkins, M. E. Walsh, and A. Miziolek. Laser-induced breakdown spectroscopy - an emerging chemical sensor technology for real-time field-portable, geochemical, mineralogical, and environmental applications. Applied Geochemistry, 21(5):730747, May 2006.

[2] A. Bertolini, G. Carelli, F. Francesconi, M. Francesconi, L. Marchesini, P. Marsili, F. Sorrentino, G. Cristoforetti, S. Legnaioli, V. Palleschi, L. Pardini, and A. Salvetti. Modi: a new mobile instrument for in situ double-pulse LIBS analysis. Analytical and Bioanalytical Chemistry, V385(2):240-247, May 2006.

[3] M. Corsi, G. Cristoforetti, M. Hidalgo, S. Legnaioli, V. Palleschi, A. Salvetti, E. Tognoni, and C. Vallebona. Double pulse, calibration-free laser-induced breakdown spectroscopy: A new technique for in situ standard-less analysis of polluted soils. Applied Geochemistry, 21(5):748-755, 2006.

[4] S. Palanco, C. Lopez-Moreno, and J. J. Laserna. Design, construction and assessment of a field-deployable laser-induced breakdown spectrometer for remote elemental sensing. Spectrochimica Acta Part B, 61(1):88-95, January 2006.

[5] Z. A. Arp, D. A. Cremers, R. C. Wiens, D. M. Wayne, B. Sallé, and S. Maurice. Analysis of water ice and water ice/soil mixtures using laser-induced breakdown spectroscopy: Application to Mars polar exploration. Applied Spectroscopy, 58:897-909, 2004.

[6] Z. A. Arp, D. A. Cremers, R. D. Harris, D. M. Oschwald, G. R. Parker Jr., and D. M. Wayne. Feasibility of generating a useful laser-induced breakdown spectroscopy plasma on rocks at high pressure: preliminary study for a Venus mission. Spectrochimica Acta Part B, 59:987-999, 2004.

[7] G. B. Courrèges-Lacoste, B. Ahlers, and F. R. Pérez. Combined Raman spectrometer/laser-induced breakdown spectrometer for the next ESA mission to Mars. Spectrochimica Acta Part A, In Press, 2007.

[8] R. Brennetot, J. L. Lacour, E. Vors, A. Rivoallan, D. Vailhen, and S. Maurice. Mars analysis by laser-induced breakdown spectroscopy (MALIS): Influence of Mars atmosphere on plasma emission and study of factors influencing plasma emission with the use of Doehlert designs. Applied Spectroscopy, 57(7):744-752, 2003.

[9] A. Knight, N. Scherbarth, D. Cremers, and M. Ferris. Characterization of laserinduced breakdown spectroscopy (LIBS) for application to space exploration. Applied Spectrosopy, 54:331-340, 2000.

[10] B. Sallé, J.-L. Lacour, P. Mauchien, P. Fichet, S. Maurice, and G. Manhes. Comparative study of different methodologies for quantitative rock analysis by 
laser-induced breakdown spectroscopy in a simulated Martian atmosphere. Spectrochimica Acta Part B, 61:301-313, 2006.

[11] C. R. German and K. L. Von Damm. Treatise on Geochemistry, chapter Hydrothermal Processes, pages 181-222. Elsevier, 2003.

[12] K. L. Von Damm. Controls on the chemisty and temporal variability of seafloor hydrothermal fluids. Seafloor hydrothermal systems: physical, chemical, biological, and geological interactions: Geophysical Monograph 91, pages 222-247, 1995.

[13] K. L. Von Damm. Chemistry of hydrothermal vent fluids from $9^{\circ}-10^{\circ} \mathrm{N}$, East Pacific Rise: 'Time zero,' The immediate posteruptive period. Journal of Geophysical Research, 105:11203-11222, 2000.

[14] D. A. Cremers, L. J. Radziemski, and T. R. Loree. Spectrochemical analysis of liquids using the laser spark. Applied Spectroscopy, 38:721-729, 1984.

[15] R. Knopp, F. J. Scherbaum, and J. I. Kim. Laser induced breakdown spectroscopy (LIBS) as an analytical tool for the detection of metal ions in aqueous solutions. Fresenius' Journal of Analytical Chemistry, 355:16-20, 1996.

[16] W. Pearman, J. Scaffidi, and S. M. Angel. Dual-pulse laser-induced breakdown spectroscopy in bulk aqueous solution with an orthogonal beam geometry. $A p$ plied Optics, 42:6085-6093, 2003.

[17] A. P. M. Michel, M. Lawrence-Snyder, S. M. Angel, and A. D. Chave. Laserinduced breakdown spectroscopy of bulk aqueous solutions at oceanic pressures: evaluation of key measurement parameters. Applied Optics, 46, 2007.

[18] M. Lawrence-Snyder, J. Scaffidi, S. M. Angel, A. P.M. Michel, and A. D. Chave. Sequential-pulse laser-induced breakdown spectroscopy of high-pressure bulk aqueous solutions. Applied Spectroscopy, 61:171-176, 2007.

[19] M. Lawrence-Snyder, J. Scaffidi, S. M. Angel, A. P. M. Michel, and A. D. Chave. Laser-induced breakdown spectroscopy of high-pressure bulk aqueous solutions. Applied Spectroscopy, 60:786-790, 2006.

[20] A. De Giacomo, M. Dell'Aglio, F. Colao, R. Fantoni, and V. Lazic. Double-pulse LIBS in bulk water and on submerged bronze samples. Applied Surface Science, 247:157-162, 2005.

[21] A. E. Pichahchy, D. A. Cremers, and M. J. Ferris. Elemental analysis of metals under water using laser-induced breakdown spectroscopy. Spectrochimica Acta Part B, 52:25-39, 1997.

[22] C. Haisch, J. Liermann, U. Panne, and R. Niessner. Characterization of colloidal particles by laser-induced plasma spectroscopy (LIPS). Analytica Chimica Acta, 346:23-25, 1997. 
[23] P. K. Kennedy, D. X. Hammer, and B. A. Rockwell. Laser-induced breakdown in aqueous media. Progress in Quantum Electronics, 21:155-248, 1997.

[24] R. Noll. Terms and notations for laser-induced breakdown spectroscopy. Analytical and Bioanalytical Chemistry, V385(2):214-218, 2006.

[25] A. P. M. Michel and A. D. Chave. Analysis of laser-induced breakdown spectroscopy (LIBS) spectra: The case for extreme value statistics. Spectrochimica Acta Part B, In Press. 
114 


\title{
Chapter 5
}

\section{Double pulse laser-induced}

\section{breakdown spectroscopy of bulk}

\author{
aqueous solutions at oceanic
}

\section{pressures: Interrelationship of gate delay, pulse energies, interpulse delay, and pressure}

\subsection{Abstract}

Laser-induced breakdown spectroscopy (LIBS) has been identified as an analytical chemistry technique suitable for field use. Mid-ocean ridge hydrothermal vents would greatly benefit from the development of an in situ LIBS sensor. In this paper, double pulse laser-induced breakdown spectroscopy is used to detect five analytes (sodium, manganese, calcium, magnesium, and potassium) that are of key importance in understanding the chemistry of hydrothermal vent fluids, and of mixtures of vent fluids and seawater. The high pressure aqueous environment of the deep ocean is simulated in the laboratory and the key double pulse experimental parameters (laser pulse energies, gate delay, and interpulse delay) are studied at pressures up to $2.76 \times 10^{7} \mathrm{~Pa}$. Each element is found to have a unique optimal set of parameters for detection, and the elements are not detectable outside of the set. For all pressures and energies, a short ( $\leq 100 \mathrm{~ns}$ ) gate delay is necessary. As pressure increases, a shorter interpulse 
delay is needed and the conditions effectively become single pulse. Calibration curves reveal the limits of detection of the elements ( $5000 \mathrm{ppm} \mathrm{Mg}, 500 \mathrm{ppm} \mathrm{K}, 500 \mathrm{ppm}$ $\mathrm{Ca}, 1000 \mathrm{ppm} \mathrm{Mn}$, and $50 \mathrm{ppm} \mathrm{Na}$ ). When compared to our previous single pulse work for $\mathrm{Ca}, \mathrm{Mn}$, and $\mathrm{Na}$, double pulse LIBS for high pressure aqueous solutions did not improve the limits of detection.

\subsection{Introduction}

Laser-induced breakdown spectroscopy (LIBS) has recently been identified as an analytical chemistry technique suitable for field deployment for the analysis of environmental and geochemical samples [1]. Several groups are evaluating the use of LIBS for space exploration [2-7]. Another environmental area in which there is a critical need for new sensors is the ocean. Sensor development for use with underwater vehicles is ongoing and a more requirement is for sensors to be developed for use on permanent ocean observatories.

One environment identified as potentially benefitting from application of an oceanic LIBS sensor is the deep-sea hydrothermal vent environment. Hydrothermal vents occur at mid-ocean ridges where seawater circulates through the permeable ocean crust, allowing the fluid to interact with the surrounding rock and resulting in major fluid chemical changes. At vent orifices, exit temperatures reach $200-405^{\circ} \mathrm{C}$ at ambient

pressures of $8.1 \times 10^{6} \mathrm{~Pa}$ to $3.6 \times 10^{7} \mathrm{~Pa}$ corresponding to ocean depths of $800 \mathrm{~m}$ to $3600 \mathrm{~m}[8]$.

At hydrothermal vents, as the hot fluids mix with seawater, rapid chemical changes occur and some elements precipitate out (e.g., sulfate minerals [9]). Obtaining in situ chemical measurements of the fluid is difficult due to the corrosive nature and high temperature of the fluid. Collection of the fluid for analysis shipboard or in a laboratory introduces chemical changes as the temperature and pressure of the fluid is changed during sample recovery. Five critical elements at hydrothermal vents are sodium, calcium, manganese, magnesium, and potassium. Sodium is the dominant cation in vent fluids, and provides insight into phase separation processes [10]. Calcium is the second most dominant cation in vent fluids, and is usually found at a greater concentration in vent fluids than seawater [11]. Ca is released into vent fluids when $\mathrm{Na}$ is taken up in albitization reactions with the host rock [11]. Manganese exists as a trace metal in seawater but has a higher concentration in vent fluids due to leaching from the host rock [10]. Magnesium is practically nonexistent in hydrothermal vent fluids; however, if any is detected in vent fluids, contamination by 
entrainment of ambient seawater is indicated [10]. Potassium is typically highly enriched in vent fluids due to leaching from basalts [10]. In vent fluids, concentrations range from approximately 250 - 23,163 ppm for $\mathrm{Na}, 0.6$ - $399 \mathrm{ppm}$ for $\mathrm{Mn},-54-4477$ $\mathrm{ppm}$ for $\mathrm{Ca},-47-3166 \mathrm{ppm}$ for $\mathrm{K}$, and $0 \mathrm{ppm}$ for $\mathrm{Mg}$ [8]. In seawater, concentrations are approximately $10,933 \mathrm{ppm} \mathrm{Na},<0.001 \mathrm{Mn}, 419 \mathrm{ppm} \mathrm{Ca}, 405 \mathrm{ppm} \mathrm{K}$, and 1300 ppm Mg [8].

Development of an oceanic LIBS sensor necessitates laboratory investigations into the system parameters for the detection of analytes under high pressure bulk aqueous conditions. Although LIBS analysis of liquids is more difficult than the analysis of solid or air samples, a few studies have focused on dissolved analytes in bulk solutions [12-18]. Some issues for LIBS in aqueous solutions include a reduction in plasma light intensity and emission lifetime due to quenching, the Stark effect may cause spectral lines to be broadened, and moving breakdown can change the distance between the plasma and the collection fiber optic [12, 13, 19-21]. The breakdown threshold in water is also significantly greater than for solids [22]. Laser-induced plasmas are weak in water, as they are cooled by Bremsstrahlung and shockwave emissions, and by thermal conduction. Rapid cooling of the plasma also increases electron-ion recombination and plasma emissions last only a few hundred nanoseconds [23].

In 1984, Cremers et al. showed that several elements, including $\mathrm{Na}, \mathrm{K}, \mathrm{Mg}$, and $\mathrm{Ca}$, could be identified in bulk aqueous solution using double pulse LIBS. This work, carried out at atmospheric pressure, showed that double pulse LIBS improved the detection limit for metals and ions in bulk aqueous solution [12]. In double pulse LIBS for dissolved analytes, the first laser pulse produces a plasma that creates a laser-induced cavitation bubble. The second laser pulse produces a plasma within the bubble [23, 24]. This is in contrast to single pulse LIBS, where the plasma is simply formed in a liquid environment. The duration of the laser-induced plasma in the bubble is on the order of a few microseconds and the bubble lifetime is on the order of a few hundred microseconds. Therefore, it can be assumed that the plasma from the second pulse is expanding in a quasi-stationary environment induced by the first laser pulse $[24,25]$. When the bubble is first formed, its pressure is greater than that of the surrounding liquid and the bubble begins to expand which leads to a pressure drop. At the point of maximum expansion, the bubble pressure is less than the pressure of the surrounding fluid and the bubble begins to collapse. During this collapsing phase, the temperature and pressure in the bubble again increases and if there is enough energy stored within the bubble, it can re-expand. Many 
such oscillations of expansion and compression are possible [23]. By adjusting the interpulse delay between the laser pulses, it is possible to select the phase that the bubble is in such that bubble pressure is at a nadir. If the interpulse delay is too long or too short, the plasma will expand in a high pressure environment so that the spectral lines will be broadened due to collisions [23]. Selection of the interpulse delay time therefore is critical for bulk liquids.

Since Cremer's pioneering work, several groups have used dual pulse LIBS for the detection of analytes in bulk liquids [12, 14, 18, 25-27] and more recently for bulk solutions at high pressures $[15,16]$. In Michel et al. [15], it was reported that analyte detection in high pressure bulk solutions was highly dependent on the interpulse delay. When a shorter interpulse delay time was used ( $\ll 1 \mu \mathrm{s})$, the signal intensity was enhanced compared to when longer delay times were employed. However, it was noted that this time may not be long enough for cavitation bubbles to fully form and expand, as occurs at low pressure. Michel et al. also found that the optimal energy levels needed for emission seemed to vary by analyte [15]. Lawrence-Snyder et al. [16] report that increasing solution pressure reduces double pulse emission enhancement so that little improvement was noted over single pulse above $1 \times 10^{7} \mathrm{~Pa}$.

In Chapter 4, optimization of single pulse conditions for three analytes (Na, $\mathrm{Mn}$ and $\mathrm{Ca}$ ) was reported and the limits of detection were not at the levels that we had hoped to achieve. Through optimization of the double pulse set-up, the goal is to improve the limits of detection and, in addition, establish limits of detection for other elements. Although Lawrence-Snyder et al. previously reported on the use of double pulses for the detection of analytes at high pressures and found no enhancements above $1 \times 10^{7} \mathrm{~Pa}$ [16], several differences exist between these studies. LawrenceSnyder et al. report their findings using an orthogonal beam geometry which would be impractical for the development of an oceanic sensor in many applications, the work does not extend to the ambient pressures for most hydrothermal vents, and optimization of laser pulse energies was not carried out. Through the completion of a thorough optimization, the use of double pulse LIBS at pressures up to $2.76 \times 10^{7} \mathrm{~Pa}$ is now investigated and the limits of detection for five key elements are determined.

\subsection{Experimental}

Double pulse high pressure aqueous LIBS experiments were completed using the laboratory set-up detailed in Figure 5-1. Two Big Sky CFR-200 Nd:YAG lasers configured with the beams co-linearly aligned prior to exiting the aperture (Particle Image Ve- 


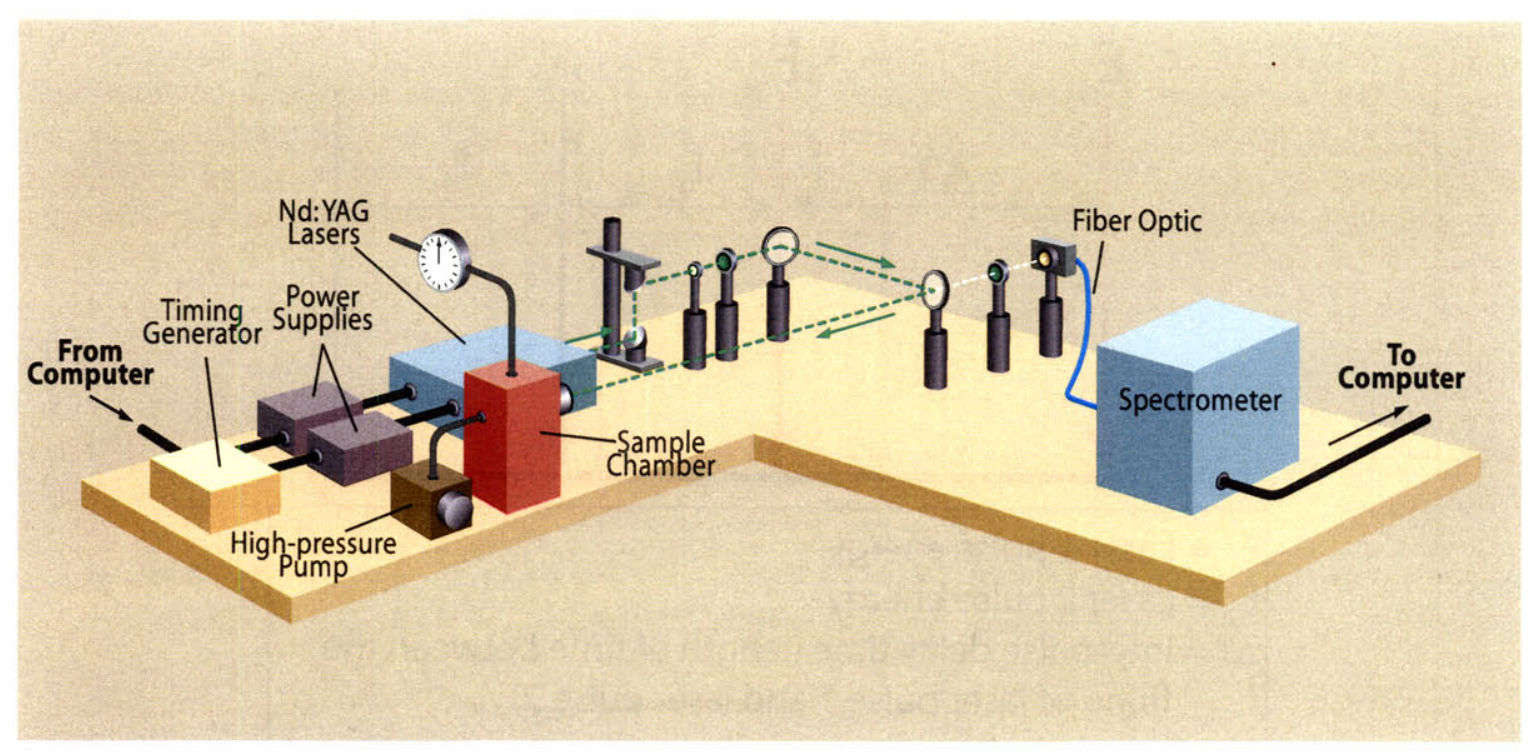

Figure 5-1: Laboratory set-up for high pressure aqueous double pulse LIBS experiments

locimetry or PIV configuration) were operated at $1064 \mathrm{~nm}$ with a $5 \mathrm{~Hz}$ repetition rate. Each laser is equipped with a motorized variable attenuator serially controlled by a computer, enabling the laser pulse energies $\left(\mathrm{E}_{1}\right.$ and $\left.\mathrm{E}_{2}\right)$ to be varied independently from 0 to $200 \mathrm{~mJ}$, in increments of approximately $1 \mathrm{~mJ}$. Plasma emission is collected with an Echelle spectrometer (LLA Echelle ESA 3000). The spectrometer is capable of detecting elements with wavelengths of $200-780 \mathrm{~nm}$ at a spectral resolution of $10-50 \mathrm{pm}$. Accurate timing of the laser firing, the interpulse delay time $(\Delta \mathrm{T}$, the time between the firing of laser pulse 1 and laser pulse 2$)$ and the gate delay $\left(t_{d}\right.$, the time between the firing of the second laser pulse and the turn-on of the spectrometer) was controlled by a timing box (Berkeley Nucleonics Corporation Model 565). The integration time of the spectrometer, gate width $\left(t_{b}\right)$, is also controllable. The double pulse parameters are clarified in Figure 5-2.

An $8.89 \mathrm{~cm} \times 8.89 \mathrm{~cm} \times 8.89 \mathrm{~cm}$ titanium sample chamber that holds $27 \mathrm{ml}$ of liquid connects to a high pressure metering pump (Eldex Model A-30-S) using Swagelok fittings to pressurize samples up to $4.1 \times 10^{7} \mathrm{~Pa}$. The sample chamber is equipped with a sapphire window (Meller Optics, $2.54 \mathrm{~cm}$ diameter $\times 0.64 \mathrm{~cm}$ thickness, AR-coated at $532 \mathrm{~nm} / 1064 \mathrm{~nm}$, custom part) that allows laser pulses to enter the sample chamber. A series of AR-coated optics are used to focus the laser beams into the sample chamber and to focus the plasma light onto an optical fiber for delivery to the spectrometer. The plasma light is collected collinear to the incoming laser beam to simulate the design that would be most practical for an ocean-going 


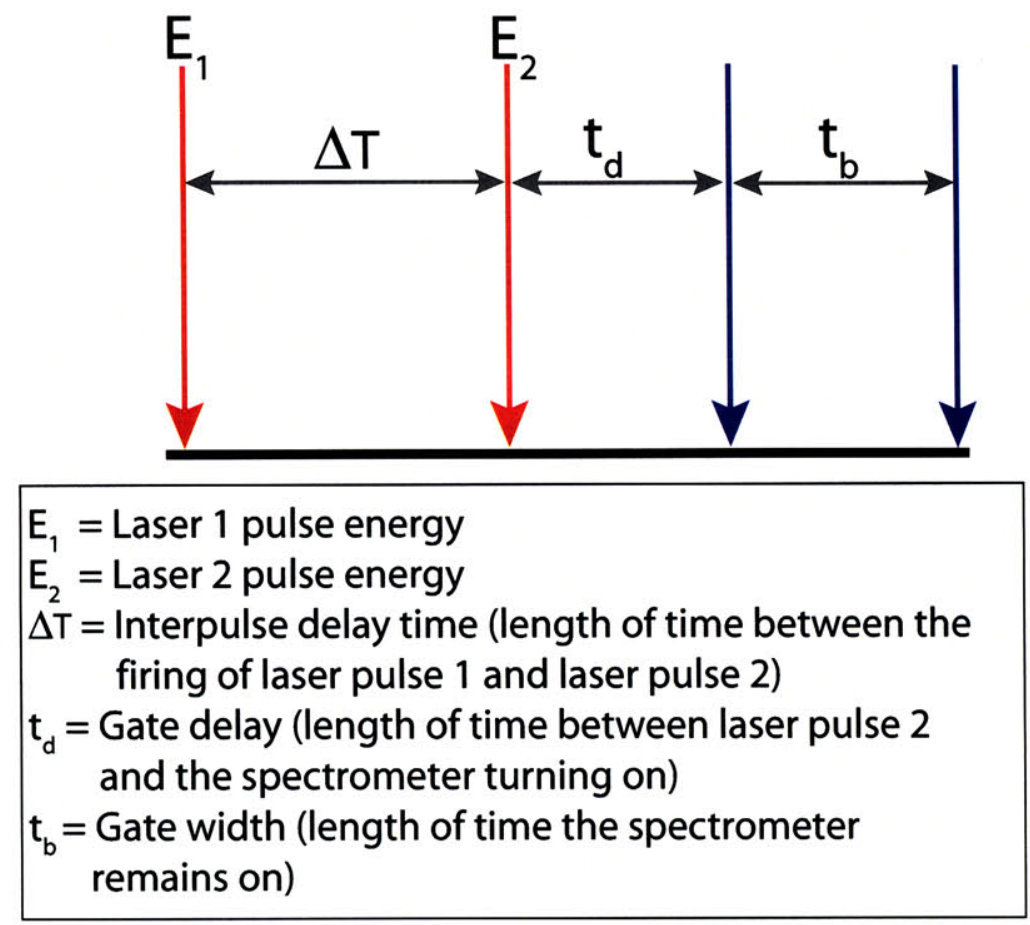

Figure 5-2: Double pulse LIBS timing parameters

LIBS system. Data are collected using ESAWIN software. Laser energy is measured using a laser energy sensor (Coherent J25LP-MB) combined with an energy meter (Coherent FieldMaxII-Top).

For double pulse optimization studies, peak intensities for five analytes $(\mathrm{Mg}, \mathrm{K}$, $\mathrm{Na}, \mathrm{Ca}$, and $\mathrm{Mn}$ ) were measured over a range of system parameters: $\mathrm{E}_{1}, \mathrm{E}_{2}, \mathrm{t}_{d}$, and $\Delta \mathrm{T} . \mathrm{E}_{1}$ and $\mathrm{E}_{2}$ were each tested at $20 \mathrm{~mJ}, 60 \mathrm{~mJ}, 100 \mathrm{~mJ}$, and $140 \mathrm{~mJ}$. The average irradiance $\left(\mathrm{I}_{f}\right)$ at the beam waist can be estimated from

$$
I_{f}=\frac{\pi E_{L} D^{2}}{4 \tau_{L} f^{2} \lambda^{2} M^{4}}
$$

where $\mathrm{E}_{L}$ is the laser pulse energy, $\mathrm{D}$ is the is the diameter of the illuminated aperture of the focusing lens $(\approx 25 \mathrm{~mm})$, and $\tau_{L}$ is the pulse duration at the full peak width at half of the maximum intensity (FWHM; $\tau_{L}=7.5 \mathrm{~ns}$ ), $\mathrm{f}$ is the focal length of the focusing lens $(35 \mathrm{~mm}), \lambda$ is the laser wavelength $(1064 \mathrm{~nm})$, and $\mathrm{M}^{2}$ is the beam propagation ratio that is typically $2-10$ for Nd:YAG lasers (we estimate a value of 6) [28]. The pulse energies of $20 \mathrm{~mJ}, 60 \mathrm{~mJ}, 100 \mathrm{~mJ}$, and $140 \mathrm{~mJ}$ correspond to irradiance at the beam waist of $\approx 2.62 \times 10^{12} \mathrm{~W} / \mathrm{cm}^{2}, 7.87 \times 10^{12} \mathrm{~W} / \mathrm{cm}^{2}, 1.31 \times$ $10^{13} \mathrm{~W} / \mathrm{cm}^{2}, 1.84 \times 10^{13} \mathrm{~W} / \mathrm{cm}^{2}$, respectively.

For optimization of experimental parameters, studies were conducted at three 
pressures, $1 \times 10^{5} \mathrm{~Pa}, 1.38 \times 10^{7} \mathrm{~Pa}$, and $2.76 \times 10^{7} \mathrm{~Pa}$, which correspond to ocean depths of approximately $0 \mathrm{~m}, 1362 \mathrm{~m}$, and $2724 \mathrm{~m}$ respectively. For $\mathrm{Mg}$ and $\mathrm{K}$, the gate delay was tested at $10 \mathrm{~ns}, 50 \mathrm{~ns}, 100 \mathrm{~ns}$, and $500 \mathrm{~ns}$ and the interpulse delay was tested at $50 \mathrm{~ns}, 100 \mathrm{~ns}, 500 \mathrm{~ns}, 1000 \mathrm{~ns}$, and $5000 \mathrm{~ns}$. For $\mathrm{Na}, \mathrm{Ca}$, and $\mathrm{Mn}$, the gate delay was held constant at $50 \mathrm{~ns}$ and the interpulse delay was tested at $50 \mathrm{~ns}, 500 \mathrm{~ns}$, and $5000 \mathrm{~ns}$. Each combination of these conditions was evaluated for a total of 320 conditions for $\mathrm{Mg}$ and $\mathrm{K}$ and 48 conditions for $\mathrm{Mn}, \mathrm{Na}$, and $\mathrm{Ca}$. For all studies, the gate width was held constant at $200 \mathrm{~ns}$ and the amplification of the Echelle spectrometer was set to the maximum value of 4000 . Five spectra were taken at each optimization condition and for calibration curves ten spectra were taken. All spectra were comprised of 100 accumulations. To account for the high resolution of the spectrometer and the peak broadening that occurs from liquids, all data were grouped into sets of 9 wavelengths. Each set of datapoints $(9 \times 5$ for the optimization or $9 \times 10$ for the calibration curves) was then processed using extreme value distribution statistics described by Michel and Chave [29].

All calibration curves were made at three pressures $\left(1 \times 10^{5} \mathrm{~Pa}, 1.38 \times 10^{7} \mathrm{~Pa}\right.$, and $2.76 \times 10^{7} \mathrm{~Pa}$ ). Where shown, error bars represent the double-sided $95 \%$ confidence limits for the extreme value parameters defined in [29].

Solutions were made using $\mathrm{MgCl}_{2} \cdot 6 \mathrm{H}_{2} \mathrm{O}, \mathrm{NaCl}, \mathrm{KCl}, \mathrm{MnSO}_{4} \cdot \mathrm{H}_{2} \mathrm{O}$, and $\mathrm{CaCl}_{2} \cdot \mathrm{H}_{2} \mathrm{O}$ dissolved in DI water. All concentrations are given in parts per million (ppm, wt./vol.). For the optimization studies the concentrations used were $5000 \mathrm{ppm} \mathrm{Mg}$, 1000 ppm K, 100 ppm Na, 1000 ppm Ca, and 1000 ppm Mn.

\subsection{Results and Discussion}

For double pulse LIBS of high pressure aqueous solutions, optimizing the key parameters $\left(E_{1}, E_{2}, t_{d}\right.$, and $\left.\Delta T\right)$ individually for each element of interest is essential for identifying the conditions under which each can be detected. The optimization studies presented here show that these conditions are pressure dependent for double pulse LIBS. Outside the range of these conditions, some of the elements prove to be undetectable. Through the optimization of the parameters, a set of conditions are established that allow calibration curves to be made for determining the limits of detection for high pressure bulk aqueous solutions using the current LIBS system setup. 


\subsubsection{Magnesium}

Results for the $518.4 \mathrm{~nm} \mathrm{Mg}$ (I) peak are presented in Figures 5-3 to 5-5. From these figures, the need for a short gate delay ( $\leq 100 \mathrm{~ns}$ ) is evident, irrespective of the pressure or the laser pulse energies. At all pressures, when $t_{d}=500 \mathrm{~ns}, \mathrm{Mg}(\mathrm{I})$ is not detectable. At $1 \times 10^{5} \mathrm{~Pa}$, the intensity was greatest with a longer interpulse delay (1000 ns to $5000 \mathrm{~ns}$ ) (Figure 5-3). It was also best to use a smaller $E_{1}$ than $E_{2}$. For example, two favorable conditions were $E_{1}=60 \mathrm{~mJ}, E_{2}=100 \mathrm{~mJ}$ and $E_{1}=$ $20 \mathrm{~mJ}, \mathrm{E}_{2}=100 \mathrm{~mJ}$. At $2.76 \times 10^{7} \mathrm{~Pa}$, the greatest intensity peak exists when $\Delta \mathrm{T}$ had the smallest value (50 ns) (Figure 5-5). The $\mathrm{E}_{1}$ and $\mathrm{E}_{2}$ that gave the greatest intensity were both in the range of $60 \mathrm{~mJ}-140 \mathrm{~mJ}$. At $1.38 \times 10^{7} \mathrm{~Pa}$, the optimal $\Delta \mathrm{T}$ was intermediate between that for $1 \times 10^{5} \mathrm{~Pa}$ and $2.76 \times 10^{7} \mathrm{~Pa}$. At $2.76 \times 10^{7}$ $\mathrm{Pa}$, a very intense peak was obtained for the condition $\mathrm{E}_{1}=60 \mathrm{~mJ}, \mathrm{E}_{2}=60 \mathrm{~mJ}, \mathrm{t}_{d}$ $=50 \mathrm{~ns}$, and $\Delta \mathrm{T}=50 \mathrm{~ns}$. Therefore, a calibration curve was constructed using these conditions as shown in Figure 5-6. From this calibration curve and from examining spectra of the calibration data (Figure 5-7), it is clear that $\mathrm{Mg}$ (I) can be detected to only $5000 \mathrm{ppm}$.
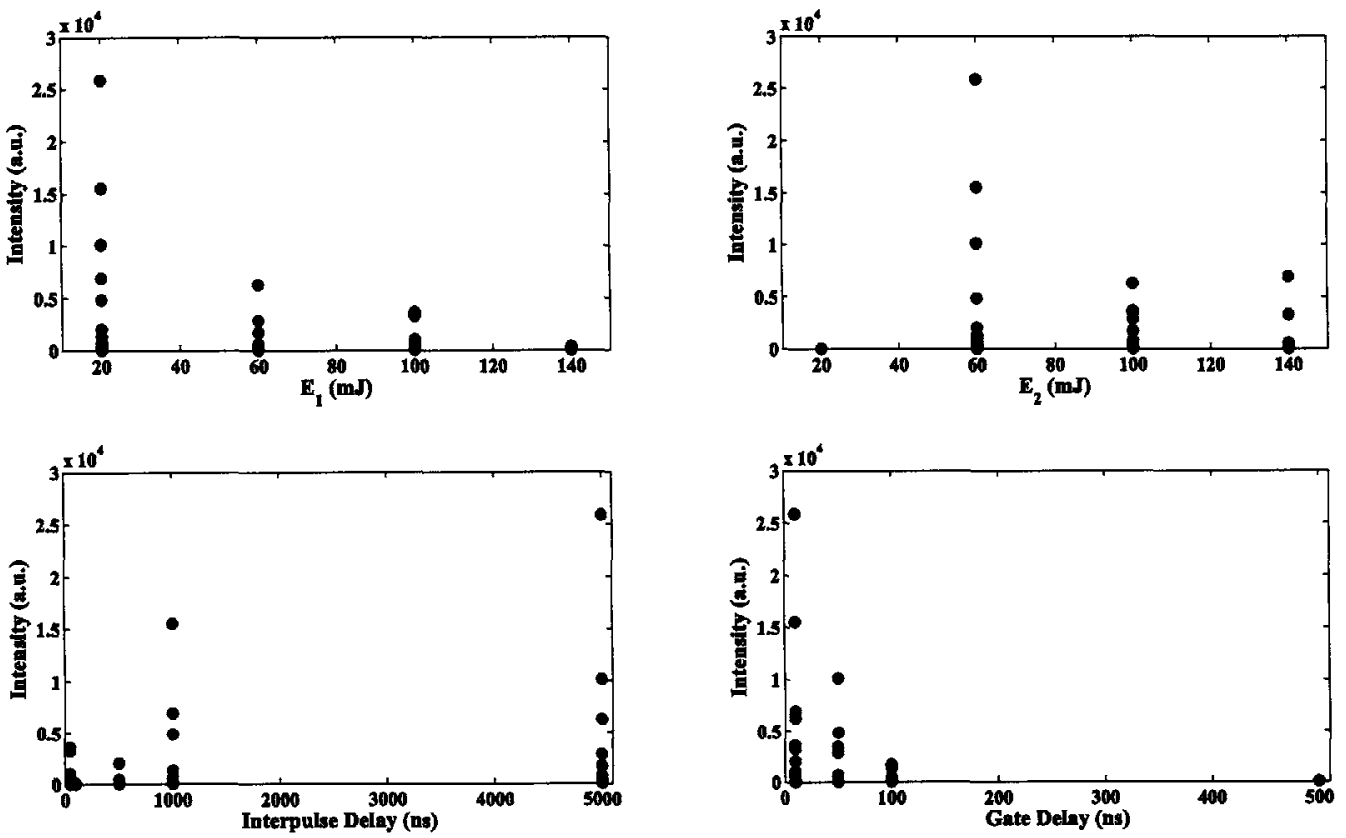

Figure 5-3: $\mathrm{Mg}(\mathrm{I})\left(518.4 \mathrm{~nm}\right.$ peak) optimization at $1 \times 10^{5} \mathrm{~Pa}$ 

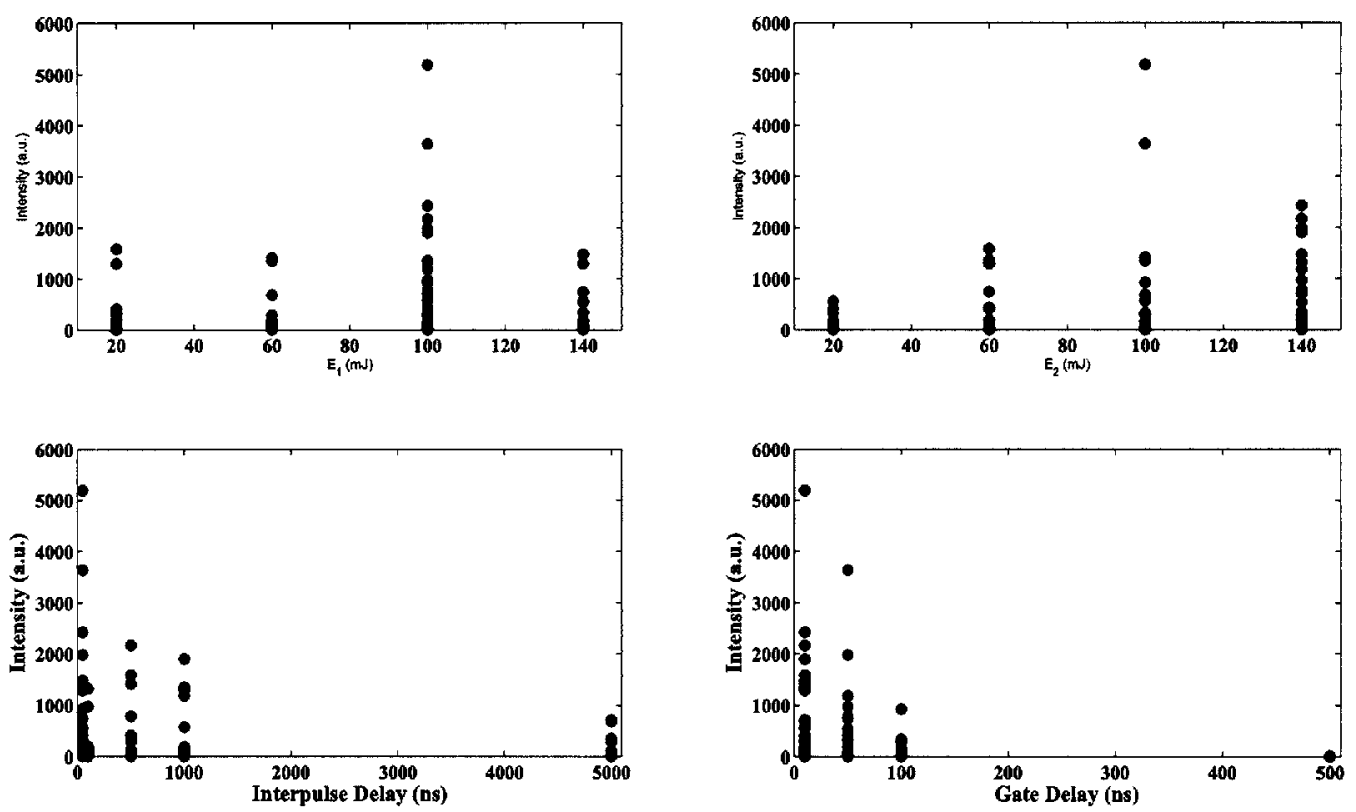

Figure 5-4: $\mathrm{Mg}$ (I) (518.4 nm peak) optimization at $1.38 \times 10^{7} \mathrm{~Pa}$
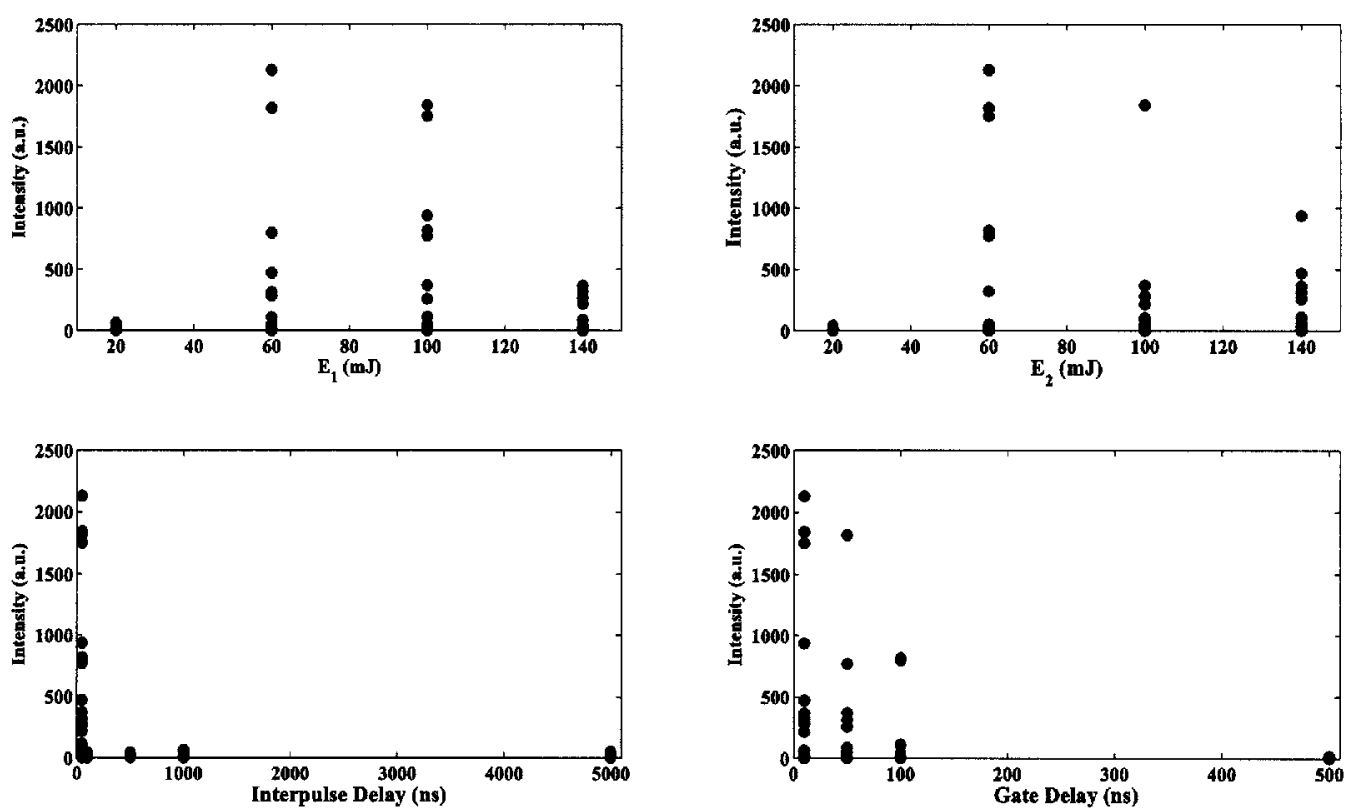

Figure 5-5: $\mathrm{Mg}(\mathrm{I})\left(518.4 \mathrm{~nm}\right.$ peak) optimization at $2.76 \times 10^{7} \mathrm{~Pa}$ 


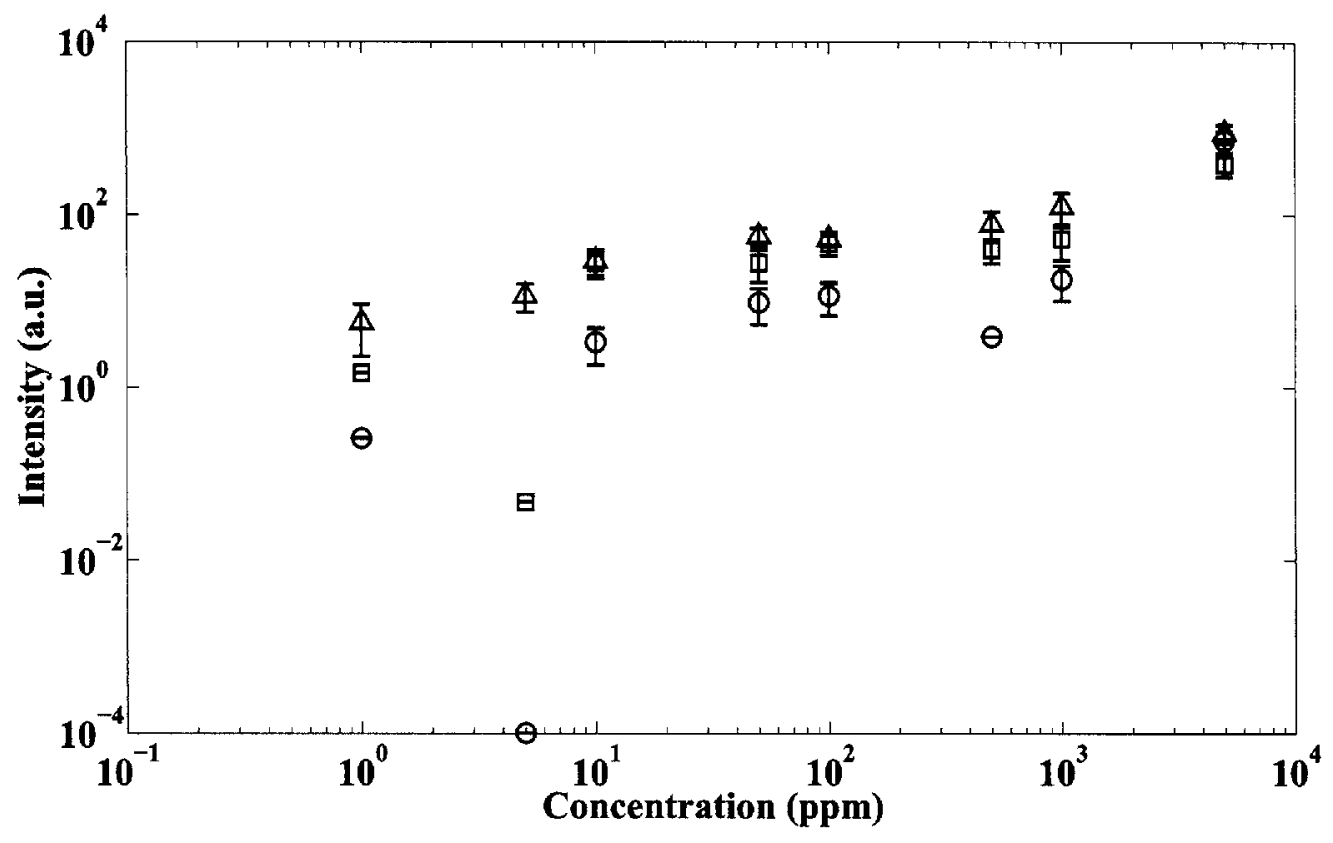

Figure 5-6: $\mathrm{Mg}$ (I) calibration curve of the $518.4 \mathrm{~nm}$ peak, $\bigcirc=1 \times 10^{5} \mathrm{~Pa}, \square=$ $1.38 \times 10^{7} \mathrm{~Pa}, \Delta=2.76 \times 10^{7} \mathrm{~Pa},\left(\mathrm{E}_{1}=60 \mathrm{~mJ}, \mathrm{E}_{2}=60 \mathrm{~mJ}, \mathrm{t}_{d}=50 \mathrm{~ns}\right.$, and $\Delta \mathrm{T}=$ $50 \mathrm{~ns})$

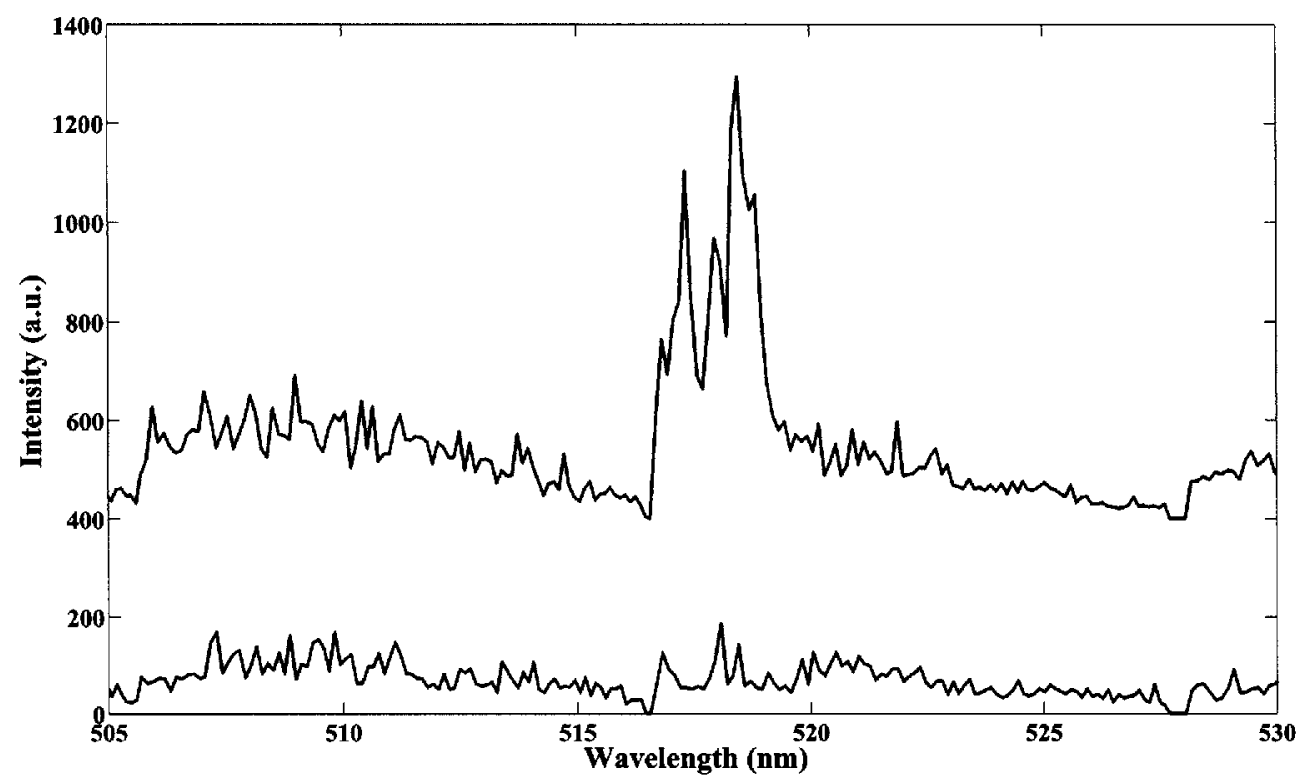

Figure 5-7: Spectra of $\mathrm{Mg}(\mathrm{I})$ peak $(518.4 \mathrm{~nm})$ at $2.76 \times 10^{7} \mathrm{~Pa}$. The concentrations from bottom to top are $1000 \mathrm{ppm}$ and $5000 \mathrm{ppm}$. ( $\mathrm{E}_{1}=60 \mathrm{~mJ}, \mathrm{E}_{2}=60 \mathrm{~mJ}, \mathrm{t}_{d}=$ $50 \mathrm{~ns}$, and $\Delta \mathrm{T}=50 \mathrm{~ns})$. For clarity, the spectra have been offset from each other by 500 a.u. 


\subsubsection{Potassium}

The results of the optimization studies for the $769.9 \mathrm{~nm} \mathrm{~K}$ (I) peak are shown in Figures 5-8 - 5-10. Potassium was detectable over an unusually wide range of conditions. Potassium has the lowest ionization energy $(4.31 \mathrm{eV})$ of the elements that were studied which contributes to ease of detection. In particular, a wide range of interpulse delay times was suitable at all pressures. At $1 \times 10^{5} \mathrm{~Pa}$ and $1.38 \times 10^{7} \mathrm{~Pa}$, the use of two high energy pulses resulted in the greatest peak intensity. At the highest pressure condition $\left(2.76 \times 10^{7} \mathrm{~Pa}\right)$, a lower energy pulse followed by a higher energy pulse was advantageous. For the calibration curve, the condition $\mathrm{E}_{1}=100 \mathrm{~mJ}, \mathrm{E}_{2}=$ $140 \mathrm{~mJ}, \mathrm{t}_{d}=1000 \mathrm{~ns}$, and $\Delta \mathrm{T}=50 \mathrm{~ns}$ was selected (Figure 5-11). The calibration curve reveals that $\mathrm{K}$ (I) is detectable to $500 \mathrm{ppm}$. Spectra of the calibration data confirm this and are shown in Figure (5-12).
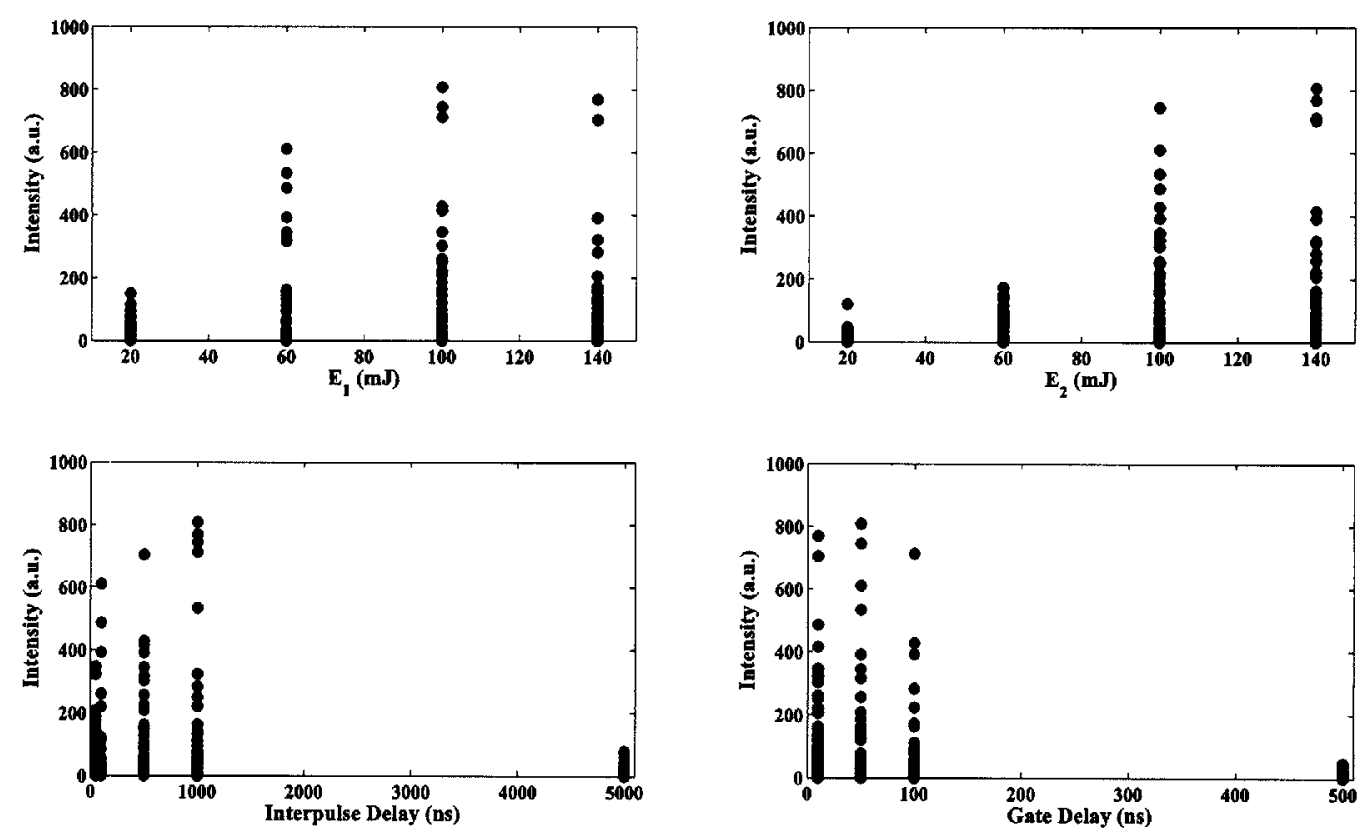

Figure 5-8: K (I) (769.9 nm peak) optimization at $1 \times 10^{5} \mathrm{~Pa}$ 

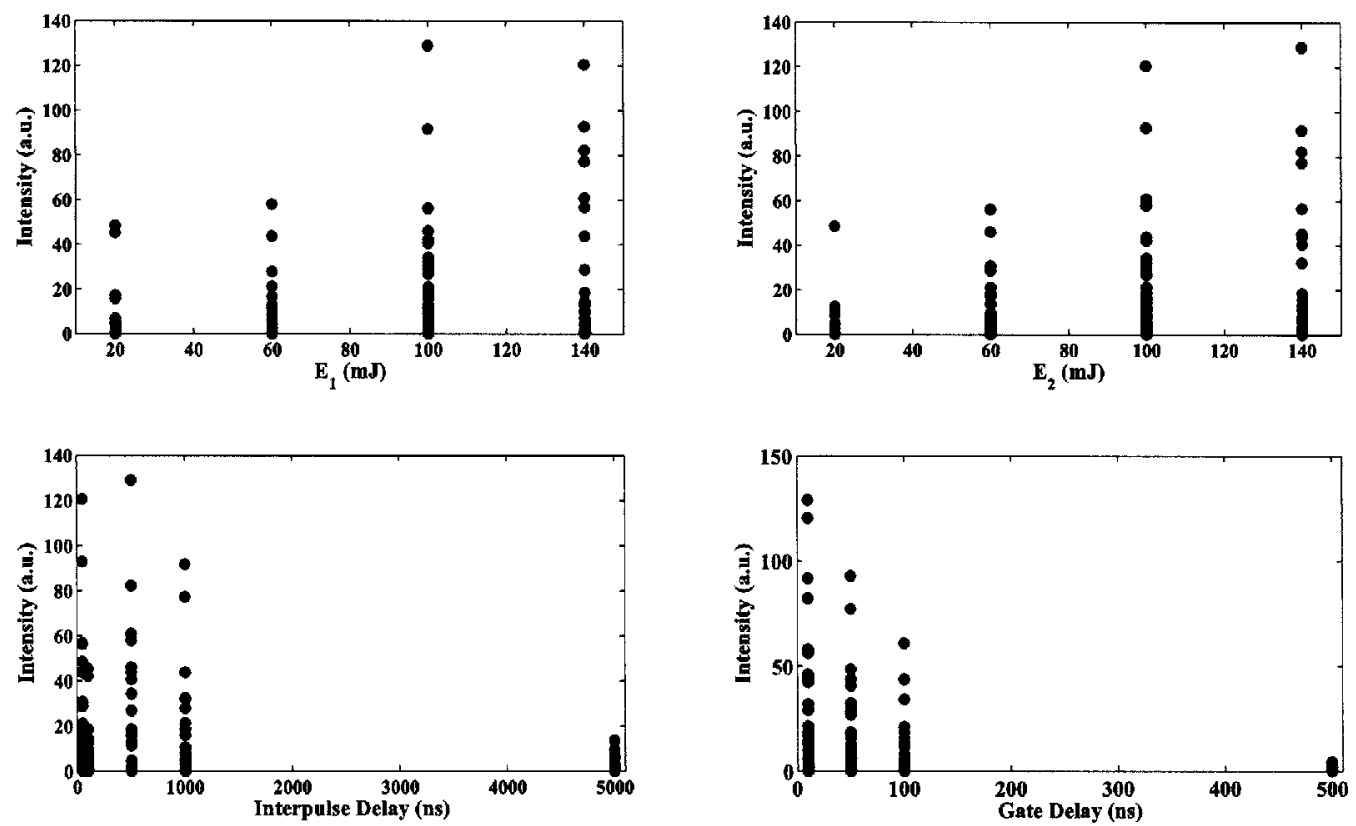

Figure 5-9: K (I) (769.9 nm peak) optimization at $1.38 \times 10^{7} \mathrm{~Pa}$
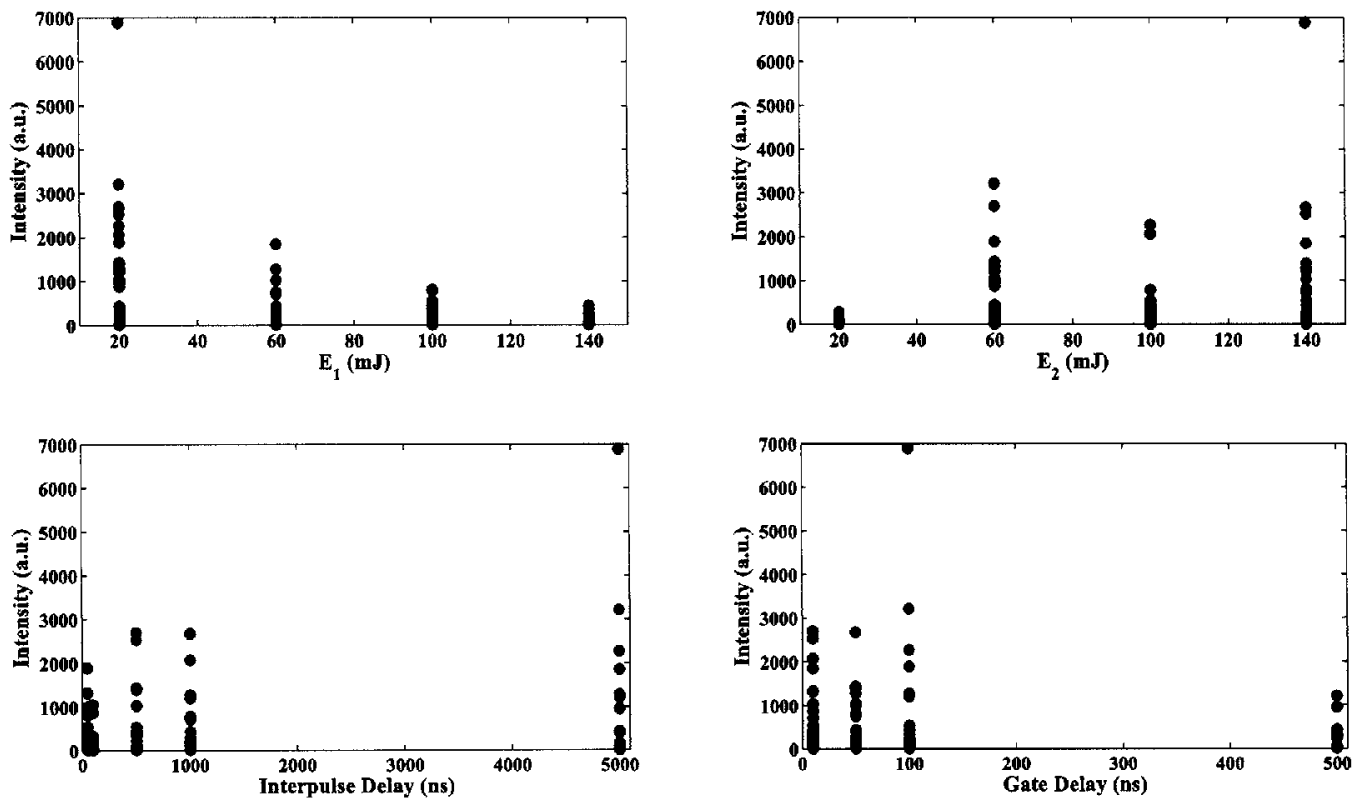

Figure 5-10: K (I) (769.9 nm peak) optimization at $2.76 \times 10^{7} \mathrm{~Pa}$ 


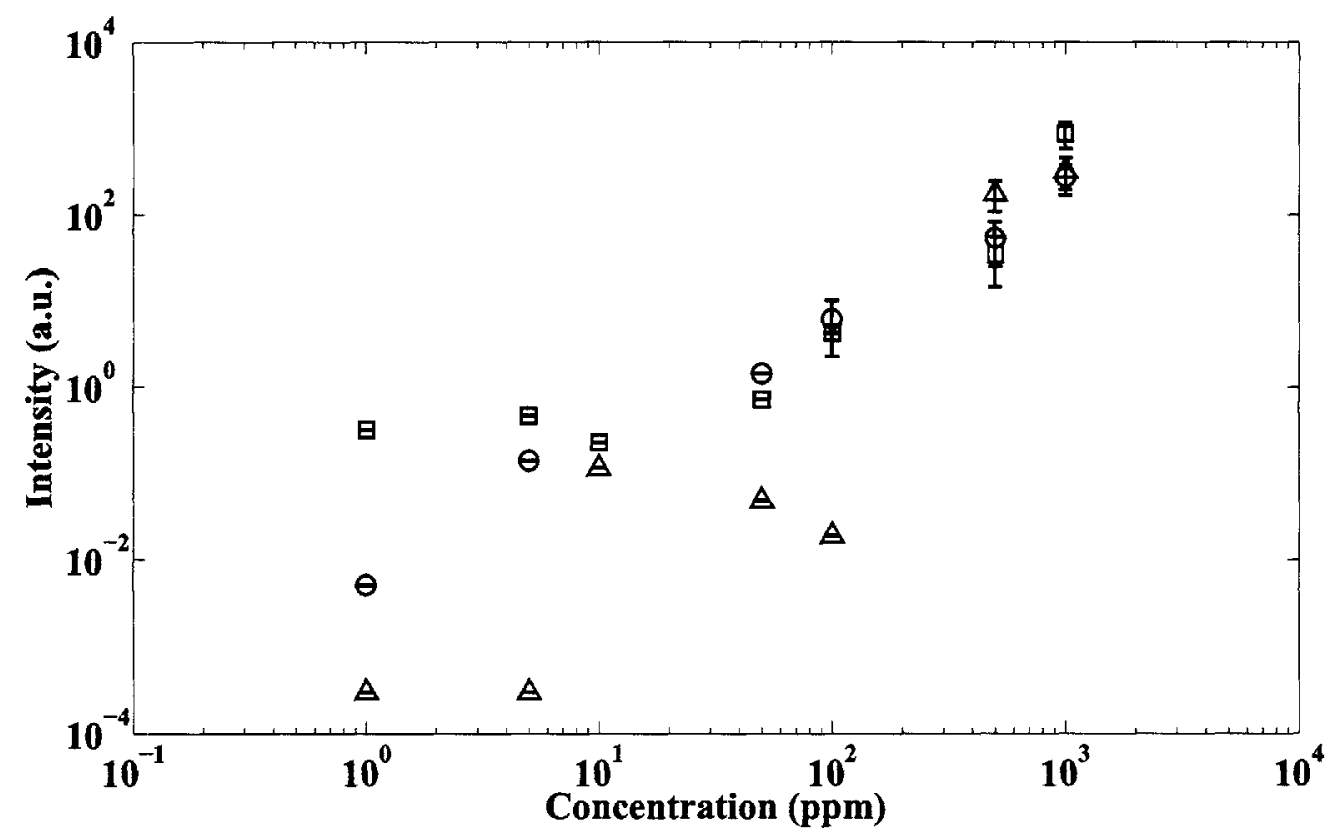

(a)

Figure 5-11: K (I) calibration curve of the $769.9 \mathrm{~nm}$ peak, $\bigcirc=1 \times 10^{5} \mathrm{~Pa}, \square=$ $1.38 \times 10^{7} \mathrm{~Pa}, \triangle=2.76 \times 10^{7} \mathrm{~Pa},\left(\mathrm{E}_{1}=100 \mathrm{~mJ}, \mathrm{E}_{2}=140 \mathrm{~mJ}, \mathrm{t}_{d}=1000 \mathrm{~ns}\right.$, and $\Delta \mathrm{T}=50 \mathrm{~ns})$

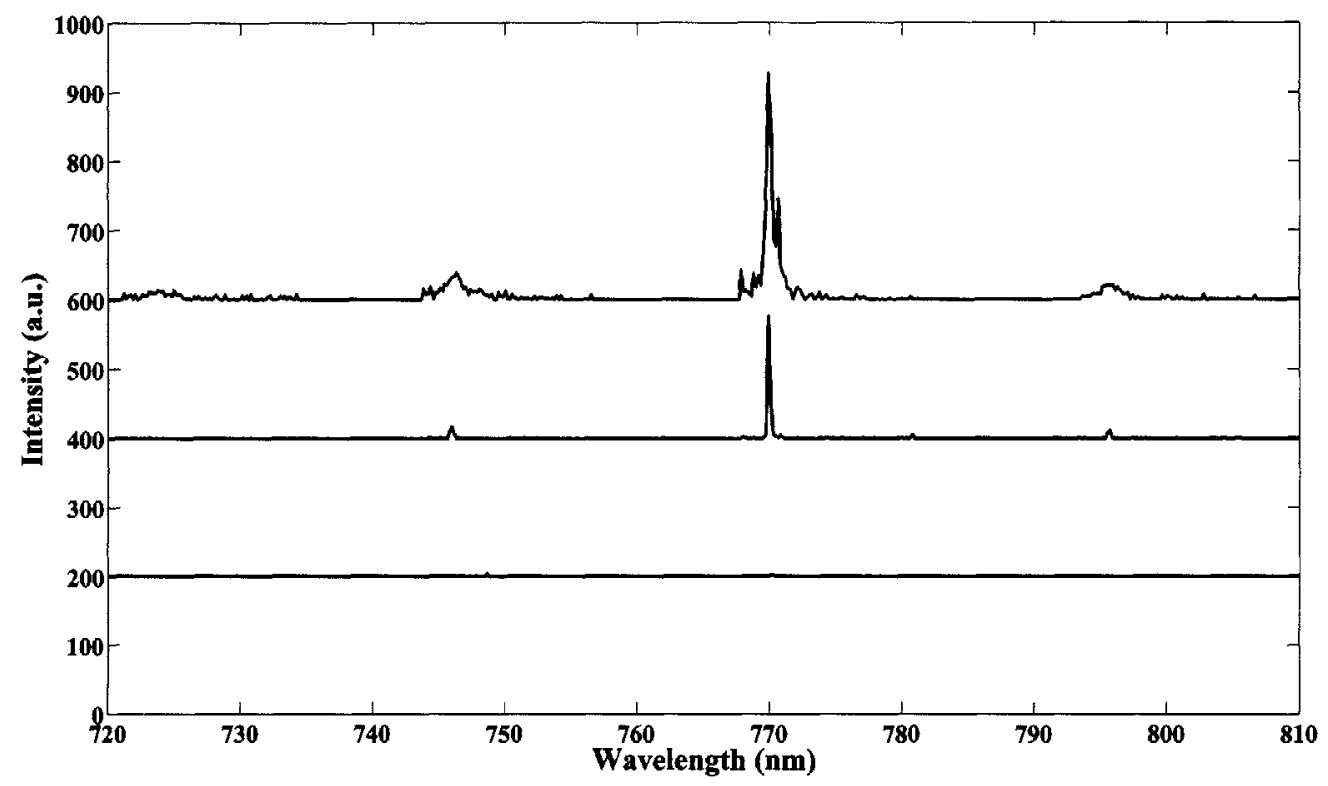

Figure 5-12: Spectra of $769.9 \mathrm{~nm} \mathrm{~K}(\mathrm{I})$ peak at $2.76 \times 10^{7} \mathrm{~Pa}$. Concentrations of spectra from bottom to top are $100 \mathrm{ppm}, 500 \mathrm{ppm}, 1000 \mathrm{ppm}$. $\left(\mathrm{E}_{1}=100 \mathrm{~mJ}, \mathrm{E}_{2}=\right.$ $140 \mathrm{~mJ}, \mathrm{t}_{d}=1000 \mathrm{~ns}$, and $\left.\Delta \mathrm{T}=50 \mathrm{~ns}\right)$. For clarity, the spectra have been offset from each other by 200 a.u. 


\subsubsection{Calcium}

The results for the $422 \mathrm{~nm} \mathrm{Ca} \mathrm{(I)} \mathrm{peak} \mathrm{are} \mathrm{shown} \mathrm{in} \mathrm{Figures} \mathrm{5-13} \mathrm{to} \mathrm{5-15.} \mathrm{At} 1 \times$ $10^{5} \mathrm{~Pa}$, the greatest intensity peak was detected when a long interpulse delay time was used (500 to $5000 \mathrm{~ns}$ ) with a low energy pulse (typically $20 \mathrm{~mJ}$ ) followed by a higher energy pulse $(60 \mathrm{~mJ}-140 \mathrm{~mJ})$. At both $1.38 \times 10^{7} \mathrm{~Pa}$ and $2.76 \times 10^{7} \mathrm{~Pa}$, the greatest intensity peak was detected when two high energy pulses (typically 100 $\mathrm{mJ}-140 \mathrm{~mJ}$ ) were separated by $50 \mathrm{~ns}$. As a result, the condition selected for the calibration curve was $\mathrm{E}_{1}=100 \mathrm{~mJ}, \mathrm{E}_{2}=100 \mathrm{~mJ}, \mathrm{t}_{d}=50 \mathrm{~ns}$, and $\Delta \mathrm{T}=50 \mathrm{~ns}$. The calcium calibration curves for both the $393 \mathrm{~nm} \mathrm{Ca} \mathrm{(II)} \mathrm{and} 422 \mathrm{~nm} \mathrm{Ca}$ (I) peaks are shown in Figure 5-16. The limit of detection for calcium using the conditions selected is $500 \mathrm{ppm}$. Spectra at these conditions are shown in Figure 5-17.
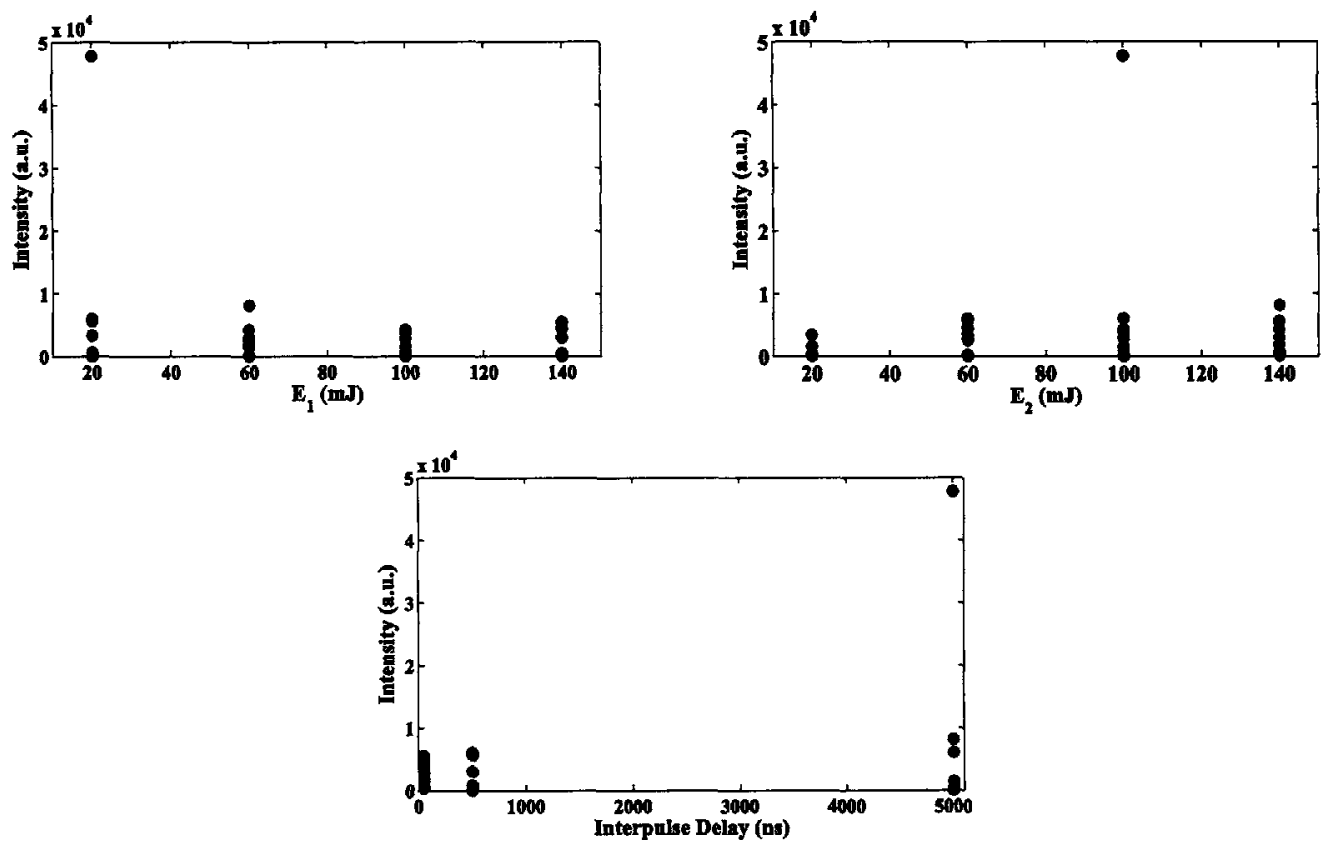

Figure 5-13: Ca (I) (422 nm peak) optimization at $1 \times 10^{5} \mathrm{~Pa}$ 

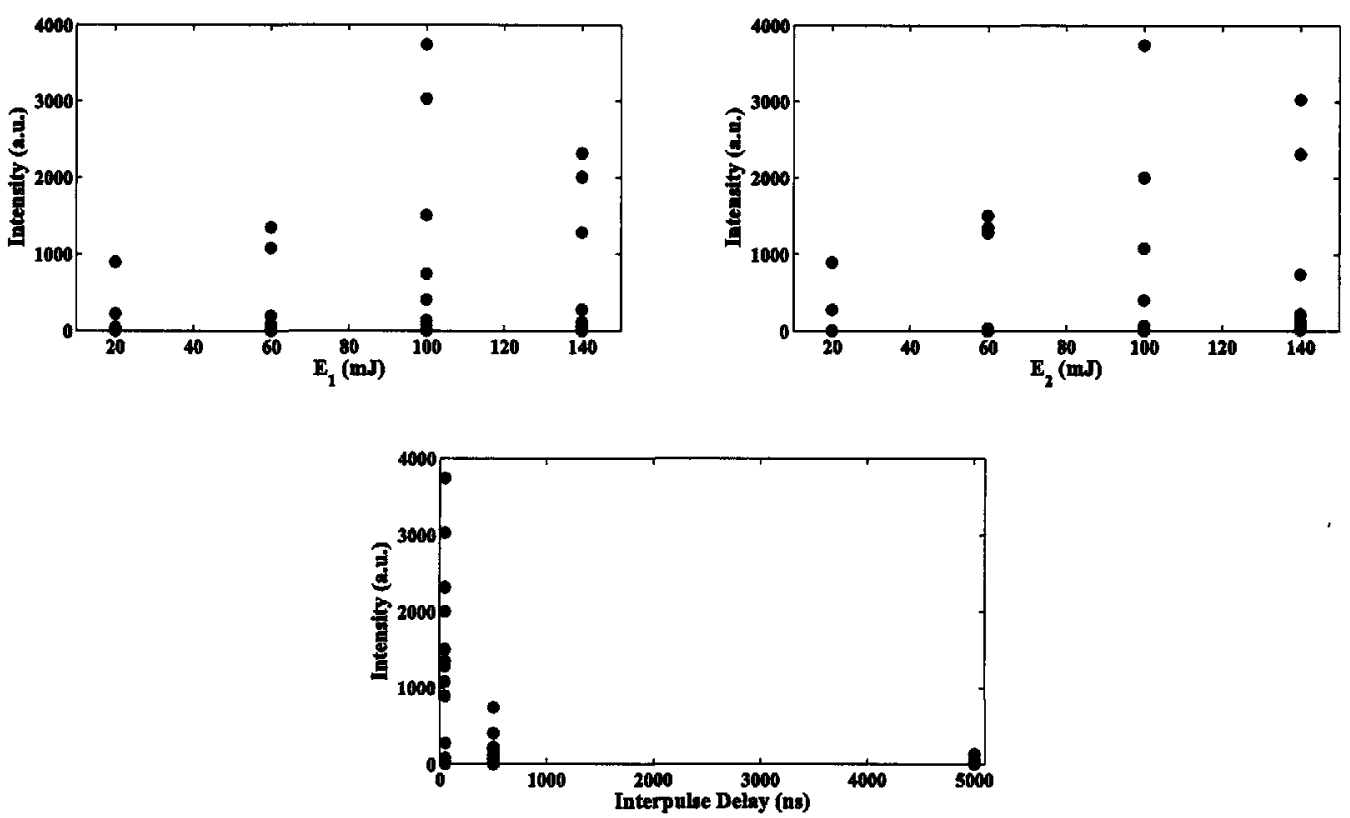

Figure 5-14: Ca (I) (422 nm peak) optimization at $1.38 \times 10^{7} \mathrm{~Pa}$
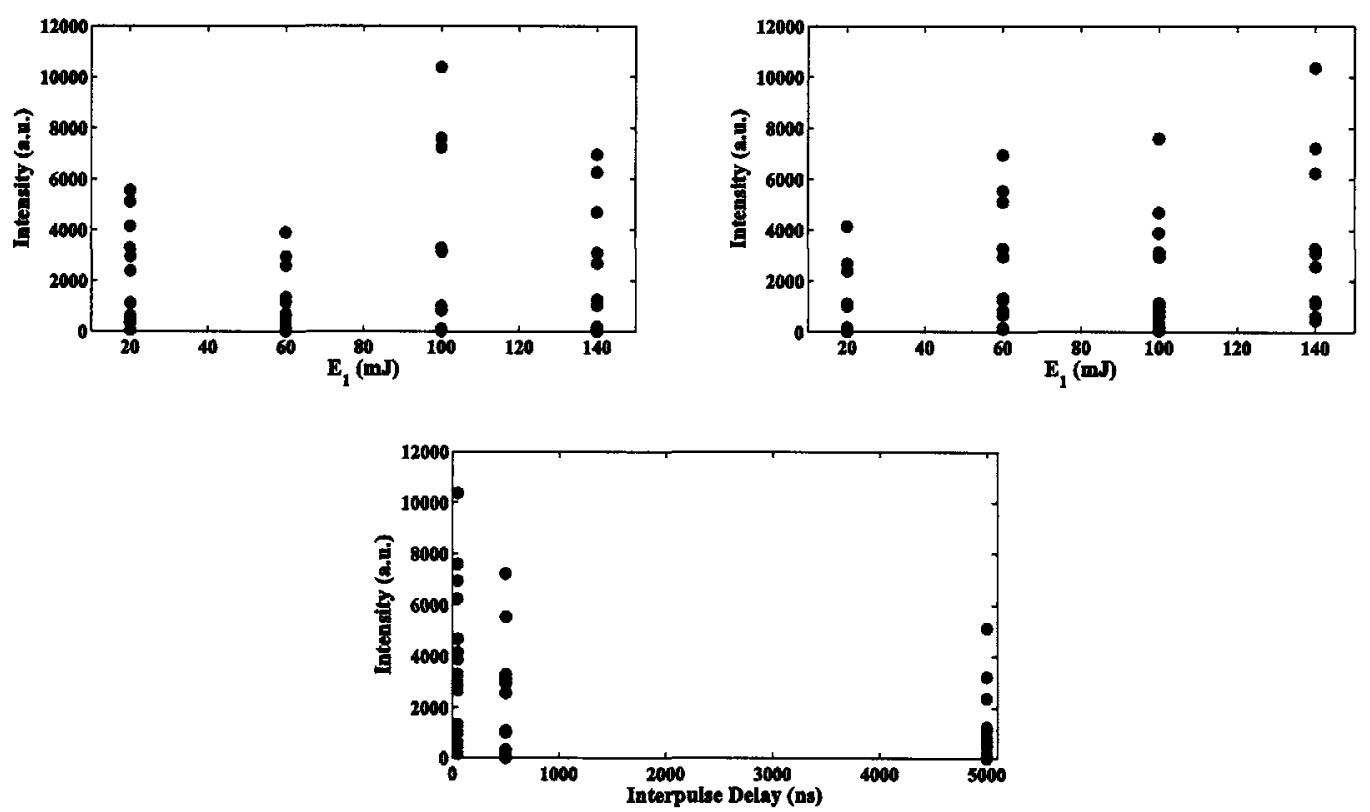

Figure 5-15: Ca (I) (422 nm peak) optimization at $2.76 \times 10^{7} \mathrm{~Pa}$ 


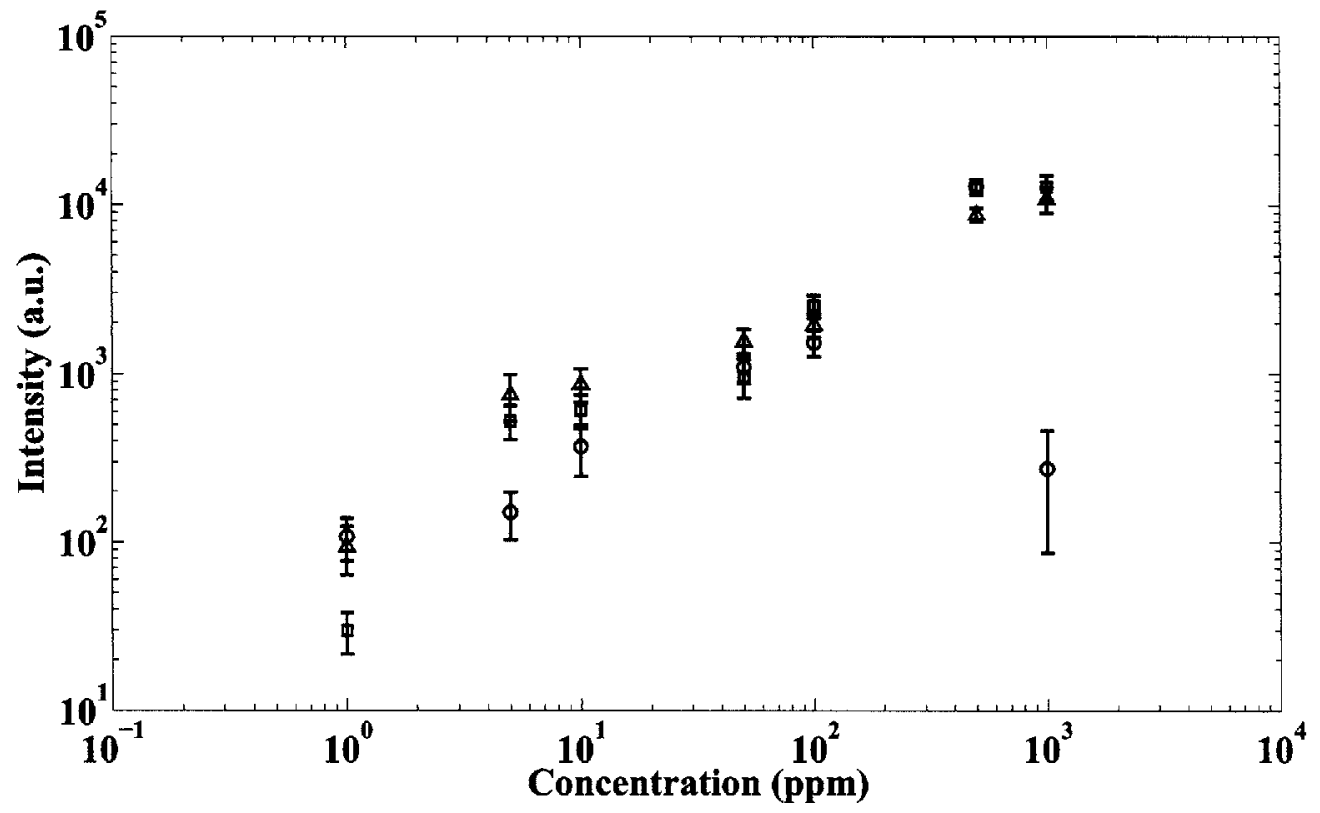

(a) $393 \mathrm{~nm} \mathrm{Ca} \mathrm{(II)} \mathrm{peak}$

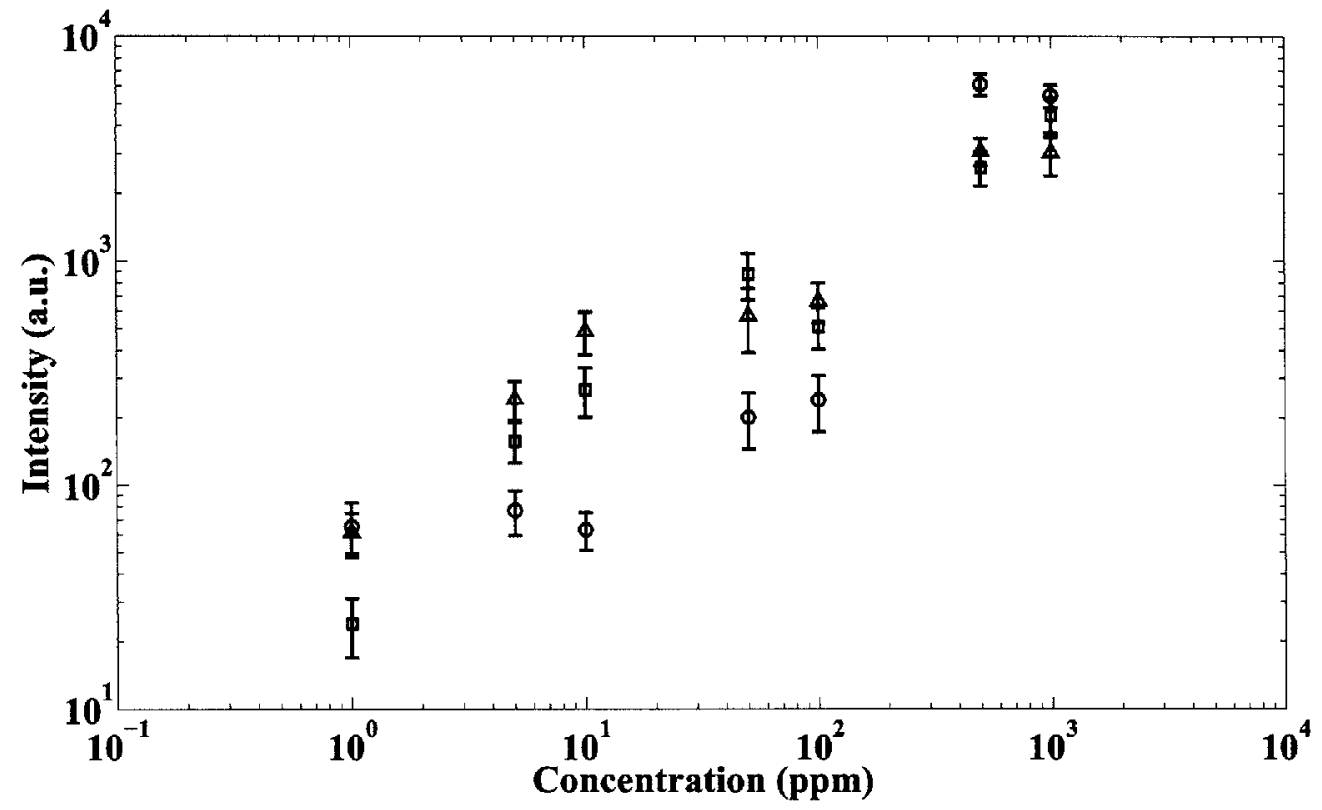

(b) $422 \mathrm{~nm} \mathrm{Ca}$ (I) peak

Figure 5-16: Calcium calibration curves, $\bigcirc=1 \times 10^{5} \mathrm{~Pa}, \square=1.38 \times 10^{7} \mathrm{~Pa}, \triangle=$ $2.76 \times 10^{7} \mathrm{~Pa},\left(\mathrm{E}_{1}=100 \mathrm{~mJ}, \mathrm{E}_{2}=100 \mathrm{~mJ}, \mathrm{t}_{d}=50 \mathrm{~ns}\right.$, and $\left.\Delta \mathrm{T}=50 \mathrm{~ns}\right)$ 


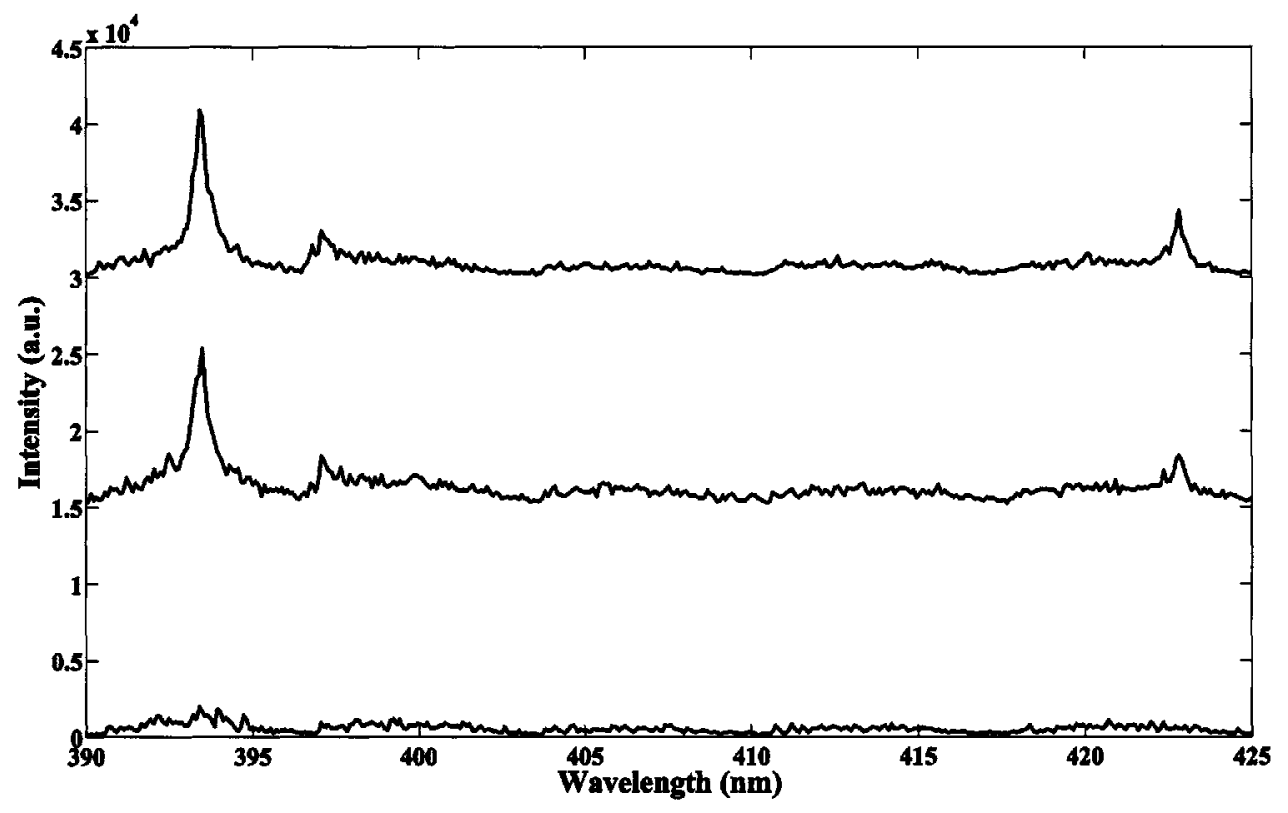

Figure 5-17: Spectra of calcium ( $393 \mathrm{~nm} \mathrm{Ca}$ (II), $396 \mathrm{~nm} \mathrm{Ca} \mathrm{(II),} \mathrm{and} 422 \mathrm{~nm} \mathrm{Ca}$ (I) peaks) at $2.76 \times 10^{7} \mathrm{~Pa}$. Concentrations of spectra from bottom to top are $100 \mathrm{ppm}$, $500 \mathrm{ppm}$, and $1000 \mathrm{ppm}$. $\left(\mathrm{E}_{1}=100 \mathrm{~mJ}, \mathrm{E}_{2}=100 \mathrm{~mJ}, \mathrm{t}_{d}=50 \mathrm{~ns}\right.$, and $\left.\Delta \mathrm{T}=50 \mathrm{~ns}\right)$. For clarity, the spectra have been offset from each other by 15,000 a.u. 


\subsubsection{Manganese}

The optimization study results for the $403 \mathrm{~nm} \mathrm{Mn} \mathrm{(I)} \mathrm{peak} \mathrm{are} \mathrm{shown} \mathrm{in} \mathrm{Figures} \mathrm{5-18}$ to 5-20. Although a $\mathrm{Mn}$ (I) triplet exists at $403 \mathrm{~nm}$, peak broadening in liquids causes it to be unresolvable, and hence a single $403 \mathrm{~nm}$ peak is used for this study. At 1 $\times 10^{5} \mathrm{~Pa}$, a low first energy pulse $(20 \mathrm{~mJ})$ followed by a higher second energy pulse $(60 \mathrm{~mJ}-140 \mathrm{~mJ})$ with a long interpulse delay time (5000 ns) gave the highest peak intensity (Figure 5-18). When the pressure was increased, the need for a significantly shorter interpulse delay time was evident (Figures 5-18-5-19). At the highest pressure condition, two high energy pulses gave the most intense peak (Figure 5-20). Using a low second energy pulse $(20 \mathrm{~mJ})$ was not beneficial at this pressure condition. At the intermediate pressure, $1.38 \times 10^{7} \mathrm{~Pa}$, several parameter combinations can be used. Either a low energy first pulse $(20 \mathrm{~mJ})$ followed by a higher pulse $(60 \mathrm{~mJ}-140 \mathrm{~mJ})$ or two higher energy pulses $(60 \mathrm{~mJ}-140 \mathrm{~mJ})$ were suitable characteristics of both the low pressure and high pressure conditions are workable and hence this is possibly a transition pressure. For $\mathrm{Mn}(\mathrm{I})$, the conditions that were selected for the calibration curve were $\mathrm{E}_{1}=100 \mathrm{~mJ}, \mathrm{E}_{2}=60 \mathrm{~mJ}, \mathrm{t}_{d}=50 \mathrm{~ns}, \Delta \mathrm{T}=50 \mathrm{~ns}$, with results shown in Figure 5-21. Spectra at these conditions are shown in Figure 5-22. From both the calibration curve (Figure 5-21) and the subsequent spectra (Figure 5-22), the limit of detection is $1000 \mathrm{ppm}$. 

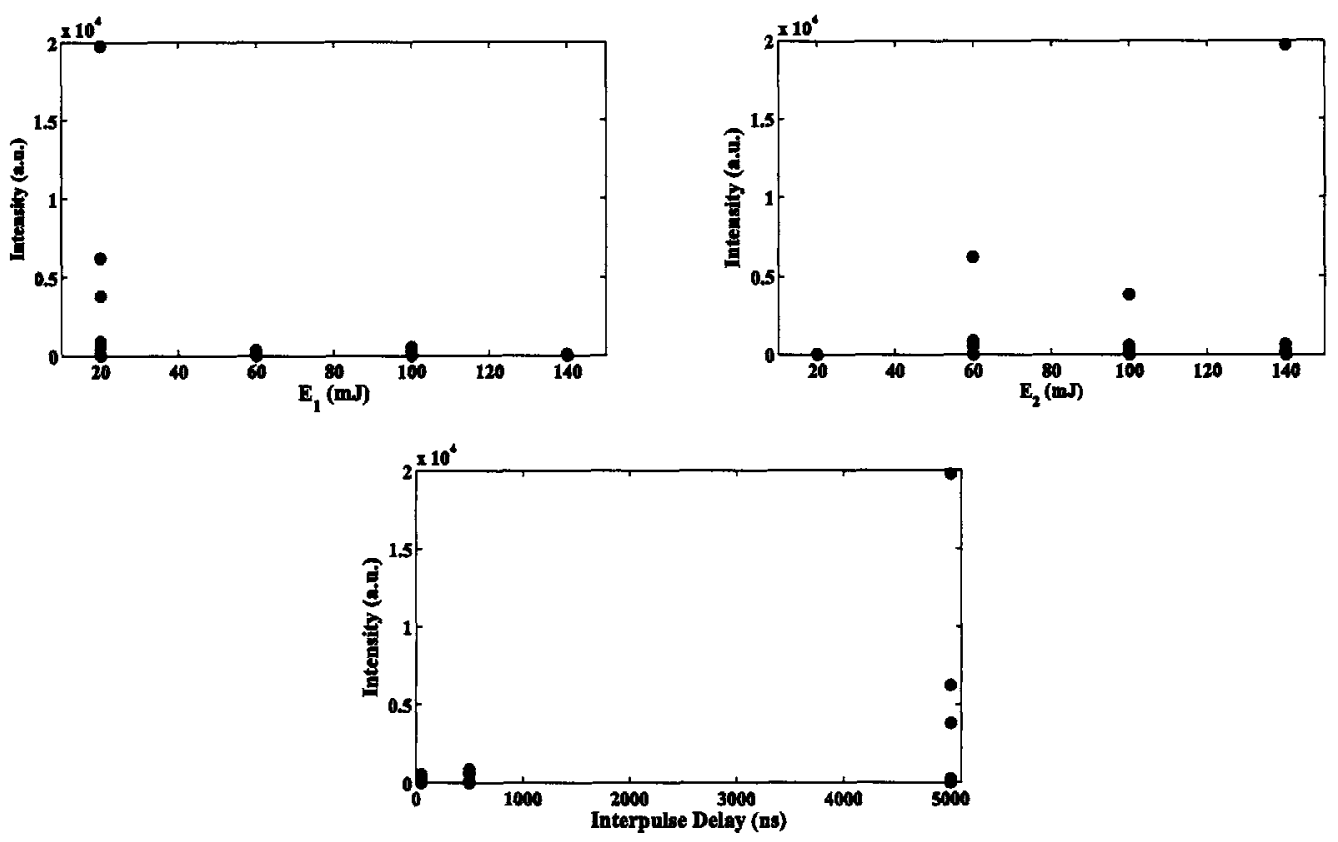

Figure 5-18: $\mathrm{Mn}$ (I) (403 nm peak) optimization at $1 \times 10^{5} \mathrm{~Pa}$
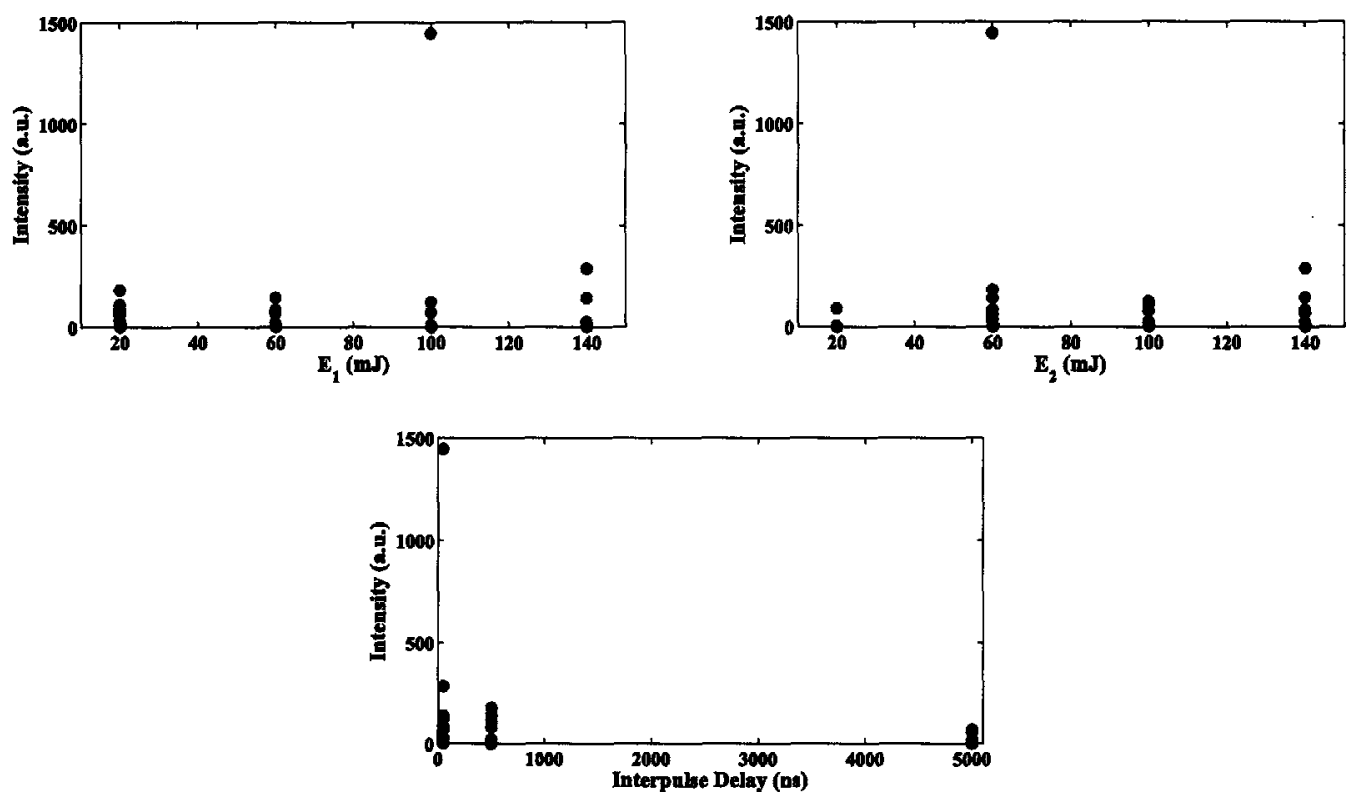

Figure 5-19: $\mathrm{Mn}(\mathrm{I})$ (403 nm peak) optimization at $1.38 \times 10^{7} \mathrm{~Pa}$ 

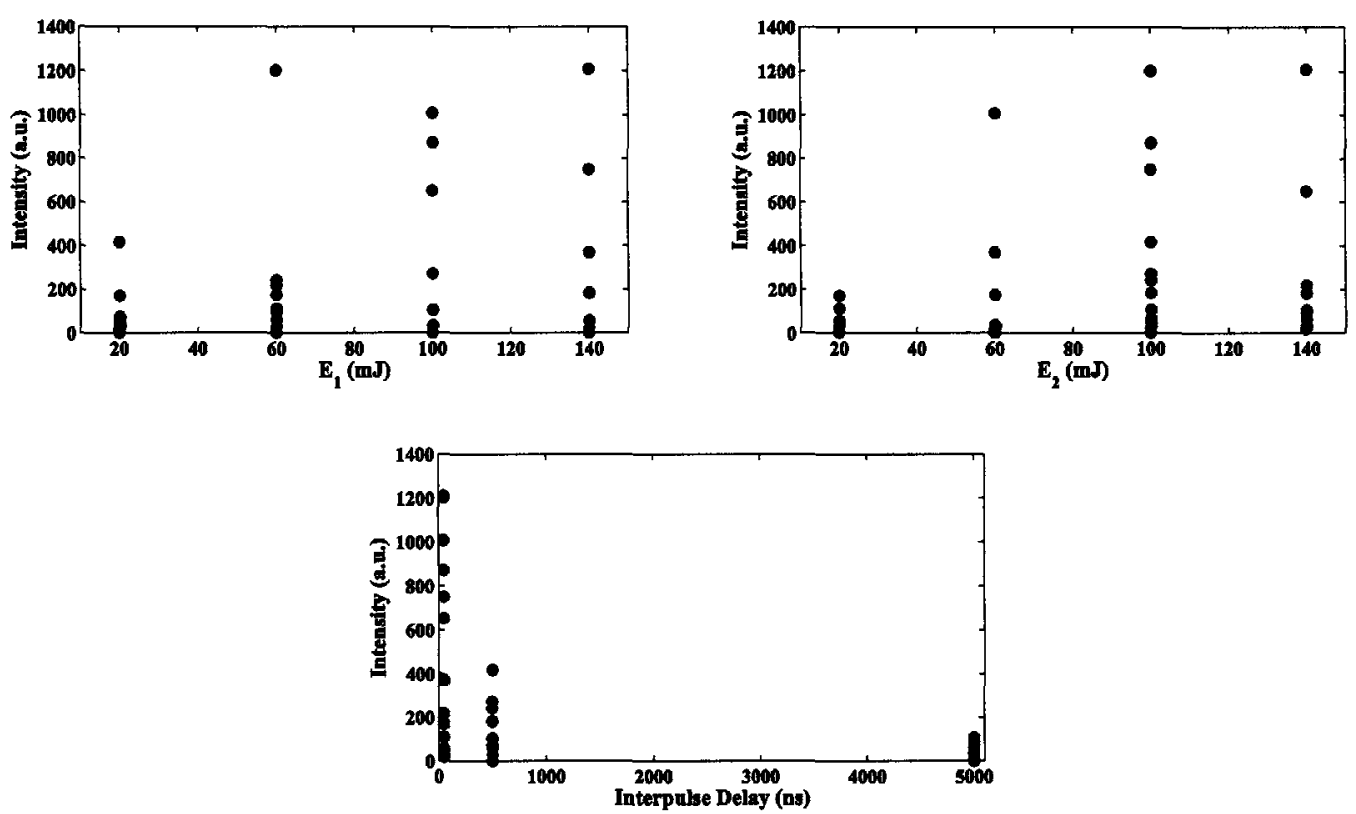

Figure 5-20: $\mathrm{Mn}(\mathrm{I})\left(403 \mathrm{~nm}\right.$ peak) optimization at $2.76 \times 10^{7} \mathrm{~Pa}$

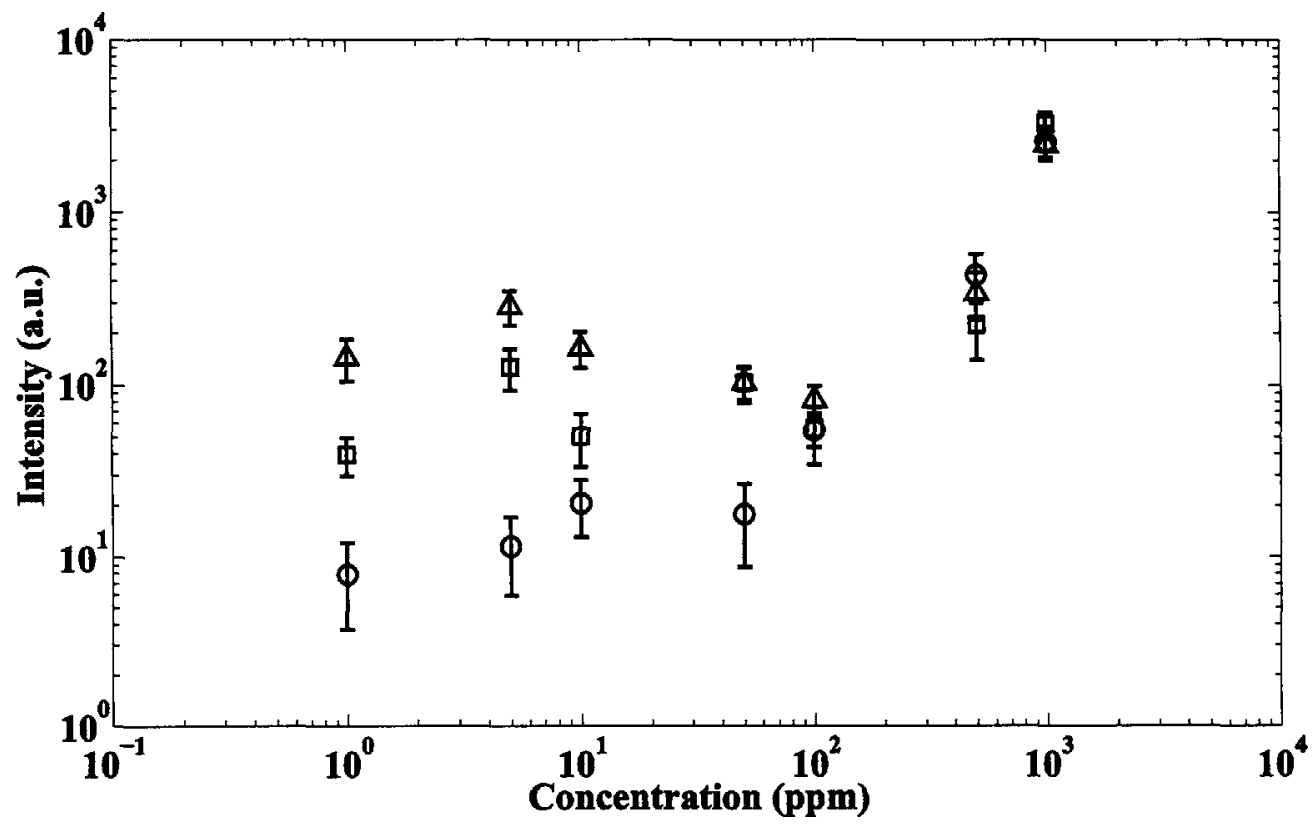

Figure 5-21: $\mathrm{Mn}$ (I) (403 nm peak) calibration curve. $\mathrm{O}=1 \times 10^{5} \mathrm{~Pa}, \square=1.38 \times$ $10^{7} \mathrm{~Pa}, \Delta=2.76 \times 10^{7} \mathrm{~Pa},\left(\mathrm{E}_{1}=100 \mathrm{~mJ}, \mathrm{E}_{2}=60 \mathrm{~mJ}, \mathrm{t}_{d}=50 \mathrm{~ns}\right.$, and $\left.\Delta \mathrm{T}=50 \mathrm{~ns}\right)$ 


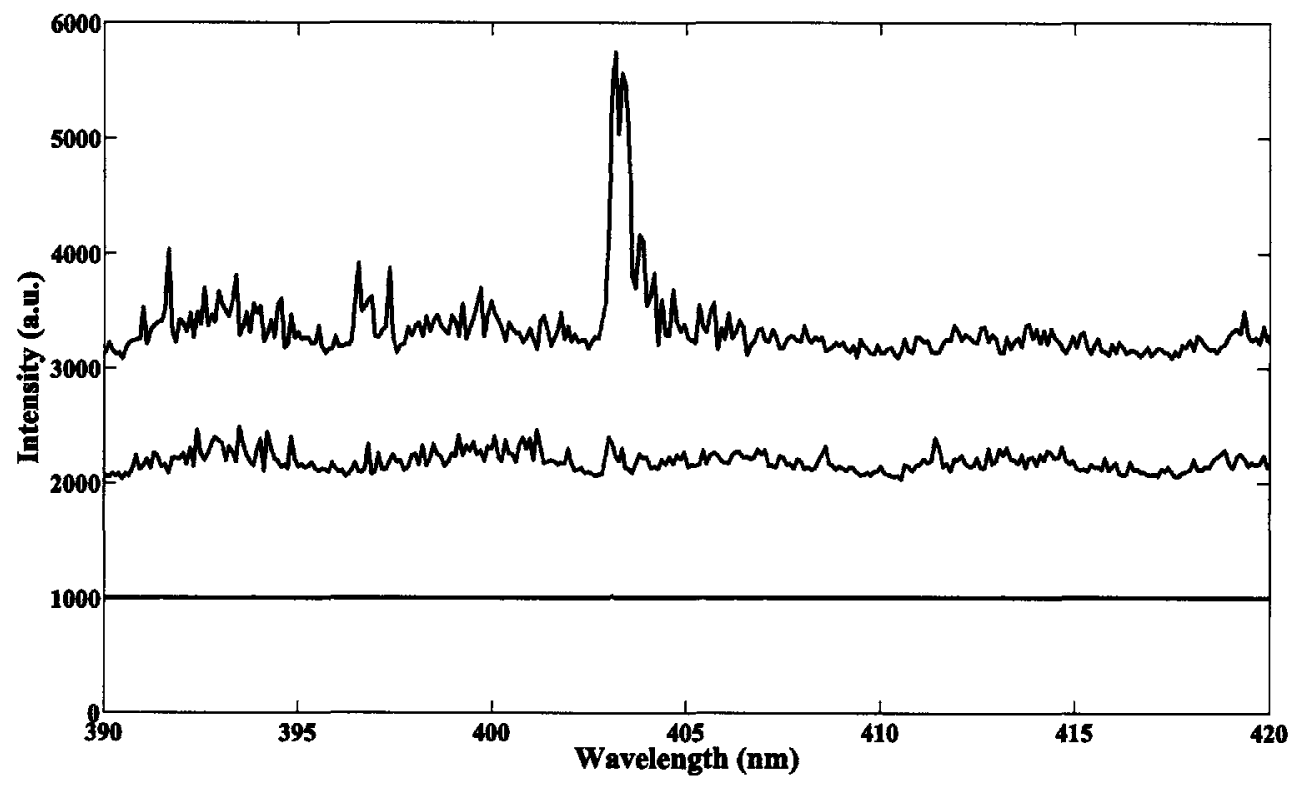

Figure 5-22: Spectra of $\mathrm{Mn}(\mathrm{I})$ peak $(403 \mathrm{~nm})$ at $2.76 \times 10^{7} \mathrm{~Pa}$. Concentrations from bottom to top are $100 \mathrm{ppm}, 500 \mathrm{ppm}$, and $1000 \mathrm{ppm}$. $\left(\mathrm{E}_{1}=100 \mathrm{~mJ}, \mathrm{E}_{2}=60 \mathrm{~mJ}, \mathrm{t}_{d}\right.$ $=50 \mathrm{~ns}$, and $\Delta \mathrm{T}=50 \mathrm{~ns})$. For clarity, the spectra have been offset from each other by 1000 a.u. 


\subsubsection{Sodium}

The $588.995 \mathrm{~nm} \mathrm{Na}$ (I) peak from the sodium doublet was used for optimization studies (Figures 5-23-5-25). The highest intensity at $1 \times 10^{5} \mathrm{~Pa}$ was recorded when a low energy pulse was followed by a high energy pulse and a long interpulse delay time was used (Figure 5-23). For example, the greatest intensity was recorded for $E_{1}=20$ $\mathrm{mJ}, \mathrm{E}_{2}=140 \mathrm{~mJ}$, and $\Delta \mathrm{T}=5000 \mathrm{~ns}$. At $1.38 \times 10^{7} \mathrm{~Pa}$, the greatest intensity peaks were recorded when two high energy pulses $(60 \mathrm{~mJ}$ to $140 \mathrm{~mJ}$ ) were fired in rapid succession in either order and separated by $50 \mathrm{~ns}$ (Figure 5-24). Since the interpulse delay time is very small, these conditions are close to that for single pulse operation with a very high energy pulse. At $2.76 \times 10^{7} \mathrm{~Pa}$, the greatest intensity peak again exists when two high energy pulses $(60 \mathrm{~mJ}$ and $140 \mathrm{~mJ})$ are rapidly fired in either order separated by $50 \mathrm{~ns}$ (Figure 5-25). The lowest intensity peaks were recorded at all pressures when the second energy pulse was $20 \mathrm{~mJ}$, suggesting that the second pulse must be of sufficient energy or irradiance to excite or re-excite plasma emission. The sodium calibration curve was therefore made at $\mathrm{E}_{1}=60 \mathrm{~mJ}, \mathrm{E}_{2}=140 \mathrm{~mJ}, \Delta \mathrm{T}=$ $50 \mathrm{~ns}$, and $\mathrm{t}_{d}=50 \mathrm{~ns}$ and is shown in Figure 5-26. Spectra made at the high pressure $\left(2.76 \times 10^{7} \mathrm{~Pa}\right)$ condition which clearly indicate the limit of detection of $50 \mathrm{ppm}$ are shown in Figure 5-27.
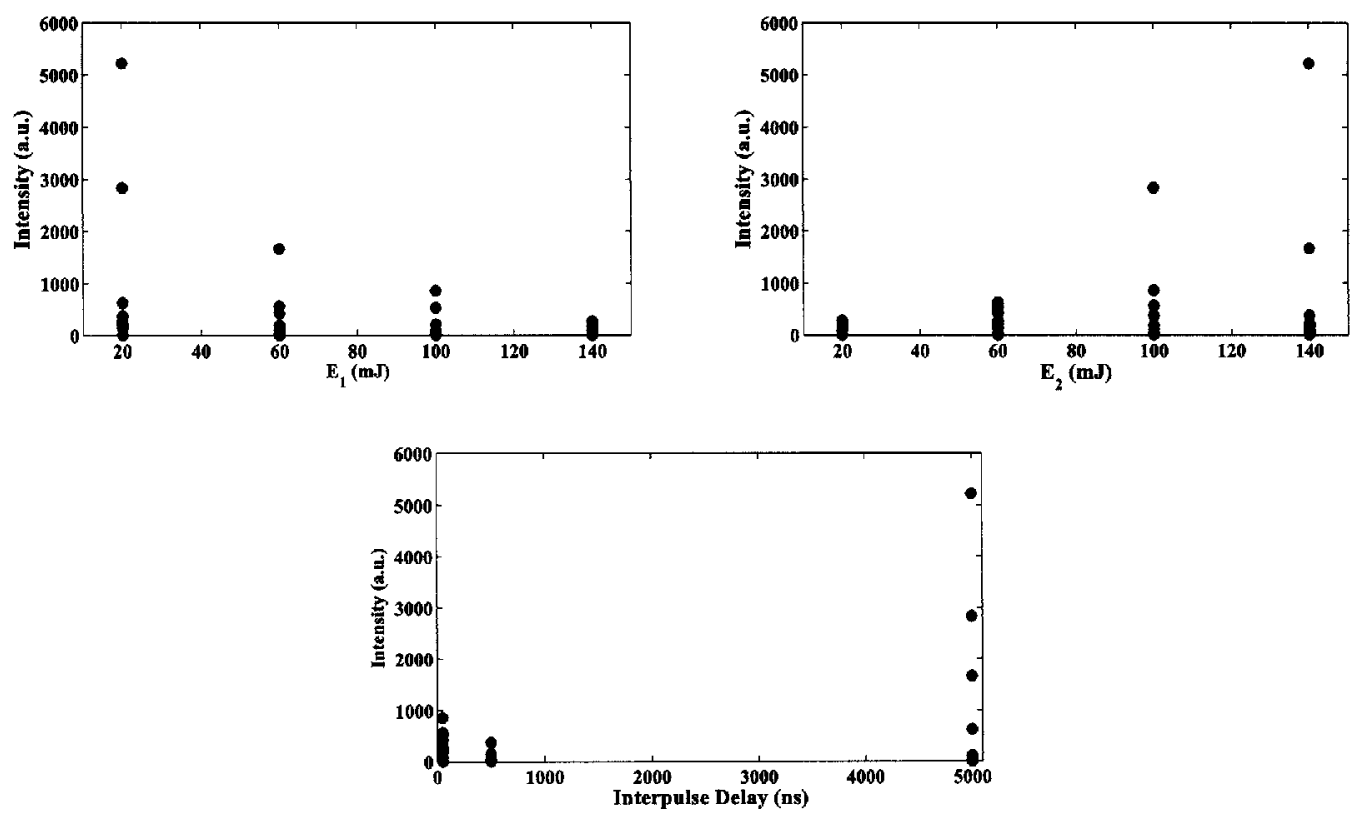

Figure 5-23: $\mathrm{Na}(\mathrm{I})(588.995 \mathrm{~nm})$ optimization at $1 \times 10^{5} \mathrm{~Pa}$ 

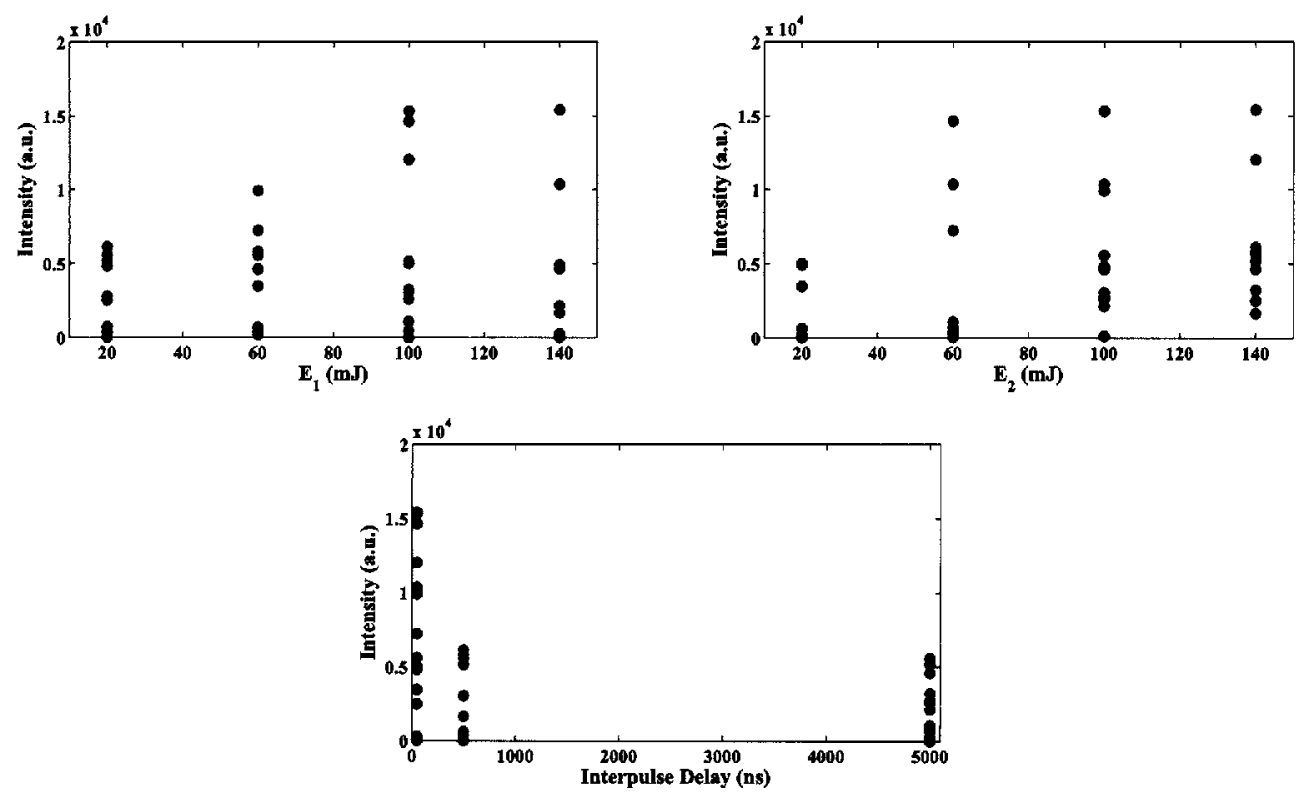

Figure 5-24: $\mathrm{Na}(\mathrm{I})$ optimization at $1.38 \times 10^{7} \mathrm{~Pa}$
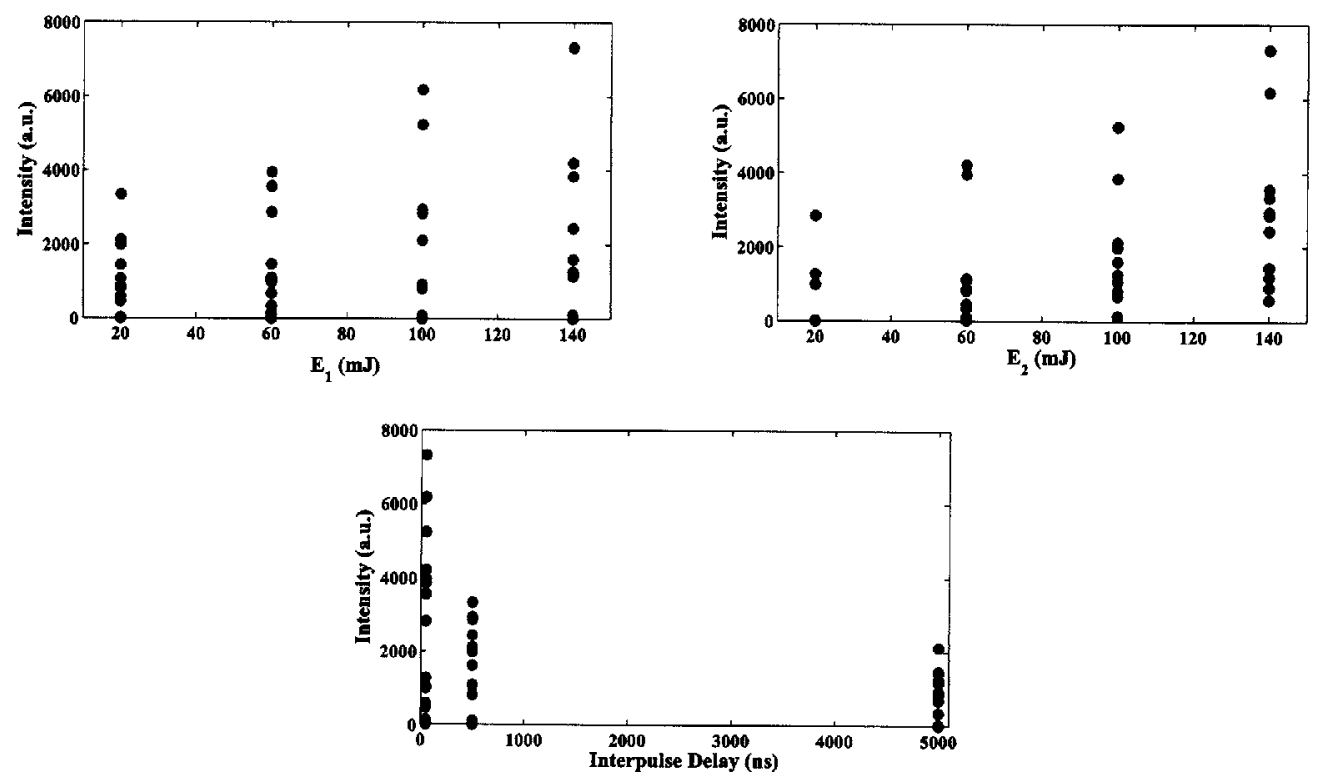

Figure 5-25: $\mathrm{Na}$ (I) $(588.995 \mathrm{~nm})$ optimization at $2.76 \times 10^{7} \mathrm{~Pa}$ 


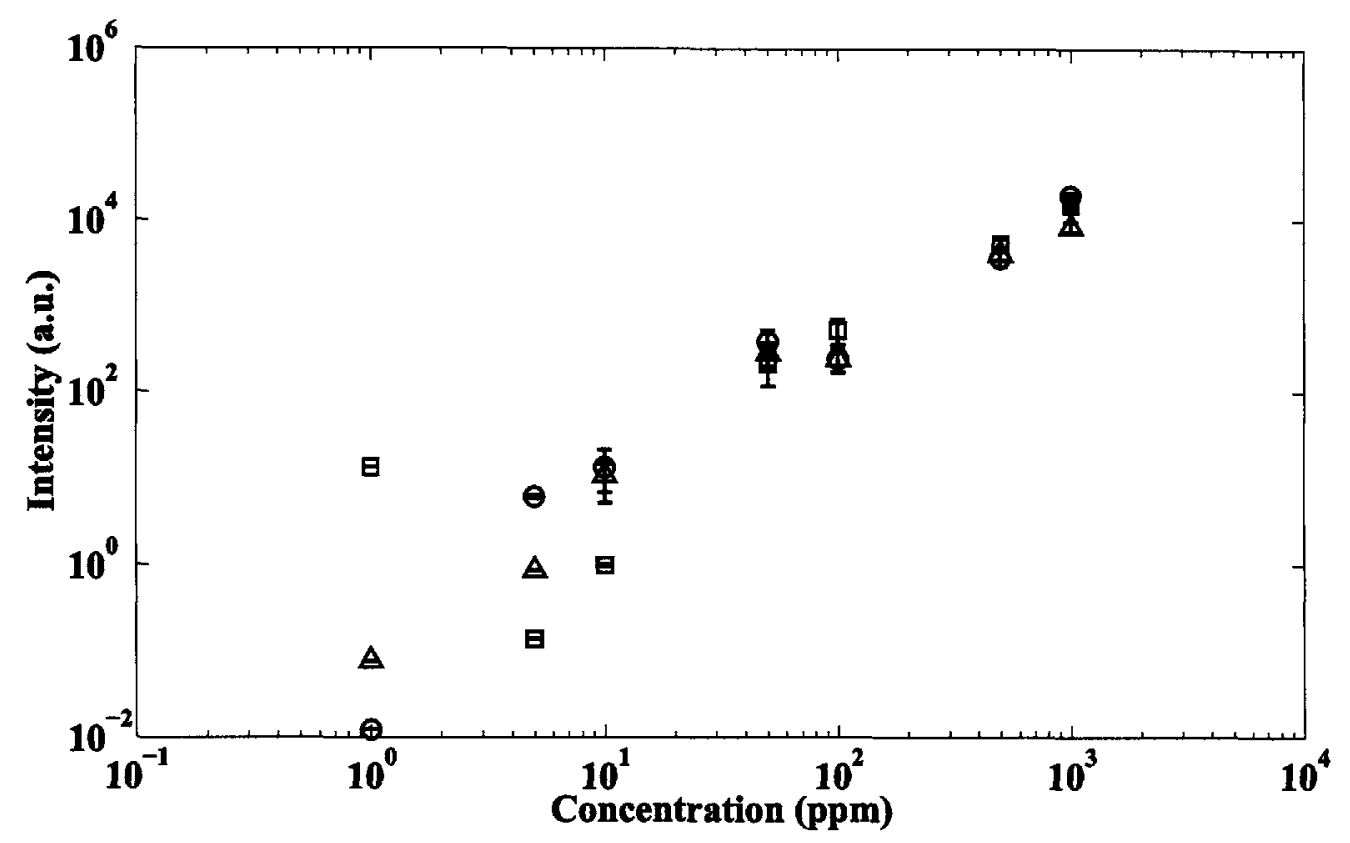

(a)

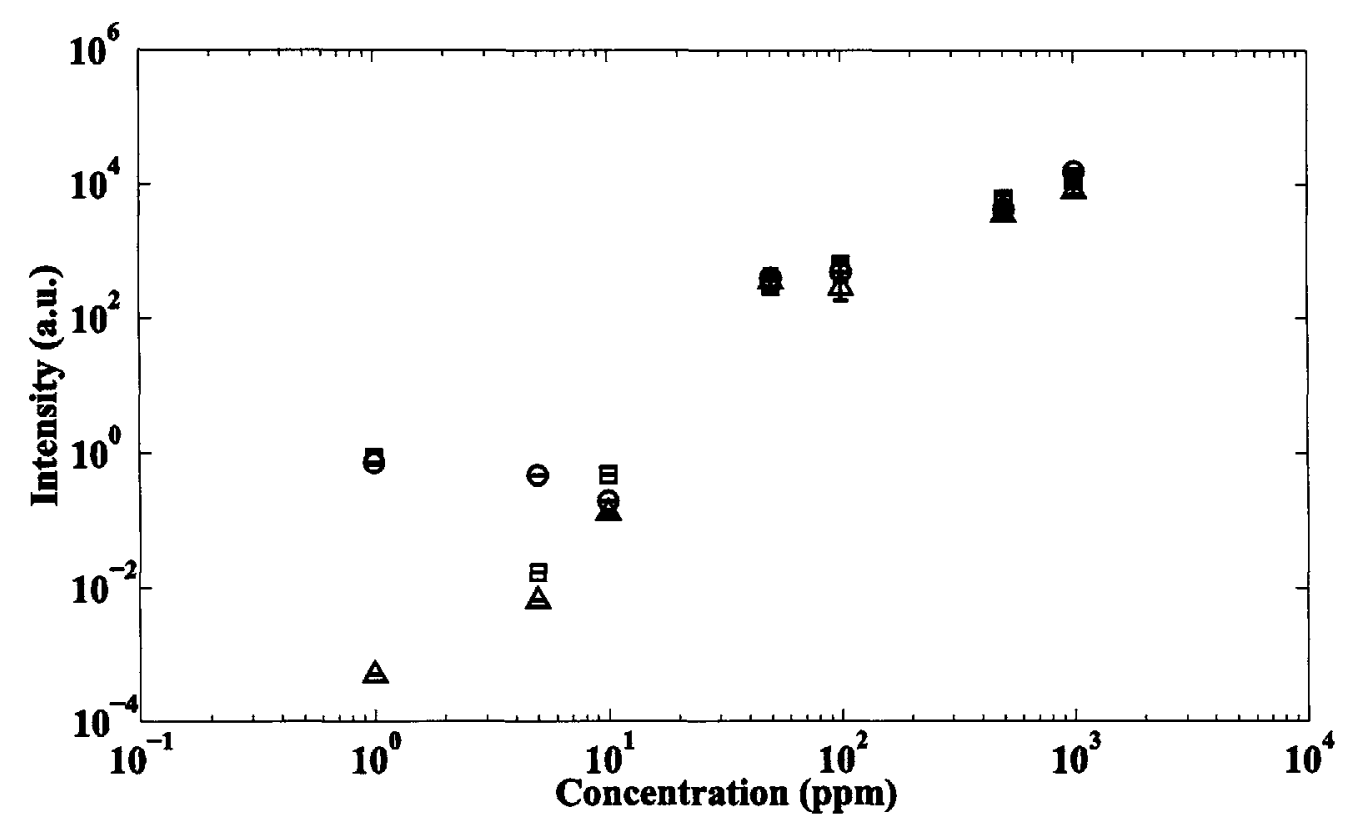

(b)

Figure 5-26: $\mathrm{Na}$ (I) calibration curves of the (a) $588.995 \mathrm{~nm}$ peak and the (b) 589.6 nm peak. $\bigcirc=1 \times 10^{5} \mathrm{~Pa}, \square=1.38 \times 10^{7} \mathrm{~Pa}, \Delta=2.76 \times 10^{7} \mathrm{~Pa}$. 


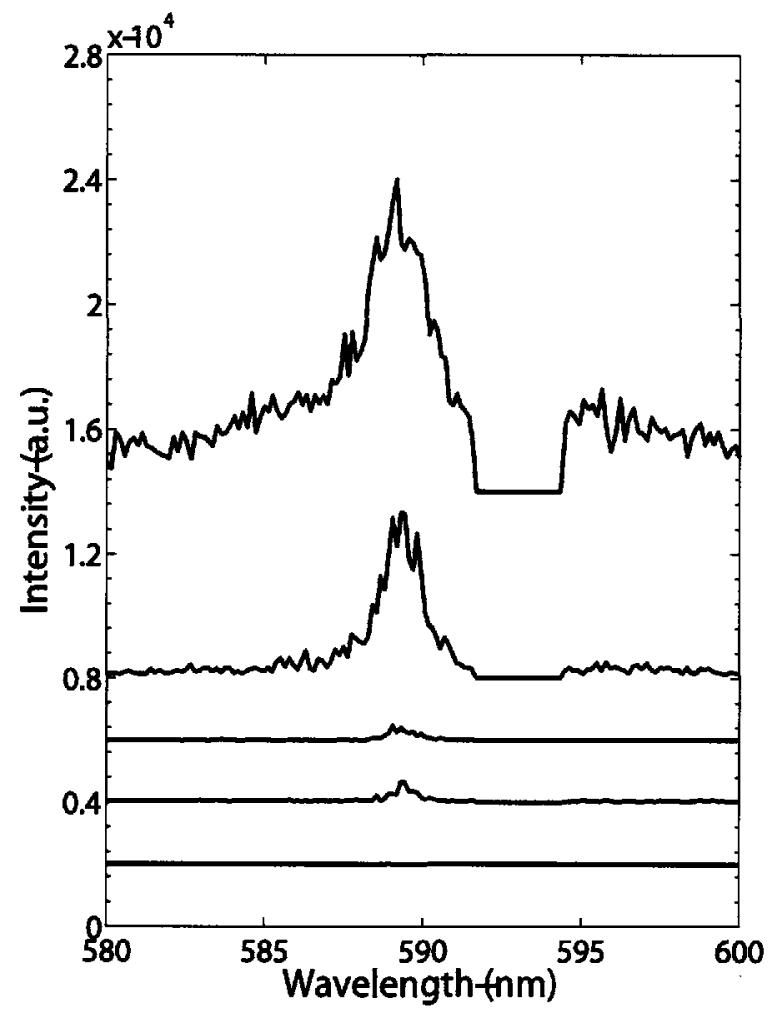

Figure 5-27: Spectra of the $\mathrm{Na}$ (I) doublet peaks (588.995 nm and $589.6 \mathrm{~nm})$ at 2.76 $\times 10^{7} \mathrm{~Pa}$. Concentrations from bottom to top are $10 \mathrm{ppm}, 50 \mathrm{ppm}, 100 \mathrm{ppm}, 500$ ppm, and $1000 \mathrm{ppm}$. ( $\mathrm{E}_{1}=60 \mathrm{~mJ}, \mathrm{E}_{2}=140 \mathrm{~mJ}, \Delta \mathrm{T}=50 \mathrm{~ns}$, and $\mathrm{t}_{d}=50 \mathrm{~ns}$ ). For clarity, the spectra have been offset from each other by 2000 a.u., except for the 1000 ppm spectrum which has been offset from the $500 \mathrm{ppm}$ spectrum by 8000 a.u. 
The limits of detection for sodium as well as the other analytes reported here are much higher than expected based on earlier work $[12,14]$. In an effort to determine if the low throughput $(f / 10)$ Echelle spectrometer is the limiting factor an additional calibration curve was completed at $1 \times 10^{5} \mathrm{~Pa}$ at an optimal atmospheric pressure condition. Lawrence-Snyder et al. report with the use of a Chromex Czerny-Turner spectrometer coupled to an ICCD camera that for $\mathrm{Na}$ at $3.4 \times 10^{6} \mathrm{~Pa}$ using $\mathrm{E}_{1}=$ $7 \mathrm{~mJ}, \mathrm{E}_{2}=48 \mathrm{~mJ}$, and $\mathrm{t}_{d}=1 \mu \mathrm{s}$, the optimal interpulse delay time is between approximately 20 and $50 \mu \mathrm{s}$ [16]. In our work, first, we selected a low energy pulse $(20 \mathrm{~mJ})$ followed by a high energy pulse $(140 \mathrm{~mJ})$ and the optimal interpulse delay time between them was determined. This interpulse delay was then used to create a calibration curve. In the optimization study for high pressure, the interpulse timing was only carried out to $5 \mu \mathrm{s}$. The first peak intensity was measured at $1 \mu \mathrm{s}$, then at $5 \mu \mathrm{s}$, then at $5 \mu \mathrm{s}$ increments to a maximum of $170 \mu \mathrm{s}$. Figure 5-28 details the effect of interpulse timing on the intensity on the $588.995 \mathrm{~nm} \mathrm{Na}$ (I) peak. The intensity is fairly uniform from $10 \mu \mathrm{s}$ until $140 \mu \mathrm{s}$. After $140 \mu \mathrm{s}$, the intensity drops off. From this plot, it appears valid to select an interpulse delay time between 1 - 140 $\mu \mathrm{s}$; therefore, we select $70 \mu \mathrm{s}$ to construct a calibration curve. Comparing this time scale to that shown in Lawrence-Snyder et al. [16], this seems consistent due to our use of a significantly higher second energy pulse. Using the $70 \mu$ s interpulse delay time, a calibration curve was constructed and is shown in Figure 5-29. Although we have now used the optimal condition for $1 \times 10^{5} \mathrm{~Pa}$ with a long interpulse delay time, the detection limit is again only $50 \mathrm{ppm}$. This can also be verified by looking at the spectra (Figure 5-30). This suggests that the Echelle spectrometer is the limiting detection factor. 


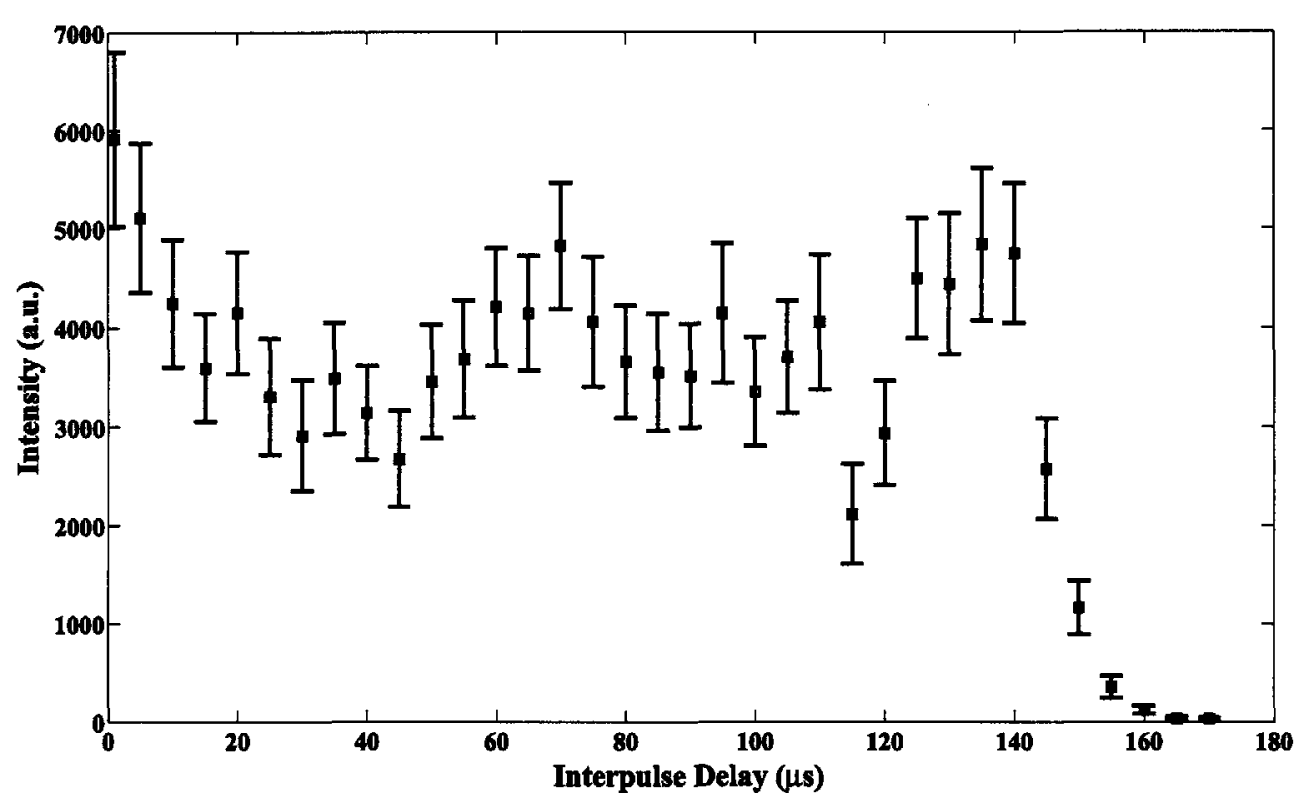

Figure 5-28: Effect of interpulse delay on intensity on the $588 \mathrm{~nm} \mathrm{Na}$ peak at $1 \times$ $10^{5} \mathrm{~Pa} .(1000 \mathrm{ppm})$

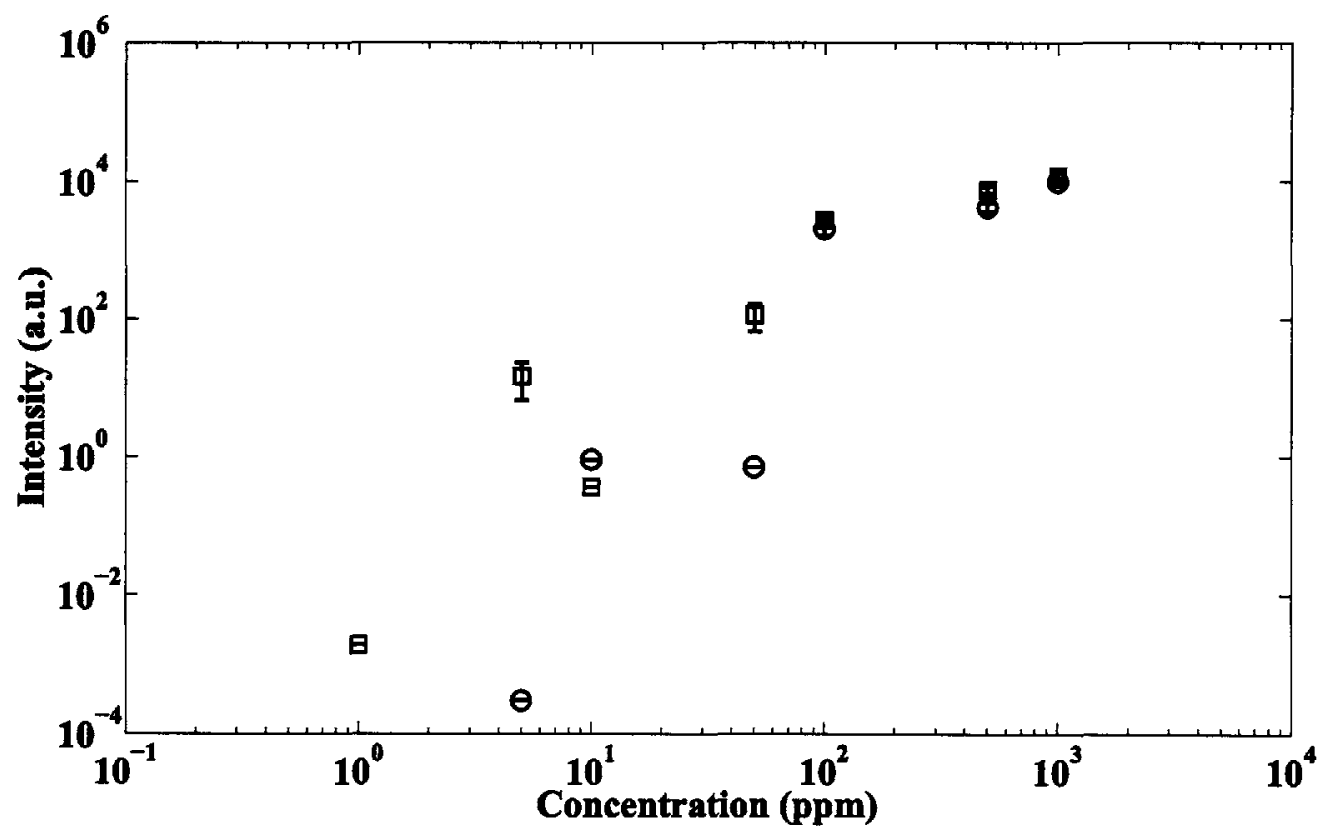

Figure 5-29: Na calibration curve at $1 \times 10^{5} \mathrm{~Pa}$ made using $\mathrm{E}_{1}=20 \mathrm{~mJ}, \mathrm{E}_{2}=140$ $\mathrm{mJ}$, and $\mathrm{t}_{d}=50 \mathrm{~ns} . \square=588 \mathrm{~nm}, \mathrm{O}=589 \mathrm{~nm}$ 


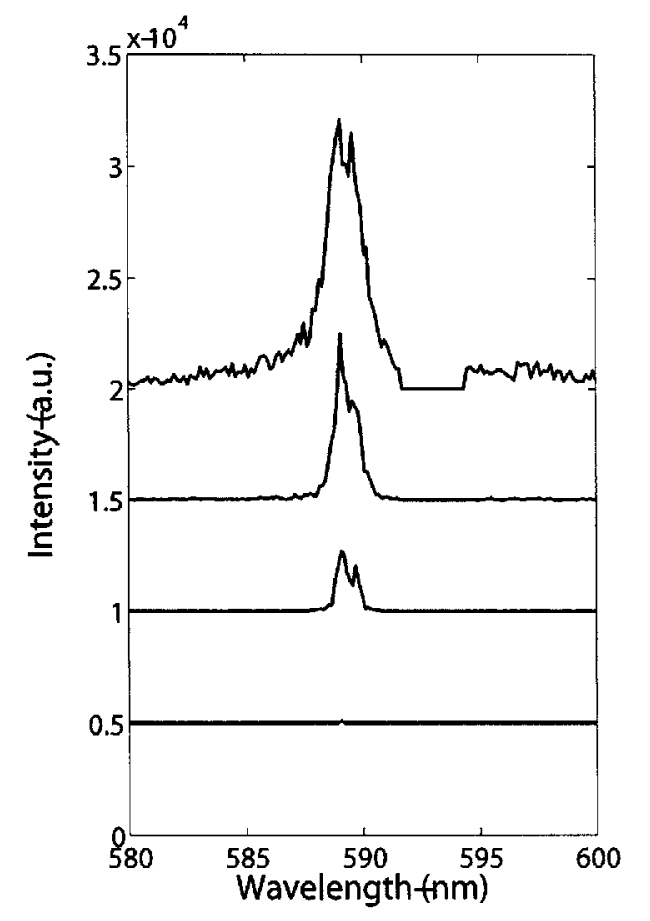

(a) Concentrations from bottom to top: $50 \mathrm{ppm}, 100 \mathrm{ppm}, 500 \mathrm{ppm}$, and 1000 ppm. For clarity, the spectra have been offset by 5000 a.u.

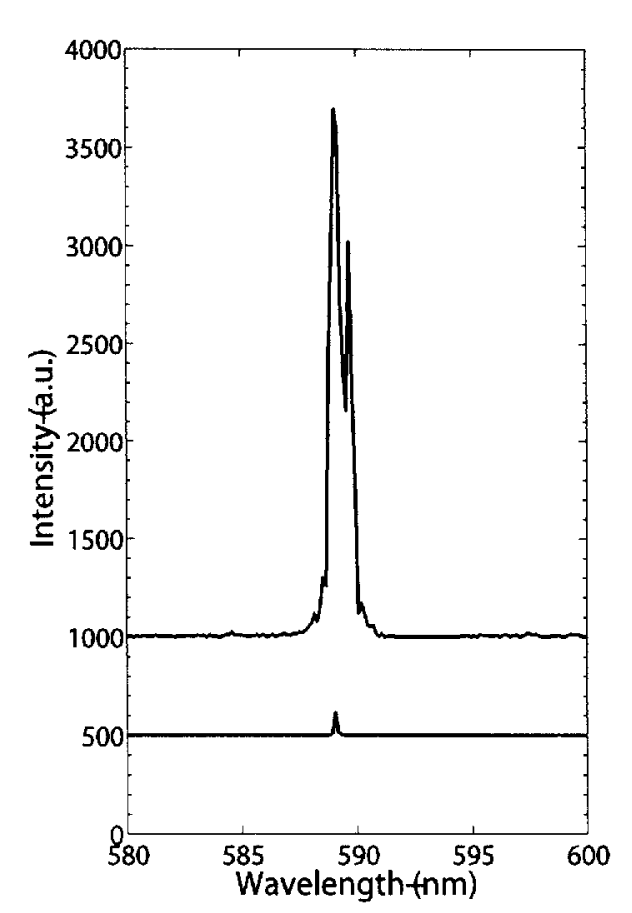

(b) Concentrations from bottom to top: $50 \mathrm{ppm}, 100 \mathrm{ppm}$. For clarity, the spectra have been offset by 500 a.u.

Figure 5-30: $\mathrm{Na}(\mathrm{I})$ spectra at $1 \times 10^{5} \mathrm{~Pa} .\left(\mathrm{E}_{1}=20 \mathrm{~mJ}, \mathrm{E}_{2}=140 \mathrm{~mJ}\right.$, and $\mathrm{t}_{d}=50$ ns) 


\subsection{Conclusions}

Double pulse LIBS was used to detect five analytes in bulk aqueous solutions important in hydrothermal vent chemistry at pressures up to $2.76 \times 10^{7} \mathrm{~Pa}$. The key double pulse parameters were optimized for each of the elements at three pressures $\left(1 \times 10^{5}\right.$ $\mathrm{Pa}, 1.38 \times 10^{7} \mathrm{~Pa}$, and $2.76 \times 10^{7} \mathrm{~Pa}$ ). The parameters needed for detection were found to be both element and pressure dependent. The use of the optimal parameters is essential because outside of this set of parameters, the elements may not be detectable. Potassium and sodium were detectable over a wide range of conditions. In general, for all elements, as pressure was increased, the use of a shorter interpulse delay was necessary and at $2.76 \times 10^{7} \mathrm{~Pa}$, an interpulse delay time on the order of 50 ns should be used. For all conditions studied, a short gate delay (usually $\leq 100$ ns) was required. This is similar to the results from single pulse LIBS (Chapter 4). The need for a short gate delay suggests that in bulk liquids, the plasma lifetime is short, possibly lasting only on the order of $500 \mathrm{~ns}$.

Using each of the optimally established conditions, calibration curves were made at three pressures $\left(1 \times 10^{5} \mathrm{~Pa}, 1.38 \times 10^{7} \mathrm{~Pa}\right.$, and $\left.2.76 \times 10^{7} \mathrm{~Pa}\right)$. From these, the limits of detection for the five analytes were found to be $5000 \mathrm{ppm} \mathrm{Mg}, 500 \mathrm{ppm} \mathrm{K}$, $500 \mathrm{ppm} \mathrm{Ca}, 1000 \mathrm{ppm} \mathrm{Mn}$, and $50 \mathrm{ppm} \mathrm{Na}$ using the current system set-up. The limits of detection were the same for all three pressures tested. The main reason that LIBS researchers choose to use double pulse LIBS instead of single pulse LIBS is to achieve improved sensitivity and improved signal. When optimization of conditions was completed using single pulse LIBS and then subsequently calibration curves were made using the same system set-up for the present work for $\mathrm{Mn}, \mathrm{Ca}$, and $\mathrm{Na}$ (Chapter 4), the resulting limits of detection were found to be $500 \mathrm{ppm} \mathrm{Mn}, 50 \mathrm{ppm} \mathrm{Ca}$, and $50 \mathrm{ppm} \mathrm{Na}$. This suggests that the use of double pulse LIBS in high pressure aqueous solutions may not be advantageous. Lawrence-Snyder et al. reported no emission enhancements using double pulse LIBS above $1 \times 10^{7} \mathrm{~Pa}$ [16]. DeGiacomo et al. emphasize the need for selecting an appropriate interpulse delay time for underwater LIBS [23]. DeGiacomo et al. stress the need to find the interpulse delay time that allows for the second pulse to form a plasma in a bubble that is maximally expanded. The high pressure environment of our experiments may cause the bubble to collapse too rapidly. As a result, the highest intensity peaks that are observed occur when two pulses are close together, similar to a single pulse. Lawrence-Snyder et al. [30] suggest that at higher solution pressures $\left(8 \times 10^{7} \mathrm{~Pa}\right)$, the bubble formed by the first laser pulse is confined by its surrounding pressure. As a result, the bubble never 
expands to the maximum volume that is observed at lower pressures. Therefore, the emission enhancements are not observed.

Although the use of double pulse LIBS proved less favorable than expected, it should be noted that one major contributing factor was the spectrometer used in these studies. The Echelle spectrometer has a very high resolution but a very low light throughput and poor sensitivity, with an $f$ number of 10 . In an effort to maximize the light throughput, it would be advisable to use a spectrometer with a smaller $f$ number. As an example, the use of a spectrometer with an $f$ number of 2 could improve the throughput by a factor of 25 and thus improve the limits of detection. Furthermore, the use of a PMT as the detector, may further improve detection limits for bulk liquids as demonstrated by Cremers et al. who measured at atmospheric pressure $\mathrm{Na}$ I $(589.00 \mathrm{~nm})$ at $0.014 \mathrm{ppm}, \mathrm{K} \mathrm{I}(766.49 \mathrm{~nm})$ at $1.2 \mathrm{ppm}, \mathrm{Mg}$ II $(279.55$ $\mathrm{nm})$ at $100 \mathrm{ppm}$, and Ca II (393.37 nm) at $0.8 \mathrm{ppm}$ [12]. Further work is needed to maximize the light collection by changing system components for bulk aqueous solution experiments.

\subsection{Acknowledgments}

We acknowledge the National Science Foundation for support of this research under grant OCE-0527927. Additional support was received from the Deep Ocean Exploration Institute and the Ocean Ventures Fund of the Woods Hole Oceanographic Institution. 


\section{Bibliography}

[1] R. S. Harmon, F. C. DeLucia, C. E. McManus, N. J. McMillan, T. F. Jenkins, M. E. Walsh, and A. Miziolek. Laser-induced breakdown spectroscopy - an emerging chemical sensor technology for real-time field-portable, geochemical, mineralogical, and environmental applications. Applied Geochemistry, 21(5):730747, May 2006.

[2] Z. A. Arp, D. A. Cremers, R. C. Wiens, D. M. Wayne, B. Sallé, and S. Maurice. Analysis of water ice and water ice/soil mixtures using laser-induced breakdown spectroscopy: Application to Mars polar exploration. Applied Spectroscopy, 58:897-909, 2004 .

[3] Z. A. Arp, D. A. Cremers, R. D. Harris, D. M. Oschwald, G. R. Parker Jr., and D. M. Wayne. Feasibility of generating a useful laser-induced breakdown spectroscopy plasma on rocks at high pressure: preliminary study for a Venus mission. Spectrochimica Acta Part B, 59:987-999, 2004.

[4] G. B. Courrèges-Lacoste, B. Ahlers, and F. R. Pérez. Combined Raman spectrometer/laser-induced breakdown spectrometer for the next ESA mission to Mars. Spectrochimica Acta Part A, In Press, 2007.

[5] R. Brennetot, J. L. Lacour, E. Vors, A. Rivoallan, D. Vailhen, and S. Maurice. Mars analysis by laser-induced breakdown spectroscopy (MALIS): Influence of Mars atmosphere on plasma emission and study of factors influencing plasma emission with the use of Doehlert designs. Applied Spectroscopy, 57(7):744-752, 2003.

[6] A. Knight, N. Scherbarth, D. Cremers, and M. Ferris. Characterization of laserinduced breakdown spectroscopy (LIBS) for application to space exploration. Applied Spectrosopy, 54:331-340, 2000.

[7] B. Sallé, J.-L. Lacour, P. Mauchien, P. Fichet, S. Maurice, and G. Manhes. Comparative study of different methodologies for quantitative rock analysis by laser-induced breakdown spectroscopy in a simulated Martian atmosphere. Spectrochimica Acta Part B, 61:301-313, 2006.

[8] C. R. German and K. L. Von Damm. Treatise on Geochemistry, chapter Hydrothermal Processes, pages 181-222. Elsevier, 2003.

[9] J. H. Trefry, D. B. Butterfield, S. Metz, G. J. Massoth, R. P. Trocine, and R. A. Feely. Trace metals in hydrothermal solutions from Cleft segment on the southern Juan de Fuca Ridge. Journal of Geophysical Research, 99:4925-4935, 1994.

[10] K. L. Von Damm. Controls on the chemisty and temporal variability of seafloor hydrothermal fluids. Seafloor hydrothermal systems: physical, chemical, biological, and geological interactions: Geophysical Monograph 91, pages 222-247, 1995. 
[11] K. L. Von Damm. Chemistry of hydrothermal vent fluids from $9^{\circ}-10^{\circ} \mathrm{N}$, East Pacific Rise: 'Time zero,' The immediate posteruptive period. Journal of Geophysical Research, 105:11203-11222, 2000.

[12] D. A. Cremers, L. J. Radziemski, and T. R. Loree. Spectrochemical analysis of liquids using the laser spark. Applied Spectroscopy, 38:721-729, 1984.

[13] R. Knopp, F. J. Scherbaum, and J. I. Kim. Laser induced breakdown spectroscopy (LIBS) as an analytical tool for the detection of metal ions in aqueous solutions. Fresenius' Journal of Analytical Chemistry, 355:16-20, 1996.

[14] W. Pearman, J. Scaffidi, and S. M. Angel. Dual-pulse laser-induced breakdown spectroscopy in bulk aqueous solution with an orthogonal beam geometry. $A p$ plied Optics, 42:6085-6093, 2003.

[15] A. P. M. Michel, M. Lawrence-Snyder, S. M. Angel, and A. D. Chave. Laserinduced breakdown spectroscopy of bulk aqueous solutions at oceanic pressures: evaluation of key measurement parameters. Applied Optics, 46, 2007.

[16] M. Lawrence-Snyder, J. Scaffidi, S. M. Angel, A. P.M. Michel, and A. D. Chave. Sequential-pulse laser-induced breakdown spectroscopy of high-pressure bulk aqueous solutions. Applied Spectroscopy, 61:171-176, 2007.

[17] M. Lawrence-Snyder, J. Scaffidi, S. M. Angel, A. P. M. Michel, and A. D. Chave. Laser-induced breakdown spectroscopy of high-pressure bulk aqueous solutions. Applied Spectroscopy, 60:786-790, 2006.

[18] A. De Giacomo, M. Dell'Aglio, F. Colao, R. Fantoni, and V. Lazic. Double-pulse LIBS in bulk water and on submerged bronze samples. Applied Surface Science, 247:157-162, 2005.

[19] A. E. Pichahchy, D. A. Cremers, and M. J. Ferris. Elemental analysis of metals under water using laser-induced breakdown spectroscopy. Spectrochimica Acta Part B, 52:25-39, 1997.

[20] C. Haisch, J. Liermann, U. Panne, and R. Niessner. Characterization of colloidal particles by laser-induced plasma spectroscopy (LIPS). Analytica Chimica Acta, 346:23-25, 1997.

[21] P. K. Kennedy, D. X. Hammer, and B. A. Rockwell. Laser-induced breakdown in aqueous media. Progress in Quantum Electronics, 21:155-248, 1997.

[22] A. De Giacomo, M. Dell'Aglio, and O. De Pascale. Single pulse-laser induced breakdown spectroscopy in aqueous solution. Applied Physics A: Materials Science $\&$ Processing, V79(4):1035-1038, September 2004.

[23] A. De Giacomo, M. Dell'Aglio, O. De Pascale, and M. Capitelli. From single pulse to double pulse ns-laser induced breakdown spectroscopy under water: elemental analysis of aqueous solutions and submerged solid samples. Spectrochimica Acta Part B, in press, 2007. 
[24] A. Casavola, A. De Giacomo, M. Dell'Aglio, F. Taccogna, G. Colonna, O. De Pascale, and S. Longo. Experimental investigation and modelling of double pulse laser induced plasma spectroscopy under water. Spectrochimica Acta Part B, 2005.

[25] A. De Giacomo, M. Dell'Aglio, F. Colao, and R. Fantoni. Double pulse laser produced plasma on metallic target in seawater: basic aspects and analytical approach. Spectrochimica Acta B, 59:1431-1438, 2004.

[26] S. Koch, R. Court, W. Garen, W. Neu, and R. Reuter. Detection of manganese in solution in cavitation bubbles using laser induced breakdown spectroscopy. Spectrochimica Acta Part B, 60(7-8):1230-1235, 2005.

[27] V. Lazic, F. Colao, R. Fantoni, and V. Spizzicchino. Laser-induced breakdown spectroscopy in water: Improvement of the detection threshold by signal processing. Spectrochimica Acta Part B, 60:1002-1013, 2005.

[28] R. Noll. Terms and notations for laser-induced breakdown spectroscopy. Analytical and Bioanalytical Chemistry, V385(2):214-218, 2006.

[29] A. P. M. Michel and A. D. Chave. Analysis of laser-induced breakdown spectroscopy (LIBS) spectra: The case for extreme value statistics. Spectrochimica Acta Part B, In Press.

[30] M. Lawrence-Snyder, J. P. Scaffidi, W. F. Pearman, and S. M. Angel. Dependence of emission intensity on bubble dynamics in dual-pulse laser-induced breakdown spectroscopy of high-pressure bulk aqueous solutions. Applied Spectroscopy, submitted. 


\section{Chapter 6}

\section{Preliminary investigations on matrix effects of $\mathrm{Na}, \mathrm{K}$, and $\mathrm{Ca}$ for bulk liquids at oceanic pressures}

\subsection{Abstract}

Chemical matrix effects occur when one element present in a sample affects the emission of another element also present in the sample. In this study, the effect of $\mathrm{NaCl}$ on the detection of $\mathrm{K}$ and $\mathrm{Ca}$ in bulk aqueous solutions at pressures up to $2.76 \times$ $10^{7} \mathrm{~Pa}$ is explored. In addition, the effect of the background matrix (chloride versus sulfate) on the detection of $\mathrm{Na}$ and $\mathrm{K}$ is examined. While the investigations into the effect of $\mathrm{NaCl}$ on $\mathrm{K}$ and $\mathrm{Ca}$ proved inconclusive, the background matrix has no effect on the ability to detect $\mathrm{Na}$ or $\mathrm{K}$.

\subsection{Introduction}

When multiple elements are present in a sample, chemical matrix effects can occur in which the presence of one element affects the emission of another element. Changing the concentration of one element can affect the signal intensity of one or more other elements even when the concentrations of those elements are not altered. This can adversely affect the ability to make quantitative measurements and lead to complications in calibration. However, if matrix effects can be understood, then the concentration effect can be quantified [1].

In a plasma, the addition of an easily ionizable element can shift the neutral-ion 
equilibrium concentration of an analyte toward the neutral species (Le Chatelier's principle). For example, addition of an easily ionizable species to a plasma can reduce the emission of an ionized species. The easily ionized species increases the electron density which decreases the concentration of the ionized species [1]. Cremers et al. [2] reported a matrix effect in bulk liquids which showed that the intensity ratio of $\mathrm{Ca}$ II/Ca I decreased with the addition of $\mathrm{NaCl}$. A similar effect was reported by Michel et al. [3] (Chapter 2) using double pulse LIBS over a range of pressures. Michel et al. also reported no effect on $\mathrm{K}$ or $\mathrm{Mn}$ emission intensity with the addition of $\mathrm{NaCl}$.

Several other matrix effects have been reported. For example, Charfi and Harith [4] showed that when $\mathrm{Mg}$ and $\mathrm{Na}$ were measured in pure solution versus in mixed solutions (both $\mathrm{Mg}$ and $\mathrm{Na}$ present), the limits of detection were lower for the pure solutions. Eppler et al. [5] investigated matrix effects of $\mathrm{Ba}$ and $\mathrm{Pb}$ in sand and soil, and saw that $\mathrm{Ba}$ (II) and $\mathrm{Pb}$ (I) emission was dependent on analyte speciation. As samples were varied from a pure sand to a pure soil composition, the $\mathrm{Ba}$ (II)/C (I) signal decreased. The decrease correlated with an increase in electron density, possibly due to a change in ionized species.

Matrix effects can be corrected by applying calibration curves for each element contained in the substrate of interest, analogous to estimating the partial derivatives for a multivariate process, as opposed to that for a single one as in most calibration curves. This requires many reference samples and is very time consuming. In addition, it is not feasible for in situ measurements with unknown, mixed component samples [6]. Several research groups have developed methods to compensate for matrix effects. St-Onge et al. have used an internal standardization method to reduce matrix effects [7]. Barrette and Turmel showed that matrix effects could be partially overcome by the use of a multivariable calibration curve [8]. Ciucci et al. developed an algorithmbased procedure for calibration-free quantitative elemental analysis of materials [9].

Understanding matrix effects is essential for quantitative LIBS. In this preliminary investigation, matrix effects of three elements $(\mathrm{Na}, \mathrm{K}$, and $\mathrm{Ca}$ ), are explored in bulk aqueous solutions at pressures up to $2.76 \times 10^{7} \mathrm{~Pa}$. In addition, the effect of a background matrix (chloride versus sulfate) on the detection of $\mathrm{Na}$ and $\mathrm{K}$ is examined.

\subsection{Experimental}

The laboratory set-up for simulating the use of LIBS in the deep ocean has been previously described in Chapter 4. For all experiments described here, single pulse LIBS experiments were run with the laser pulse energy kept constant at $40 \mathrm{~mJ}$ (which 
corresponds to an irradiance of the beam at the beam waist of $\approx 5.25 \times 10^{12} \mathrm{~W} / \mathrm{cm}^{2}$ for this system). For all experiments, $t_{d}=50 \mathrm{~ns}$, and $t_{b}=200 \mathrm{~ns}$ and the Echelle spectrometer amplification was set to the maximum value of 4000. All spectra taken were composed of 100 accumulated shots. All raw spectral data were processed using generalized extreme value distribution statistics detailed in a paper by Michel and Chave [10] after binning the data over 20 wavelengths. Where shown, error bars represent $95 \%$ confidence intervals of the GEVD.

Solutions were made from $\mathrm{NaCl}, \mathrm{KCl}, \mathrm{NaSO}_{4} \cdot \mathrm{H}_{2} \mathrm{O}, \mathrm{MnSO}_{4} \cdot \mathrm{H}_{2} \mathrm{O}$, and $\mathrm{CaCl}_{2} \cdot 2 \mathrm{H}_{2} \mathrm{O}$ dissolved in de-ionized water. All concentrations are given in parts per million (ppm, wt./vol.). All experiments were completed at three pressures, $1 \times 10^{5} \mathrm{~Pa}, 1.38 \times 10^{7}$ $\mathrm{Pa}$, and $2.76 \times 10^{7} \mathrm{~Pa}$.

\subsection{Results and Discussion}

\subsubsection{Matrix Effects of $\mathrm{K}$ and $\mathrm{Na}$}

\section{Effect of Sodium Chloride on the Emission from Potassium}

Four different conditions (Table 6.1) were used to study the effect of $\mathrm{NaCl}$ on the emission intensity of the $769.9 \mathrm{~nm} \mathrm{~K}$ peak. 120 spectra were taken at each of Conditions 1 and 3 to establish a low and high calibration point for $\mathrm{K}$ alone. Three replicate measurements each consisting of 60 spectra were taken at Conditions 2 and 4 to assess the effect of $\mathrm{NaCl}$ on $\mathrm{K}$. Figure 6-1 shows the results. When $\mathrm{NaCl}$ was added to low concentration (102 ppm) K, no peak intensity change was seen at all three pressures. In contrast, in high concentration $(1022 \mathrm{ppm}) \mathrm{K}$, when $\mathrm{NaCl}$ was added, the $\mathrm{K}$ peak intensity decreased at all three pressures. This is in contrast to prior work [3] (Chapter 2) where no effect of $\mathrm{NaCl}$ was seen on the peak intensity of $\mathrm{K}$.

Table 6.1: Conditions used to study the K-Na matrix effect

\begin{tabular}{|c|c|c|c|}
\hline Condition & $\mathrm{K}$ & $\mathrm{Cl}$ & $\mathrm{Na}$ \\
\hline 1 & $102 \mathrm{ppm}$ & $93 \mathrm{ppm}$ & $0 \mathrm{ppm}$ \\
\hline 2 & $102 \mathrm{ppm}$ & $4959 \mathrm{ppm}$ & $3155 \mathrm{ppm}$ \\
\hline 3 & $1022 \mathrm{ppm}$ & $927 \mathrm{ppm}$ & $0 \mathrm{ppm}$ \\
\hline 4 & $1022 \mathrm{ppm}$ & $4959 \mathrm{ppm}$ & $2614 \mathrm{ppm}$ \\
\hline
\end{tabular}




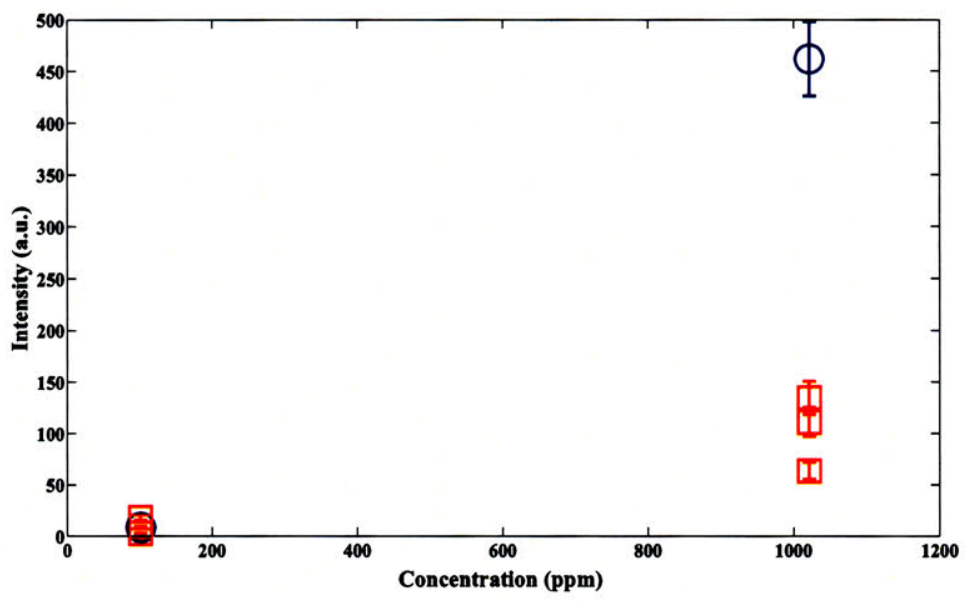

(a) $1 \times 10^{5} \mathrm{~Pa}$

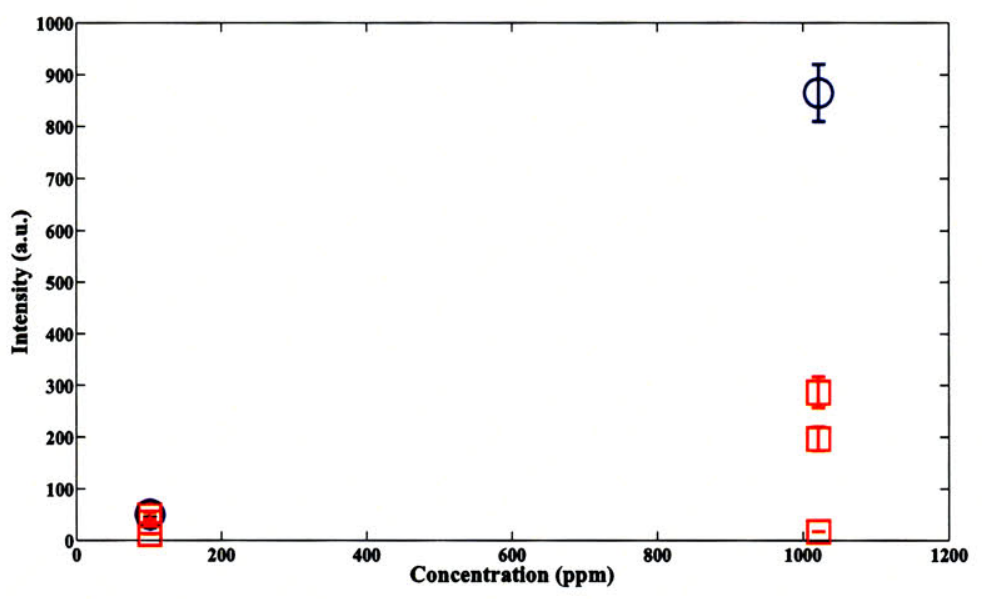

(b) $1.38 \times 10^{7} \mathrm{~Pa}$

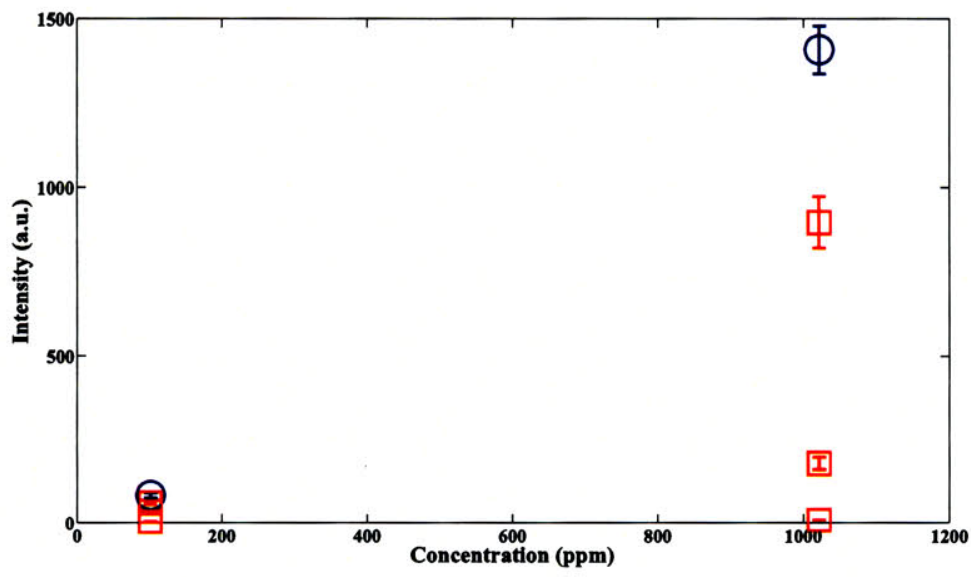

(c) $2.76 \times 10^{7} \mathrm{~Pa}$

Figure 6-1: Effect of presence of $\mathrm{Na}$ on peak intensity of $\mathrm{K}(769.9 \mathrm{~nm})$ for two concentrations of $\mathrm{K} . \mathrm{O}=\mathrm{K}, \square=\mathrm{K}+\mathrm{NaCl}$ 


\section{Effect of Potassium Chloride on Emission from Sodium}

Four different conditions (Table 6.2) were used to study the effect of $\mathrm{KCl}$ on the detection of the $588 \mathrm{~nm}$ Na peak. 120 spectra were taken of $\mathrm{Na}$ at Conditions 1 and 3 to create low and high concentration calibration points for $\mathrm{Na}$ alone. Three replicate measurements each consisting of 60 spectra were taken at Conditions 2 and 4 to assess the effect of $\mathrm{KCl}$ on Na. The results are shown in Figure 6-2. The high variability from low to high pressure without any discernible trend suggests that more laboratory work is needed to determine if a matrix effect exists.

Table 6.2: Conditions used to study the Na-K matrix effect

\begin{tabular}{|c|c|c|c|}
\hline Condition & $\mathrm{K}$ & $\mathrm{Cl}$ & $\mathrm{Na}$ \\
\hline 1 & $0 \mathrm{ppm}$ & $4865 \mathrm{ppm}$ & $3155 \mathrm{ppm}$ \\
\hline 2 & $102 \mathrm{ppm}$ & $4959 \mathrm{ppm}$ & $3155 \mathrm{ppm}$ \\
\hline 3 & $0 \mathrm{ppm}$ & $4032 \mathrm{ppm}$ & $2614 \mathrm{ppm}$ \\
\hline 4 & $1022 \mathrm{ppm}$ & $4959 \mathrm{ppm}$ & $2614 \mathrm{ppm}$ \\
\hline
\end{tabular}




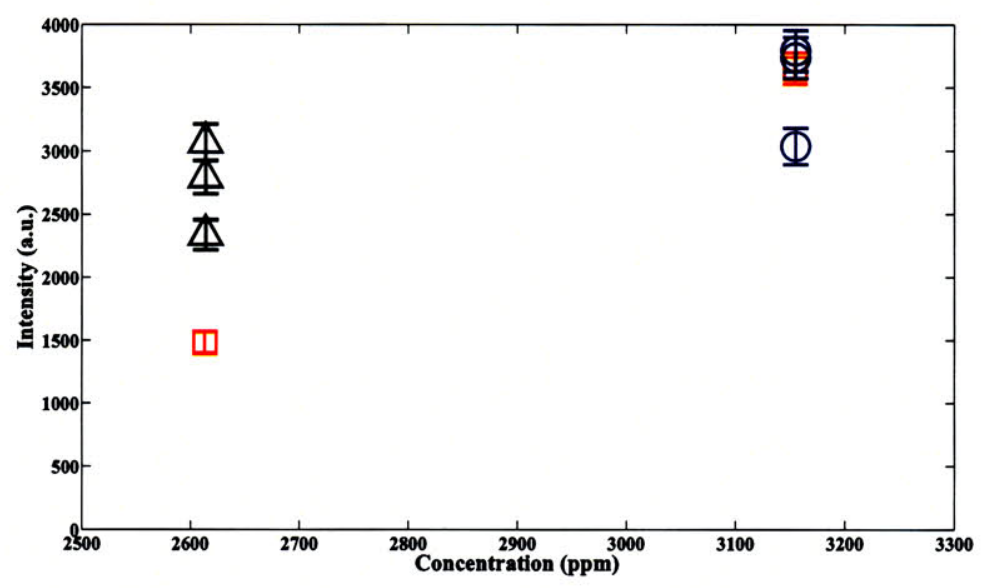

(a) $1 \times 10^{5} \mathrm{~Pa}$

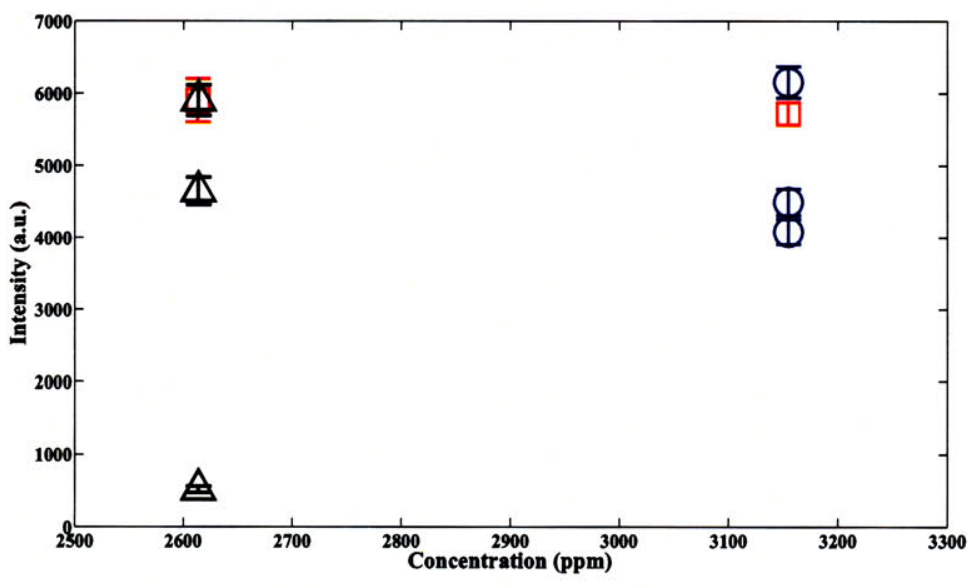

(b) $1.38 \times 10^{7} \mathrm{~Pa}$

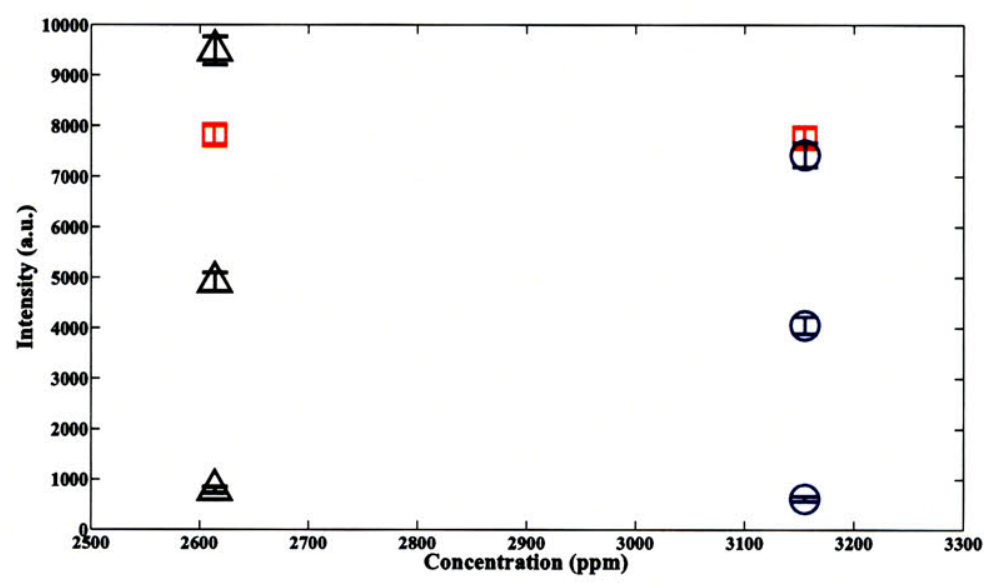

(c) $2.76 \times 10^{7} \mathrm{~Pa}$

Figure 6-2: Effect of presence of $\mathrm{K}$ on peak intensity of $\mathrm{Na}(588 \mathrm{~nm}) . \square=\mathrm{Na}, \bigcirc=$ $\mathrm{Na}+102 \mathrm{ppm} \mathrm{K}, \triangle=\mathrm{Na}+1022 \mathrm{ppm} \mathrm{K}$ 


\subsubsection{Matrix Effects of $\mathrm{Ca}$ and $\mathrm{Na}$}

\section{Effect of Sodium Chloride on Emission from Calcium}

Four different conditions (Table 6.3) were used study the effect of $\mathrm{NaCl}$ on the emission intensity of $\mathrm{Ca}$ [393 Ca (II) and $422 \mathrm{~nm} \mathrm{Ca} \mathrm{(I)].} 120$ spectra were taken at Conditions 1 and 3 to establish low and high concentration calibration points for $\mathrm{Ca}$ alone. Three replicate measurements each consisting of 60 spectra were taken at Conditions 2 and 4 to assess the effect of $\mathrm{NaCl}$ on the $393 \mathrm{~nm} \mathrm{Ca}$ (II) ionic peak and the $422 \mathrm{~nm}$ (I) atomic peak. Figure 6-3 shows the effect of $\mathrm{NaCl}$ on the $393 \mathrm{~nm} \mathrm{Ca}$ (II) ionic peak. For $106 \mathrm{ppm} \mathrm{Ca}$, the peak intensity was not measurable at any pressure, both in the presence and absence of $\mathrm{NaCl}$. When $\mathrm{NaCl}$ is added to a $1055 \mathrm{ppm} \mathrm{Ca}$ solution, the emission intensity is significantly lower. It should be noted that at $1 \times 10^{5} \mathrm{~Pa}$ and $1.38 \times 10^{7} \mathrm{~Pa}$, the measured intensity under all conditions is relatively low. Figure 6-4 shows the results for the effect of $\mathrm{NaCl}$ on the $422 \mathrm{~nm} \mathrm{Ca}$ (I) atomic peak. The results are inconclusive. To assess possible drift in the spectrometer between the pure $\mathrm{Ca}$ data and the $\mathrm{Ca}$ plus $\mathrm{NaCl}$ data, the ratio of the intensity of the $393 \mathrm{~nm}$ peak to the $422 \mathrm{~nm}$ peak is plotted in Figure 6-5. The result suggests that the variability is not due to simple drift, but to another cause of systematic error.

Table 6.3: Conditions used to study the Ca-Na Matrix Effect

\begin{tabular}{|c|c|c|c|}
\hline Condition & $\mathrm{Ca}$ & $\mathrm{Cl}$ & $\mathrm{Na}$ \\
\hline 1 & $106 \mathrm{ppm}$ & $187 \mathrm{ppm}$ & $0 \mathrm{ppm}$ \\
\hline 2 & $106 \mathrm{ppm}$ & $4959 \mathrm{ppm}$ & $3094 \mathrm{ppm}$ \\
\hline 3 & $1055 \mathrm{ppm}$ & $1867 \mathrm{ppm}$ & $0 \mathrm{ppm}$ \\
\hline 4 & $1055 \mathrm{ppm}$ & $4959 \mathrm{ppm}$ & $2005 \mathrm{ppm}$ \\
\hline
\end{tabular}




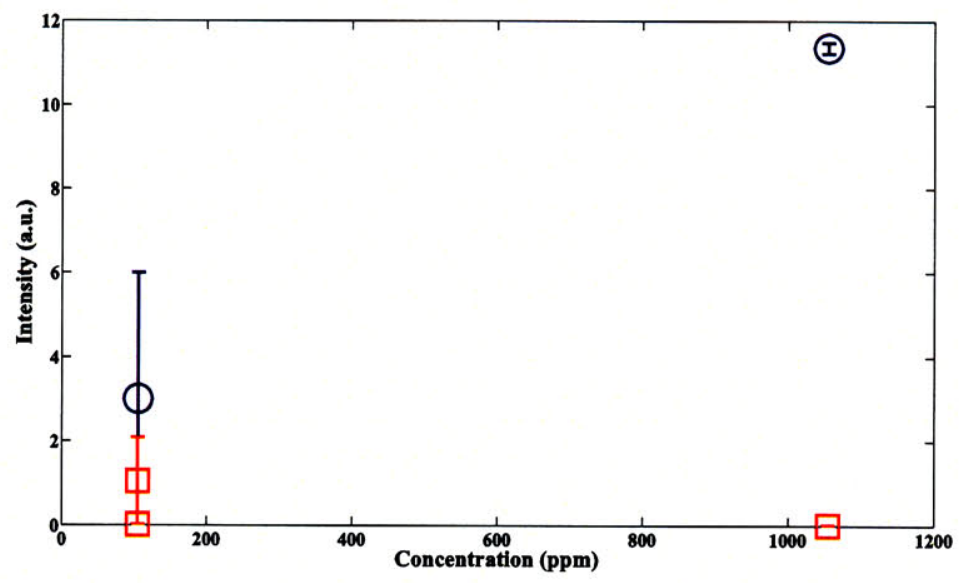

(a) $1 \times 10^{5} \mathrm{~Pa}$

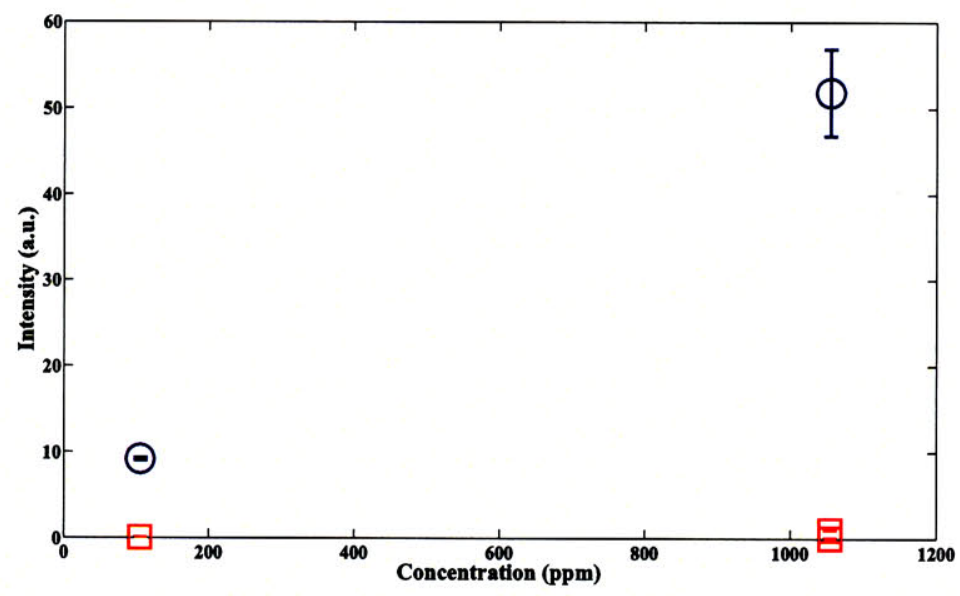

(b) $1.38 \times 10^{7} \mathrm{~Pa}$

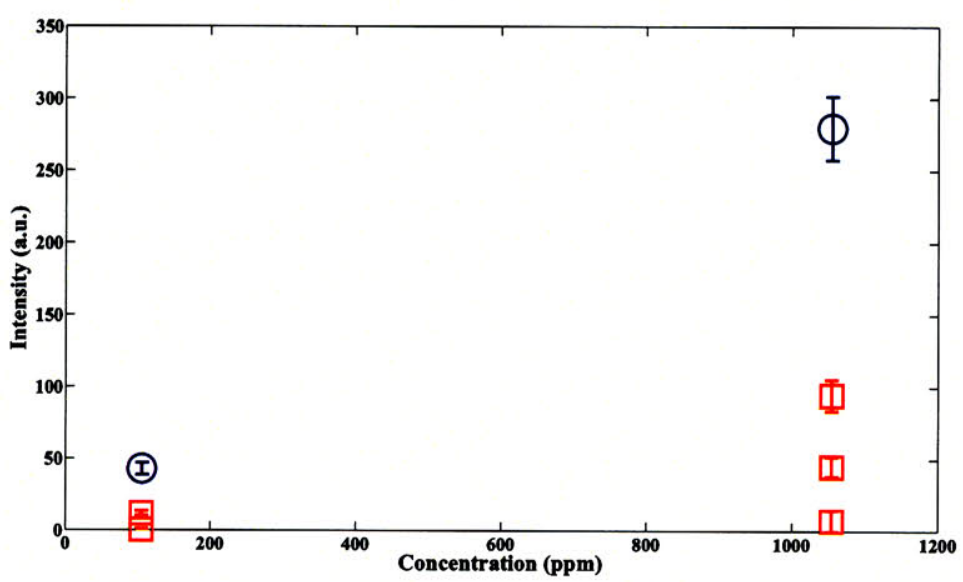

(c) $2.76 \times 10^{7} \mathrm{~Pa}$

Figure 6-3: Effect of presence of $\mathrm{Na}$ on peak intensity of $\mathrm{Ca}$ (II) (393 nm) for two concentrations of $\mathrm{Ca} . \mathrm{O}=\mathrm{Ca}, \square=\mathrm{Ca}+\mathrm{NaCl}$ 


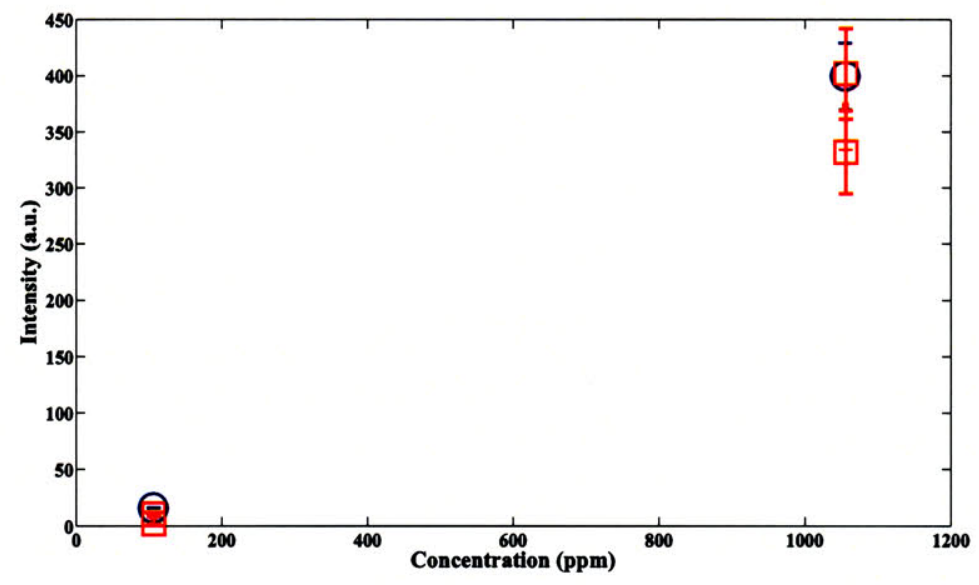

(a) $1 \times 10^{5} \mathrm{~Pa}$

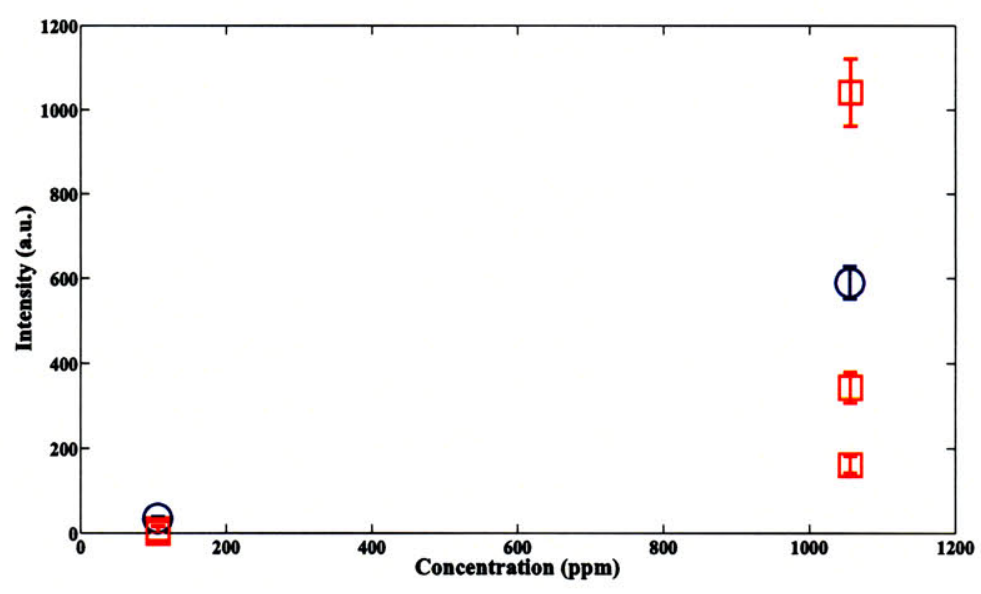

(b) $1.38 \times 10^{7} \mathrm{~Pa}$

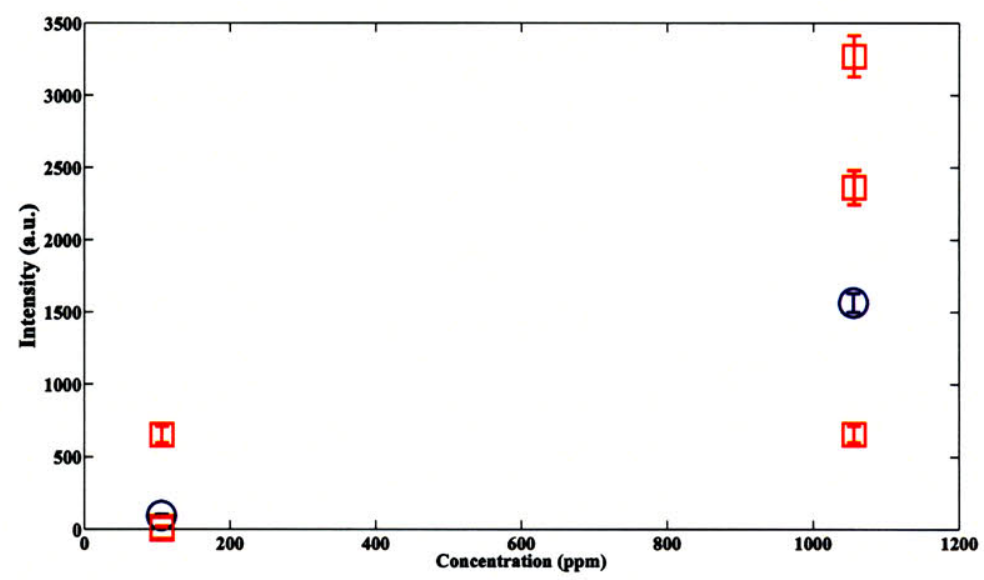

(c) $2.76 \times 10^{7} \mathrm{~Pa}$

Figure 6-4: Effect of presence of $\mathrm{Na}$ on peak intensity on $\mathrm{Ca}$ (I) (422 nm) for two concentrations of $\mathrm{Ca} . \mathrm{O}=\mathrm{Ca}, \square=\mathrm{Ca}+\mathrm{NaCl}$ 


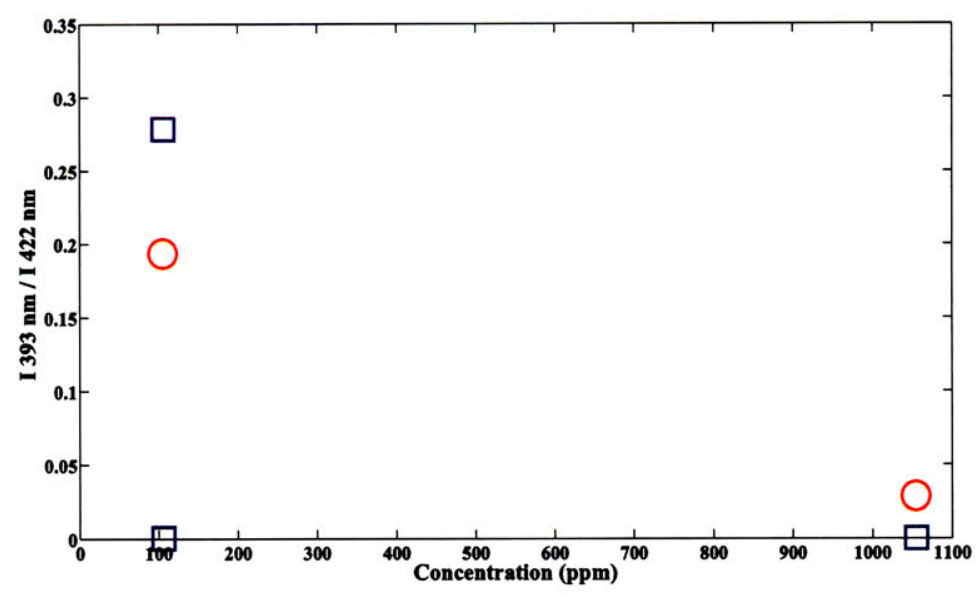

(a) $1 \times 10^{5} \mathrm{~Pa}$

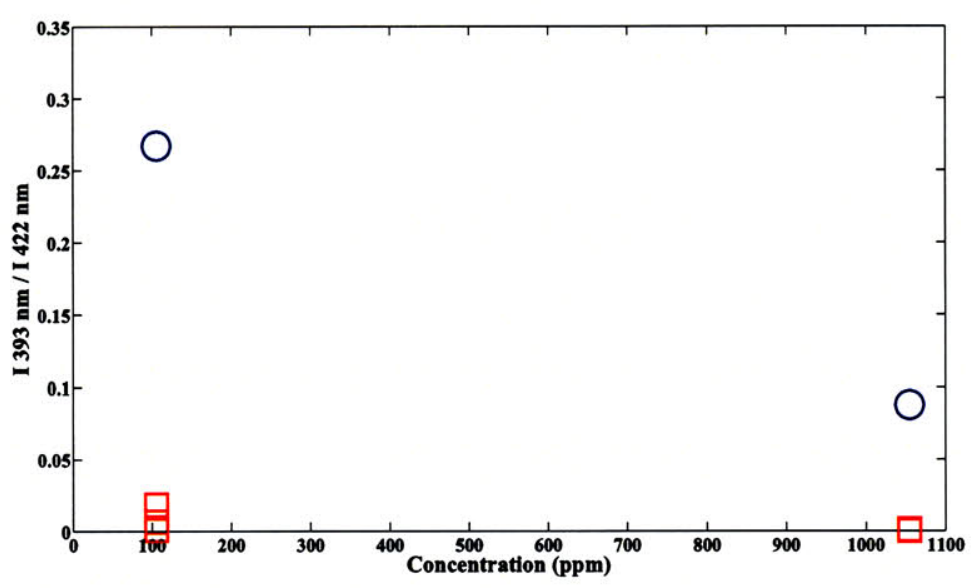

(b) $1.38 \times 10^{7} \mathrm{~Pa}$

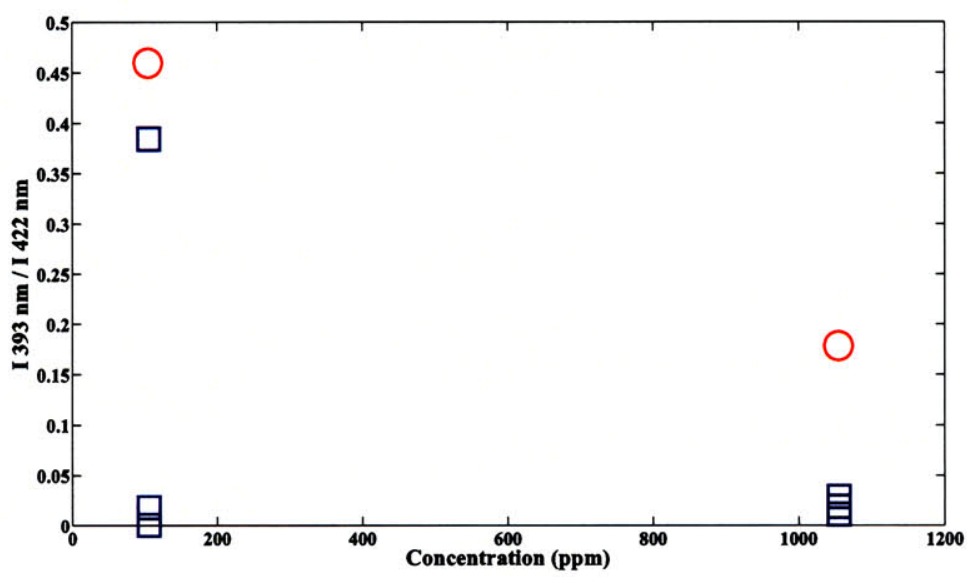

(c) $2.76 \times 10^{7} \mathrm{~Pa}$

Figure 6-5: Ratio of $393 \mathrm{~nm} \mathrm{Ca}$ (II) peak to $422 \mathrm{~nm} \mathrm{Ca}$ (I) peak $\bigcirc=\mathrm{Ca}, \square=\mathrm{Ca}$ $+\mathrm{NaCl}$ 


\section{Effect of Calcium Chloride on the Emission of Sodium}

A sodium calibration curve was made with 120 spectra taken at three concentrations (Conditions $1-3$ shown in Table 6.4). Three replicates of 60 spectra were taken at two concentrations of $\mathrm{Ca}$ plus $\mathrm{NaCl}$. The data shown in Figure 6-6 reveal high variability in the LIBS system measurements. In general, when Ca was present, the $\mathrm{Na}$ peak intensity was reduced. However, the systematic error denoted by the scatter in the data suggests that more data collection is needed to confirm the result.

Table 6.4: Conditions used to study the effect of $\mathrm{CaCl}_{2} \cdot 2 \mathrm{H}_{2} \mathrm{O}$ on emission of $\mathrm{Na}$

\begin{tabular}{|c|c|c|c|}
\hline Condition & $\mathrm{Ca}$ & $\mathrm{Cl}$ & $\mathrm{Na}$ \\
\hline 1 & $0 \mathrm{ppm}$ & $3091 \mathrm{ppm}$ & $2005 \mathrm{ppm}$ \\
\hline 2 & $0 \mathrm{ppm}$ & $4032 \mathrm{ppm}$ & $2614 \mathrm{ppm}$ \\
\hline 3 & $0 \mathrm{ppm}$ & $4865 \mathrm{ppm}$ & $3155 \mathrm{ppm}$ \\
\hline 4 & $1055 \mathrm{ppm}$ & $4959 \mathrm{ppm}$ & $2005 \mathrm{ppm}$ \\
\hline 5 & $106 \mathrm{ppm}$ & $4959 \mathrm{ppm}$ & $3094 \mathrm{ppm}$ \\
\hline
\end{tabular}




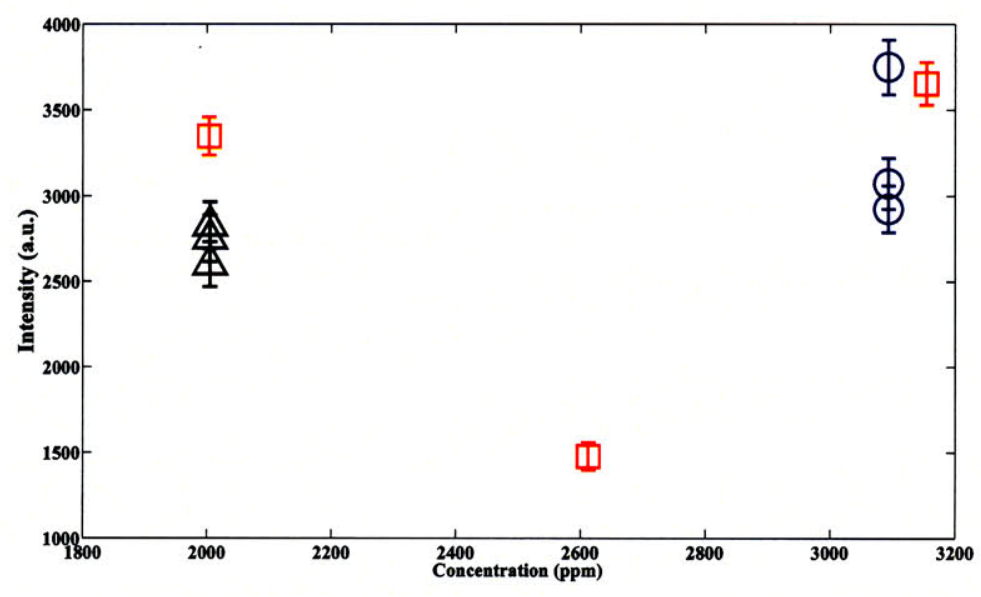

(a) $1 \times 10^{5} \mathrm{~Pa}$

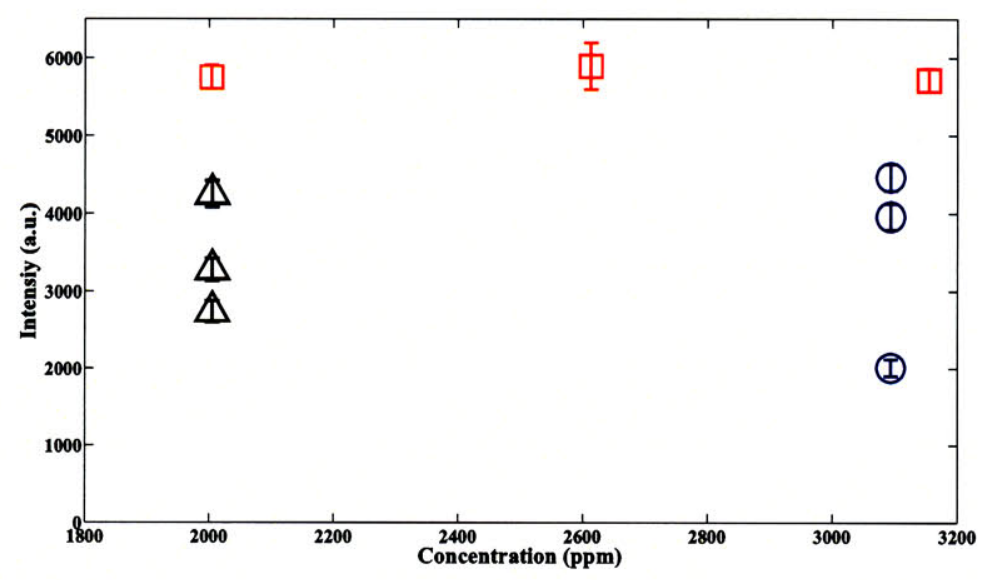

(b) $1.38 \times 10^{7} \mathrm{~Pa}$

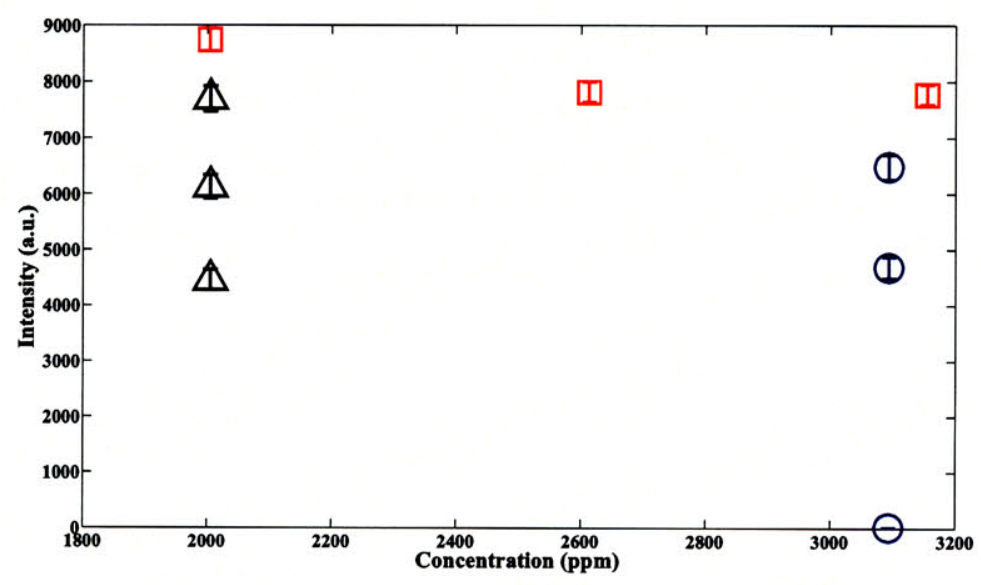

(c) $2.76 \times 10^{7} \mathrm{~Pa}$

Figure 6-6: Effect of presence of $\mathrm{Ca}$ on peak intensity on $\mathrm{Na}(588 \mathrm{~nm}), \square=\mathrm{Na}, \triangle$ $=\mathrm{Na}+1055 \mathrm{ppm} \mathrm{Ca}, \bigcirc=106 \mathrm{ppm} \mathrm{Ca}+\mathrm{Na}$ 


\subsubsection{Detection of $\mathrm{Na}$ and $\mathrm{K}$ in a Chloride Versus Sulfate Matrix}

Two experiments were carried out to determine if the presence of a chloride or sulfate substrate affects the detection of an element. The intensity of potassium (1002 ppm $\mathrm{K}$ ) in two matrices, $\mathrm{KCl}$ and $\mathrm{K}_{2} \mathrm{SO}_{4}$, and the intensity of sodium (2356 ppm Na), in two matrices, $\mathrm{NaCl}$ and $\mathrm{NaSO}_{4}$, were measured. Figures 6-7 and 6-8 contrast the ability to detect $\mathrm{K}$ and $\mathrm{Na}$, respectively, in a chloride matrix versus a sulfate matrix. For K, no matrix effect is seen at any of the pressures $\left(1 \times 10^{5} \mathrm{~Pa}, 1.38 \times 10^{7} \mathrm{~Pa}\right.$, $2.76 \times 10^{7} \mathrm{~Pa}$ ) tested. For $\mathrm{Na}$ (Figure 6-8), there is a possible matrix effect, although additional experiments are necessary to determine this due to scatter in the data. In the development of an oceanic LIBS sensor operable in the vent environment, the sensors must be capable of detecting both $\mathrm{K}$ and $\mathrm{Na}$ in the presence of both sulfate and chloride, which these data support.

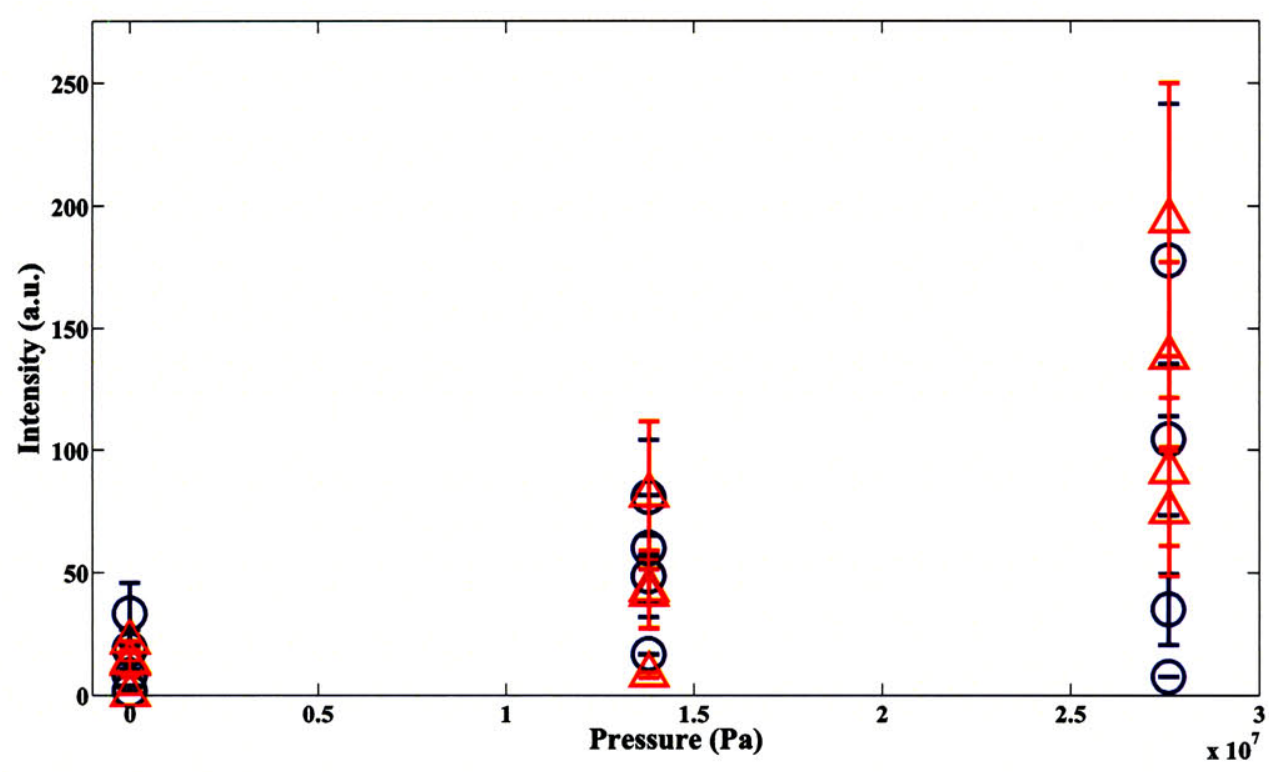

(a)

Figure 6-7: Detection of $769 \mathrm{~nm}$ potassium (1002 ppm) in a chloride versus sulfate matrix. $\bigcirc=\mathrm{KCl}, \triangle=\mathrm{K}_{2} \mathrm{SO}_{4}$ 


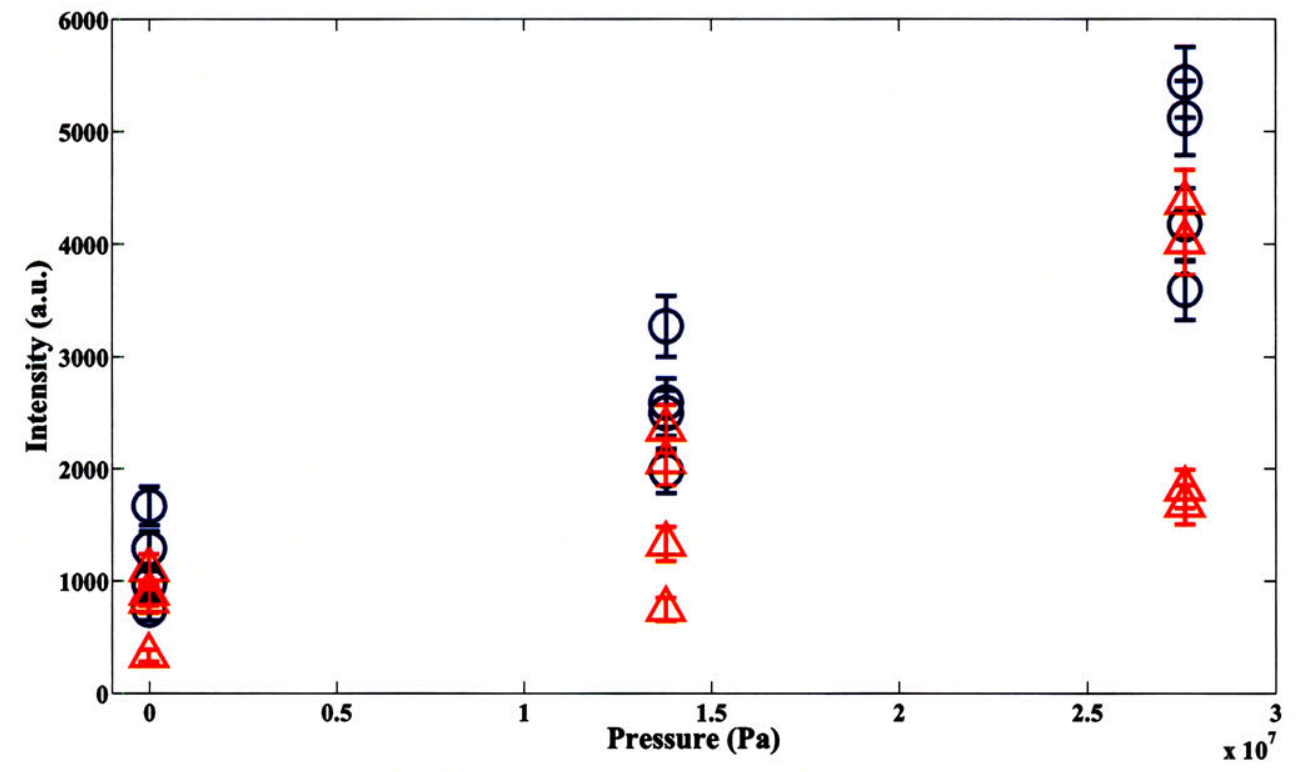

(a) $588 \mathrm{~nm} \mathrm{Na} \mathrm{Peak}$

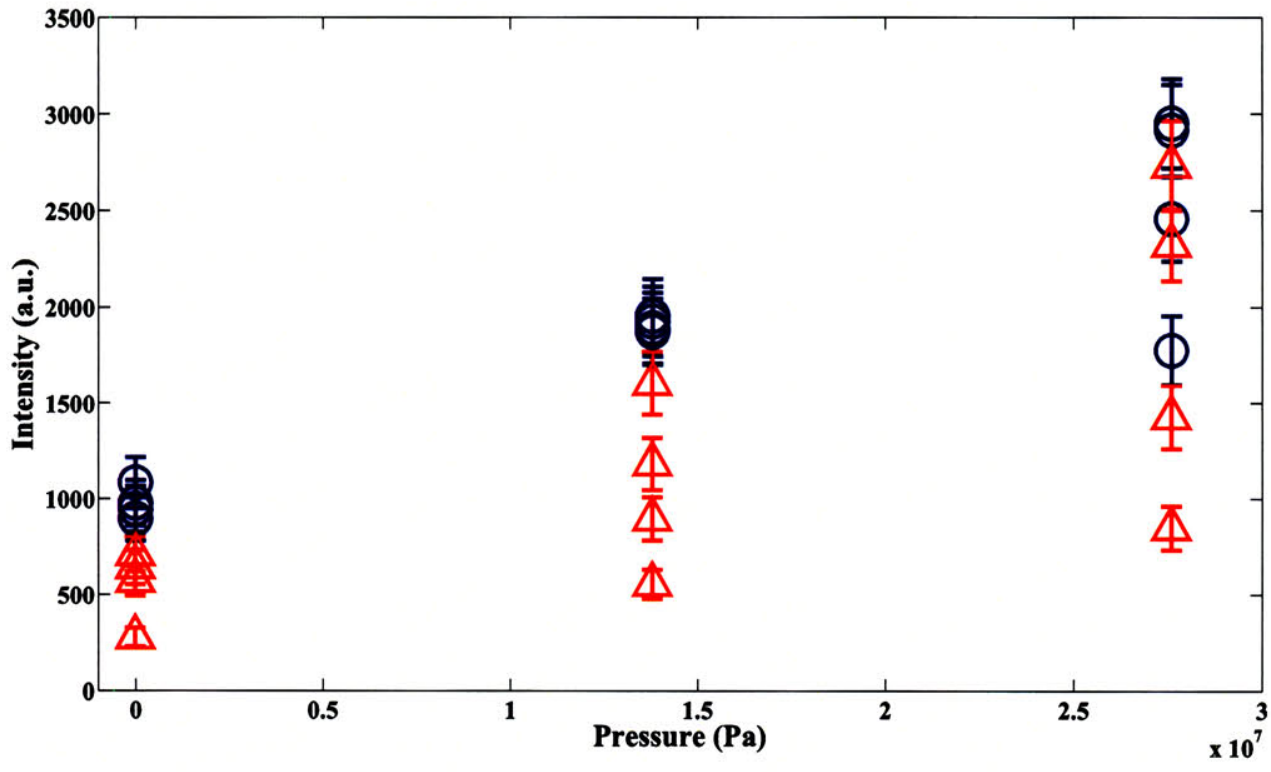

(b) $589 \mathrm{~nm} \mathrm{Na}$ Peak

Figure 6-8: Detection of sodium (2356 ppm Na) in a chloride versus sulfate matrix. $\mathrm{O}=\mathrm{NaCl}, \triangle=\mathrm{NaSO}_{4}$ 


\subsection{Conclusions}

Matrix effects of $\mathrm{Na}, \mathrm{K}$, and $\mathrm{Ca}$ were examined in a preliminary study. Although the main goal was determining how the presence of $\mathrm{NaCl}$ affects the peak intensities of $\mathrm{K}$ and $\mathrm{Ca}$, the data showed inconsistencies and were therefore inconclusive. In addition, the results were not consistent with previous preliminary findings reported by Cremers et al. [1] and Michel et al. [3]. The data suggest that matrix effects are smaller than the systematic variability of the measurements, and suggest that further laboratory experimentation is needed to elucidate if significant matrix effects exist.

A comparative study to investigate the ability to detect analytes in a chloride versus a sulfate matrix showed no significant difference. The results indicate that $\mathrm{Na}$ and $K$ are both detectable in chloride and sulfate matrices. The $K$ peak intensities were not influenced by the substrate present (sulfate and chloride) at pressures up to $2.76 \times 10^{7} \mathrm{~Pa}$. The $\mathrm{Na}$ peak intensities were possibly influenced by the background matrix (sulfate and chloride); yet, more experiments are needed to determine this conclusively.

\subsection{Acknowledgments}

Support for this research was provided by the National Science Foundation under grant OCE-0527927. Additional support was received from the Deep Ocean Exploration Institute and the Ocean Ventures Fund of the Woods Hole Oceanographic Institution. 


\section{Bibliography}

[1] D. A. Cremers and L. J. Radziemski. Laser-Induced Breakdown Spectroscopy (LIBS): Fundamentals and Applications, chapter History and Fundamentals of LIBS, pages 1-39. Cambridge University Press, 2006.

[2] D. A. Cremers, L. J. Radziemski, and T. R. Loree. Spectrochemical analysis of liquids using the laser spark. Applied Spectroscopy, 38:721-729, 1984.

[3] A. P. M. Michel, M. Lawrence-Snyder, S. M. Angel, and A. D. Chave. Laserinduced breakdown spectroscopy of bulk aqueous solutions at oceanic pressures: evaluation of key measurement parameters. Applied Optics, 46, 2007.

[4] B. Charfi and M. A. Harith. Panoramic laser-induced breakdown spectrometry of water. Spectrochimica Acta Part B, 57:1141-1153, 2002.

[5] A. S. Eppler, D. A. Cremers, D. D. Hickmott, M. J. Ferris, and A. C. Koskelo. Matrix effects in the detection of $\mathrm{Pb}$ and $\mathrm{Ba}$ in soils using laser-induced breakdown spectroscopy. Applied Spectroscopy, 50:1175-1181, 1996.

[6] B. Sallé, J.-L. Lacour, P. Mauchien, P. Fichet, S. Maurice, and G. Manhes. Comparative study of different methodologies for quantitative rock analysis by laser-induced breakdown spectroscopy in a simulated Martian atmosphere. Spectrochimica Acta Part B, 61:301-313, 2006.

[7] L. St-Onge, E. Kwong, M. Sabsabi, and E. B. Vadas. Quantitative analysis of pharmaceutical products by laser-induced breakdown spectroscopy. Spectrochimica Acta Part B, 57(7):1131-1140, 2002.

[8] L. Barrette and S. Turmel. On-line iron-ore slurry monitoring for real-time process control of pellet making processes using laser-induced breakdown spectroscopy: graphitic vs. total carbon detection. Spectrochimica Acta Part B, $56(6): 715-723,2001$.

[9] A. Ciucci, M. Corsi, V. Palleschi, S. Rastelli, A. Salvetti, and E. Tognoni. New procedure for quantitative elemental analysis by laser-induced plasma spectroscopy. Applied Spectroscopy, 53:960-964, 1999.

[10] A. P. M. Michel and A. D. Chave. Analysis of laser-induced breakdown spectroscopy (LIBS) spectra: The case for extreme value statistics. Spectrochimica Acta Part B, In Press. 


\section{Chapter 7}

\section{Conclusions and Future Directions}

\subsection{Conclusions}

In this thesis, laser-induced breakdown spectroscopy was evaluated for its potential for development into a new in situ chemical sensor for the deep ocean. The elements of focus for this work were selected for their importance in hydrothermal vent chemistry. Although it is potentially and theoretically possible to use LIBS to detect all elements, it was found during this laboratory investigation that it is more difficult to detect elements in bulk liquids at the concentrations desired than was anticipated. However, one important finding was that if an element could be detected in a bulk liquid at atmospheric pressure, then it could also be detected in the same liquid at high pressures. This thesis shows that the LIBS technique can be used successfully to detect dissolved $\mathrm{Li}, \mathrm{Na}, \mathrm{K}, \mathrm{Mg}, \mathrm{Ca}$, and $\mathrm{Mn}$ at pressures up to $2.76 \times 10^{7} \mathrm{~Pa}$, although not at the levels observed naturally in seawater or vent fluids for all of these elements. The work in this thesis was completed using two different LIBS systems, one with a Czerny-Turner spectrometer and one with an Echelle spectometer, and with two different pressure cells.

\subsubsection{Development of a New Data Processing Scheme}

A new data processing scheme for LIBS spectra was developed in this thesis and was applied to all data, except that presented in Chapter 2. In an examination of the variability of peak intensities for both single shot and ensemble-averaged LIBS spectra, LIBS data were found to have a dramatically non-normal statistical distribution. The distribution of the peak intensities was instead found to follow the generalized extreme value distribution. A preliminary investigation into the sources of the vari- 
ability was carried out. Laser pulse fluctuations, while identified as a contributing source of variability, were ruled out as the the primary source. Plasma images revealed large spatial and intensity differences on a shot-to-shot basis. This analysis led to the development of a data processing scheme that accurately deals with the extreme nature of laser-induced plasma formation and should be used for statistically accurate comparisons of LIBS spectra instead of simply averaging spectra, the standard method used by LIBS researchers. This scheme was found to be applicable for both solid and liquid samples and for use with data taken with both a Czerny-Turner and an Echelle spectrometer.

\subsubsection{Single Pulse LIBS}

\section{Results Using a Czerny-Turner Spectrometer}

Preliminary investigations were carried out using a Czerny-Turner spectrometer that showed that $\mathrm{Li}, \mathrm{Ca}, \mathrm{Mn}, \mathrm{K}$, and $\mathrm{Na}$ were detectable in high pressure bulk aqueous solutions. This work focused on the energy levels needed for the detection of these analytes and revealed that an optimal range of low laser pulse energies exists for their detection in both low and high pressure solutions. It was hypothesized that a low energy pulse could create a smaller, more tightly focused plasma that forms only at the focal spot. However, for a high energy pulse, the high energy density may cause breakdown even before the pulse reaches the focal spot causing breakdown to occur over a longer distance. The effect of pressure on emission intensity was investigated for $\mathrm{Ca}, \mathrm{Na}$, and $\mathrm{Mn}$ with no pressure effect seen for $\mathrm{Ca}$ and $\mathrm{Na}$, yet, with an increase in intensity with increased pressure observed for $\mathrm{Mn}$.

\section{Results Using an Echelle Spectrometer}

Using an Echelle spectrometer, $\mathrm{Na}, \mathrm{Mn}$, and $\mathrm{Ca}$ were again shown to be detectable with little effect of pressure on the spectra. Irrespective of the laser pulse energy selected or the solution pressure, the need for a short (less than $200 \mathrm{~ns}$ ) gate delay was found for the detection of analytes. This study confirmed that a low energy pulse (less than $\approx 60 \mathrm{~mJ}$ ) is optimal. Calibration curves showed that $\mathrm{Na}, \mathrm{Mn}$, and $\mathrm{Ca}$ are detectable at $50 \mathrm{ppm}, 500 \mathrm{ppm}$, and $50 \mathrm{ppm}$, respectively. However, the limits of detection were higher than expected which was attributed to both the poor sensitivity and the low light throughput of the system used. 


\subsubsection{Double Pulse LIBS}

\section{Results Using a Czerny-Turner Spectrometer}

In this preliminary work, double pulse LIBS was used to detect four analytes (Ca, $\mathrm{Li}, \mathrm{Na}$, and $\mathrm{Mn}$ ) and the energy levels for maximum emission were found to vary by analyte. Analyte detection was found to be highly dependent on the interpulse delay. If the interpulse delay is short $(\ll 1 \mu \mathrm{s})$, signal intensity is greatly enhanced when compared to that measured using longer delay times. Two pulses separated by a short $\Delta \mathrm{T}$ approaches single pulse conditions. Such a small interpulse delay may not be sufficient for a cavitation bubble to fully form before the second laser pulse creates a spark. This was an early suggestion that dual pulse LIBS might not be advantageous at elevated pressure.

\section{Results Using an Echelle Spectrometer}

Double pulse LIBS was used to detect five analytes ( $\mathrm{Mg}, \mathrm{K}, \mathrm{Mn}, \mathrm{Na}$, and $\mathrm{Ca}$ ) at pressures up to $2.76 \times 10^{7} \mathrm{~Pa}$. The key double pulse parameters were optimized for each of the elements at three pressures $\left(1 \times 10^{5} \mathrm{~Pa}, 1.38 \times 10^{7} \mathrm{~Pa}\right.$, and $2.76 \times$ $10^{7} \mathrm{~Pa}$ ). The parameters needed for detection were found to be both element and pressure dependent. The use of the optimal parameters is essential because outside this set of parameters, some of the elements were not detectable, although $\mathrm{K}$ and $\mathrm{Na}$ were detectable over a wide range of conditions. In general, for all elements, as pressure was increased, the use of a shorter interpulse delay was necessary and at 2.76 $\times 10^{7} \mathrm{~Pa}$ an interpulse delay time on the order of $50 \mathrm{~ns}$ was ideal. For all conditions studied, a short gate delay (usually $\leq 100 \mathrm{ns)} \mathrm{was} \mathrm{required,} \mathrm{suggesting} \mathrm{that} \mathrm{in} \mathrm{bulk}$ liquids, the plasma lifetime is short, possibly lasting only on the order of $500 \mathrm{~ns}$.

Calibration curves were made that established the limits of detection for the five analytes: $5000 \mathrm{ppm} \mathrm{Mg}, 500 \mathrm{ppm} \mathrm{K}, 500 \mathrm{ppm} \mathrm{Ca}, 1000 \mathrm{ppm} \mathrm{Mn}$, and $50 \mathrm{ppm} \mathrm{Na}$ using the current system set-up. Using single pulse LIBS, limits of detection were found to be $500 \mathrm{ppm} \mathrm{Mn}, 50 \mathrm{ppm} \mathrm{Ca}$, and $50 \mathrm{ppm} \mathrm{Na}$ which suggests that the use of double pulse LIBS in high pressure aqueous solutions may not be advantageous. The high pressure environment may cause the bubble to collapse too rapidly and as a result the bubble does not expand to the maximum volume observed at lower pressures [1]. As a result, the emission enhancements seen at atmospheric pressure are not observed in the high pressure environment.

Although the use of double pulse LIBS proved less favorable than expected, it should be noted that one major contributing factor was the spectrometer used in 
these studies. The Echelle spectrometer has a very high resolution but a very low light throughput and poor sensitivity, with an $f$ number of 10 . Further work is needed to maximize the light collection by changing system components for bulk aqueous solution experiments.

\subsubsection{Matrix}

\section{Results Using a Czerny-Turner Spectrometer}

The addition of $\mathrm{NaCl}$ was found to enhance the emission intensity for $\mathrm{Ca}$.

\section{Results Using an Echelle Spectrometer}

The matrix effect of $\mathrm{Na}, \mathrm{K}$, and $\mathrm{Ca}$ was examined to determine how the presence of $\mathrm{NaCl}$ affects the peak intensity of $\mathrm{K}$ and $\mathrm{Ca}$, although the data showed inconsistencies and were therefore inconclusive. $\mathrm{Na}$ and $\mathrm{K}$ were found to be detectable in both chloride and sulfate matrices. For $\mathrm{Na}$ the peak intensities were possibly influenced and for $\mathrm{K}$ the peak intensities were not influenced by the background matrix (sulfate versus chloride) at pressures up to $2.76 \times 10^{7} \mathrm{~Pa}$.

\subsection{Future Work}

\subsubsection{Laboratory Work}

Significantly more laboratory work is needed before a robust ocean-going system can be built and used successfully in the field. Although this thesis showed that many elements could be detected in a high pressure aqueous environment, and several were detectable at levels found at or below the concentrations present in vent fluids, there are many issues that need to be addressed to improve upon the current LIBS system.

Due to the attenuation of light in water, $532 \mathrm{~nm}$ or green laser light will travel substantially further than $1064 \mathrm{~nm}$ laser light in the ocean. Therefore, it will be advantageous to develop a LIBS system that uses $532 \mathrm{~nm}$ laser pulses as the excitation source. The disadvantage to using $532 \mathrm{~nm}$ laser pulses as the excitation source is the need for a filter before the collection fiber optic. Since $532 \mathrm{~nm}$ is in the range that can be detected by the spectrometer, it is important to never collect the $532 \mathrm{~nm}$ laser pulse light. To prevent capturing the laser light, a $532 \mathrm{~nm}$ notch filter is added before the collection fiber optic to filter out the light from the laser pulses. The addition of this filter will minimally reduce the light available to the spectrometer. LIBS of 
liquids using $532 \mathrm{~nm}$ should be feasible; therefore, the next phase of laboratory work should explore this option.

Improvements to the limits of detection could be made by using a spectrometer with a smaller $f$ number than the Echelle spectrometer that was used for much of this thesis work. Although an Echelle spectrometer has the advantage of being able to simultaneously detect multiple elements due to its broad wavelength coverage, its high resolution yields low throughput. The Echelle spectrometer also had a small slit width which limited light input. In addition, the use of a PMT instead of an ICCD as the detector could be beneficial for increasing sensitivity. Changes therefore to the detection system may allow for the elements presented in this thesis to be detected at much lower limits of detection and for additional elements to be detected. For example, the detection of $\mathrm{Cu}, \mathrm{Fe}, \mathrm{Cl}$, and $\mathrm{Br}$ was attempted as part of this research without success. It is recommended that a new spectrometer with a smaller $f$ number be selected for continued work on this project. The Echelle spectrometer used in this work has an $f$ number of 10 and it is strongly recommended to use a spectrometer with an $f$ number of 4 or 2 , which would have greater throughput.

Future work should include significant studies on the variability of plasma formation. This can include imaging of both laser-induced plasmas and bubbles. Plasma dynamics studies should be carried out in an effort to find ways to minimize shotto-shot plasma variability. Although this thesis included some plasma images taken orthogonal from the incoming laser beam, plasma images could also be taken from multiple angles to gain a multi-dimensional understanding of plasma formation. Then by looking at what factors influence plasma dynamics (e.g., the shape of the plasma, the length of emission, emission intensity), more control over the plasma variability may be obtainable. The factors that influence the plasma dynamics include the laser (e.g., beam quality, wavelength), focusing optics, and sample pressure and should also be studied for their impact on variability.

Calibration curves were used in this thesis to determine the limits of detection. In future work, much work should be completed on the calibration curves to both decrease the variability of the curves and to verify repeatability of the curves. The calibration curves should also be extended to higher concentrations to verify that the curves are linear. In addition, if a new spectrometer is used, calibration curves can again be used to determine limits of detection. Once the variability issues are resolved and the repeatability of calibration curves are established, more work can focus on matrix effects. Matrix effect data showed inconsistencies that are thought to arise from the variability issues and from the spectrometer used. Selecting a new 
spectrometer may improve these studies; however, the reduction of plasma variability again should first be addressed.

There are many additional challenges to studying liquids in the ocean environment that were not addressed in this thesis. For example, the effect of particles in the water on the detection of analytes should be addressed. In addition, the effect of a flowing solution on LIBS spectra and especially the shot-to-shot variability in a flowing system should be examined. Furthermore, laboratory work should emphasize elements not yet targeted. In theory, all elements are detectable using LIBS; thus, significant work is needed to determine all of the elements which are detectable in high pressure aqueous environments.

\subsubsection{Design of an Ocean-Going Sensor}

Although there are several issues that need to be addressed in the laboratory to deal with the variability issues and to improve upon the calibration curves and limits of detection, this thesis shows that the use of LIBS in a high pressure aqueous environment is feasible. Once these issues have been addressed, a LIBS sensor can be designed for use in the ocean. The natural extension of this research therefore is the development of the first ever sea-going LIBS system. This will entail the design of an instrument that can be used at hydrothermal vents aboard an underwater vehicle (Figure 7-1). The major components of an underwater LIBS system are a spectrometer, source laser(s), fiber optic links and probes for these units, and data acquisition/control electronics. All of these components will need to be packaged in underwater pressure housings and provided with power and data communications connections. Several critical issues related to integrating the system onto an underwater vehicle also need to be addressed, including vehicle payload, power resources, and system control. Software modifications for laser control and data collection will be a necessary component of this work. The design of an optical probe head is a critical element of a sea-going LIBS system. The fiber optic design must pass the laser pulses into the fiber, image the fiber spot onto the target, and image the plasma emission onto a fiber bundle that couples to the spectrometer. The fiber bundle must be designed to withstand both the pressure effects of the ocean and also the high energy laser pulses. In the ocean environment, there are other types of samples that ocean scientists will be interested in using an in situ chemical LIBS sensor for making measurements of in the ocean. For example, LIBS could be used for analyzing sediments, rocks, underwater archaeological artifacts, and the air-sea interface. The 
successful design and testing of an ocean-going system will pave the way for its use by oceanographers for numerous applications. 


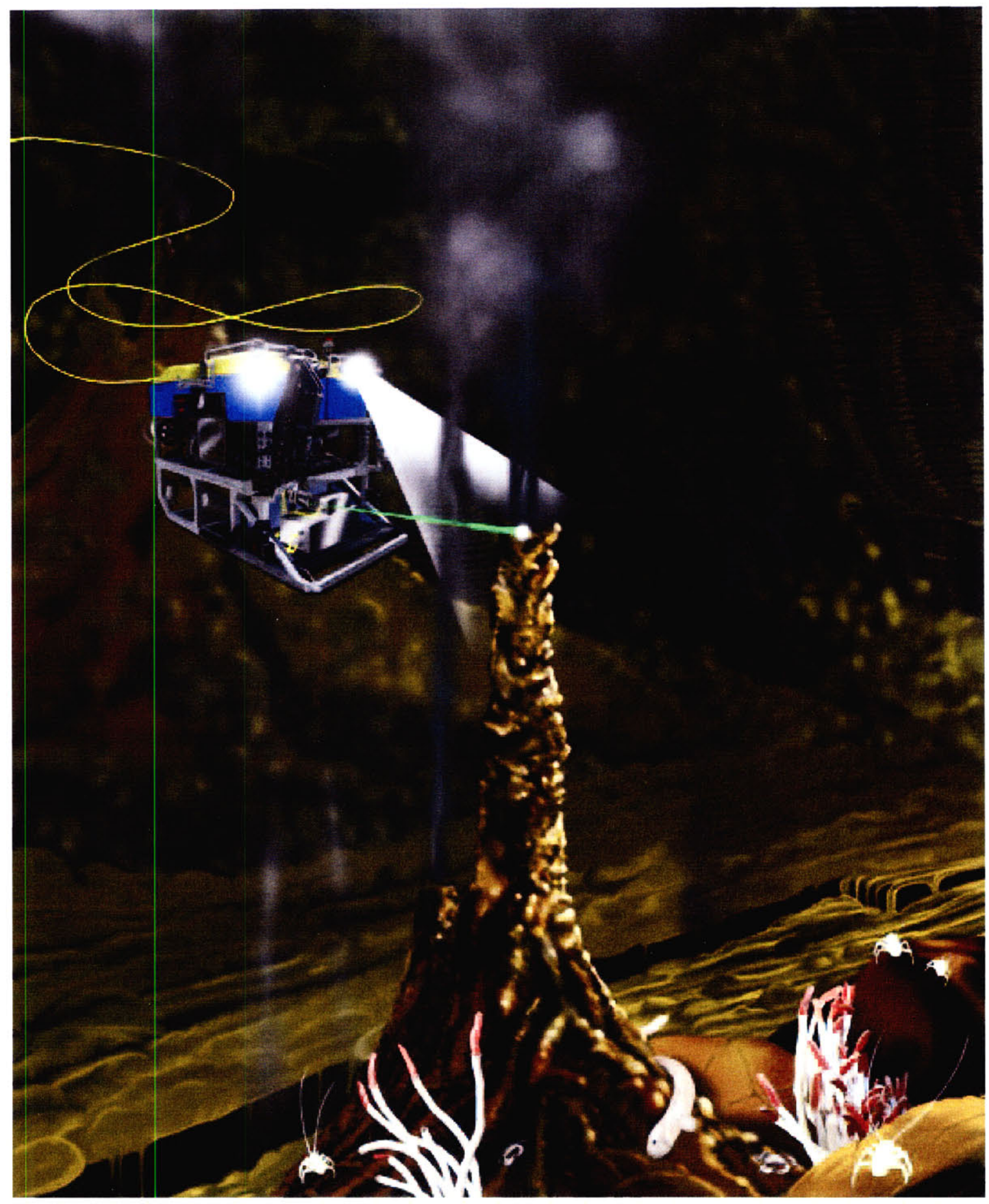

Figure 7-1: Future oceanic LIBS system. Illustration by E. Paul Oberlander, WHOI. 


\section{Bibliography}

[1] M. Lawrence-Snyder, J. P. Scaffidi, W. F. Pearman, and S. M. Angel. Dependence of emission intensity on bubble dynamics in dual-pulse laser-induced breakdown spectroscopy of high-pressure bulk aqueous solutions. Applied Spectroscopy, submitted. 